\title{
Hydrogen Isotope Exchange with Superbulky Alkaline Earth Metal Amide Catalysts
}

\author{
Johannes Martin, Jonathan Eyselein, Samuel Grams and Sjoerd Harder*
}

Inorganic and Organometallic Chemistry, Universität Erlangen-Nürnberg, Egerlandstrasse 1, 91058 Erlangen, Germany

*E-mail: sjoerd.harder@fau.de 


\section{Table of Contents}

1 General Experimental Procedures $\quad$ S3

2 Catalytic Deuterium for Hydrogen Exchange in Perdeuterated Arenes S5

3 Catalytic Deuteration of Arenes $\quad$ S50

$4 \quad$ Hydrogen Isotope Exchange in Ferrocene $\quad$ S119

$5 \quad$ Catalytic Deuteration of Silanes $\quad$ S125

$6 \quad$ Theoretical Calculations $\quad$ S143

$\begin{array}{llr}7 & \text { References } & \text { S145 }\end{array}$ 


\section{General Experimental Procedures}

All air- and moisture-sensitive manipulations were carried out in dry glassware under an atmosphere of $\mathrm{N}_{2}$ using standard Schlenk techniques or in a glovebox (MBraun, Labmaster SP). Benzene and toluene were degassed with $\mathrm{N}_{2}$ and dried over activated aluminum oxide (Solvent Purification System: Pure Solv 400-4-MD, Innovative Technology), while cyclohexane was dried by stirring over freshly ground $\mathrm{CaH}_{2}$ at room temperature overnight followed by distillation. All solvents were stored over molecular sieves (3 $\AA$ ) under an inert atmosphere. Deuterated benzene $\left(\mathrm{C}_{6} \mathrm{D}_{6} ; 99.6+\% \mathrm{D}\right),\left[d_{8}\right]$ toluene $(99.6+\% \mathrm{D}), \mathrm{CDCl}_{3}$ $(99.8+\% \mathrm{D})$ and $\left[d_{12}\right]$ cyclohexane $(99.5+\% \mathrm{D})$ were purchased from Sigma Aldrich or Deutero $\mathrm{GmbH}$ and dried over molecular sieves ( $3 \AA$ ) before use.

Multinuclear NMR spectra were recorded on a Bruker Avance III HD 600 MHz spectrometer at ambient temperature. Chemical shifts $\delta$ are reported in parts per million (ppm) relative to $\mathrm{Me}_{4} \mathrm{Si}$ as external standard and referenced internally to the carbon nuclei $\left({ }^{13} \mathrm{C}\left\{{ }^{1} \mathrm{H}\right\}\right)$ or residual protio-solvent resonances $\left({ }^{1} \mathrm{H}\right)$ of the deuterated solvents. ${ }^{29} \mathrm{Si}\left\{{ }^{1} \mathrm{H}\right\}$ NMR spectra were referenced using $\mathrm{Me}_{4} \mathrm{Si}$ as external standard. To allow full relaxation of all hydrogen environments for accurate integration, all quantitative ${ }^{1} \mathrm{H} N M R$ spectra on isotopic exchange reactions were acquired using 32 scans with a 30 s relaxation delay time.

Infrared spectra were acquired on a Bruker Alpha II FT-IR spectrometer equipped with a Platinum ATR diamond from the neat compounds under inert conditions inside a glovebox. All spectra were recorded at room temperature in the range of $400-4000 \mathrm{~cm}^{-1}$ with a resolution of $4 \mathrm{~cm}^{-1}$ and baseline corrected.

GC-MS measurements were performed on a Thermo Scientific ${ }^{\mathrm{TM}}$ Trace $^{\mathrm{TM}} 1310$ gas chromatography system (carrier gas: He) with detection by a Thermo Scientific ${ }^{\mathrm{TM}}$ ISQ $^{\mathrm{TM}}$ LT single quadrupole mass

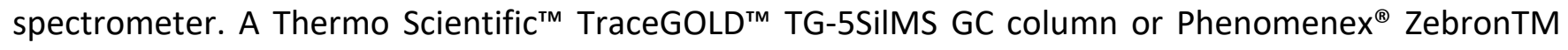
ZB-5 GC column of the dimensions $0.25 \mathrm{~mm} \times 30 \mathrm{~m}$ with a film thickness of $0.25 \mu \mathrm{m}$ was used. The samples $(1 \mu \mathrm{L})$ were injected with an instant connect-SSL module in the split mode (injector temperature: $280^{\circ} \mathrm{C}$ ). Temperature programs were started at $40^{\circ} \mathrm{C}$ followed by heating ramps, optimized for the separation problem, until $280^{\circ} \mathrm{C}$. Baseline separation of each analyte was achieved by choosing the different temperature programs. The molecular identities were confirmed by comparison with entries in the NIST/EPA/NIH mass spectral library (v2.2; built 2014-06-10). 
All Hydrogen Isotope Exchange (HIE) experiments were carried out on a high vacuum Schlenk line attached to either a hydrogen or deuterium gas cylinder in high-pressure miniature autoclaves $(15 \mathrm{~mL}$ capacity) made of stainless steel by Amtech, which were previously dried by heating in an oven at $80^{\circ} \mathrm{C}$ overnight. Research grade hydrogen $\left(\mathrm{H}_{2} ;\right.$ Air Liquide) and deuterium gas $\left(\mathrm{D}_{2}\right.$; Linde) used in catalytic reactions were of $99.999 \%$ and $99.9 \%$ purity, respectively, and used without additional purification.

The following alkaline earth (Ae) metal amide pre-catalysts were synthesized according to previously reported procedures: $\mathrm{Ae}\left[\mathrm{N}\left(\mathrm{SiMe}_{3}\right)_{2}\right]_{2},{ }^{1} \mathrm{Ae}\left[\mathrm{N}(\mathrm{DIPP})\left(\mathrm{Si}^{i} \mathrm{Pr}_{3}\right)\right]_{2}{ }^{2}$ and $\mathrm{Ae}\left[\mathrm{N}\left(\mathrm{Si}^{i} \mathrm{Pr}_{3}\right)_{2}\right]_{2}{ }_{2}(\mathrm{Ae}=\mathrm{Ca}, \mathrm{Sr}, \mathrm{Ba})$.

The commercially available liquid arene substrates ethylbenzene (Fluka, $\geq 99 \%$ ), cumene (Sigma Aldrich, 99\%), tert-butylbenzene ( $\mathrm{TCl}$ Chemicals, >98\%), trimethyl(phenyl)silane (Sigma Aldrich, 99\%), N,N-dimethylbenzylamine (Sigma Aldrich, $\geq 99 \%$ ), 1,2,3,4-tetrahydronaphthalene (Sigma Aldrich, 97\%), $\mathrm{N}, \mathrm{N}$-dimethyl-o-toluidine (Sigma Aldrich, 99\%), meta-xylene (ABCR, 99\%), 4-tert-butyltoluene (Alfa Aesar, 95\%), and 1,3,5-trimethylbenzene (TCl Chemicals, 98\%) were dried by stirring over freshly ground $\mathrm{CaH}_{2}$ at room temperature overnight, distilled under reduced pressure and stored in an $\mathrm{N}_{2}$-filled glovebox over activated molecular sieves (3 $\AA$ ) prior to catalytic experiments. The hydrosilanes $n$-hexylsilane (ABCR, 95\%), diethylsilane (Alfa Aesar, $\geq 97 \%$ ) and triethylsilane (ABCR, 99\%) were obtained commercially and used without further purification. 1,3,5-Trimethoxybenzene (Acros Organics, 99\%) used as internal standard and ferrocene (Sigma Aldrich, 98\%) were sublimed under a dynamic vacuum and stored under an inert $\mathrm{N}_{2}$ atmosphere before usage. 


\section{Catalytic Deuterium for Hydrogen Exchange in Perdeuterated Arenes}

To establish the Hydrogen Isotope Exchange in arenes, perdeuterated benzene and toluene were employed as model substrates and the following initial experiments were performed:
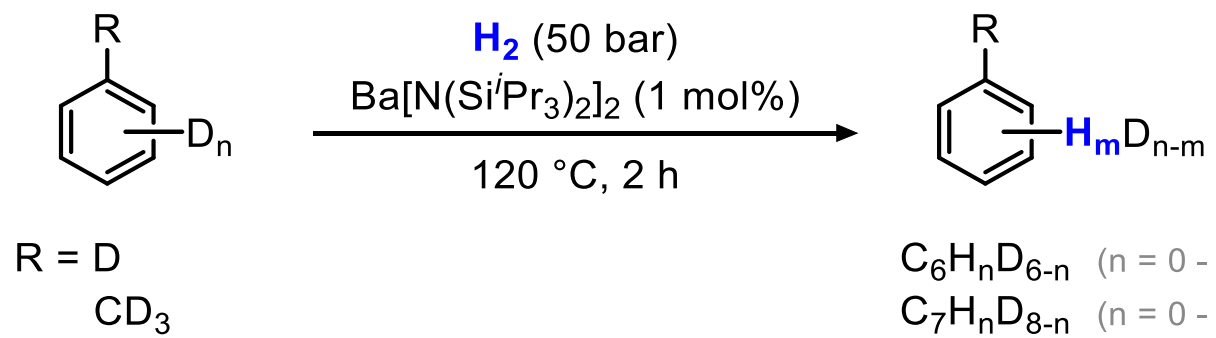

$\mathrm{CD}_{3}$

$$
\begin{array}{ll}
\mathrm{C}_{6} \mathrm{H}_{n} \mathrm{D}_{6-\mathrm{n}} & (\mathrm{n}=0-6) \\
\mathrm{C}_{7} \mathrm{H}_{\mathrm{n}} \mathrm{D}_{8-\mathrm{n}} \quad(\mathrm{n}=0-8)
\end{array}
$$

Crystalline $\mathrm{Ba}\left[\mathrm{N}\left(\mathrm{Si}^{i} \mathrm{Pr}_{3}\right)_{2}\right]_{2}$ (1 mol\%) was added to an oven-dried miniature stainless steel autoclave $(15 \mathrm{~mL})$ containing a magnetic stir bar and then dissolved in the appropriate deuterated aromatic solvent (1 mL C ${ }_{6} \mathrm{D}_{6}, 950 \mathrm{mg}, 11.29 \mathrm{mmol}$ or $1 \mathrm{~mL}$ [ $d_{8}$ ] toluene, $943 \mathrm{mg}, 9.41 \mathrm{mmol}$ ) under an atmosphere of $\mathrm{N}_{2}$. The pressure vessel was sealed, removed from the glovebox, and connected to a $\mathrm{H}_{2}$ gas manifold. Upon evacuation and refilling of the supply line successively with $\mathrm{N}_{2}$ and $\mathrm{H}_{2}$ several times each, $\mathrm{H}_{2}$ (50 bar) was introduced into the reactor. The reaction mixture was stirred for 2 hours at $120^{\circ} \mathrm{C}$ in a preheated aluminum heating block before it was allowed to cool to room temperature and the remaining $\mathrm{H}_{2}$ gas was carefully released. For $\mathrm{C}_{6} \mathrm{D}_{6}$ as substrate, the volatiles of the reaction mixture were collected by distillation under a dynamic vacuum into a separate flask in order to remove $\left({ }^{i} \mathrm{Pr}_{3} \mathrm{Si}\right)_{2} \mathrm{NH}$ and catalyst decompositions products. Cyclohexane $(20 \mu \mathrm{L})$ was added to an aliquot of the colorless distillate $(500 \mu \mathrm{L})$ and the mixture analyzed by NMR spectroscopy. The presence of the respective protio-arene, i.e. $\mathrm{C}_{6} \mathrm{H}_{n} \mathrm{D}_{6-n}(n=0-6)$ isotopologues, ${ }^{3}$ was further confirmed by IR spectroscopy and GC/MS analysis. In case of $\left[d_{8}\right]$ toluene, at the end of the reaction, the crude reaction mixture was filtered through a glass microfiber filter in a Pasteur pipette and analyzed by NMR spectroscopy following addition of 1,3,5-trimethoxybenzene $(15 \mathrm{mg}, 89 \mu \mathrm{mol})$ as an internal standard to a NMR sample $(500 \mu \mathrm{L})$ of the crude filtrate for quantification of hydrogen incorporation. 


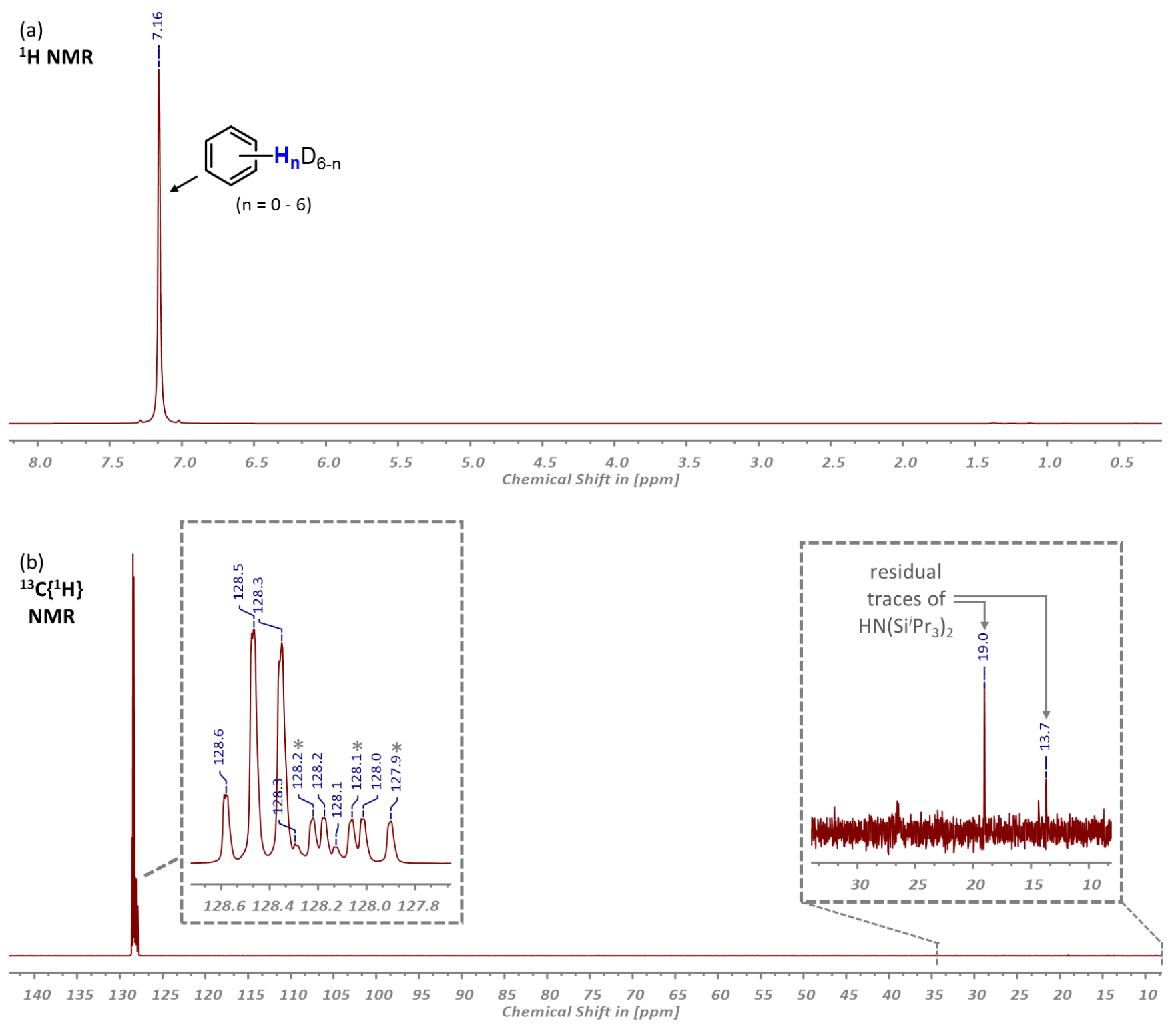

Figure S1. (a) ${ }^{1} \mathrm{H}$ NMR spectrum (600 MHz, $\mathrm{C}_{6} \mathrm{D}_{6}, 25^{\circ} \mathrm{C}$ ) and $(b){ }^{13} \mathrm{C}\left\{{ }^{1} \mathrm{H}\right\} \mathrm{NMR}$ spectrum $\left(151 \mathrm{MHz}, \mathrm{C}_{6} \mathrm{D}_{6}, 25^{\circ} \mathrm{C}\right)$ of the purified $\mathrm{C}_{6} \mathrm{H}_{n} \mathrm{D}_{6-n}(n=0-6)$ isotopologues mixture after the catalytic deuterium for hydrogen exchange in $\mathrm{C}_{6} \mathrm{D}_{6}(*)$ with $\mathrm{H}_{2}(50 \mathrm{bar})$ and $\mathrm{Ba}\left[\mathrm{N}\left(\mathrm{Si}^{i} \mathrm{Pr}_{3}\right)_{2}\right]_{2}(1 \mathrm{~mol} \%)$ as catalyst precursor at $120{ }^{\circ} \mathrm{C}$ for 2 hours. Note: No formation of cyclohexane isotopologues (i.e. $\mathrm{C}_{6} \mathrm{H}_{6+n} \mathrm{D}_{6-n} ; n=0-6$ ) as a result of hydrogenation of $\mathrm{C}_{6} \mathrm{D}_{6}$ was observed. 
(a)

${ }^{1} \mathrm{H}$ NMR

residual

protio-solvent

resonance of

$\left[d_{6}\right]$ benzene

(i.e. $\mathrm{C}_{6} \mathrm{D}_{5} \mathrm{H}$ )

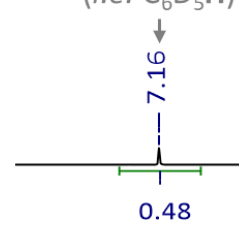

(b) Э

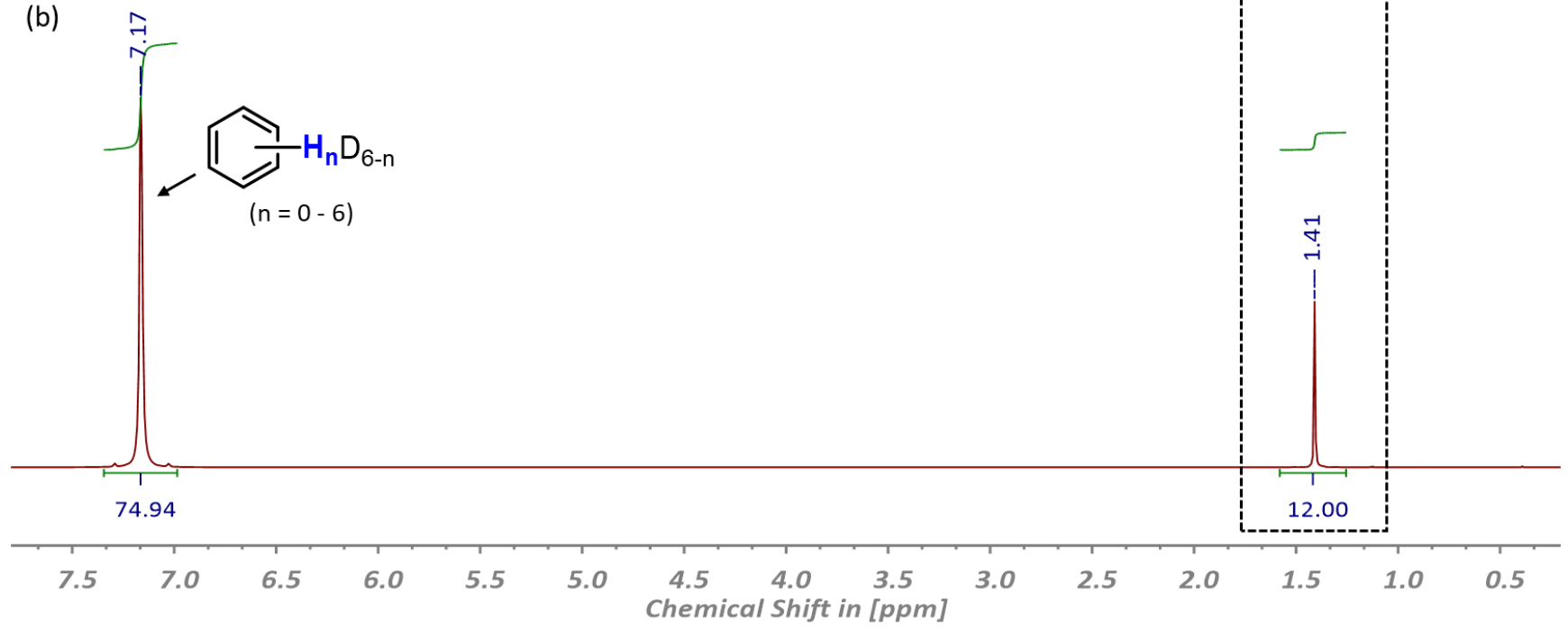

Figure S2. Stacked ${ }^{1} \mathrm{H}$ NMR spectra $\left(600 \mathrm{MHz}, \mathrm{C}_{6} \mathrm{D}_{6}, 25^{\circ} \mathrm{C}\right)$ of $(a)$ the authentic $\mathrm{C}_{6} \mathrm{D}_{6}$ substrate and $(b)$ the isolated isotopologues mixture after the catalytic deuterium for hydrogen exchange with $\mathrm{H}_{2}(50 \mathrm{bar})$ and $\mathrm{Ba}\left[\mathrm{N}\left(\mathrm{Si}^{i} \mathrm{Pr}_{3}\right)_{2}\right]_{2}$

(1 mol\%) as pre-catalyst at $120^{\circ} \mathrm{C}$ for 2 hours. Note: Cyclohexane was added as an internal standard for quantification of hydrogen incorporation. 


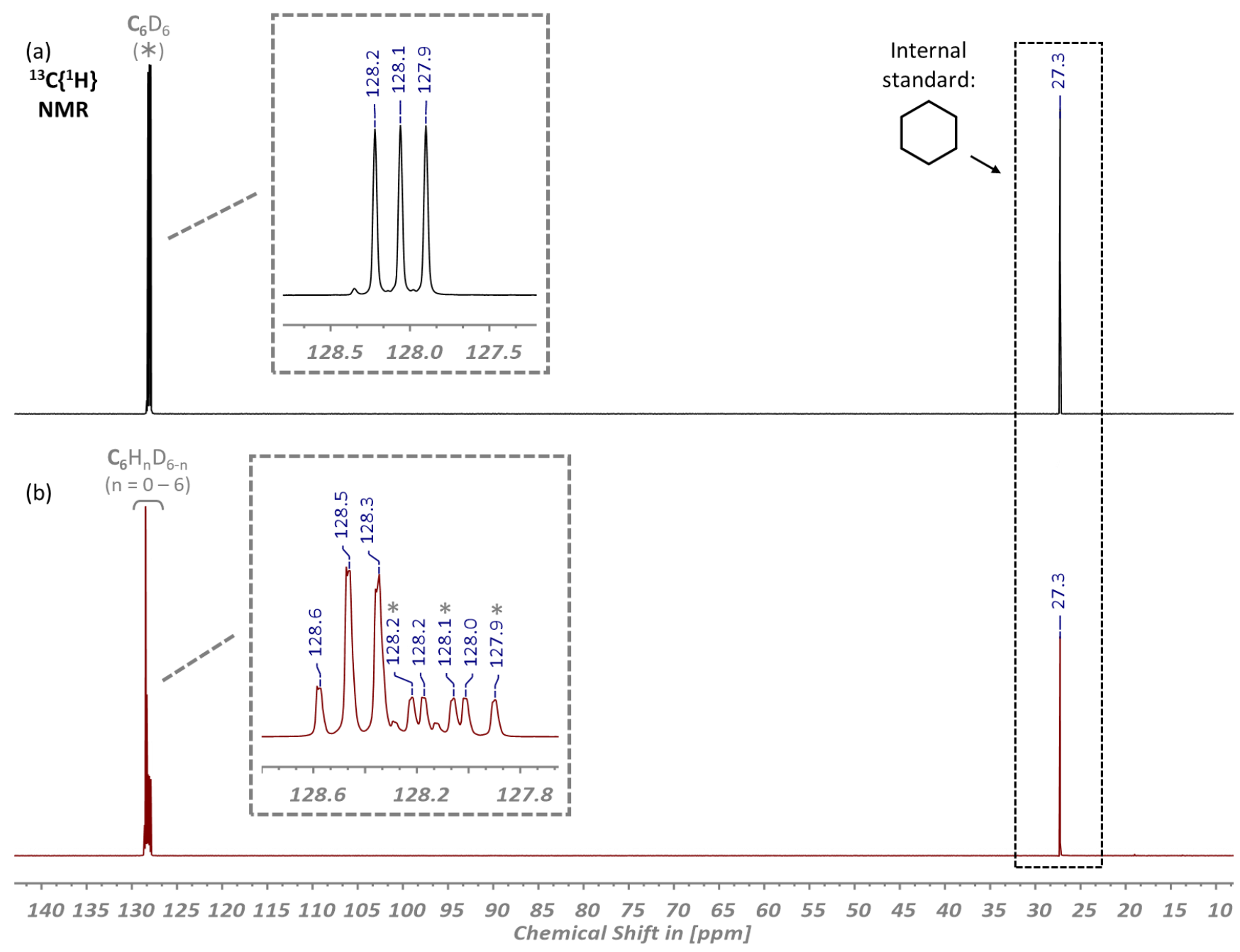

Figure S3. Stacked ${ }^{13} \mathrm{C}\left\{{ }^{1} \mathrm{H}\right\}$ NMR spectra $\left(151 \mathrm{MHz}, \mathrm{C}_{6} \mathrm{D}_{6}, 25^{\circ} \mathrm{C}\right)$ of $(a)$ the authentic $\mathrm{C}_{6} \mathrm{D}_{6}$ substrate and $(b)$ the isolated isotopologues mixture after the catalytic deuterium for hydrogen exchange with $\mathrm{H}_{2}(50 \mathrm{bar})$ and $\mathrm{Ba}\left[\mathrm{N}\left(\mathrm{Si}^{i} \mathrm{Pr}_{3}\right)_{2}\right]_{2}(1 \mathrm{~mol} \%)$ as catalyst precursor at $120^{\circ} \mathrm{C}$ for 2 hours. Note: Cyclohexane was added as an internal standard. 


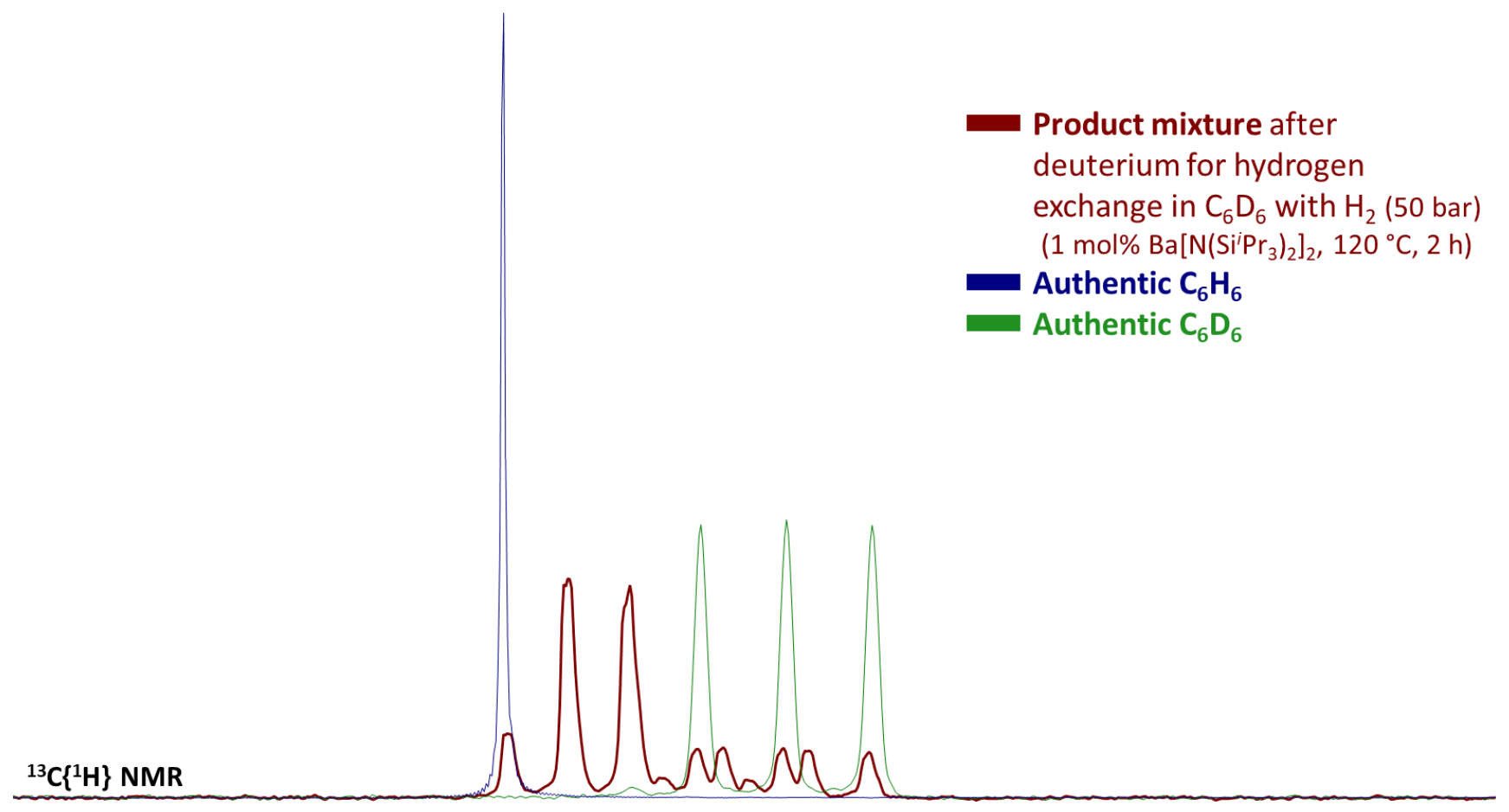

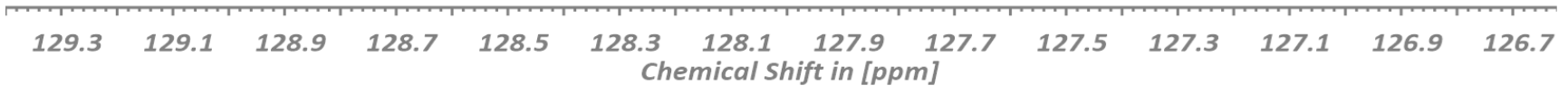

Figure S4. Superimposed ${ }^{13} \mathrm{C}\left\{{ }^{1} \mathrm{H}\right\} \mathrm{NMR}$ spectra $\left(151 \mathrm{MHz}, \mathrm{CDCl}_{3}, 25^{\circ} \mathrm{C}\right)$ of $(\square)$ the $\mathrm{C}_{6} \mathrm{H}_{n} \mathrm{D}_{6-n}(n=0-6)$ isotopologues mixture obtained after the catalytic deuterium for hydrogen exchange in $\mathrm{C}_{6} \mathrm{D}_{6}$ with $\mathrm{H}_{2}(50$ bar) and $\mathrm{Ba}\left[\mathrm{N}\left(\mathrm{Si}^{i} \mathrm{Pr}_{3}\right)_{2}\right]_{2}(1 \mathrm{~mol} \%)$ as catalyst precursor as well as authentic ( $\left.\square\right) \mathrm{C}_{6} \mathrm{D}_{6}$ and $(\square) \mathrm{C}_{6} \mathrm{H}_{6}$ in $\mathrm{CDCl}_{3}$ for reference. ${ }^{4}$ 


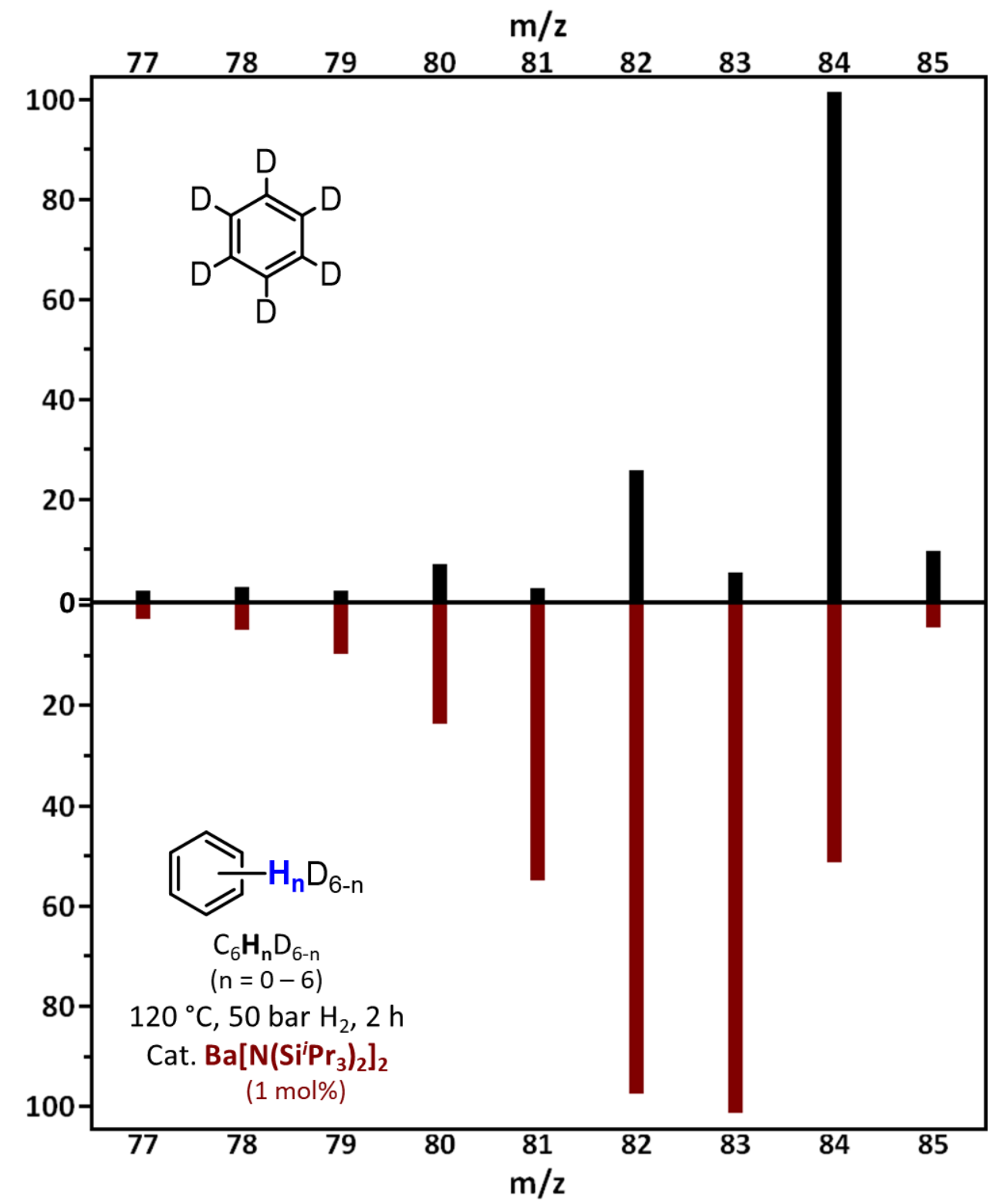

Figure S5. Stacked mass spectra of (top) the authentic $\mathrm{C}_{6} \mathrm{D}_{6}$ substrate and (bottom) the distilled $\mathrm{C}_{6} \mathrm{H}_{n} \mathrm{D}_{6-n}$ $(n=0-6)$ product after the deuterium for hydrogen exchange with $\mathrm{H}_{2}\left(50 \mathrm{bar}\right.$ ) and $\mathrm{Ba}\left[\mathrm{N}\left(\mathrm{Si}^{i} \mathrm{Pr}_{3}\right)_{2}\right]_{2}(1 \mathrm{~mol} \%)$ as catalyst precursor at $120^{\circ} \mathrm{C}$ for 2 hours. 


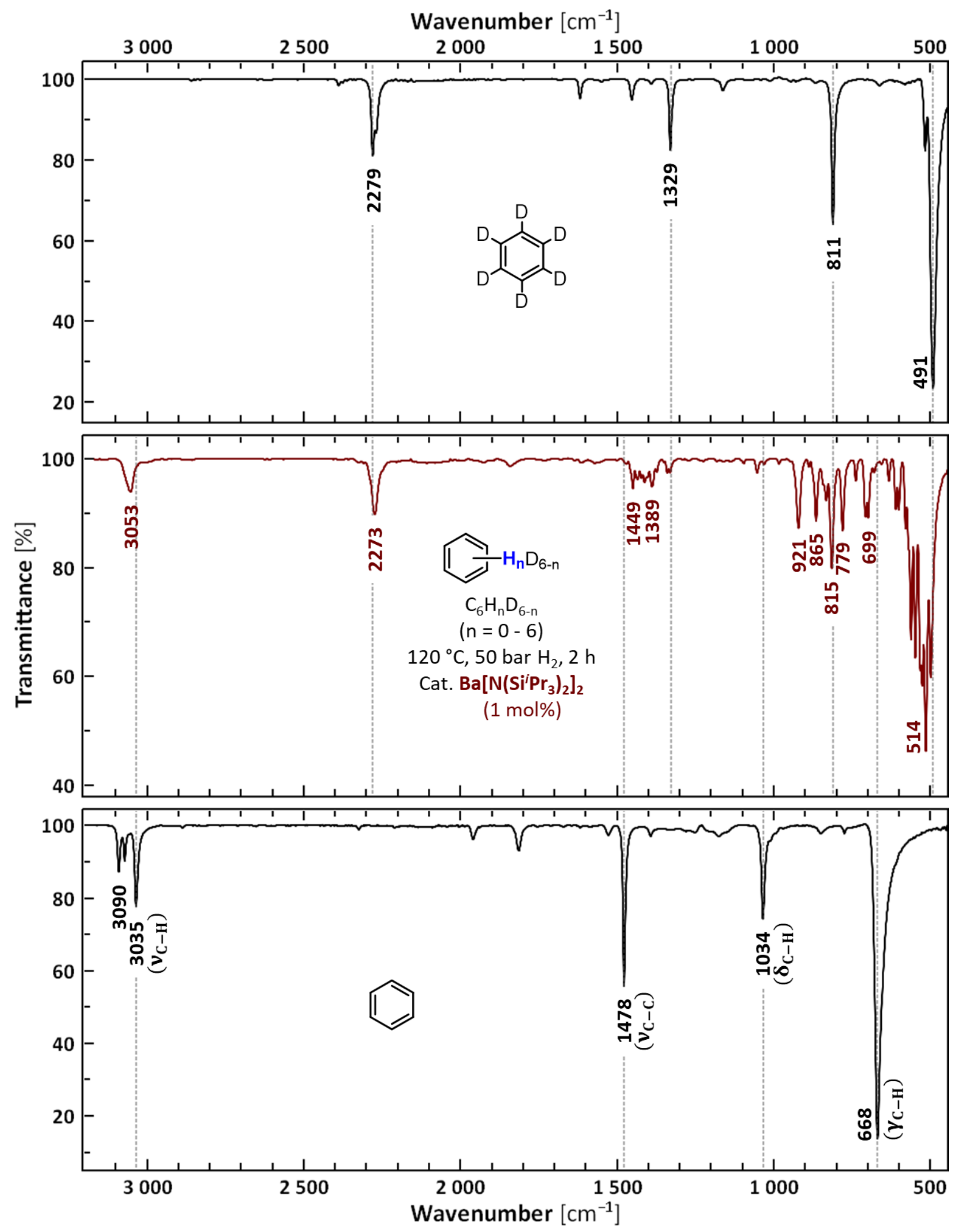

Figure S6. Stacked FT-IR spectra of (center) the distilled $\mathrm{C}_{6} \mathrm{H}_{n} \mathrm{D}_{6-n}(n=0-6)$ isotopologues mixture after the catalytic deuterium for hydrogen exchange in $\mathrm{C}_{6} \mathrm{D}_{6}$ with $\mathrm{H}_{2}\left(50\right.$ bar) and $\mathrm{Ba}\left[\mathrm{N}\left(\mathrm{Si}^{i} \mathrm{Pr}_{3}\right)_{2}\right]_{2}(1 \mathrm{~mol} \%)$ as pre-catalyst as well as authentic (top) $\mathrm{C}_{6} \mathrm{D}_{6}$ and (bottom) all-protio $\mathrm{C}_{6} \mathrm{H}_{6}$ for reference. 
(a)

${ }^{1}$ H NMR

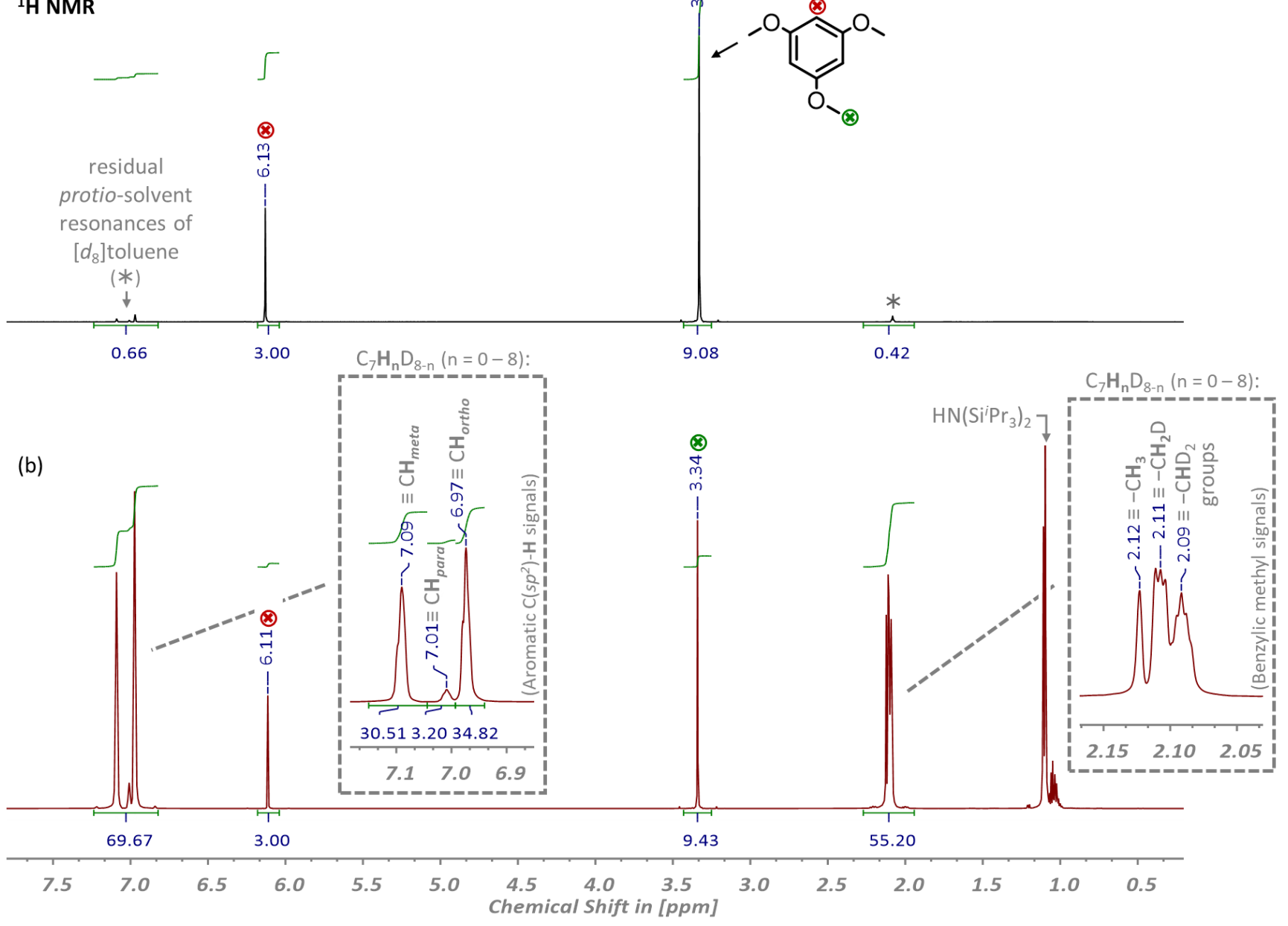

Figure S7. Stacked ${ }^{1} \mathrm{H}$ NMR spectra $\left(600 \mathrm{MHz},\left[d_{8}\right]\right.$ toluene, $\left.25^{\circ} \mathrm{C}\right)$ of $(a)$ the authentic $\left[d_{8}\right]$ toluene substrate and (b) the $\mathrm{C}_{7} \mathrm{H}_{n} \mathrm{D}_{8-n}(n=0-8)$ isotopologues mixture obtained after the catalytic deuterium for hydrogen exchange with $\mathrm{H}_{2}$ (50 bar) and $\mathrm{Ba}\left[\mathrm{N}\left(\mathrm{Si}^{i} \mathrm{Pr}_{3}\right)_{2}\right]_{2}(1 \mathrm{~mol} \%)$ as catalyst precursor at $120^{\circ} \mathrm{C}$ for 2 hours. Note: 1,3,5-Trimethoxybenzene was added as an internal standard. 
Aromatic $\mathrm{C}\left(s p^{2}\right)-\mathrm{D}$ resonances

of $\left[d_{8}\right]$ toluene $(*)$ :

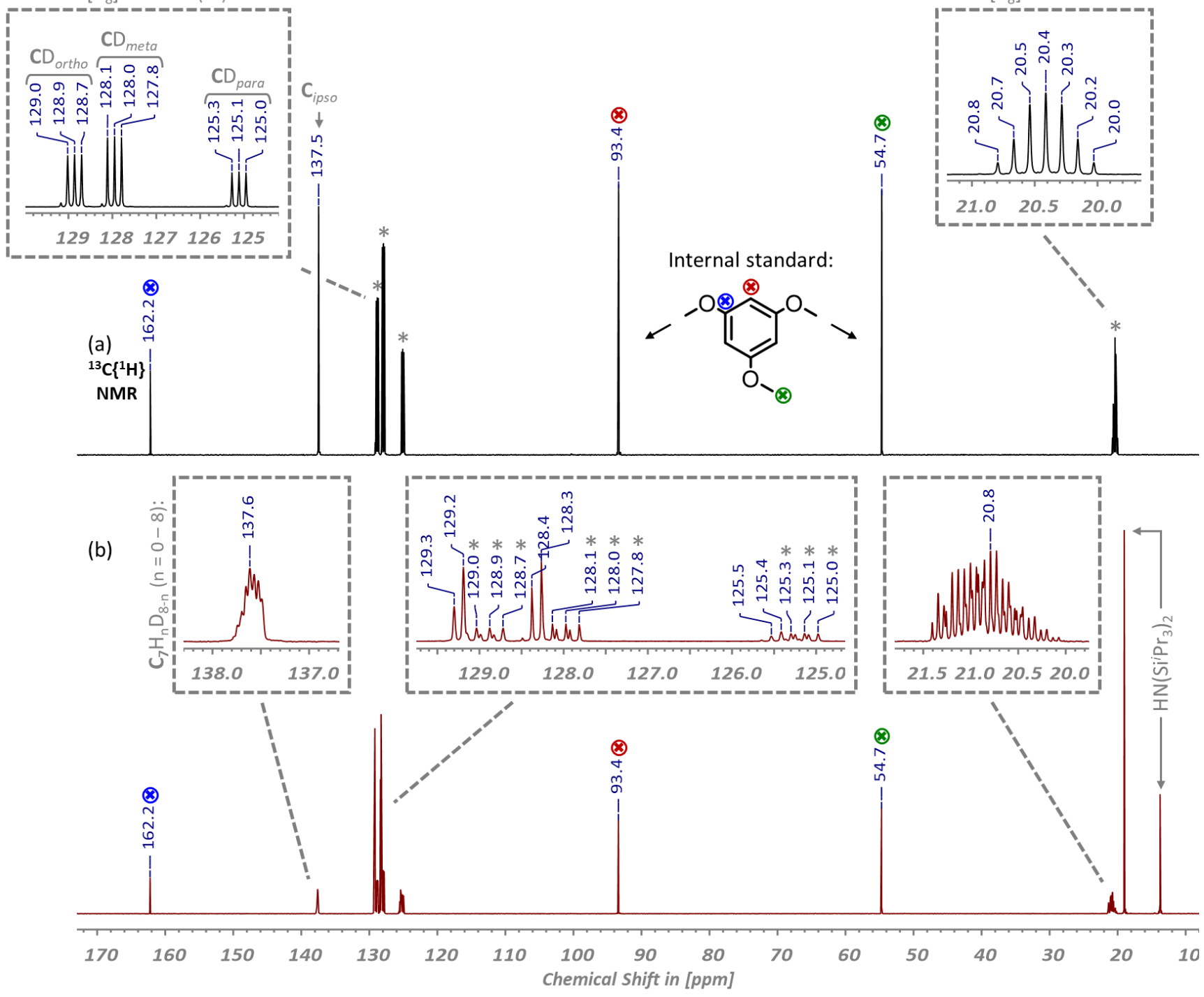

Figure S8. Stacked ${ }^{13} \mathrm{C}\left\{{ }^{1} \mathrm{H}\right\}$ NMR spectra $\left(151 \mathrm{MHz},\left[d_{8}\right]\right.$ toluene, $\left.25^{\circ} \mathrm{C}\right)$ of $(a)$ the authentic $\left[d_{8}\right]$ toluene substrate and $(b)$ the $\mathrm{C}_{7} \mathrm{H}_{n} \mathrm{D}_{8-n}(n=0-8)$ isotopologues mixture obtained after the catalytic deuterium for hydrogen exchange with $\mathrm{H}_{2}\left(50\right.$ bar) and $\mathrm{Ba}\left[\mathrm{N}\left(\mathrm{Si}^{i} \mathrm{Pr}_{3}\right)_{2}\right]_{2}\left(1\right.$ mol\%) as catalyst precursor at $120^{\circ} \mathrm{C}$ for 2 hours. Note: 1,3,5-Trimethoxybenzene was used as an internal standard. 


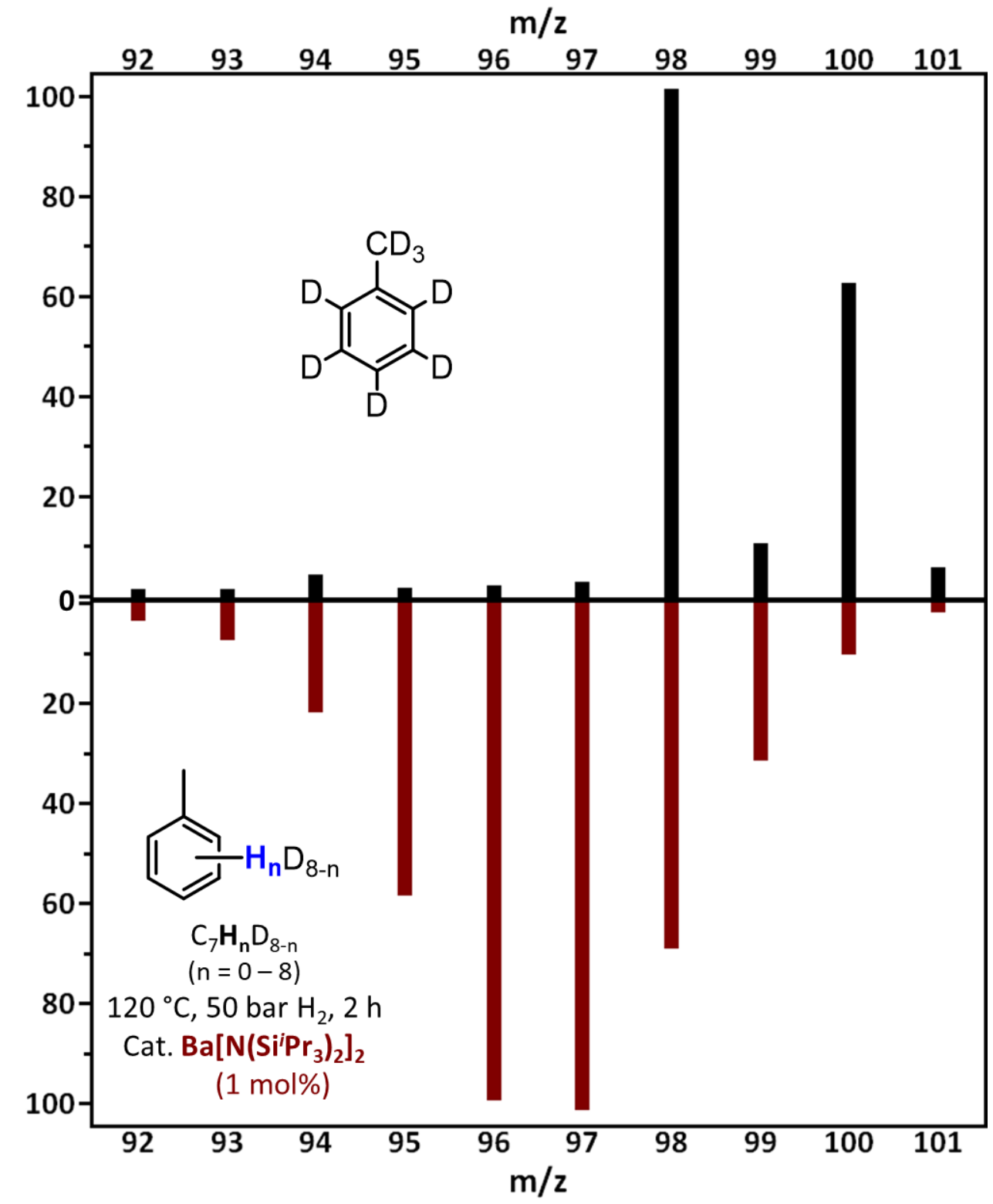

Figure S9. Stacked mass spectra of (top) the authentic $\left[d_{8}\right]$ toluene substrate and (bottom) the $\mathrm{C}_{7} \mathrm{H}_{n} \mathrm{D}_{8-n}(n=0-8)$ product obtained after the catalytic deuterium for hydrogen exchange with $\mathrm{H}_{2}\left(50 \text { bar) and } \mathrm{Ba}\left[\mathrm{N}\left(\mathrm{Si}^{\mathrm{i}} \mathrm{Pr}_{3}\right)_{2}\right)\right]_{2}$ (1 mol\%) as catalyst precursor at $120^{\circ} \mathrm{C}$ for 2 hours. 


\section{General Catalytic Procedure for Hydrogen Isotope Exchange in $C_{6} D_{6}$ with $H_{2}$ and Quantification of Isotopic Incorporation:}

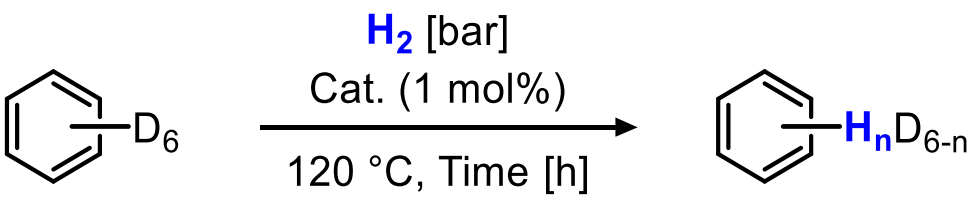

Unless otherwise stated, all deuterium for hydrogen exchange reactions in $\mathrm{C}_{6} \mathrm{D}_{6}$ with $\mathrm{H}_{2}$ were performed as follows:

In an $\mathrm{N}_{2}$-filled glovebox, an oven-dried miniature stainless steel autoclave (15 $\mathrm{mL}$ ) equipped with a magnetic stir bar was charged with the specified crystalline alkaline earth metal pre-catalyst $(0.11 \mathrm{mmol}$, $1 \mathrm{~mol} \%)$ and $\mathrm{C}_{6} \mathrm{D}_{6}(1 \mathrm{~mL}, 950 \mathrm{mg}, 11.29 \mathrm{mmol})$. The tightly sealed pressure vessel was transferred out of the glovebox, connected to $\mathrm{a}_{2}$ gas manifold and the supply line was evacuated and refilled several times with $\mathrm{N}_{2}$, followed by three times with $\mathrm{H}_{2}$. The reactor was then pressurized to the desired pressure with $\mathrm{H}_{2}$ gas $\left(10,30\right.$ or 50 bar), re-sealed and heated at $120^{\circ} \mathrm{C}$ in a preheated aluminum block. After stirring the reaction mixture for the indicated amount of time, the autoclave was allowed to cool to room temperature and carefully vented in a fume hood. Catalyst decomposition products were separated by filtration through a glass microfiber filter in a Pasteur pipette. An aliquot of the crude filtrate $(500 \mu \mathrm{L})$ was charged with cyclohexane $(20 \mu \mathrm{L}, 15.6 \mathrm{mg}, 0.19 \mathrm{mmol})$ as internal standard for determining the isotopic incorporation and analyzed by ${ }^{1} \mathrm{H}$ NMR spectroscopy without additional purification. The hydrogen incorporation was further qualitatively verified via ${ }^{13} \mathrm{C}\left\{{ }^{1} \mathrm{H}\right\} \mathrm{NMR}$ spectroscopy and GC/MS analysis. In case of $\mathrm{Ae}\left[\mathrm{N}(\mathrm{DIPP})\left(\mathrm{Si}^{i} \mathrm{Pr}_{3}\right)\right]_{2}(\mathrm{Ae}=\mathrm{Ca}, \mathrm{Sr}, \mathrm{Ba})$ as pre-catalysts, the crude reaction mixture was additionally purified by vacuum distillation for removal of $\mathrm{HN}(\mathrm{DIPP})\left(\mathrm{Si}^{i} \mathrm{Pr}_{3}\right)$ prior to NMR analysis. Note: Under the present reaction conditions, no reduction of aromatic $\left[d_{6}\right]$ benzene to cyclohexane isotopologues (i.e. $\mathrm{C}_{6} \mathrm{H}_{6+n} \mathrm{D}_{6-n} ; n=0-6$ ) was observed. ${ }^{2}$

The \% hydrogen incorporation was defined as percentage of $\mathrm{C}-\mathrm{D}$ bonds converted to $\mathrm{C}-\mathrm{H}$ bonds and determined experimentally by comparing the ${ }^{1} \mathrm{H}$ NMR integral intensity of the protio-benzene signal to the resonance of the internal cyclohexane standard. ${ }^{5}$ The reported values have been corrected for the minor amounts of protio-solvent residues (i.e. mainly $\left.\mathrm{C}_{6} \mathrm{D}_{5} \mathrm{H}\right)^{6}$ in the $\mathrm{C}_{6} \mathrm{D}_{6}$ starting material. 
Turnover numbers (TONs) were calculated as mol of hydrogen incorporated per mol of catalyst: ${ }^{5}$

$$
\text { TON }=\frac{\text { mol of hydrogen incorporated }}{\text { mol of catalyst }}
$$

The theoretical maximum turnover number (TON $\mathrm{Nax}_{\max }$ corresponds to the TON required for complete hydrogen incorporation (600\%) in $\mathrm{C}_{6} \mathrm{D}_{6}$ as substrate, i.e. if only $\mathrm{C}_{6} \mathrm{H}_{6}$ would be observed after the hydrogen isotope exchange reaction. ${ }^{5}$ Thus, for a catalyst loading of 1 mol\%, the TON $\max$ would amount to 600 .

The turnover frequency (TOF) was defined as follows:

$$
\text { TOF }=\frac{\text { TON }}{\text { reaction time }[\mathrm{h}]}
$$

The turnover numbers (and TOFs) for the catalytic deuterium for hydrogen exchange in $\mathrm{C}_{6} \mathrm{D}_{6}$ with $\mathrm{H}_{2}$ mediated by representative alkaline earth metal amide pre-catalysts are summarized in Table S1 (vide infra). 
Table S1. Deuterium for hydrogen exchange in $\mathrm{C}_{6} \mathrm{D}_{6}$ with $\mathrm{H}_{2}$ mediated by alkaline earth metal amide catalyst precursors. $^{a}$

\begin{tabular}{|c|c|c|c|c|c|}
\hline \multirow[b]{3}{*}{ Entry } & \multirow{3}{*}{\multicolumn{2}{|c|}{$\begin{array}{c}\mathbf{H}_{\mathbf{2}} \text { [bar] } \\
\text { Cat. }(1 \mathrm{~mol} \%) \\
120{ }^{\circ} \mathrm{C} \text {, Time }[\mathrm{h}] \\
\mathbf{H}_{2} \text { [bar] }\end{array}$}} & \multirow[b]{3}{*}{ Time $[\mathrm{h}]$} & \multirow[b]{3}{*}{$\mathbf{T O N}^{b}$} & \multirow[b]{3}{*}{ TOF $\left[h^{-1}\right]$} \\
\hline & & & & & \\
\hline & & & & & \\
\hline 1 & $\mathrm{Ca}\left[\mathrm{N}\left(\mathrm{SiMe}_{3}\right)_{2}\right]_{2}$ & 10 & 2 & 0 & 0 \\
\hline 2 & $\mathrm{Ca}\left[\mathrm{N}(\mathrm{DIPP})\left(\mathrm{Si}^{\mathrm{i}} \mathrm{Pr}_{3}\right)\right]_{2}$ & 10 & 2 & 0.7 & 0.3 \\
\hline 3 & $\mathrm{Ca}\left[\mathrm{N}\left(\mathrm{Si}^{i} \mathrm{Pr}_{3}\right)_{2}\right]_{2}$ & 10 & 2 & 5.3 & 2.6 \\
\hline 4 & $\mathrm{Sr}\left[\mathrm{N}\left(\mathrm{SiMe}_{3}\right)_{2}\right]_{2}$ & 10 & 2 & 0 & 0 \\
\hline 5 & $\mathrm{Sr}\left[\mathrm{N}(\mathrm{DIPP})\left(\mathrm{Si}^{i} \mathrm{Pr}_{3}\right)\right]_{2}$ & 10 & 2 & 2.0 & 1.0 \\
\hline 6 & $\mathrm{Sr}\left[\mathrm{N}\left(\mathrm{Si}^{i} \mathrm{Pr}_{3}\right)_{2}\right]_{2}$ & 10 & 2 & 36 & 18 \\
\hline 7 & $\mathrm{Ba}\left[\mathrm{N}\left(\mathrm{SiMe}_{3}\right)_{2}\right]_{2}$ & 10 & 2 & 2.3 & 1.2 \\
\hline 8 & $\mathrm{Ba}\left[\mathrm{N}\left(\mathrm{SiMe}_{3}\right)_{2}\right]_{2}$ & 10 & 24 & 8.1 & 0.3 \\
\hline 9 & $\mathrm{Ba}\left[\mathrm{N}\left(\mathrm{SiMe}_{3}\right)_{2}\right]_{2}$ & 10 & 48 & 11 & 0.2 \\
\hline 10 & $\mathrm{Ba}\left[\mathrm{N}\left(\mathrm{SiMe}_{3}\right)_{2}\right]_{2}$ & 50 & 2 & 1.4 & 0.7 \\
\hline 11 & $\mathrm{Ba}\left[\mathrm{N}(\mathrm{DIPP})\left(\mathrm{Si}^{i} \mathrm{Pr}_{3}\right)\right]_{2}$ & 10 & 2 & 10 & 5.0 \\
\hline 12 & $\mathrm{Ba}\left[\mathrm{N}(\mathrm{DIPP})\left(\mathrm{Si}^{i} \mathrm{Pr}_{3}\right)\right]_{2}$ & 10 & 24 & 46 & 1.9 \\
\hline 13 & $\mathrm{Ba}\left[\mathrm{N}(\mathrm{DIPP})\left(\mathrm{Si}^{i} \mathrm{Pr}_{3}\right)\right]_{2}$ & 10 & 48 & 65 & 1.4 \\
\hline 14 & $\mathrm{Ba}\left[\mathrm{N}(\mathrm{DIPP})\left(\mathrm{Si}^{i} \mathrm{Pr}_{3}\right)\right]_{2}$ & 50 & 2 & 8.3 & 4.2 \\
\hline
\end{tabular}


Table S1 (contd.). Deuterium for hydrogen exchange in $\mathrm{C}_{6} \mathrm{D}_{6}$ with $\mathrm{H}_{2}$ mediated by alkaline earth metal pre-catalysts. $^{a}$

\begin{tabular}{cccccc}
\hline Entry & Catalyst & $\mathbf{H}_{2}[$ bar $]$ & Time $[\mathrm{h}]$ & TON $^{b}$ & TOF $\left.^{-1}{ }^{-1}\right]$ \\
\hline 15 & $\mathrm{Ba}\left[\mathrm{N}\left(\mathrm{Si}^{\mathrm{i}} \mathrm{Pr}_{3}\right)_{2}\right]_{2}$ & 10 & 0.5 & 62 & 123 \\
16 & $\mathrm{Ba}\left[\mathrm{N}\left(\mathrm{Si}^{\mathrm{P}} \mathrm{Pr}_{3}\right)_{2}\right]_{2}$ & 10 & 1 & 69 & 69 \\
17 & $\mathrm{Ba}\left[\mathrm{N}\left(\mathrm{Si}^{i} \mathrm{Pr}_{3}\right)_{2}\right]_{2}$ & 10 & 2 & 69 & 35 \\
18 & $\mathrm{Ba}\left[\mathrm{N}\left(\mathrm{Si}^{i} \mathrm{Pr}_{3}\right)_{2}\right]_{2}$ & 10 & 8 & 72 & 9.1 \\
19 & $\mathrm{Ba}\left[\mathrm{N}\left(\mathrm{Si}^{i} \mathrm{Pr}_{3}\right)_{2}\right]_{2}$ & 10 & 24 & 71 & 3.0 \\
20 & $\mathrm{Ba}\left[\mathrm{N}\left(\mathrm{Si}^{i} \mathrm{Pr}_{3}\right)_{2}\right]_{2}$ & 30 & 2 & 159 & 80 \\
21 & $\mathrm{Ba}\left[\mathrm{N}\left(\mathrm{Si}^{i} \mathrm{Pr}_{3}\right)_{2}\right]_{2}$ & 50 & 0.5 & 134 & 268 \\
22 & $\mathrm{Ba}\left[\mathrm{N}\left(\mathrm{Si}^{i} \mathrm{Pr}_{3}\right)_{2}\right]_{2}$ & 50 & 2 & 205 & 102 \\
\hline
\end{tabular}

${ }^{a}$ General catalytic reaction conditions: $\mathrm{C}_{6} \mathrm{D}_{6}(1 \mathrm{~mL}, 950 \mathrm{mg}, 11.29 \mathrm{mmol})$, Ae metal catalyst precursor $(0.11 \mathrm{mmol}, 1 \mathrm{~mol} \%)$, $120^{\circ} \mathrm{C}$. ${ }^{b}$ Turnover numbers (TONs) were defined as the number of $\mathrm{D} / \mathrm{H}$ exchanges per catalyst molecule and determined experimentally by ${ }^{1} \mathrm{H}$ NMR spectroscopy using cyclohexane as an internal standard. ). With $1 \mathrm{~mol} \%$ catalyst, the TON equals the percentage of conversion for a single deuteration (numbers $>100$ relate to multiple $\mathrm{D} / \mathrm{H}$ exchange and for benzene a maximum TON of 600 , i.e. full deuteration, can be achieved). 


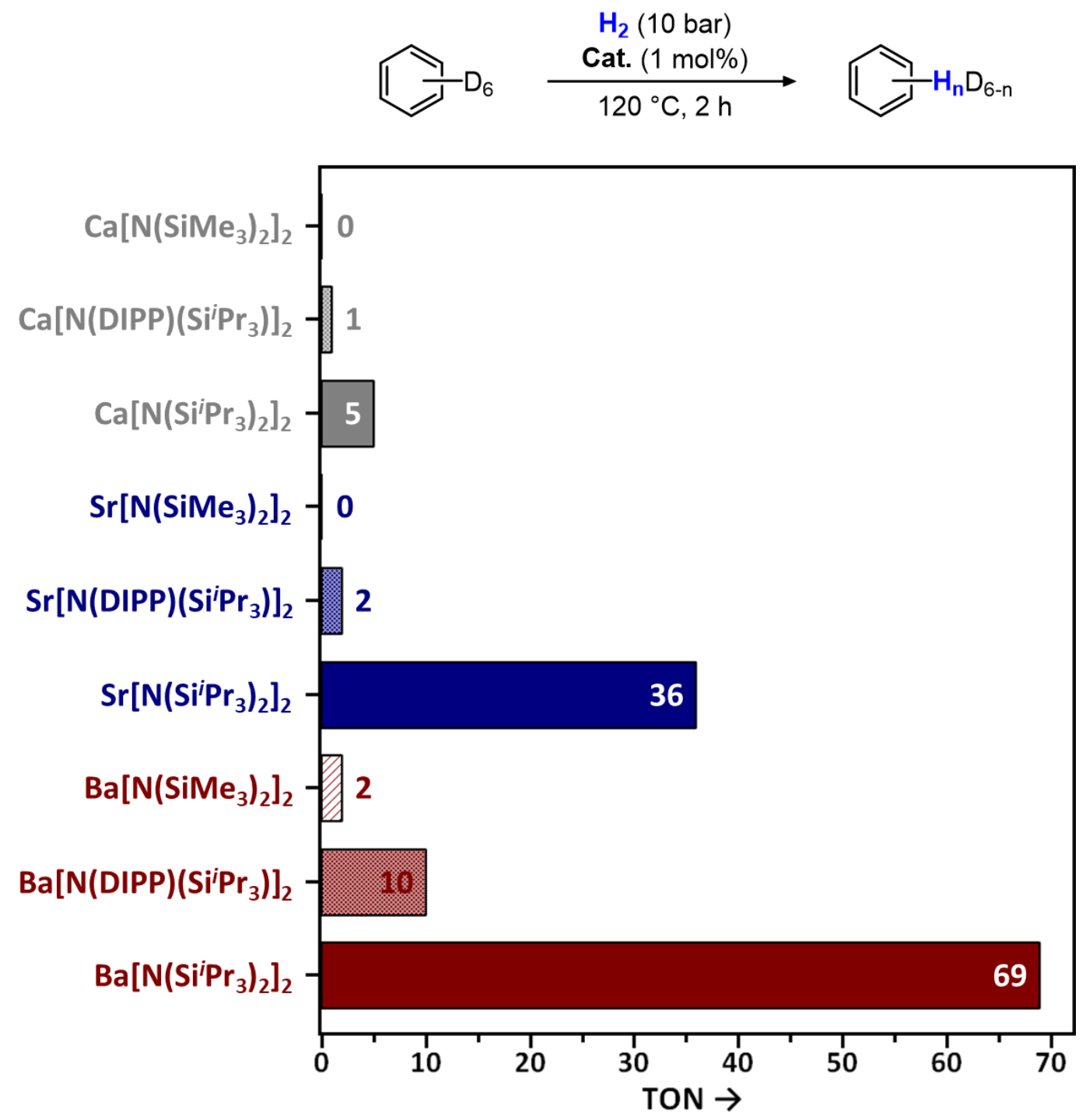

Figure S10. Turnover numbers (TONs) for the catalytic deuterium for hydrogen exchange between $\mathrm{C}_{6} \mathrm{D}_{6}$ and $\mathrm{H}_{2}$ using various alkaline earth metal amide complexes as catalyst precursors.

Reaction conditions: $\mathrm{C}_{6} \mathrm{D}_{6}(1 \mathrm{~mL}, 950 \mathrm{mg}, 11.29 \mathrm{mmol})$, Ae metal amide pre-catalyst $(0.11 \mathrm{mmol}, 1 \mathrm{~mol} \%)$, $\mathrm{H}_{2}$ (10 bar), $120^{\circ} \mathrm{C}, 2 \mathrm{~h}$. 
(a)

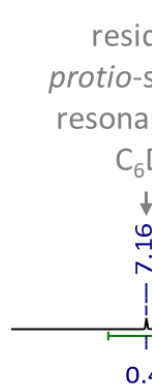

(b)

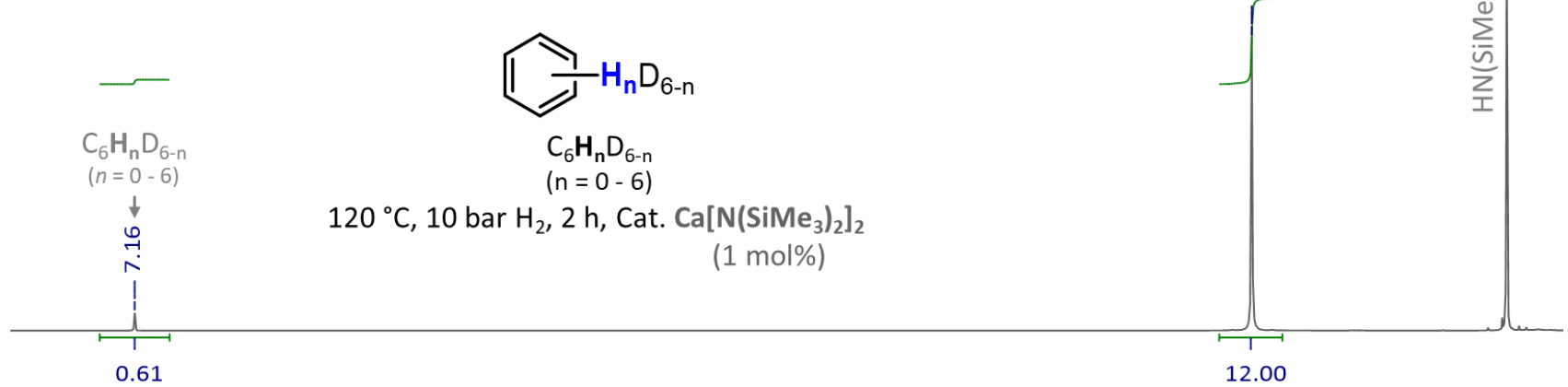

(c)

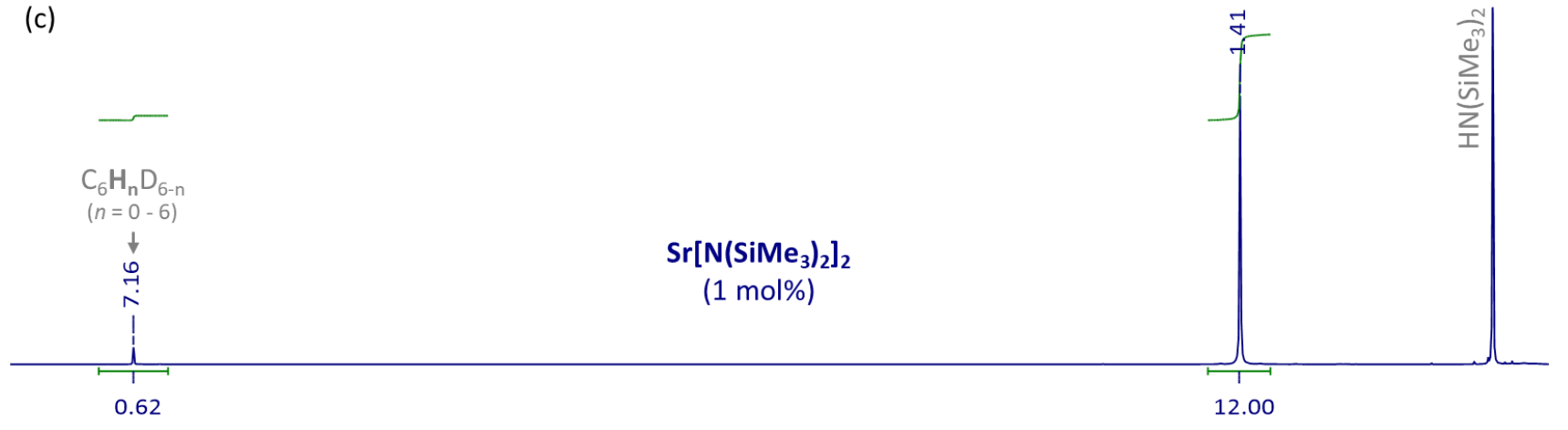

(d)

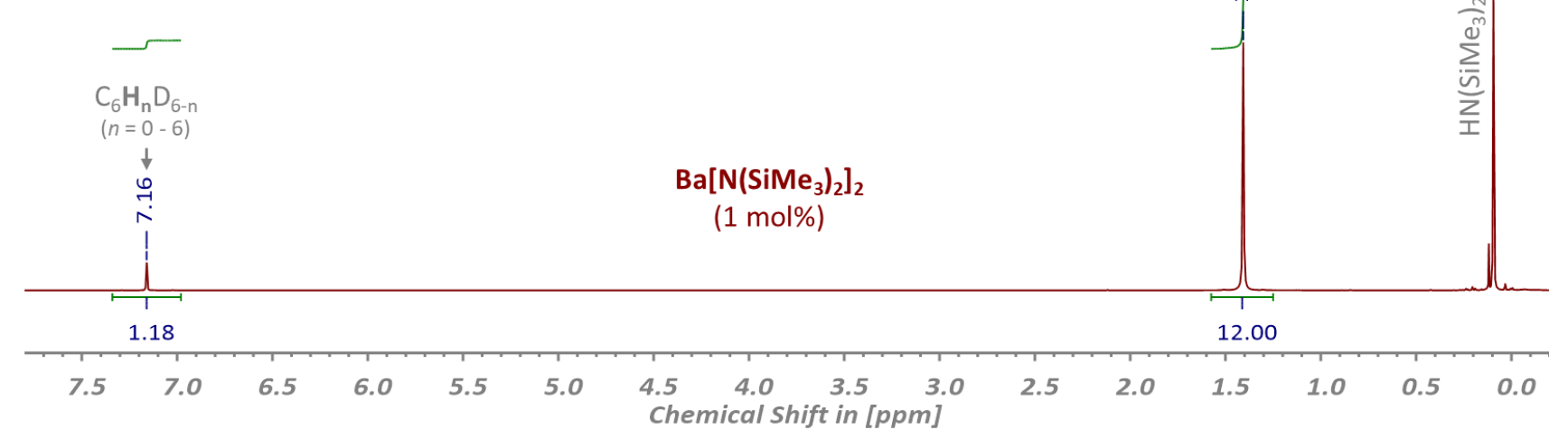

Figure S11. Stacked ${ }^{1} \mathrm{H}$ NMR spectra $\left(600 \mathrm{MHz}, \mathrm{C}_{6} \mathrm{D}_{6}, 25^{\circ} \mathrm{C}\right)$ of $(a)$ the authentic $\mathrm{C}_{6} \mathrm{D}_{6}$ substrate and the products obtained after the catalytic deuterium for hydrogen exchange with $\mathrm{H}_{2}\left(10\right.$ bar) at $120{ }^{\circ} \mathrm{C}$ for 2 hours using $\mathrm{Ae}\left[\mathrm{N}\left(\mathrm{SiMe}_{3}\right)_{2}\right]_{2}(1 \mathrm{~mol} \%)$ as catalyst precursors: $\mathrm{Ae}=(b) \mathrm{Ca},(c) \mathrm{Sr}$ and $(d) \mathrm{Ba}$ (Table S1, entries 1, 4 and 7). 
(a)

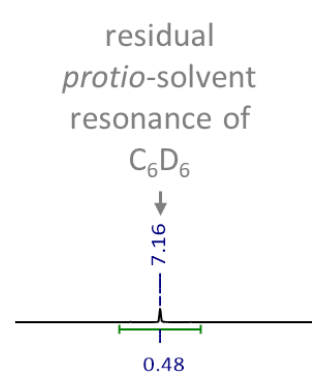

(b)

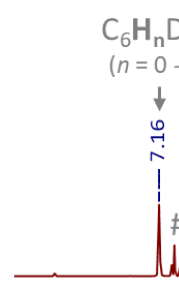

(c)
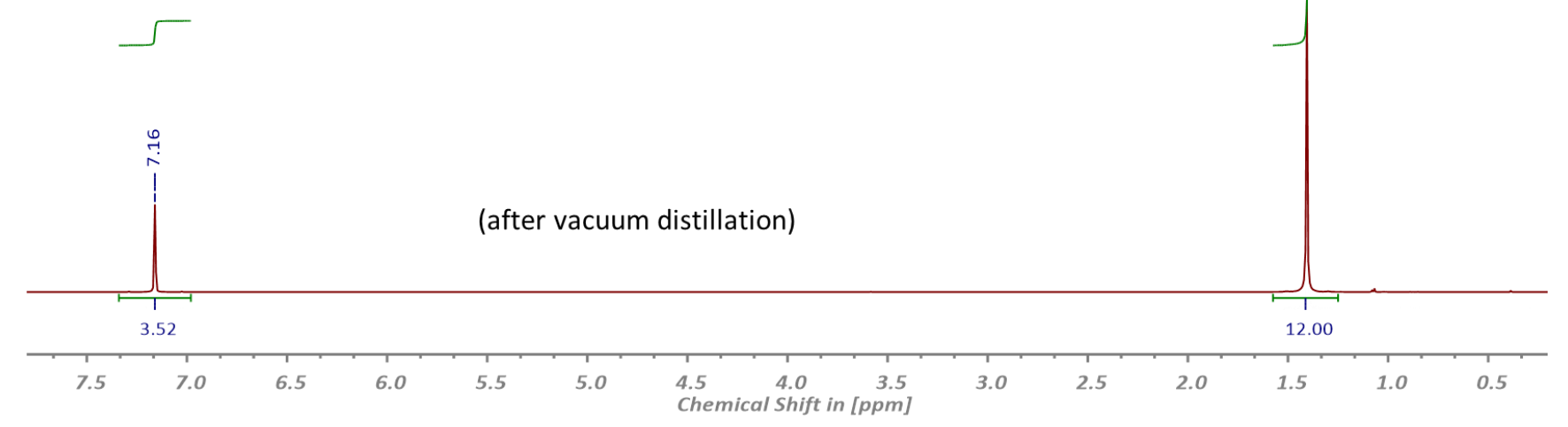

Figure S12. Stacked ${ }^{1} \mathrm{H}$ NMR spectra $\left(600 \mathrm{MHz}, \mathrm{C}_{6} \mathrm{D}_{6}, 25^{\circ} \mathrm{C}\right.$ ) of $(\mathrm{a})$ the authentic $\mathrm{C}_{6} \mathrm{D}_{6}$ starting material and the product mixture $(b)$ directly after the catalytic HIE reaction with $\mathrm{H}_{2}\left(10\right.$ bar) and $\mathrm{Ba}\left[\mathrm{N}(\mathrm{DIPP})\left(\mathrm{Si}^{i} \mathrm{Pr}_{3}\right)\right]_{2}(1 \mathrm{~mol} \%)$ as pre-catalyst at $120^{\circ} \mathrm{C}$ for 2 hours and (c) after purification via vacuum distillation (Table S1, entry 11). Notes: (i) Cyclohexane was added as an internal standard. (ii) \# denotes HN(DIPP)( $\left.\operatorname{Si}^{i} \mathrm{Pr}_{3}\right)$. 
(a)

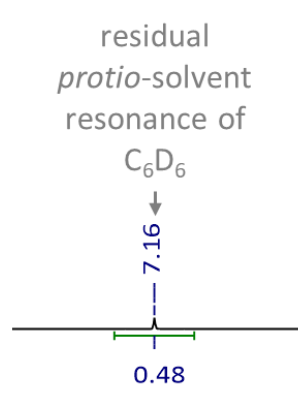

(b)

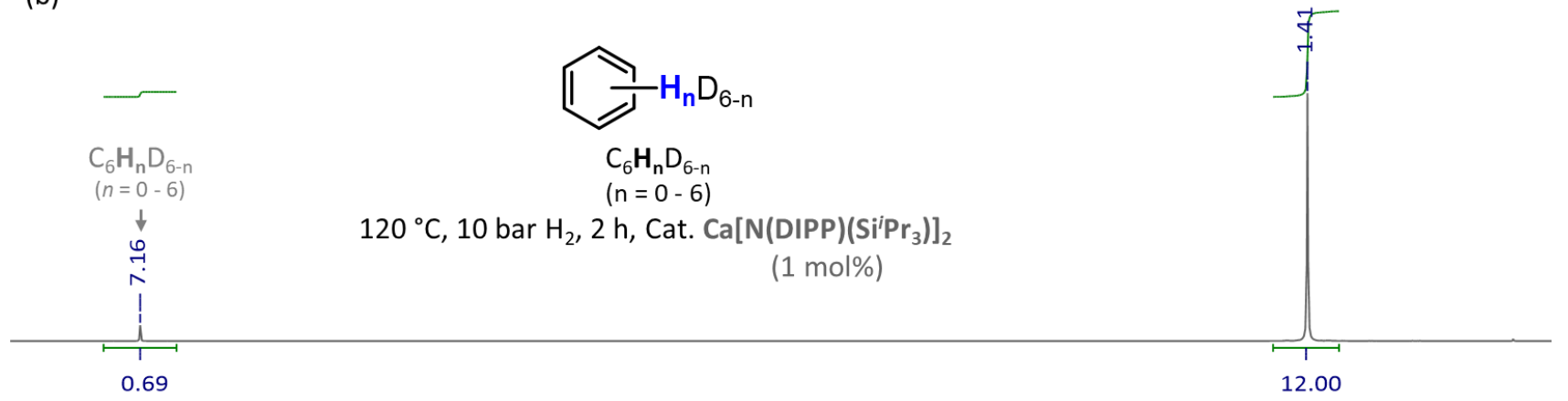

(c)

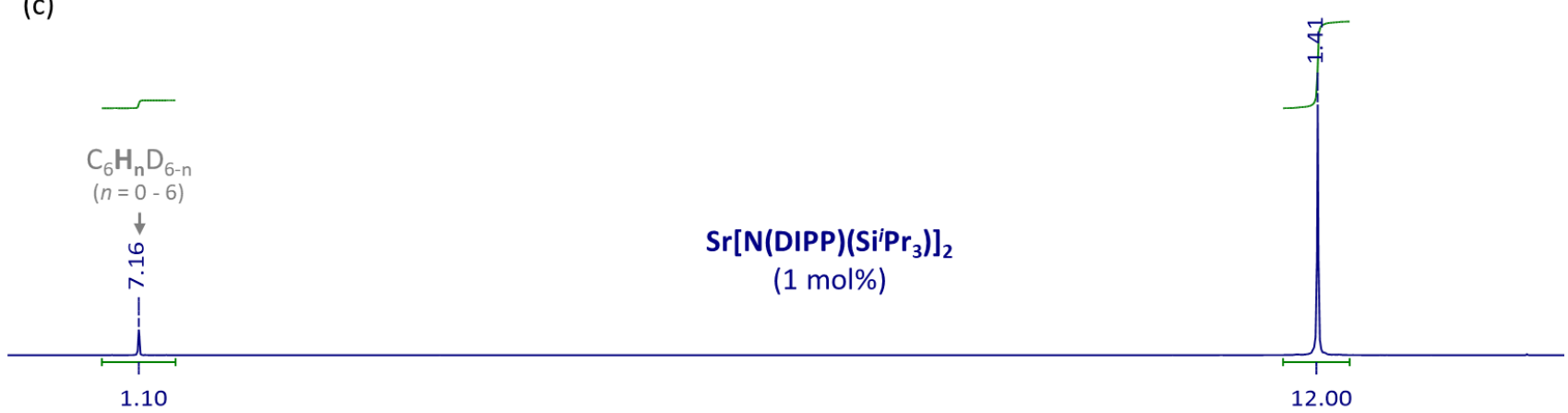

(d)
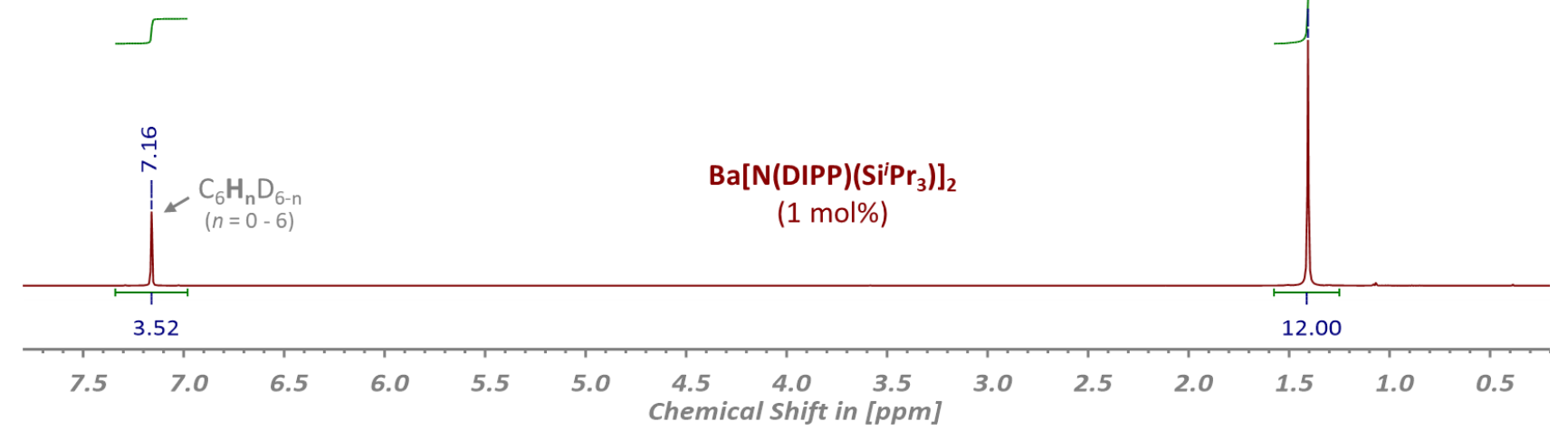

Figure S13. Stacked ${ }^{1} \mathrm{H}$ NMR spectra $\left(600 \mathrm{MHz}, \mathrm{C}_{6} \mathrm{D}_{6}, 25^{\circ} \mathrm{C}\right)$ of $(a)$ the authentic $\mathrm{C}_{6} \mathrm{D}_{6}$ substrate and the products obtained after the catalytic deuterium for hydrogen exchange with $\mathrm{H}_{2}$ (10 bar) at $120{ }^{\circ} \mathrm{C}$ for 2 hours using $\mathrm{Ae}\left[\mathrm{N}(\mathrm{DIPP})\left(\mathrm{Si}^{i} \mathrm{Pr}_{3}\right)\right]_{2}(1 \mathrm{~mol} \%)$ as catalyst precursors: $\mathrm{Ae}=(b) \mathrm{Ca},(c) \mathrm{Sr}$ and $(d) \mathrm{Ba}$ (Table S1, entries 2, 5 and 11). 


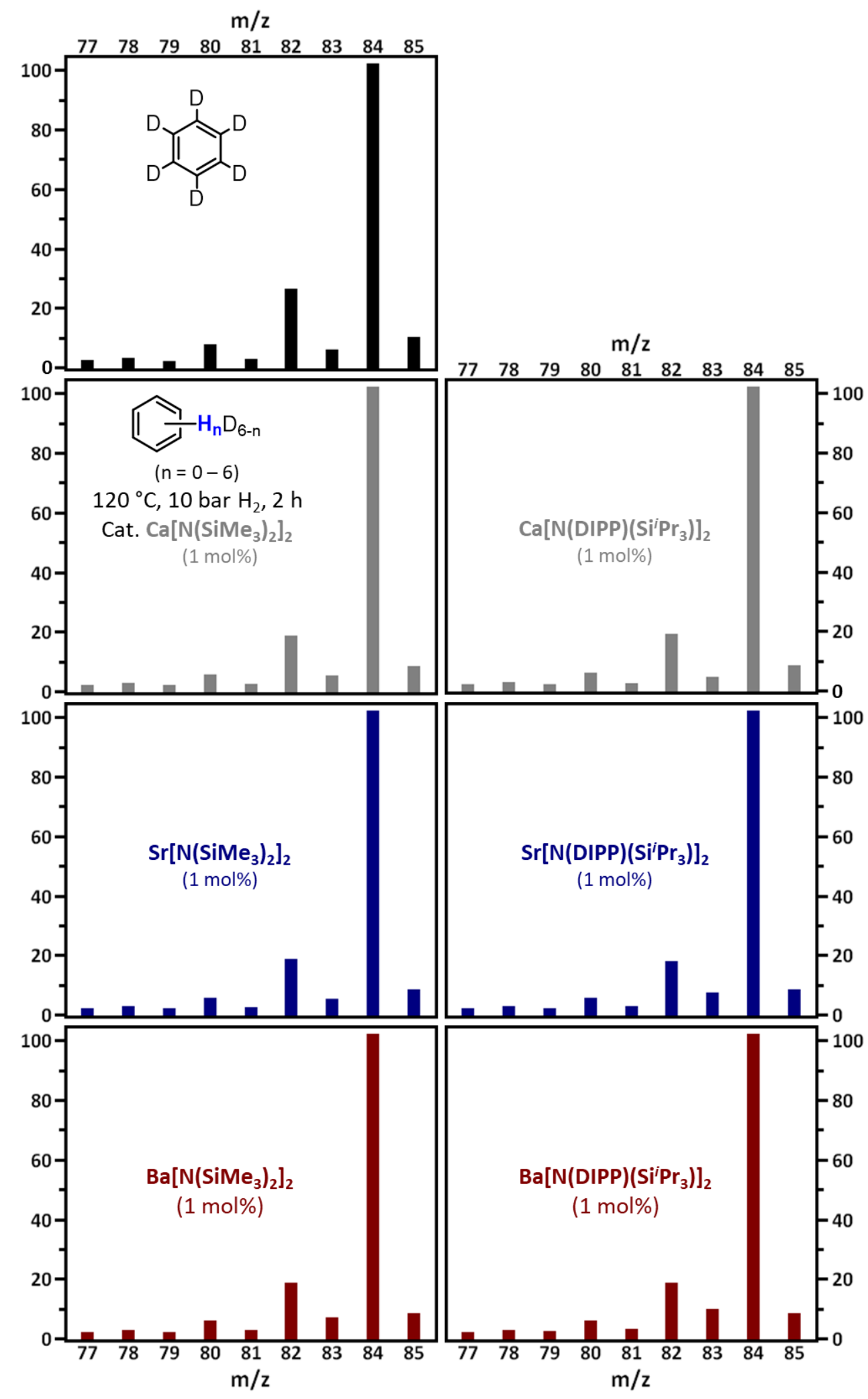

Figure S14. Mass spectra of the authentic $\mathrm{C}_{6} \mathrm{D}_{6}$ substrate and the products obtained after the catalytic deuterium for hydrogen exchange with $\mathrm{H}_{2}(10 \mathrm{bar})$ at $120{ }^{\circ} \mathrm{C}$ for 2 hours using $\mathrm{Ae}\left[\mathrm{N}\left(\mathrm{SiMe}_{3}\right)_{2}\right]_{2}(1 \mathrm{~mol} \%)$ and $\mathrm{Ae}\left[\mathrm{N}(\mathrm{DIPP})\left(\mathrm{Si}^{i} \mathrm{Pr}_{3}\right)\right]_{2}(1 \mathrm{~mol} \%)(\mathrm{Ae}=\mathrm{Ca}, \mathrm{Sr}, \mathrm{Ba})$ as catalyst precursors (Table S1, entries 1, 2, 4, 5, 7 and 11). 
(a)

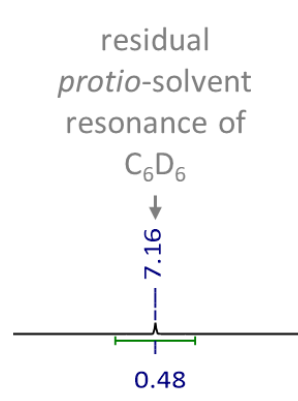

(b)

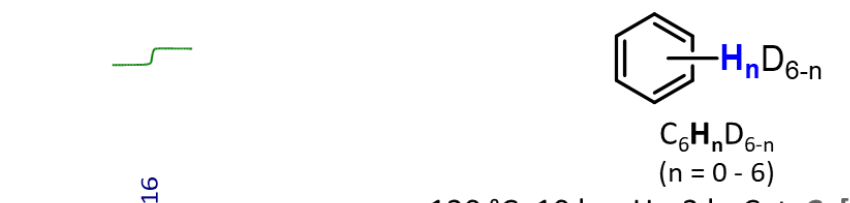<smiles>[2H]c1c([2H])c([2H])c([2H])c([2H])c1[2H]</smiles>

Internal standard:

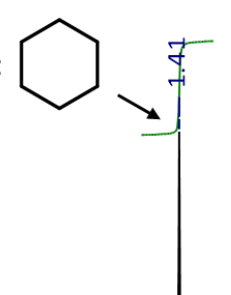

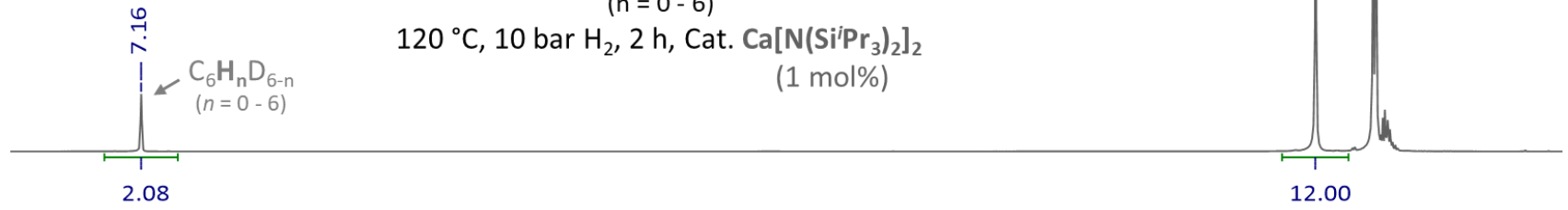

(c)

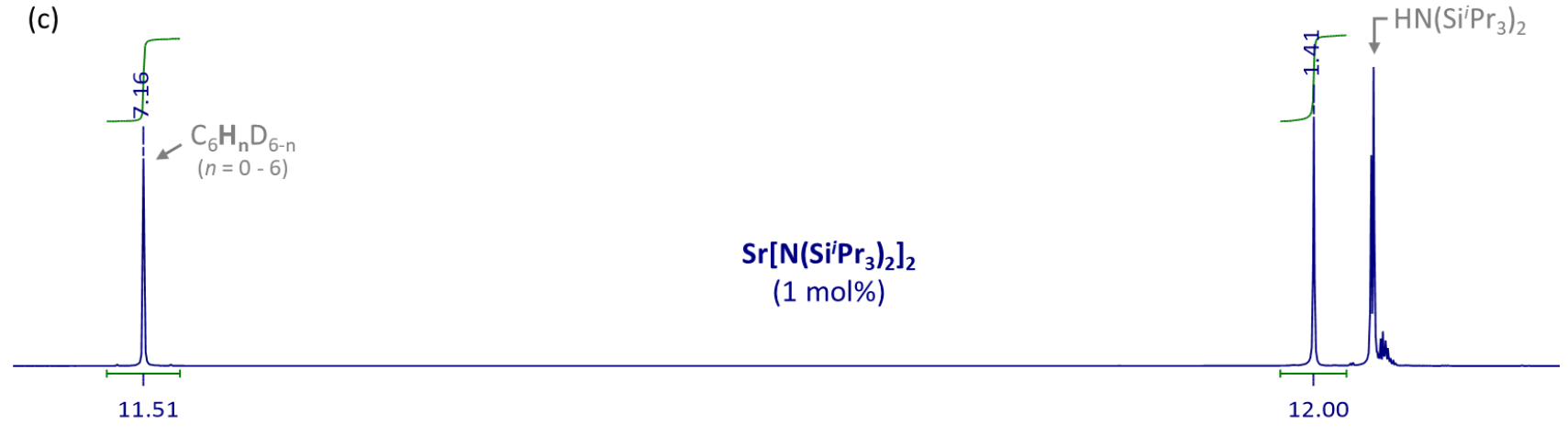

(d)

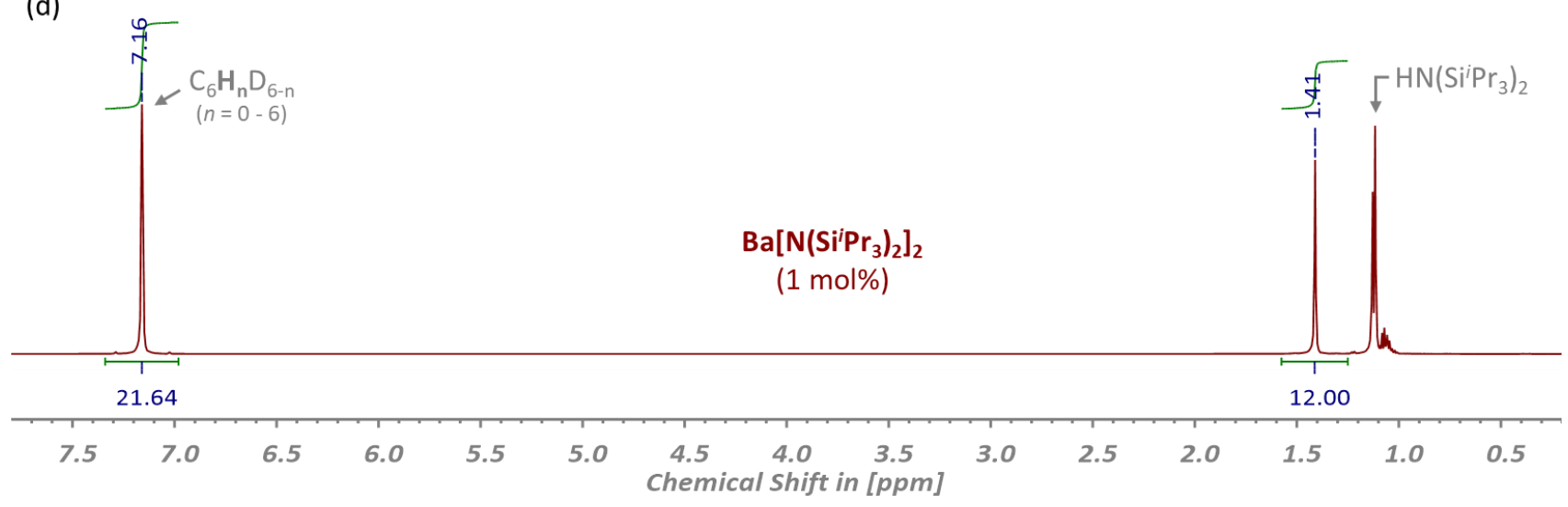

Figure S15. Stacked ${ }^{1} \mathrm{H}$ NMR spectra $\left(600 \mathrm{MHz}, \mathrm{C}_{6} \mathrm{D}_{6}, 25^{\circ} \mathrm{C}\right)$ of $(a)$ the authentic $\mathrm{C}_{6} \mathrm{D}_{6}$ substrate and the obtained products of the catalytic deuterium for hydrogen exchange with $\mathrm{H}_{2}\left(10\right.$ bar) at $120{ }^{\circ} \mathrm{C}$ for 2 hours using $\mathrm{Ae}\left[\mathrm{N}\left(\mathrm{Si}^{i} \mathrm{Pr}_{3}\right)_{2}\right]_{2}(1 \mathrm{~mol} \%)$ as catalyst precursors: $\mathrm{Ae}=(b) \mathrm{Ca},(c) \mathrm{Sr}$ and $(d) \mathrm{Ba}$ (Table S1, entries 3, 6 and 17). 

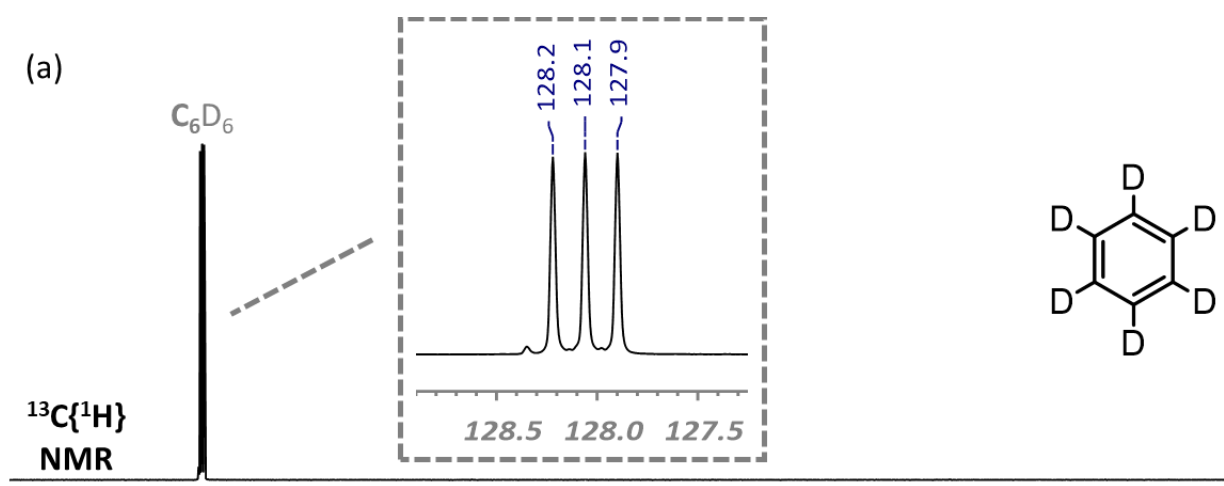

Internal

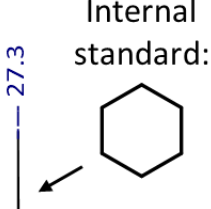

(b)
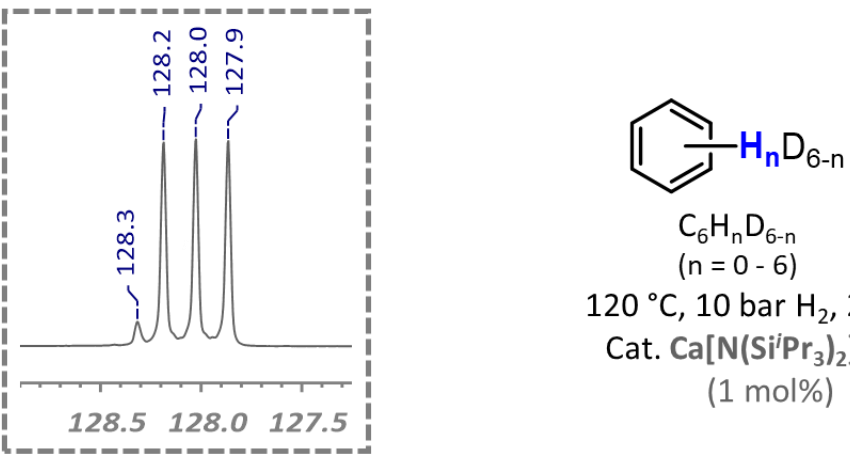

$120^{\circ} \mathrm{C}, 10$ bar $\mathrm{H}_{2}, 2 \mathrm{~h}$

Cat. $\mathrm{Ca}\left[\mathrm{N}\left(\mathrm{Si}^{\mathrm{P}} \mathrm{Pr}_{3}\right)_{2}\right]_{2}$

(1 mol\%)

(c)
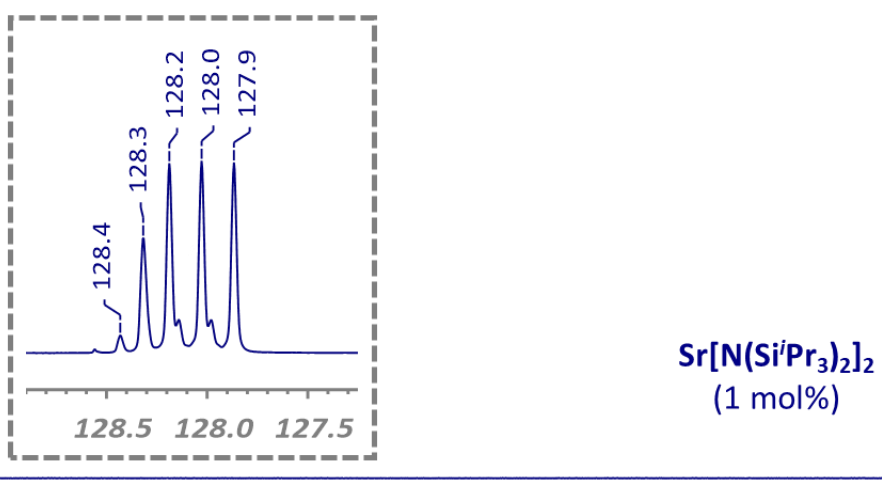

(d)
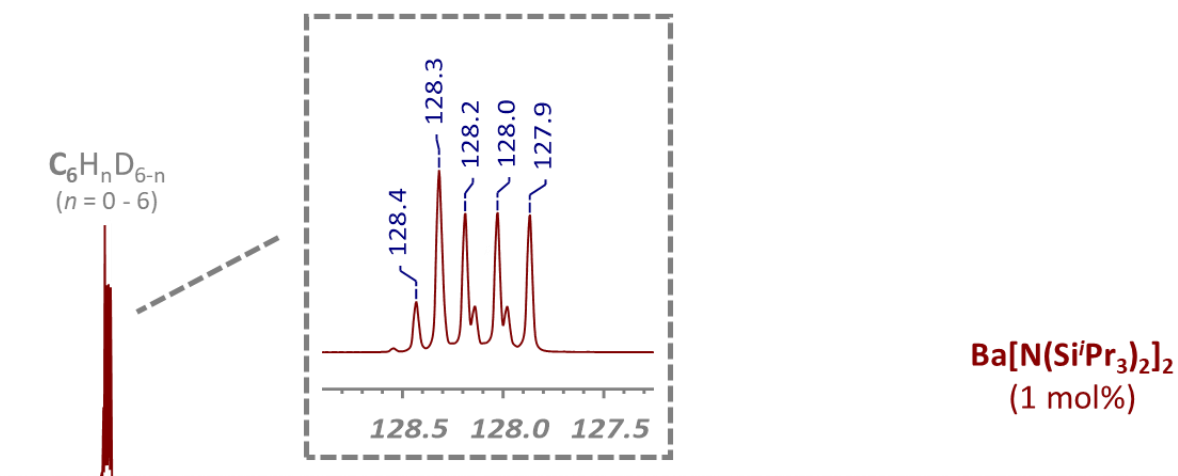

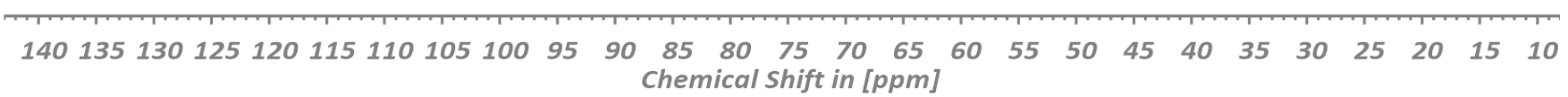

Figure S16. Stacked ${ }^{13} \mathrm{C}\left\{{ }^{1} \mathrm{H}\right\}$ NMR spectra $\left(151 \mathrm{MHz}, \mathrm{C}_{6} \mathrm{D}_{6}, 25^{\circ} \mathrm{C}\right)$ of $(a)$ the authentic $\mathrm{C}_{6} \mathrm{D}_{6}$ substrate and the products obtained after the catalytic deuterium for hydrogen exchange with $\mathrm{H}_{2}$ (10 bar) at $120^{\circ} \mathrm{C}$ for 2 hours using $\mathrm{Ae}\left[\mathrm{N}\left(\mathrm{Si}^{\prime} \mathrm{Pr}_{3}\right)_{2}\right]_{2}(1 \mathrm{~mol} \%)$ as catalyst precursors: $\mathrm{Ae}=(b) \mathrm{Ca},(c) \mathrm{Sr}$ and $(d) \mathrm{Ba}$ (Table S1, entries 3, 6 and 17). 

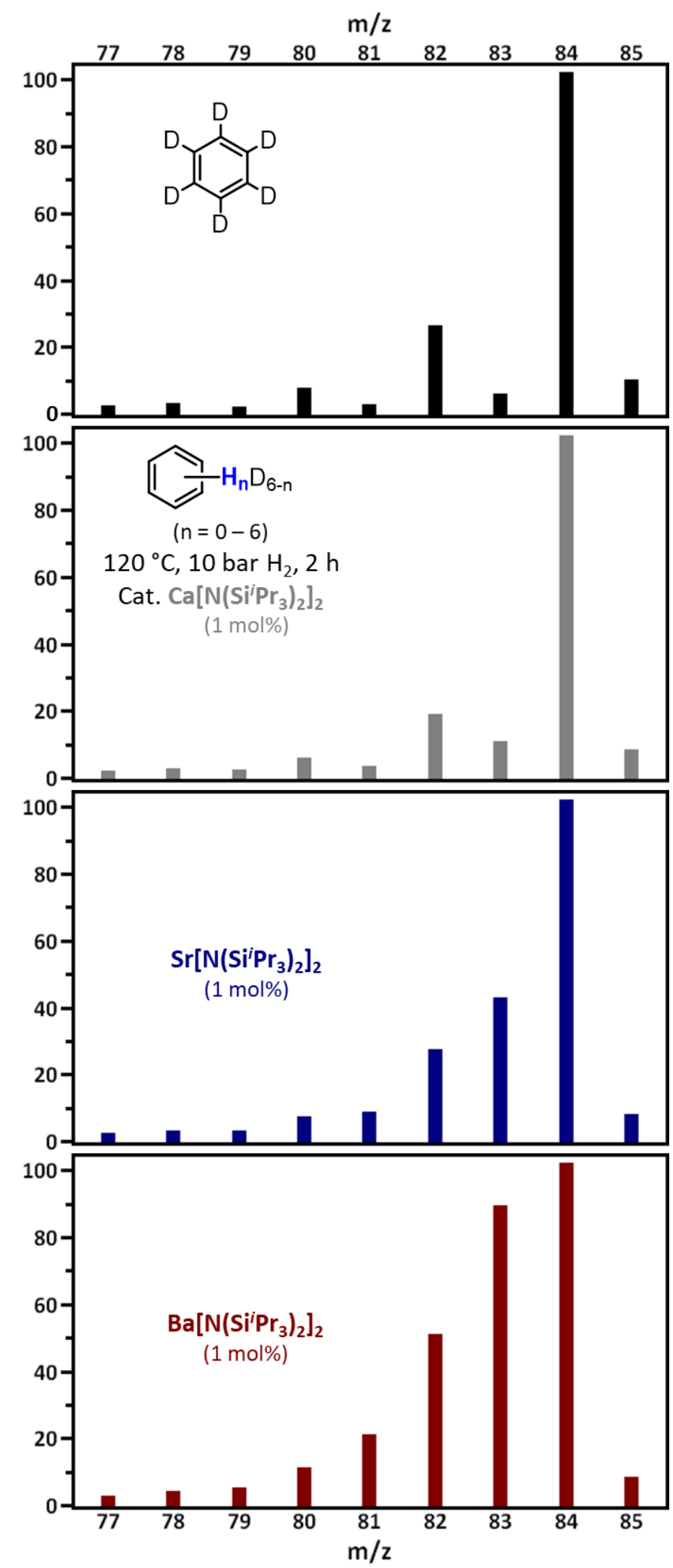

Figure S17. Stacked mass spectra of the authentic $\mathrm{C}_{6} \mathrm{D}_{6}$ substrate and the products obtained after the catalytic deuterium for hydrogen exchange with $\mathrm{H}_{2}(10 \mathrm{bar})$ and $\mathrm{Ae}\left[\mathrm{N}\left(\mathrm{Si}^{i} \mathrm{Pr}_{3}\right)_{2}\right]_{2}(1 \mathrm{~mol} \%)(\mathrm{Ae}=\mathrm{Ca}, \mathrm{Sr}, \mathrm{Ba})$ as catalyst precursors at $120^{\circ} \mathrm{C}$ for 2 hours (Table S1, entries 3, 6 and 17). 


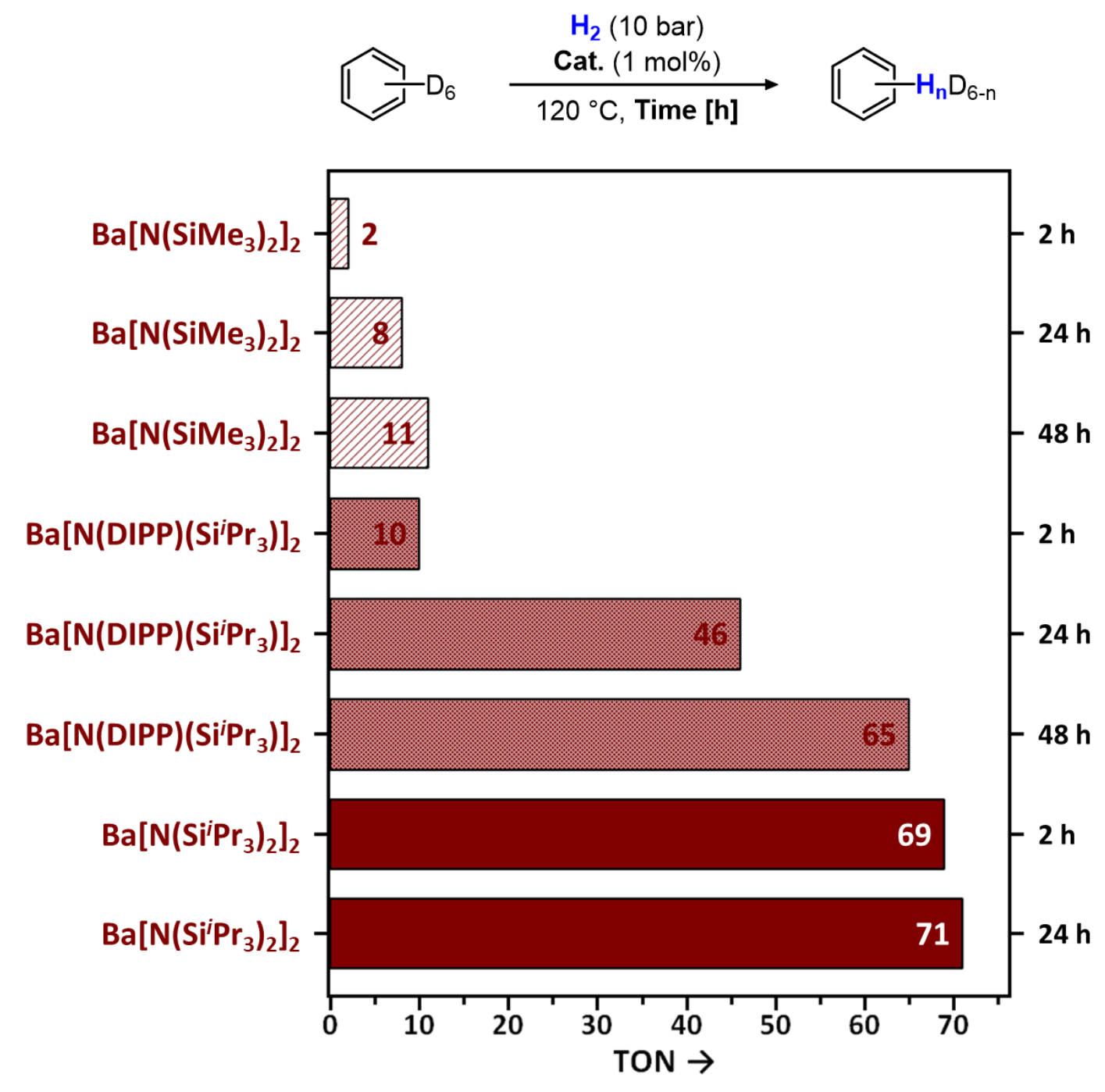

Figure S18. Evaluation of selected $\mathrm{Ba}$ amide catalyst precursors for the catalytic deuterium for hydrogen exchange between $\mathrm{C}_{6} \mathrm{D}_{6}$ and $\mathrm{H}_{2}$ as a function of reaction time (reported as turnover numbers).

Reaction conditions: $\mathrm{C}_{6} \mathrm{D}_{6}(1 \mathrm{~mL}, 950 \mathrm{mg}, 11.29 \mathrm{mmol})$, Cat. $\mathrm{Ba}\left[\mathrm{NR}_{2}\right]_{2}$ pre-catalyst $(0.11 \mathrm{mmol}, 1 \mathrm{~mol} \%), \mathrm{H}_{2}(10 \mathrm{bar})$, $120^{\circ} \mathrm{C}$. 
(a)

$$
\text { residual }
$$

protio-solvent

resonance of
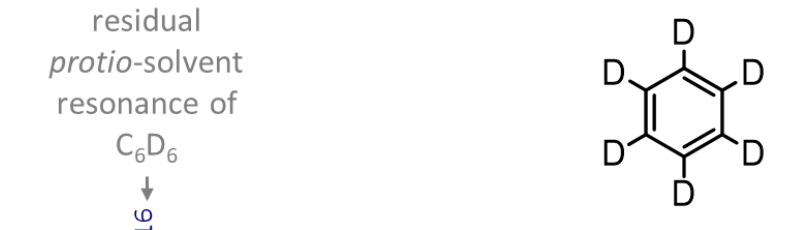

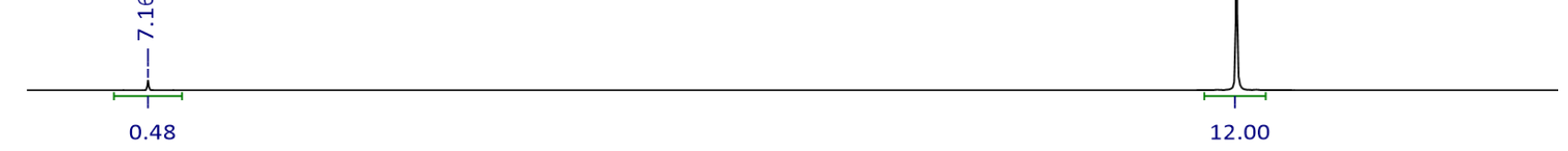

(b)

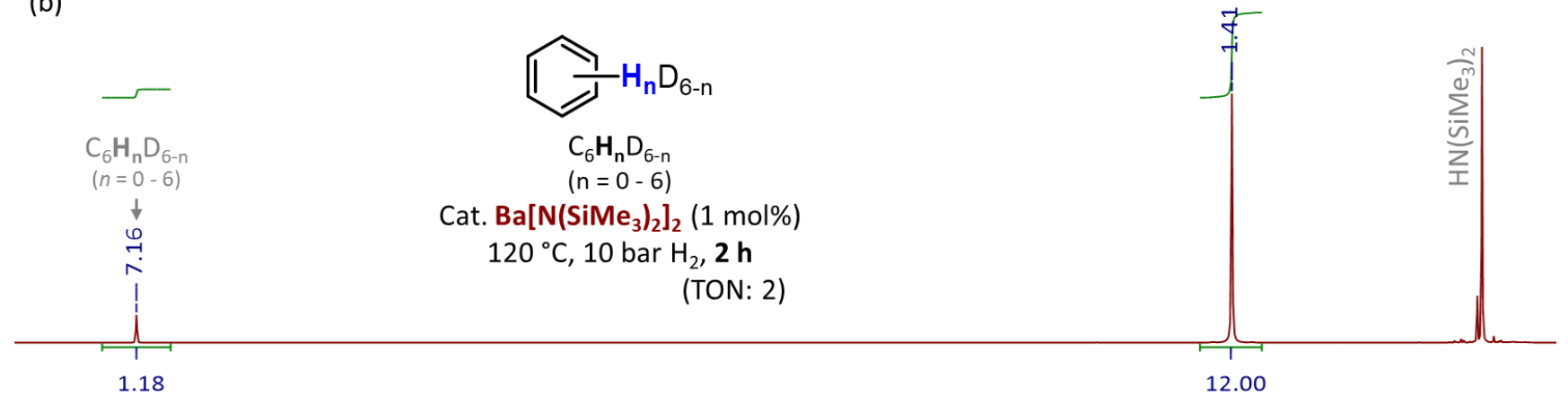

(c)
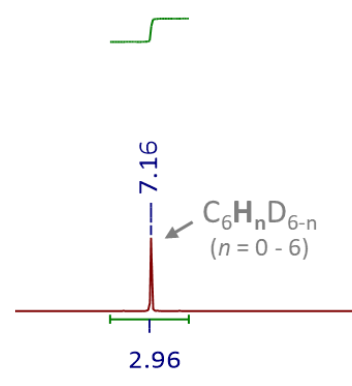

$24 \mathrm{~h}$

(TON: 8)

(d)

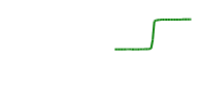

$\stackrel{\oplus}{\stackrel{\sim}{*}}$

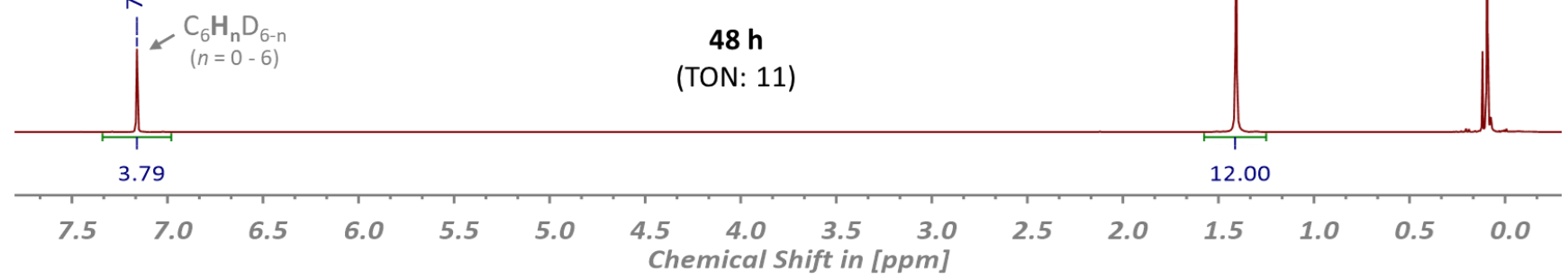

Figure S19. Stacked ${ }^{1} \mathrm{H}$ NMR spectra $\left(600 \mathrm{MHz}, \mathrm{C}_{6} \mathrm{D}_{6}, 25^{\circ} \mathrm{C}\right)$ of $(a)$ the authentic $\mathrm{C}_{6} \mathrm{D}_{6}$ substrate and the products of the catalytic deuterium for hydrogen exchange with $\mathrm{H}_{2}$ (10 bar) and $\mathrm{Ba}\left[\mathrm{N}\left(\mathrm{SiMe}_{3}\right)_{2}\right]_{2}(1 \mathrm{~mol} \%)$ as catalyst precursor at $120^{\circ} \mathrm{C}$ for $(b) 2,(c) 24$ and $(d) 48$ hours, respectively (Table S1, entries $7-9$ ). 
(a)

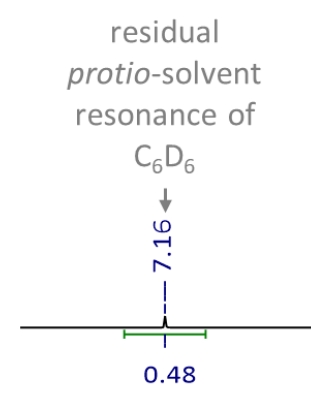

(b)
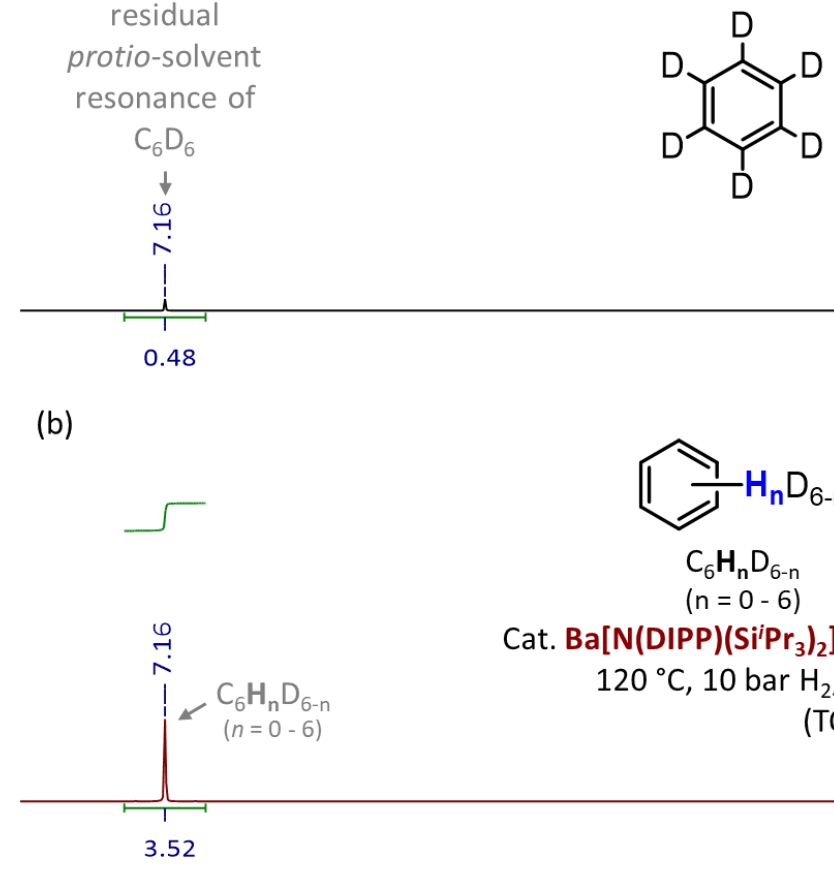

Internal

standard:

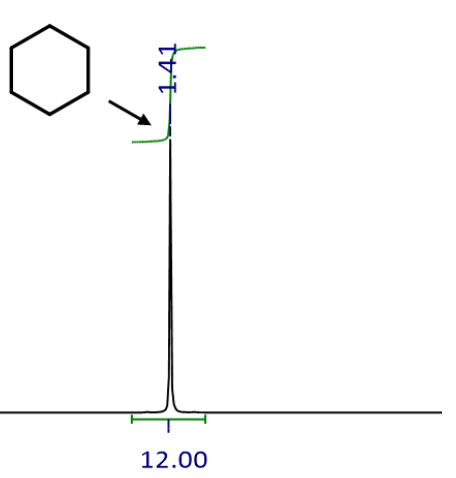

(c)

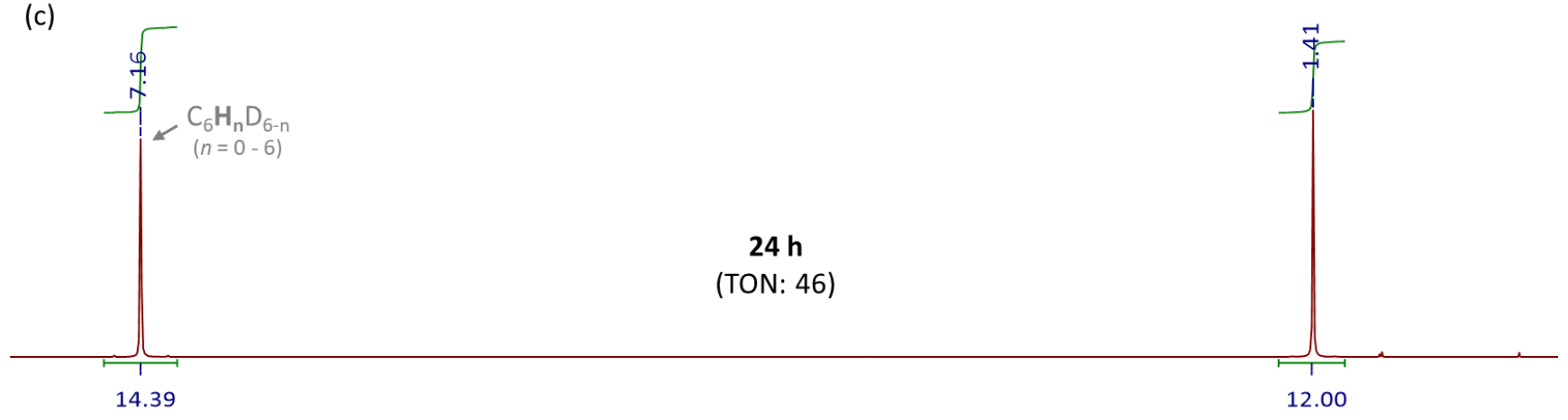

(d)

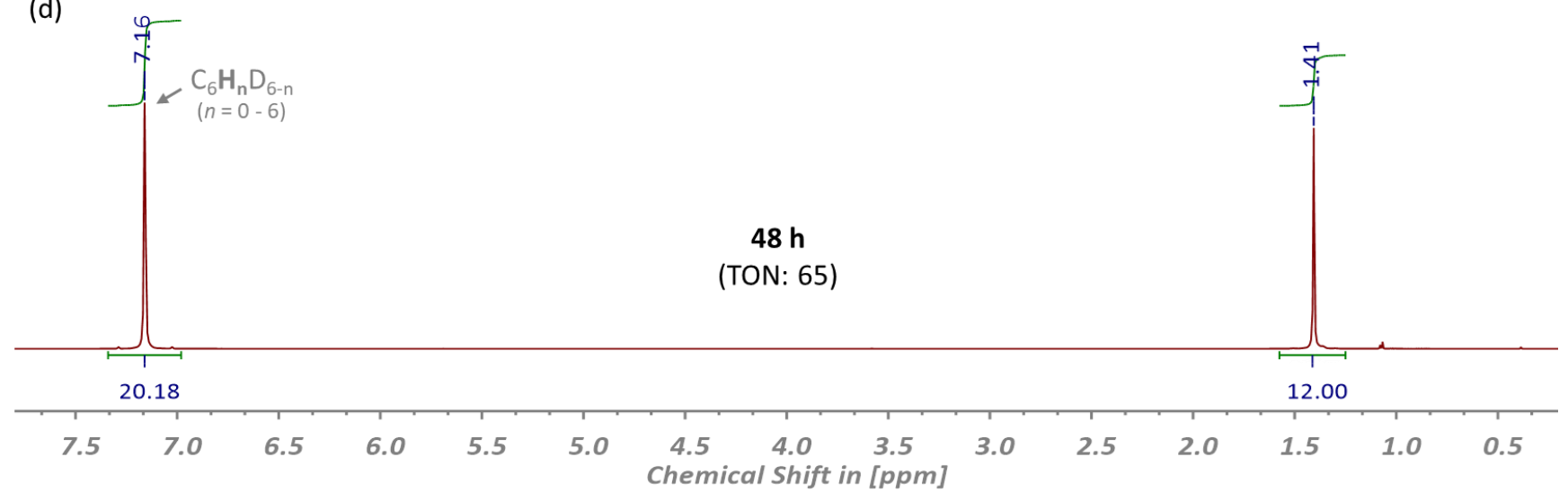

Figure S20. Stacked ${ }^{1} \mathrm{H}$ NMR spectra $\left(600 \mathrm{MHz}, \mathrm{C}_{6} \mathrm{D}_{6}, 25^{\circ} \mathrm{C}\right)$ of $(a)$ the authentic $\mathrm{C}_{6} \mathrm{D}_{6}$ substrate and the distilled products of the catalytic deuterium for hydrogen exchange with $\mathrm{H}_{2}\left(10\right.$ bar) and $\mathrm{Ba}\left[\mathrm{N}(\mathrm{DIPP})\left(\mathrm{Si}^{\mathrm{i}} \mathrm{Pr}_{3}\right)\right]_{2}(1 \mathrm{~mol} \%)$ as catalyst precursor at $120^{\circ} \mathrm{C}$ for $(b) 2,(c) 24$ and (d) 48 hours, respectively (Table S1, entries $11-13$ ). 


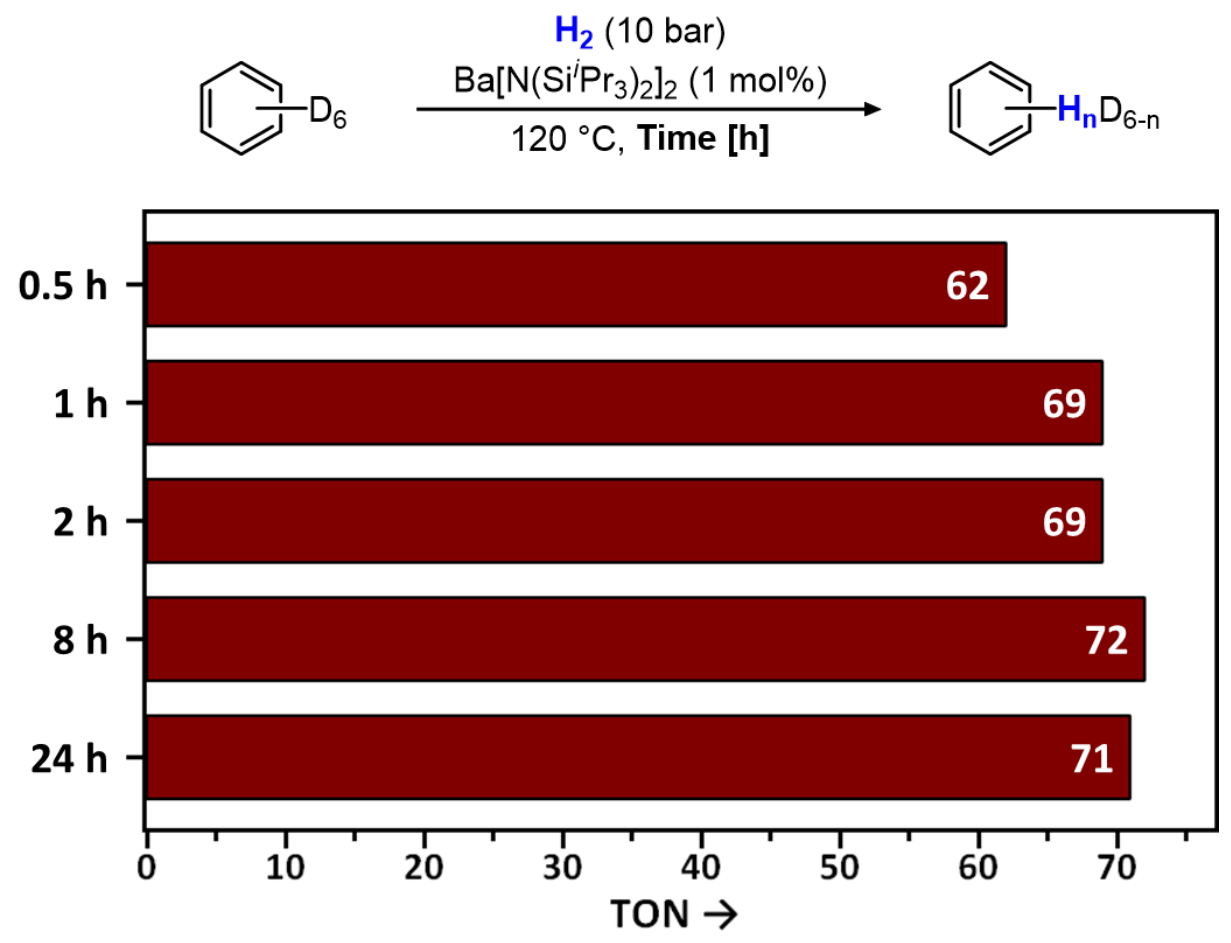

Figure S21. Catalytic deuterium for hydrogen exchange in $\mathrm{C}_{6} \mathrm{D}_{6}$ with $\mathrm{H}_{2}$ as a function of reaction time using $\mathrm{Ba}\left[\mathrm{N}\left(\mathrm{Si}^{i} \mathrm{Pr}_{3}\right)_{2}\right]_{2}$ as catalyst precursor (reported as turnover numbers).

Reaction conditions: $\mathrm{C}_{6} \mathrm{D}_{6}(1 \mathrm{~mL}, 950 \mathrm{mg}, 11.29 \mathrm{mmol})$, Cat. $\mathrm{Ba}\left[\mathrm{N}\left(\mathrm{Si}^{i} \mathrm{Pr}_{3}\right)_{2}\right]_{2}(90 \mathrm{mg}, 0.11 \mathrm{mmol}, 1 \mathrm{~mol} \%), \mathrm{H}_{2}(10 \mathrm{bar})$, $120^{\circ} \mathrm{C}$. 
(a)

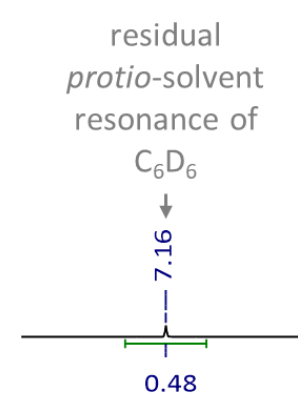

(b)

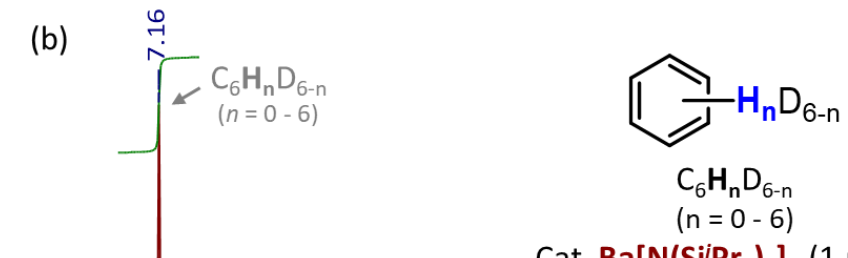

Cat. $\mathrm{Ba}\left[\mathrm{N}\left(\mathrm{Si}^{i} \mathrm{Pr}_{3}\right)_{2}\right]_{2}$ (1 mol\%)

$120{ }^{\circ} \mathrm{C}, 10$ bar $\mathrm{H}_{2}, \mathbf{0 . 5} \mathbf{~ h}$

(TON: 62)

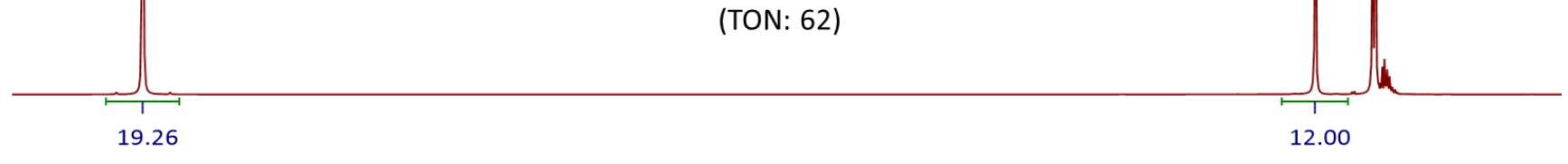

(c)

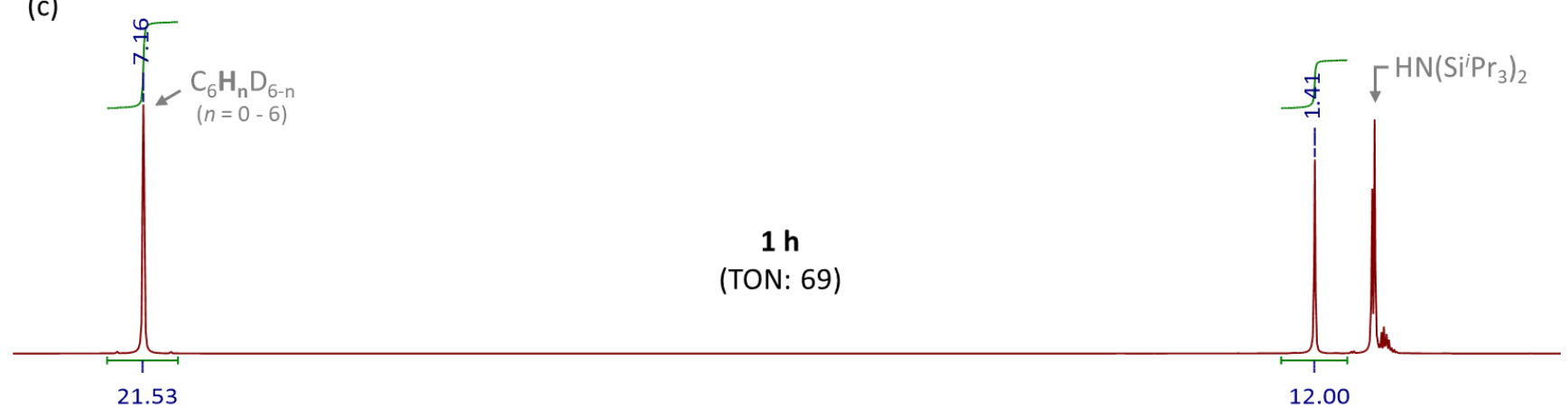

(d)

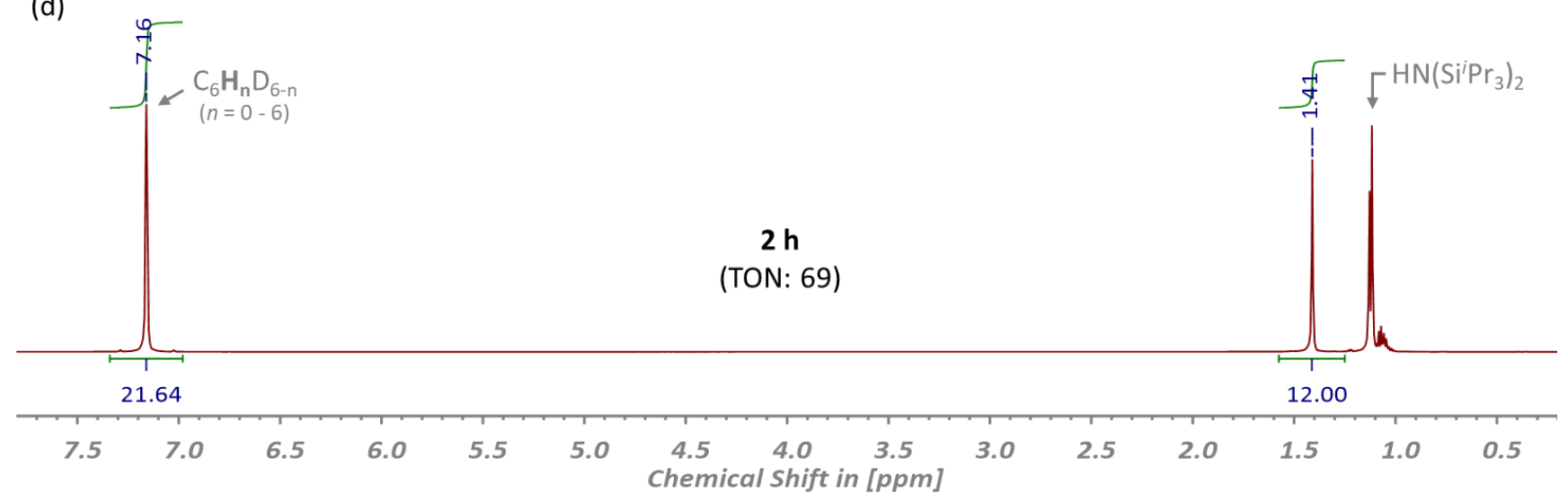

Figure S22. Stacked ${ }^{1} \mathrm{H}$ NMR spectra $\left(600 \mathrm{MHz}, \mathrm{C}_{6} \mathrm{D}_{6}, 25^{\circ} \mathrm{C}\right)$ of $(a)$ the authentic $\mathrm{C}_{6} \mathrm{D}_{6}$ substrate and the products of the catalytic deuterium for hydrogen exchange with $\mathrm{H}_{2}\left(10\right.$ bar) and $\mathrm{Ba}\left[\mathrm{N}\left(\mathrm{Si}^{i} \mathrm{Pr}_{3}\right)_{2}\right]_{2}(1$ mol\%) as catalyst precursor at $120^{\circ} \mathrm{C}$ for $(b) 0.5,(c) 1$ and $(d) 2$ hours, respectively (Table S1, entries $15-17$ ). 
(a)

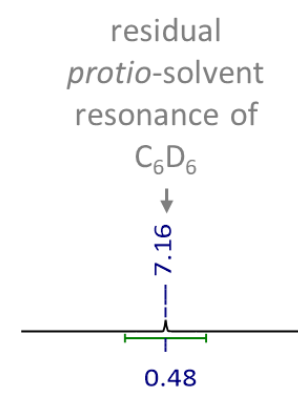

(b)

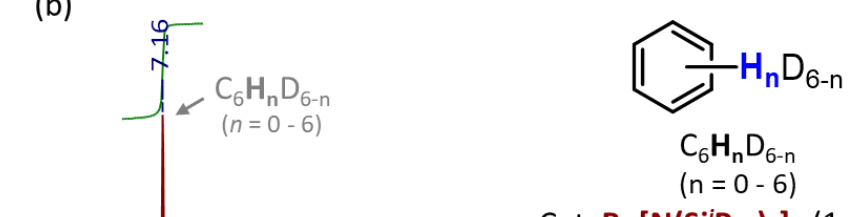

Cat. $\mathrm{Ba}\left[\mathrm{N}\left(\mathrm{Si}^{\mathrm{i} P r_{3}}\right)_{2}\right]_{2}(1 \mathrm{~mol} \%)$

$120^{\circ} \mathrm{C}, 10$ bar $\mathrm{H}_{2}, 8 \mathrm{~h}$

(TON: 72)

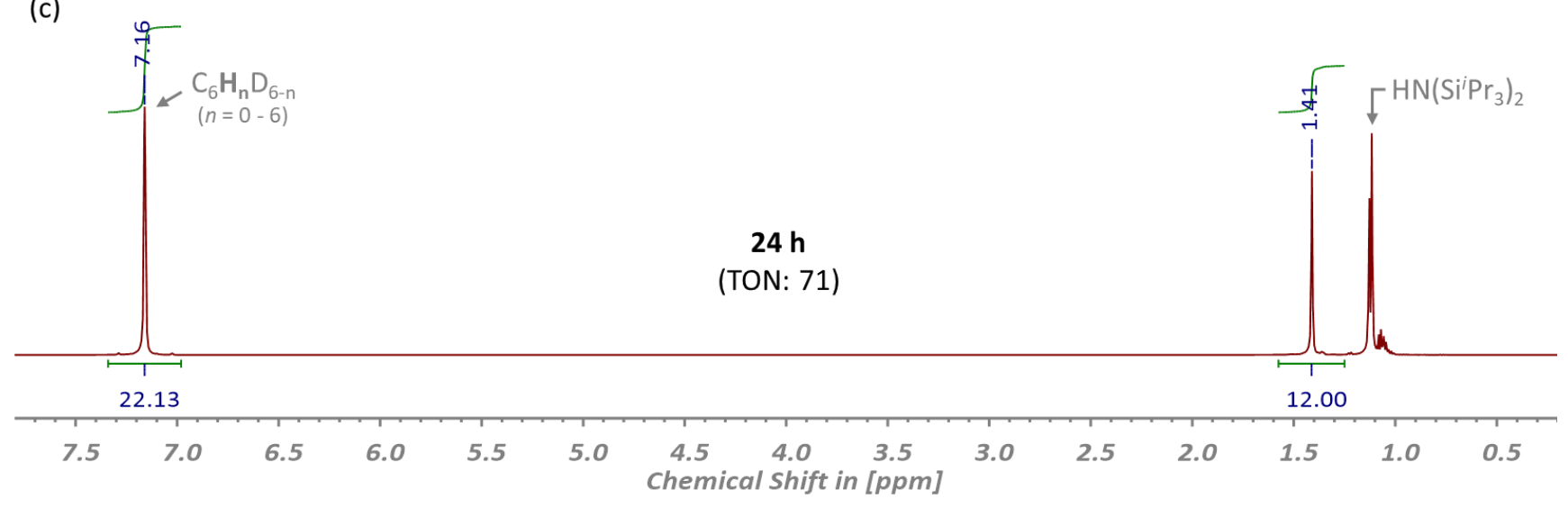

Figure S23. Stacked ${ }^{1} \mathrm{H}$ NMR spectra $\left(600 \mathrm{MHz}, \mathrm{C}_{6} \mathrm{D}_{6}, 25^{\circ} \mathrm{C}\right)$ of $(a)$ the authentic $\mathrm{C}_{6} \mathrm{D}_{6}$ substrate and the products obtained after the catalytic deuterium for hydrogen exchange with $\mathrm{H}_{2}\left(10 \mathrm{bar}\right.$ ) and $\mathrm{Ba}\left[\mathrm{N}\left(\mathrm{Si}^{i} \mathrm{Pr}_{3}\right)_{2}\right]_{2}(1 \mathrm{~mol} \%)$ as catalyst precursor at $120^{\circ} \mathrm{C}$ for $(b) 8$ and (c) 24 hours, respectively (Table S1, entries 18 and 19). 


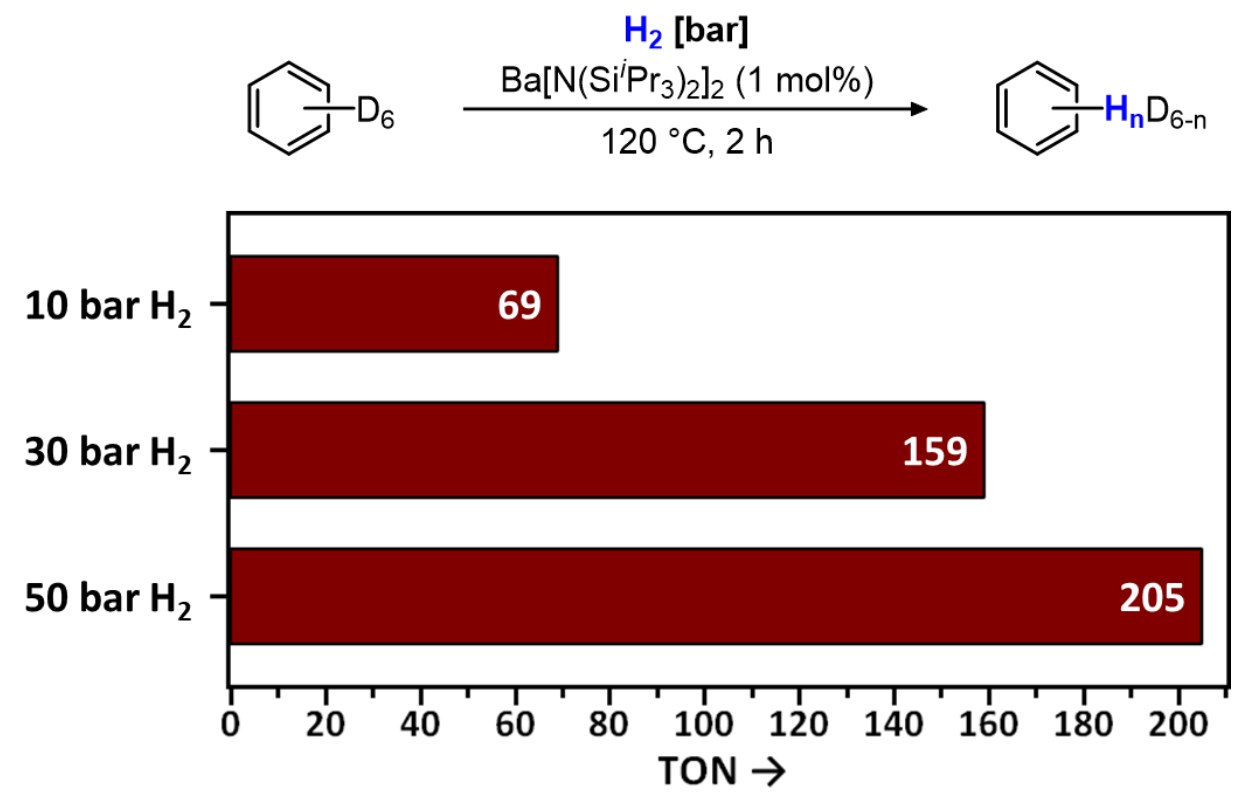

Figure S24. Turnover numbers for the catalytic deuterium for hydrogen exchange between $\mathrm{C}_{6} \mathrm{D}_{6}$ and $\mathrm{H}_{2}$ as a function of the $\mathrm{H}_{2}$ pressure using $\mathrm{Ba}\left[\mathrm{N}\left(\mathrm{Si}^{i} \mathrm{Pr}_{3}\right)_{2}\right]_{2}$ as catalyst precursor.

Reaction conditions: $\mathrm{C}_{6} \mathrm{D}_{6}(1 \mathrm{~mL}, 950 \mathrm{mg}, 11.29 \mathrm{mmol})$, Cat. $\mathrm{Ba}\left[\mathrm{N}\left(\mathrm{Si}^{\prime} \mathrm{Pr}_{3}\right)_{2}\right]_{2}(90 \mathrm{mg}, 0.11 \mathrm{mmol}, 1 \mathrm{~mol} \%), 120{ }^{\circ} \mathrm{C}, 2 \mathrm{~h}$. 
(a)

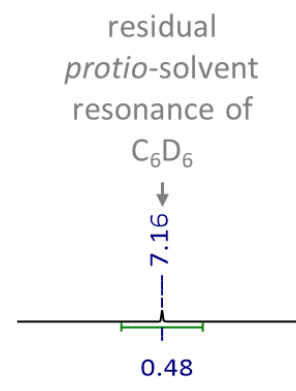

Internal

standard:

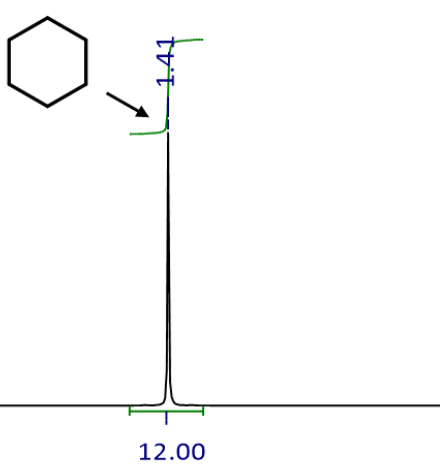

(b)

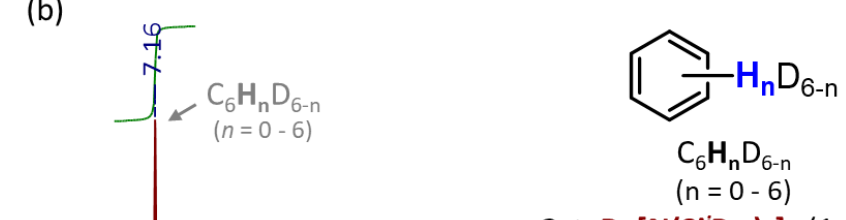

Cat. $\mathrm{Ba}\left[\mathrm{N}\left(\mathrm{Si}^{\mathrm{i} P \mathrm{Pr}_{3}}\right)_{2}\right]_{2}(1 \mathrm{~mol} \%)$

$120^{\circ} \mathrm{C}, 2 \mathrm{~h}, 10$ bar $\mathrm{H}_{2}$

(TON: 69)

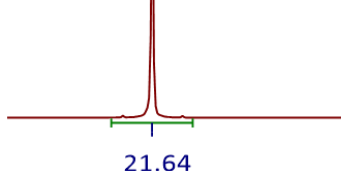

(TON: 69$)$

(c)
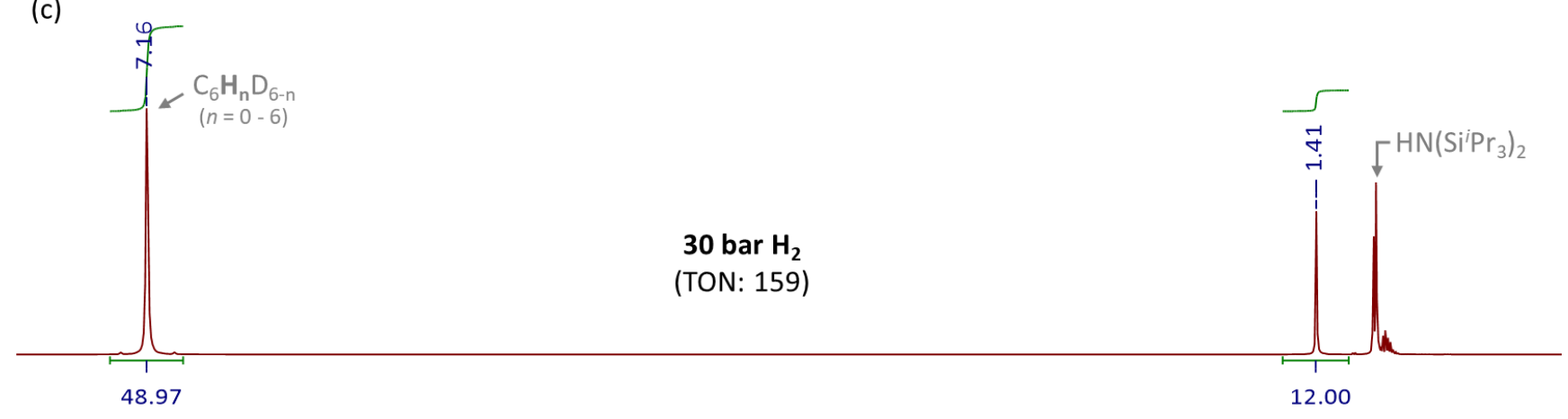

(d)

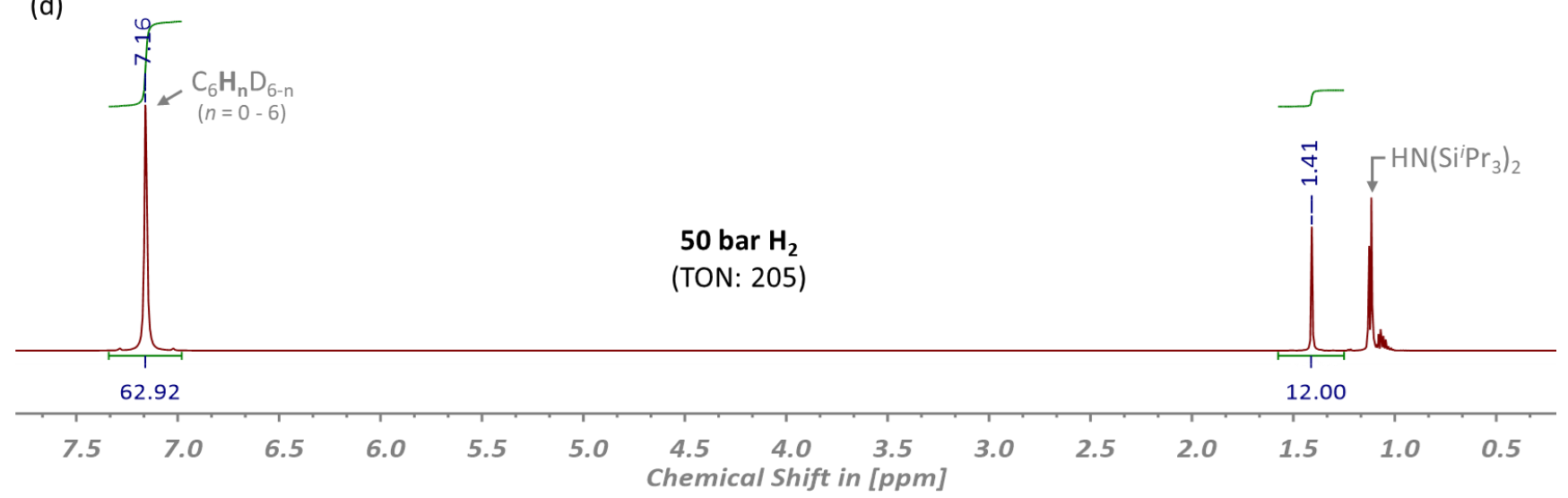

Figure S25. Stacked ${ }^{1} \mathrm{H}$ NMR spectra $\left(600 \mathrm{MHz}, \mathrm{C}_{6} \mathrm{D}_{6}, 25^{\circ} \mathrm{C}\right)$ of $(a)$ the authentic $\mathrm{C}_{6} \mathrm{D}_{6}$ substrate and the products obtained after the catalytic D/H exchange with $\mathrm{H}_{2}\left((b) 10,(c) 30\right.$ and $(d) 50$ bar) and $\mathrm{Ba}\left[\mathrm{N}\left(\mathrm{Si}^{\mathrm{i}} \mathrm{Pr}_{3}\right)_{2}\right]_{2}(1 \mathrm{~mol} \%)$ as catalyst precursor at $120^{\circ} \mathrm{C}$ for 2 hours (Table S1, entries 17,20 and 22). 


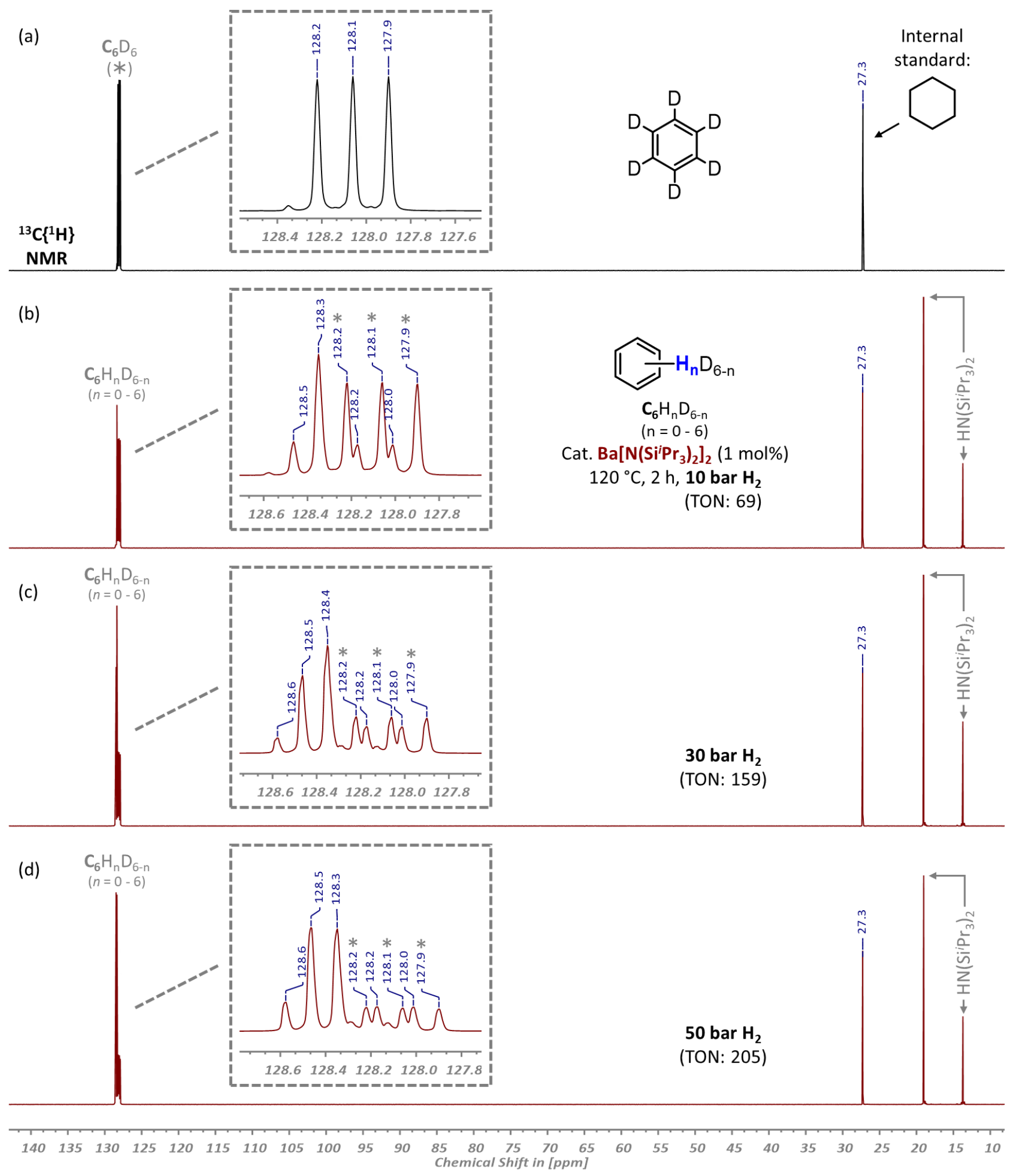

Figure S26. Stacked ${ }^{13} \mathrm{C}\left\{{ }^{1} \mathrm{H}\right\}$ NMR spectra $\left(151 \mathrm{MHz}, \mathrm{C}_{6} \mathrm{D}_{6}, 25^{\circ} \mathrm{C}\right)$ of $(a)$ the authentic $\mathrm{C}_{6} \mathrm{D}_{6}$ substrate and the products of the catalytic deuterium for hydrogen exchange with $\mathrm{H}_{2}((b) 10,(c) 30$ and (d) 50 bar) and $\mathrm{Ba}\left[\mathrm{N}\left(\mathrm{Si}^{i} \mathrm{Pr}_{3}\right)_{2}\right]_{2}(1 \mathrm{~mol} \%)$ as catalyst precursor at $120^{\circ} \mathrm{C}$ for 2 hours (Table S1, entries 17,20 and 22). 

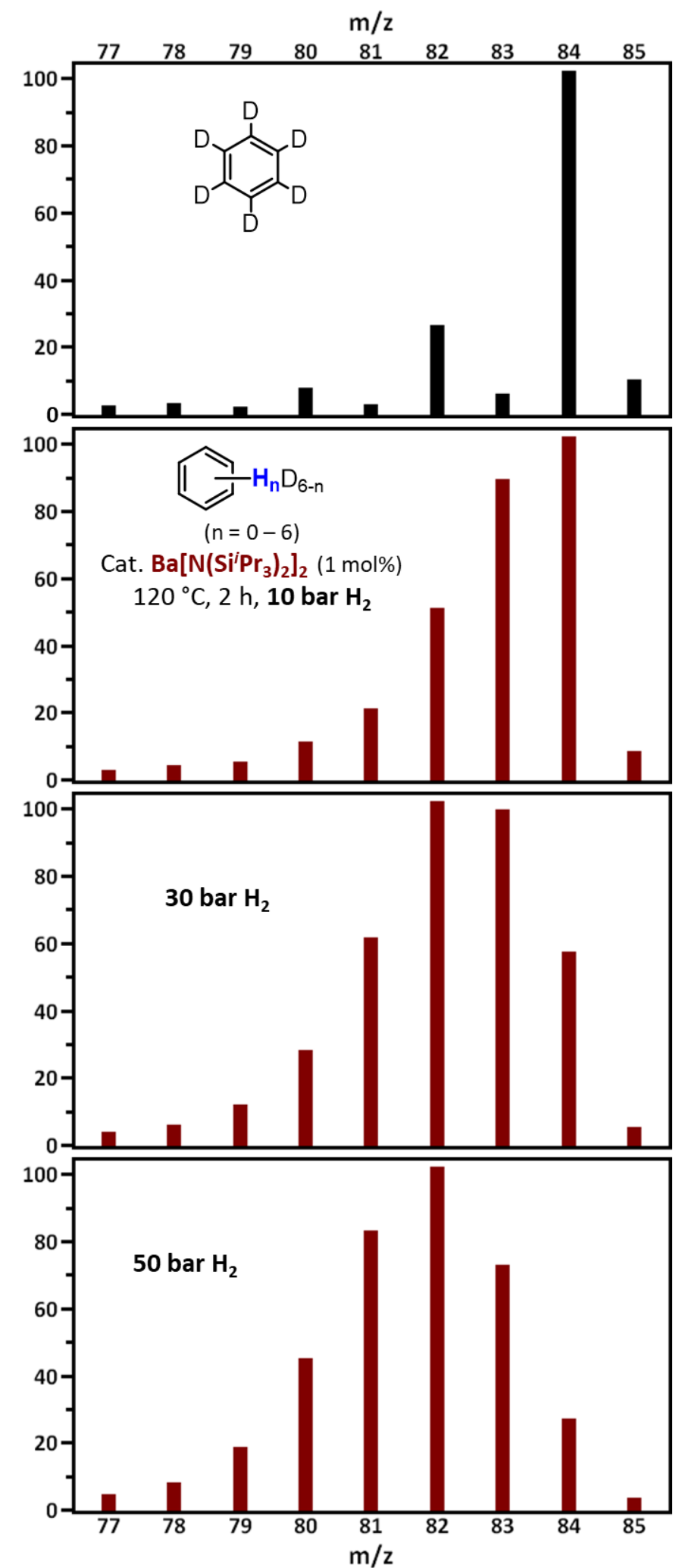

Figure S27. Stacked mass spectra of the authentic $\mathrm{C}_{6} \mathrm{D}_{6}$ substrate and the products obtained after the catalytic deuterium for hydrogen exchange with $\mathrm{H}_{2}\left(10,30\right.$ and 50 bar) and $\mathrm{Ba}\left[\mathrm{N}\left(\mathrm{Si}^{i} \mathrm{Pr}_{3}\right)_{2}\right]_{2}(1 \mathrm{~mol} \%)$ as pre-catalyst at $120^{\circ} \mathrm{C}$ for 2 hours (Table S1, entries 17, 20 and 22). 
(a)

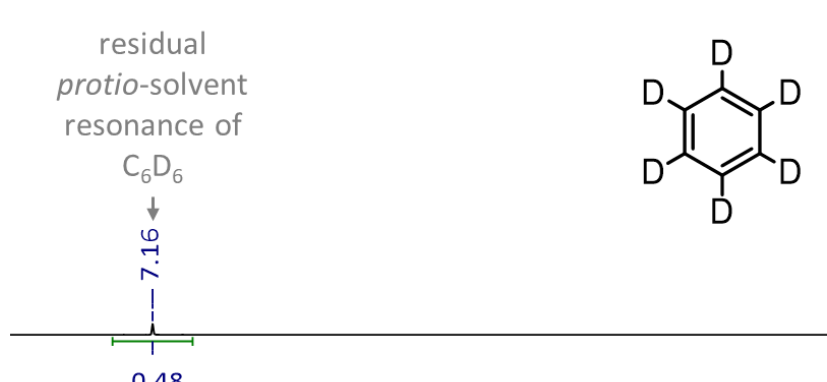

(b)

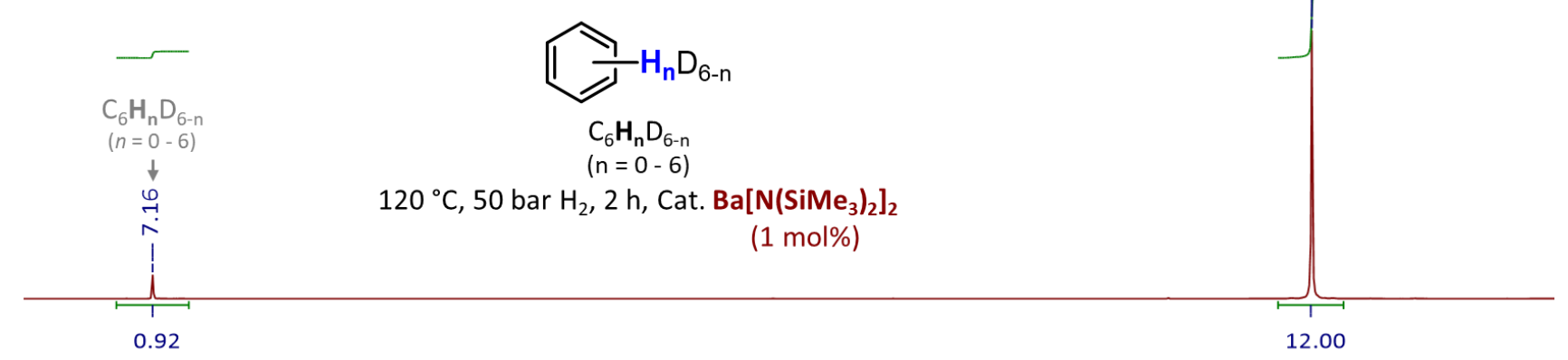

(c)
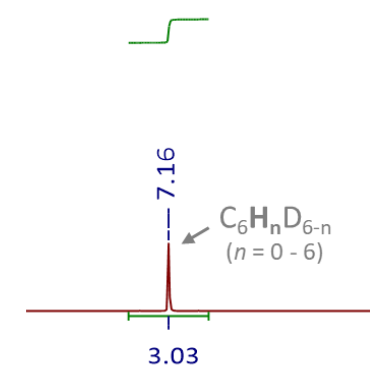

$\mathrm{Ba}\left[\mathrm{N}(\mathrm{DIPP})\left(\mathrm{Si}^{i} \mathrm{Pr}_{3}\right)\right]_{2}$

(1 mol\%)

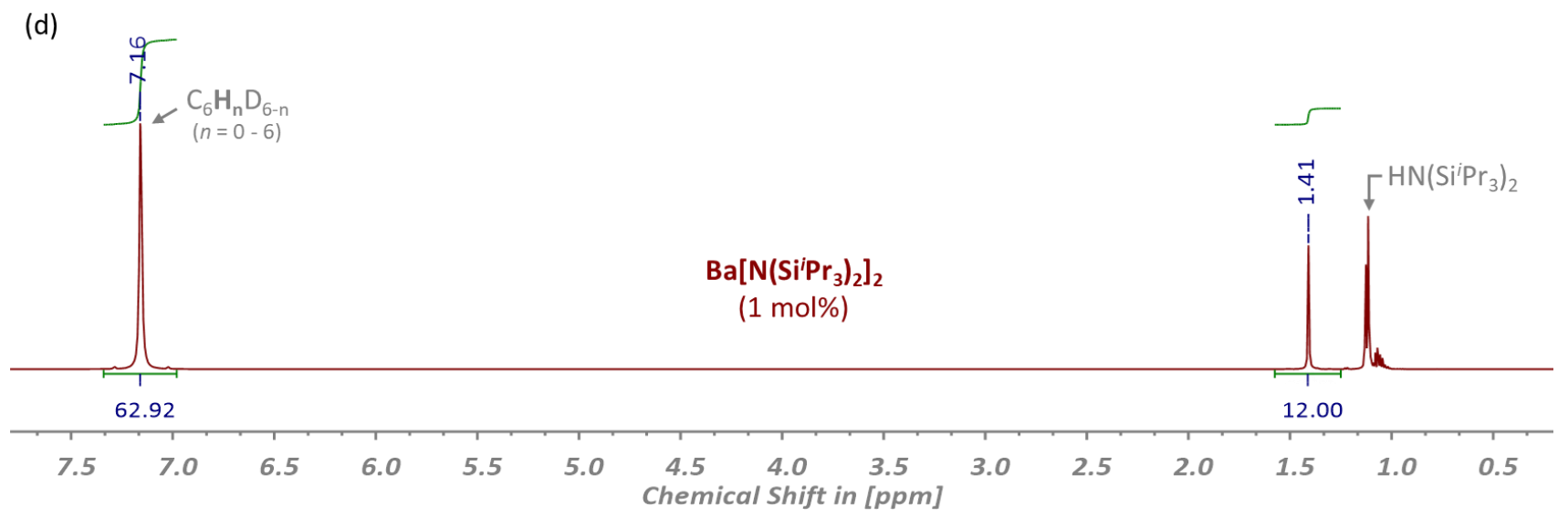

Figure S28. Stacked ${ }^{1} \mathrm{H}$ NMR spectra $\left(600 \mathrm{MHz}, \mathrm{C}_{6} \mathrm{D}_{6}, 25^{\circ} \mathrm{C}\right)$ of $(a)$ the authentic $\mathrm{C}_{6} \mathrm{D}_{6}$ substrate and the products of the catalytic deuterium for hydrogen exchange with $\mathrm{H}_{2}\left(50 \mathrm{bar}\right.$ ) at $120^{\circ} \mathrm{C}$ for 2 hours using $1 \mathrm{~mol} \%$

(b) $\mathrm{Ba}\left[\mathrm{N}\left(\mathrm{SiMe}_{3}\right)_{2}\right]_{2},(c) \mathrm{Ba}\left[\mathrm{N}(\mathrm{DIPP})\left(\mathrm{Si}^{i} \mathrm{Pr}_{3}\right)\right]_{2}$ and (d) $\mathrm{Ba}\left[\mathrm{N}\left(\mathrm{Si}^{\prime} \mathrm{Pr}_{3}\right)_{2}\right]_{2}$ as catalyst precursors (Table S1, entries 10, 14 and 22). 


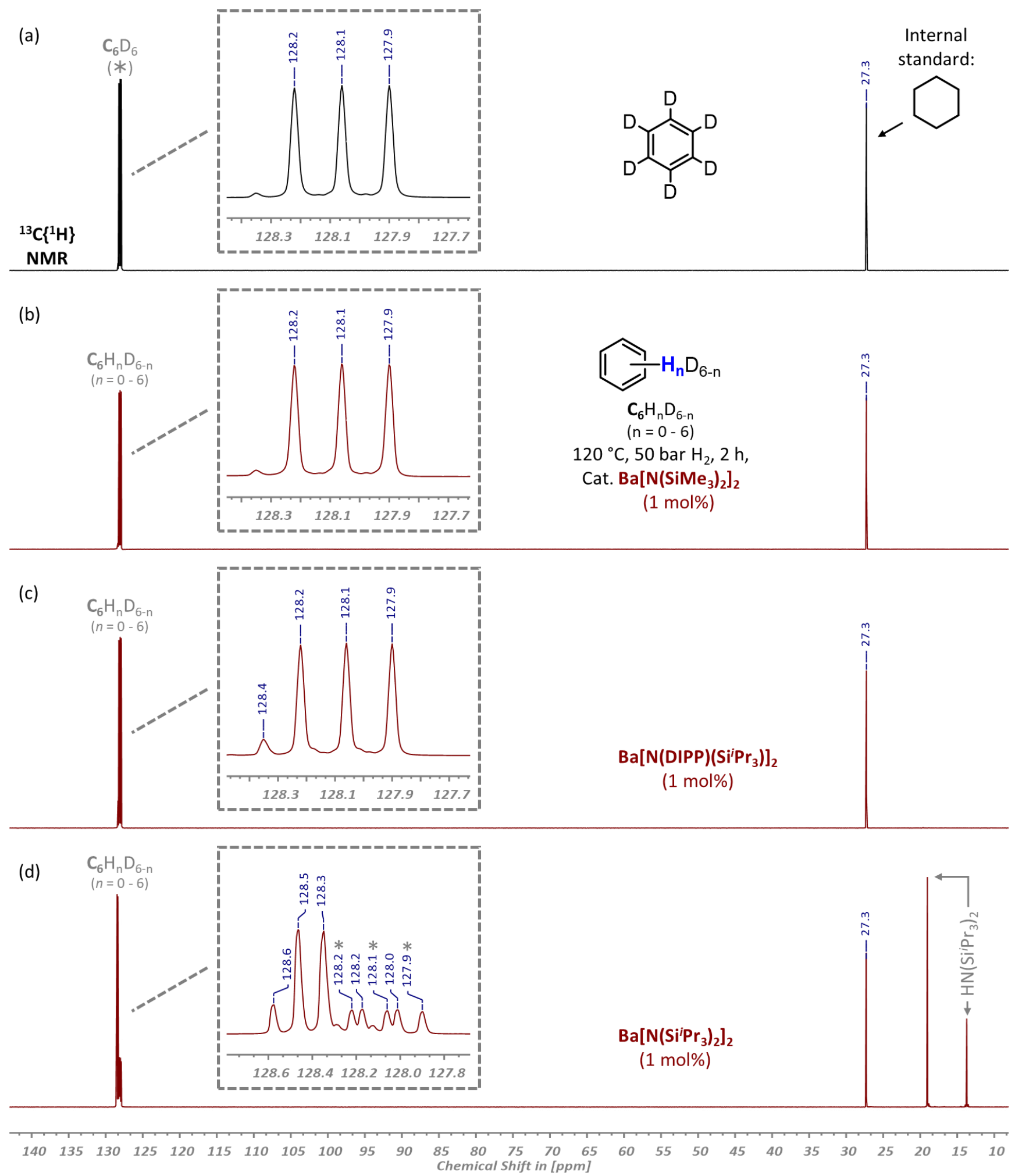

Figure S29. Stacked ${ }^{13} \mathrm{C}\left\{{ }^{1} \mathrm{H}\right\}$ NMR spectra $\left(151 \mathrm{MHz}, \mathrm{C}_{6} \mathrm{D}_{6}, 25^{\circ} \mathrm{C}\right)$ of $(a)$ the authentic $\mathrm{C}_{6} \mathrm{D}_{6}$ substrate and the products of the catalytic deuterium for hydrogen exchange with $\mathrm{H}_{2}(50 \mathrm{bar})$ at $120^{\circ} \mathrm{C}$ for 2 hours using 1 mol\% (b) $\mathrm{Ba}\left[\mathrm{N}\left(\mathrm{SiMe}_{3}\right)_{2}\right]_{2},(c) \mathrm{Ba}\left[\mathrm{N}(\mathrm{DIPP})\left(\mathrm{Si}^{i} \mathrm{Pr} r_{3}\right)\right]_{2}$ and (d) $\mathrm{Ba}\left[\mathrm{N}\left(\mathrm{Si}^{\prime} \mathrm{Pr}_{3}\right)_{2}\right]_{2}$ as catalyst precursors (Table S1, entries 10, 14 and 22). 


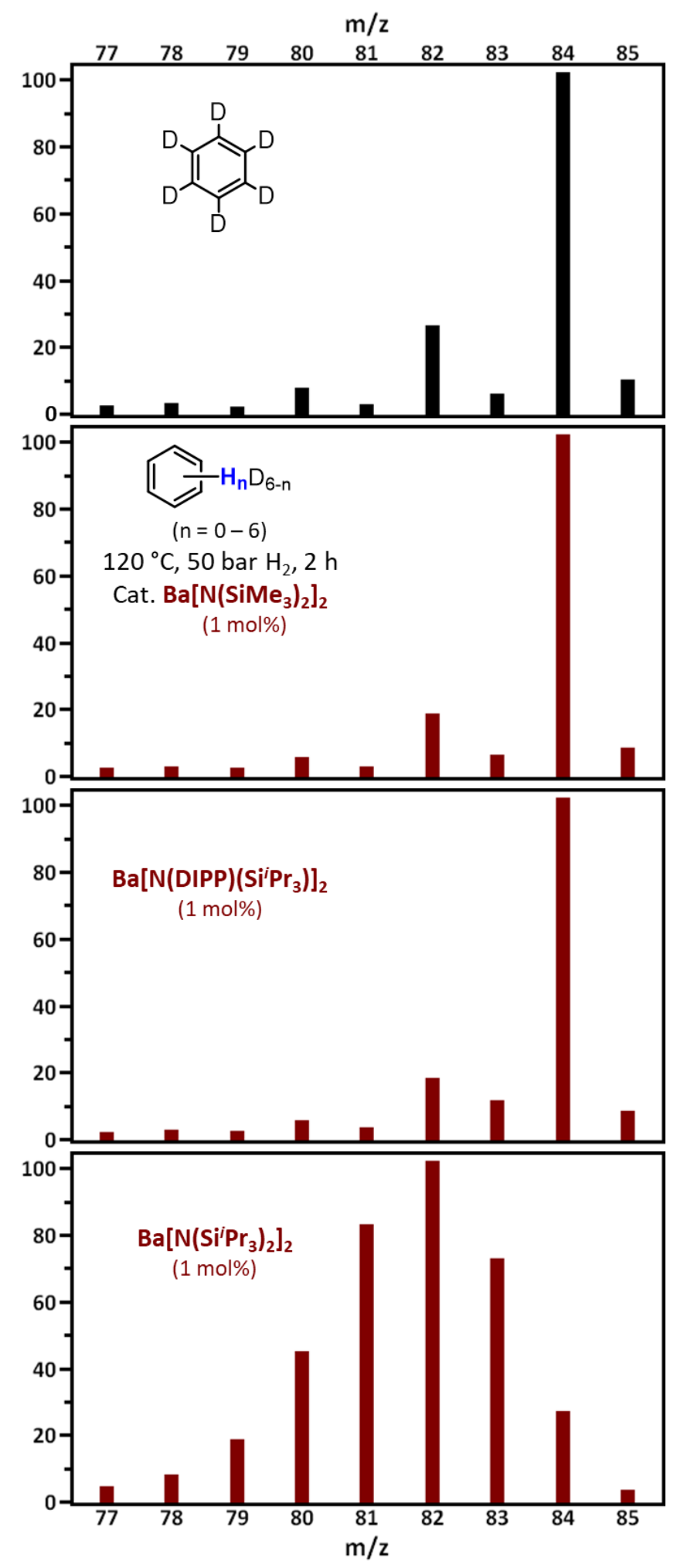

Figure S30. Stacked mass spectra of the authentic $\mathrm{C}_{6} \mathrm{D}_{6}$ substrate and the products obtained after the catalytic deuterium for hydrogen exchange with $\mathrm{H}_{2}(50 \mathrm{bar})$ at $120{ }^{\circ} \mathrm{C}$ for 2 hours using $\mathrm{Ba}\left[\mathrm{N}\left(\mathrm{SiMe}_{3}\right)_{2}\right]_{2}(1 \mathrm{~mol} \%)$, $\mathrm{Ba}\left[\mathrm{N}(\mathrm{DIPP})\left(\mathrm{Si}^{i} \mathrm{Pr}_{3}\right)\right]_{2}(1 \mathrm{~mol} \%)$ and $\mathrm{Ba}\left[\mathrm{N}\left(\mathrm{Si}^{i} \mathrm{Pr}_{3}\right)_{2}\right]_{2}(1 \mathrm{~mol} \%)$, respectively, as catalyst precursors (Table $\mathrm{S} 1$, entries 10,14 and 22). 
(a)

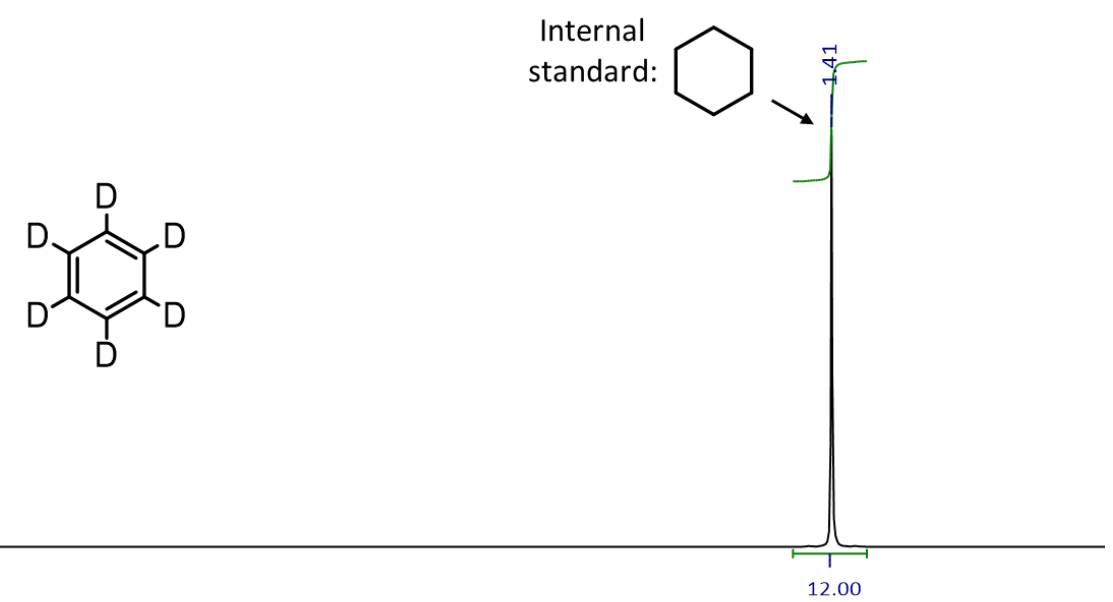

(b)

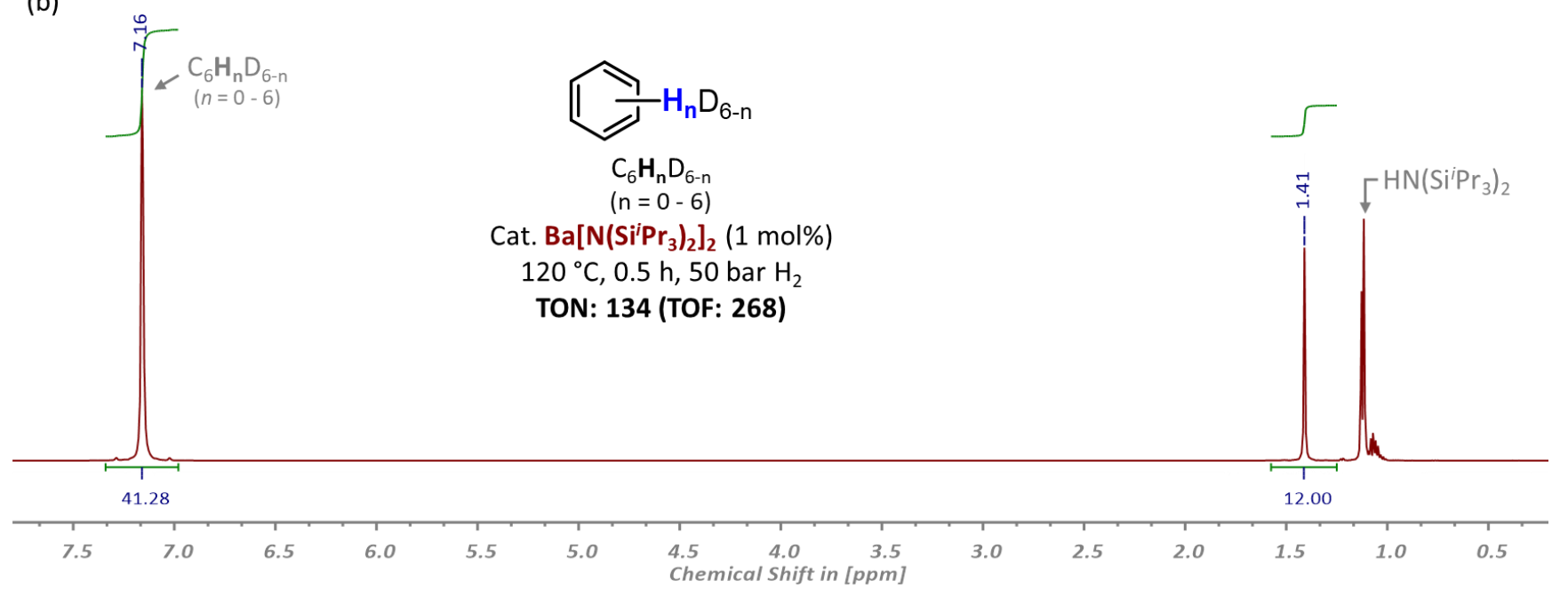

Figure S31. Stacked ${ }^{1} \mathrm{H}$ NMR spectra $\left(600 \mathrm{MHz}, \mathrm{C}_{6} \mathrm{D}_{6}, 25^{\circ} \mathrm{C}\right)$ of $(a)$ the authentic $\mathrm{C}_{6} \mathrm{D}_{6}$ substrate and $(b)$ the product of the catalytic deuterium for hydrogen exchange with $\mathrm{H}_{2}(50 \mathrm{bar})$ and $\mathrm{Ba}\left[\mathrm{N}\left(\mathrm{Si}^{i} \mathrm{Pr}_{3}\right)_{2}\right]_{2}(1 \mathrm{~mol} \%)$ as pre-catalyst at $120^{\circ} \mathrm{C}$ for 0.5 hours (Table S1, entry 21 ). 

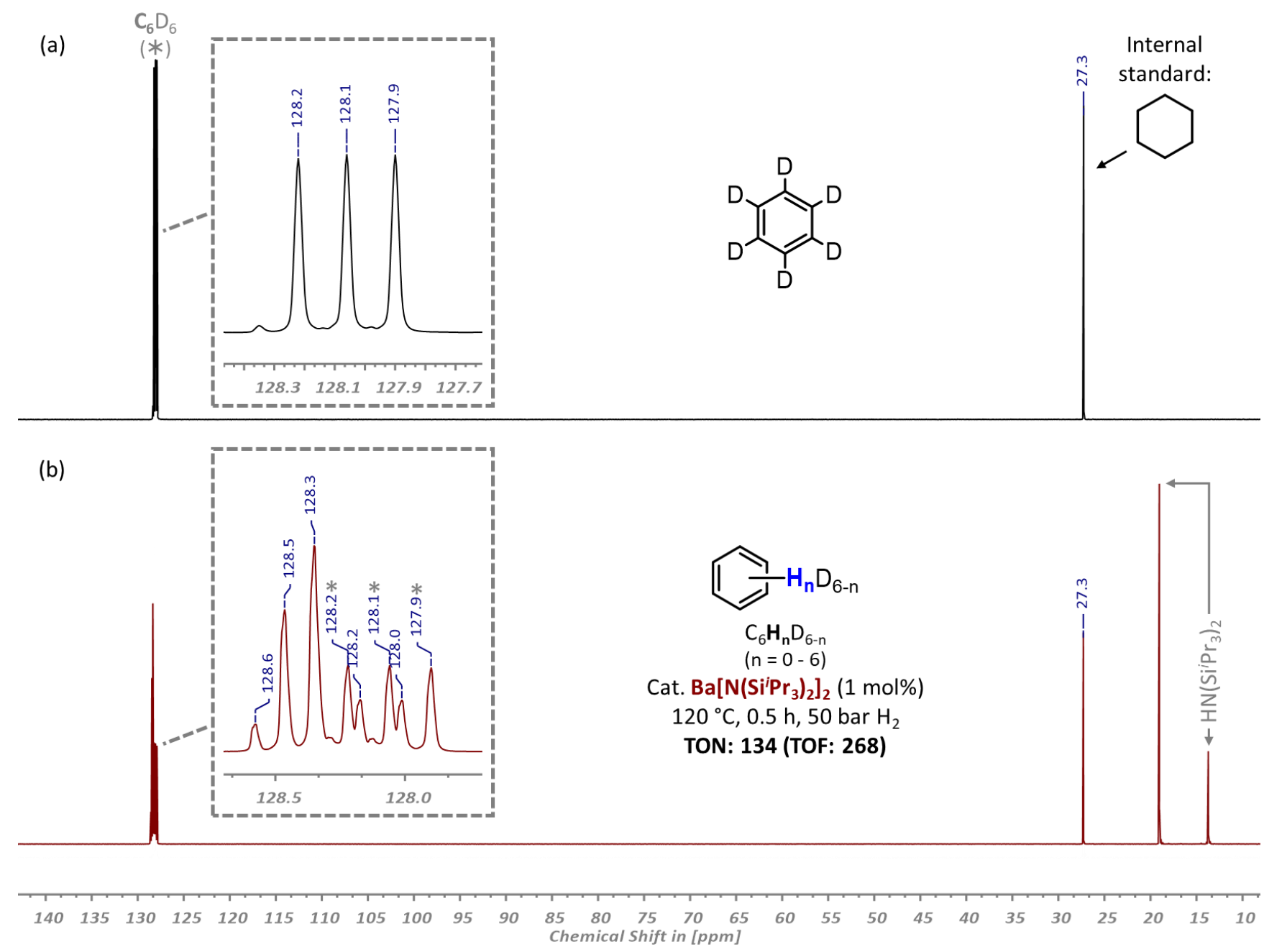

Figure S32. Stacked ${ }^{13} \mathrm{C}\left\{{ }^{1} \mathrm{H}\right\}$ NMR spectra $\left(151 \mathrm{MHz}, \mathrm{C}_{6} \mathrm{D}_{6}, 25^{\circ} \mathrm{C}\right)$ of $(a)$ the authentic $\mathrm{C}_{6} \mathrm{D}_{6}$ substrate and $(b)$ the product of the catalytic deuterium for hydrogen exchange with $\mathrm{H}_{2}\left(50 \mathrm{bar}\right.$ ) and $\mathrm{Ba}\left[\mathrm{N}\left(\mathrm{Si}^{i} \mathrm{Pr}_{3}\right)_{2}\right]_{2}(1 \mathrm{~mol} \%)$ as catalyst precursor at $120^{\circ} \mathrm{C}$ for 0.5 hours (Table S1, entry 21). 

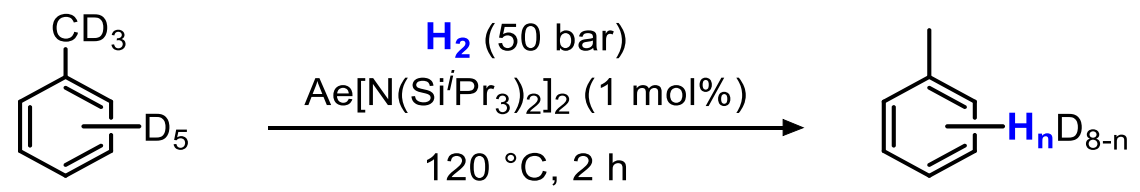

In a typical $\mathrm{D} / \mathrm{H}$ exchange experiment in $\left[d_{8}\right]$ toluene, the appropriate crystalline $\operatorname{Ae}\left[\mathrm{N}\left(\mathrm{Si}^{i} \mathrm{Pr}_{3}\right)_{2}\right]_{2}$ $(\mathrm{Ae}=\mathrm{Ca}, \mathrm{Sr}, \mathrm{Ba})$ pre-catalyst $(94 \mu \mathrm{mol}, 1 \mathrm{~mol} \%)$ and $\left[d_{8}\right]$ toluene $(1 \mathrm{~mL}, 943 \mathrm{mg}, 9.41 \mathrm{mmol})$ were added to an oven-dried miniature stainless steel autoclave $(15 \mathrm{~mL})$ containing a magnetic stir bar under an atmosphere of $\mathrm{N}_{2}$. The reactor was sealed tightly, brought out of the glovebox, and attached to a $\mathrm{H}_{2}$ gas manifold. Following evacuation and refilling of the supply line with $\mathrm{N}_{2}$ and then $\mathrm{H}_{2}$ three times each, the autoclave was pressurized to 50 bars with $\mathrm{H}_{2}$ gas, re-sealed and placed in a preheated aluminum block set to $120^{\circ} \mathrm{C}$. The reaction mixture was mechanically stirred under the $\mathrm{H}_{2}$ pressure for 2 hours, at which point the reactor was left to cool to ambient temperature and carefully depressurized in a fume hood. Catalyst decomposition products were then removed by filtration through a glass microfiber filter in a Pasteur pipette. For quantifying levels of hydrogen incorporation by ${ }^{1} \mathrm{H}$ NMR spectroscopy, 1,3,5-trimethoxybenzene $(15 \mathrm{mg}, 89 \mu \mathrm{mol})$ as internal standard was added to a portion of the crude filtrate $(500 \mu \mathrm{L})$. The hydrogen incorporation was evaluated by comparing the integration of the summarized protio-toluene signals to the aromatic resonance of the internal standard. The reported values have been corrected for the minimal amount of protio-solvent residues in the $\left[d_{8}\right]$ toluene substrate. In addition, the hydrogen incorporation was qualitatively verified by ${ }^{13} \mathrm{C}\left\{{ }^{1} \mathrm{H}\right\} \mathrm{NMR}$ spectroscopy and GC/MS analysis. The turnover numbers (and TOFs) are summarized in Table S2 (vide infra). 
Table S2. Deuterium for hydrogen exchange in [ $d_{8}$ ]toluene with $\mathrm{H}_{2}$ mediated by $\mathrm{Ae}\left[\mathrm{N}\left(\mathrm{Si}^{i} \mathrm{Pr}_{3}\right)_{2}\right]_{2}$

$$
(\mathrm{Ae}=\mathrm{Ca}, \mathrm{Sr}, \mathrm{Ba}) \text { catalyst precursors. }^{a}
$$

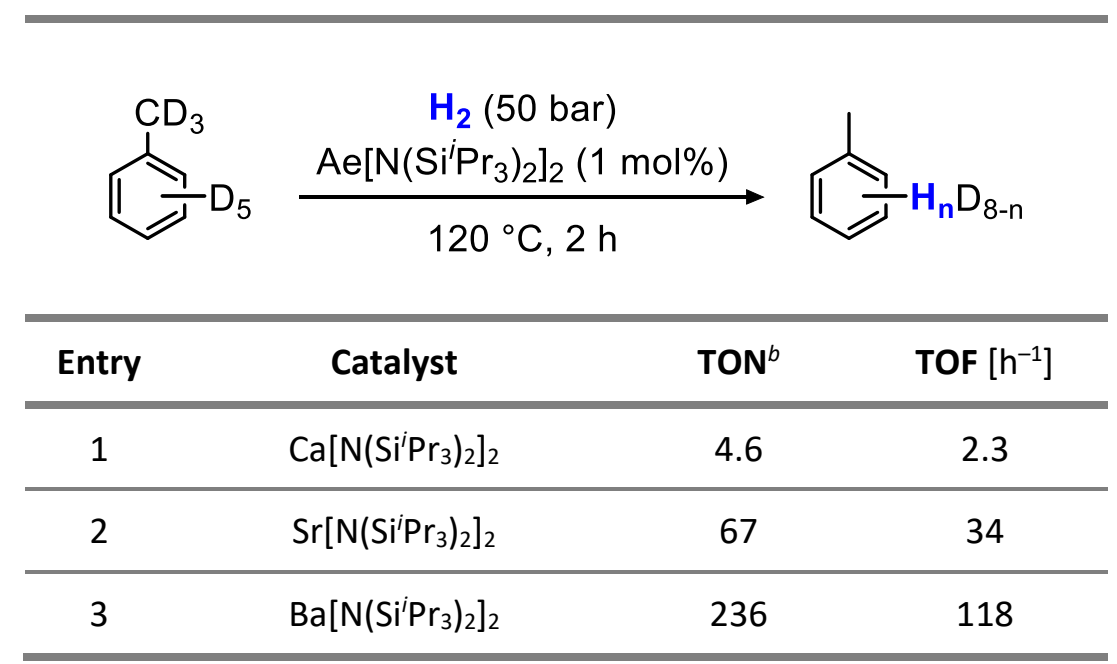

${ }^{a}$ General catalytic reaction conditions: [ $\left.d_{8}\right]$ toluene $(1 \mathrm{~mL}, 943 \mathrm{mg}, 9.41 \mathrm{mmol})$, Cat. Ae[N( $\left.\left(\mathrm{Si}^{i} \mathrm{Pr}_{3}\right)_{2}\right]_{2}(94 \mu \mathrm{mol}, 1 \mathrm{~mol} \%)$, $\mathrm{H}_{2}(50 \mathrm{bar}), 120^{\circ} \mathrm{C}, 2 \mathrm{~h}$. ${ }^{b}$ Determined experimentally by ${ }^{1} \mathrm{H}$ NMR spectroscopy using $1,3,5$-trimethoxybenzene as an internal standard. 


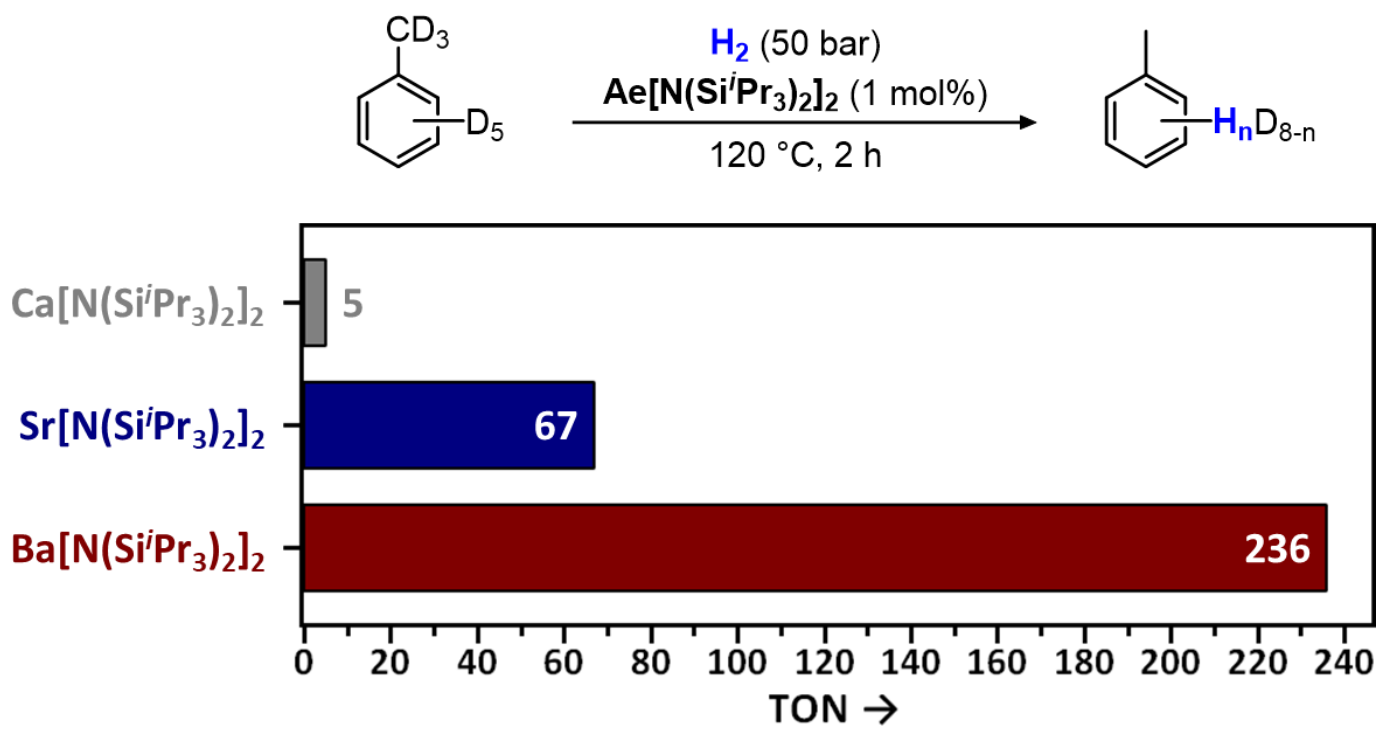

Figure S33. Catalytic deuterium for hydrogen exchange in $\left[d_{8}\right]$ toluene with $\mathrm{H}_{2}$ using $\mathrm{Ae}\left[\mathrm{N}\left(\mathrm{Si}^{i} \mathrm{Pr}_{3}\right)_{2}\right]_{2}$ $(\mathrm{Ae}=\mathrm{Ca}, \mathrm{Sr}, \mathrm{Ba})$ as catalyst precursors (reported as turnover numbers).

Reaction conditions: [ $\left.d_{8}\right]$ toluene $(1 \mathrm{~mL}, 943 \mathrm{mg}, 9.41 \mathrm{mmol})$, Cat. Ae[N(Si $\left.\left.\mathrm{Pr}_{3}\right)_{2}\right]_{2}(94 \mu \mathrm{mol}, 1 \mathrm{~mol} \%), \mathrm{H}_{2}(50 \mathrm{bar})$, $120^{\circ} \mathrm{C}, 2 \mathrm{~h}$. 
(a)

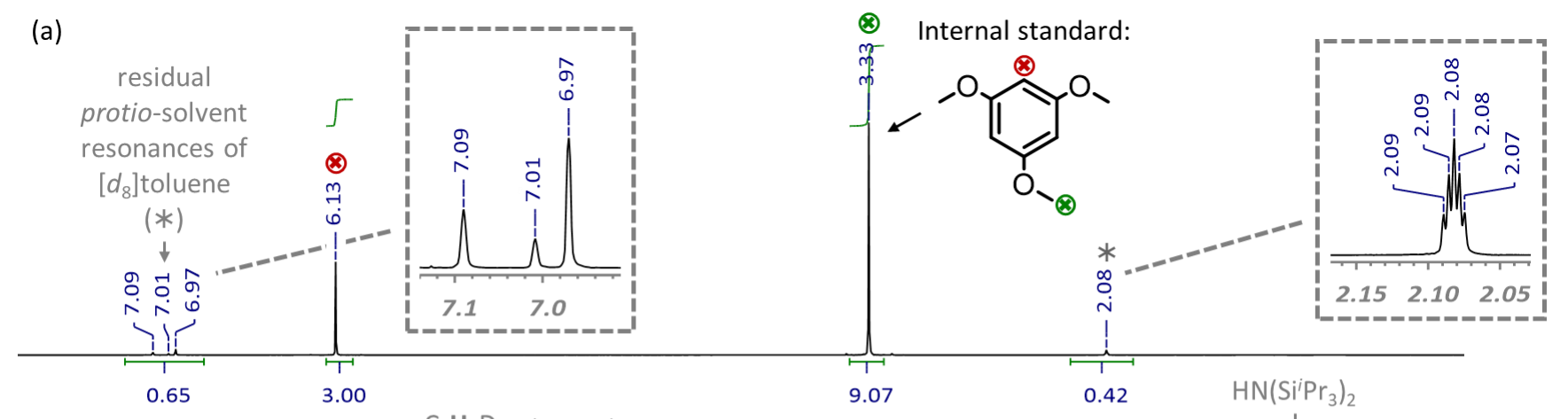

(b)
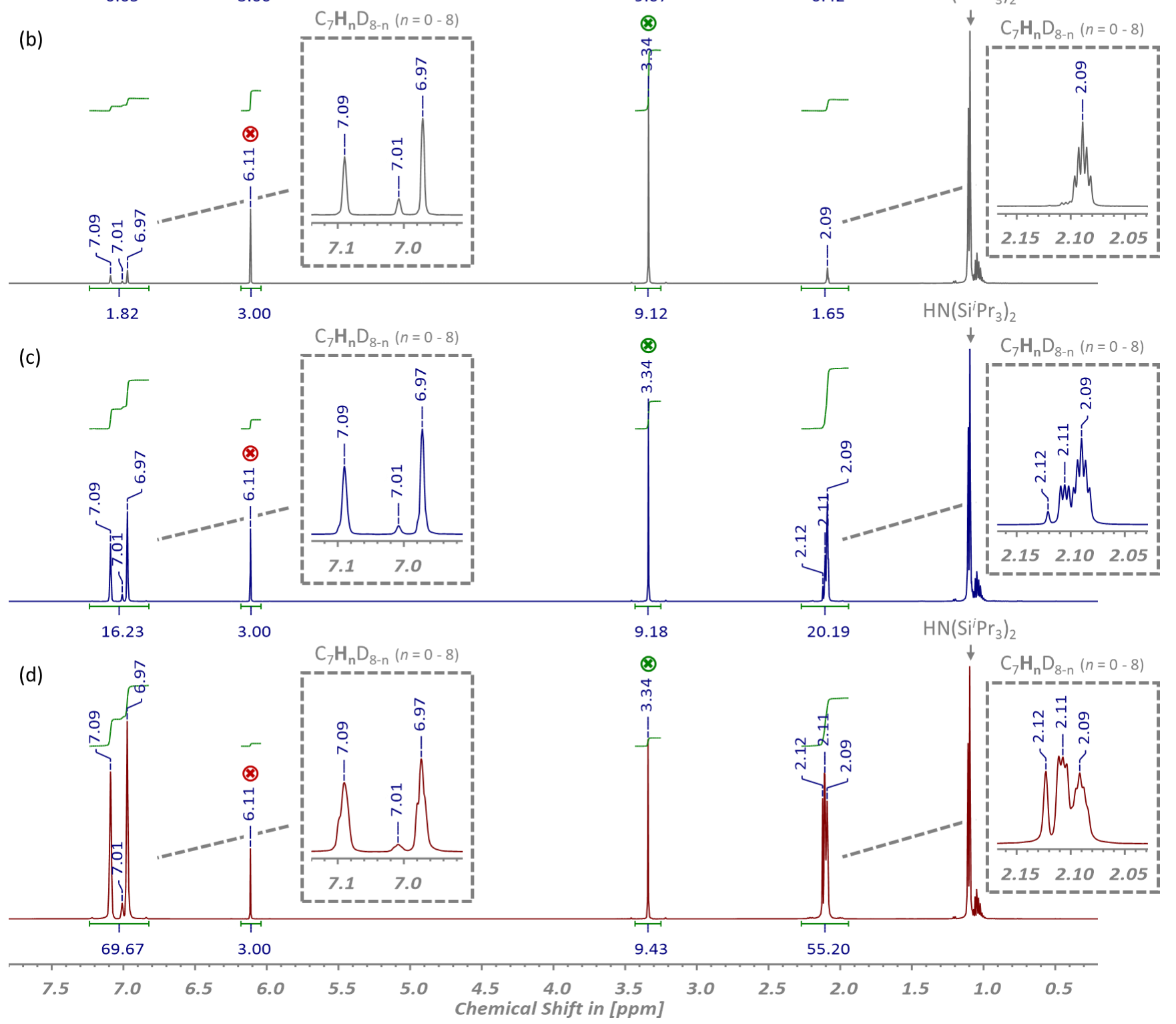

Figure S34. Stacked ${ }^{1} \mathrm{H}$ NMR spectra $\left(600 \mathrm{MHz},\left[d_{8}\right]\right.$ toluene, $\left.25^{\circ} \mathrm{C}\right)$ of $(a)$ the authentic $\left[d_{8}\right]$ toluene substrate and the products of the catalytic deuterium for hydrogen exchange with $\mathrm{H}_{2}(50 \mathrm{bar})$ at $120^{\circ} \mathrm{C}$ for 2 hours using $\mathrm{Ae}\left[\mathrm{N}\left(\mathrm{Si}^{i} \mathrm{Pr}_{3}\right)_{2}\right]_{2}(1 \mathrm{~mol} \%)$ as catalyst precursors: $\mathrm{Ae}=(b) \mathrm{Ca},(c) \mathrm{Sr}$ and $(d)$ Ba (Table S2, entries $\left.1-3\right)$. 
(a)

${ }^{13} \mathrm{C}\left\{{ }^{1} \mathrm{H}\right\}$

NMR
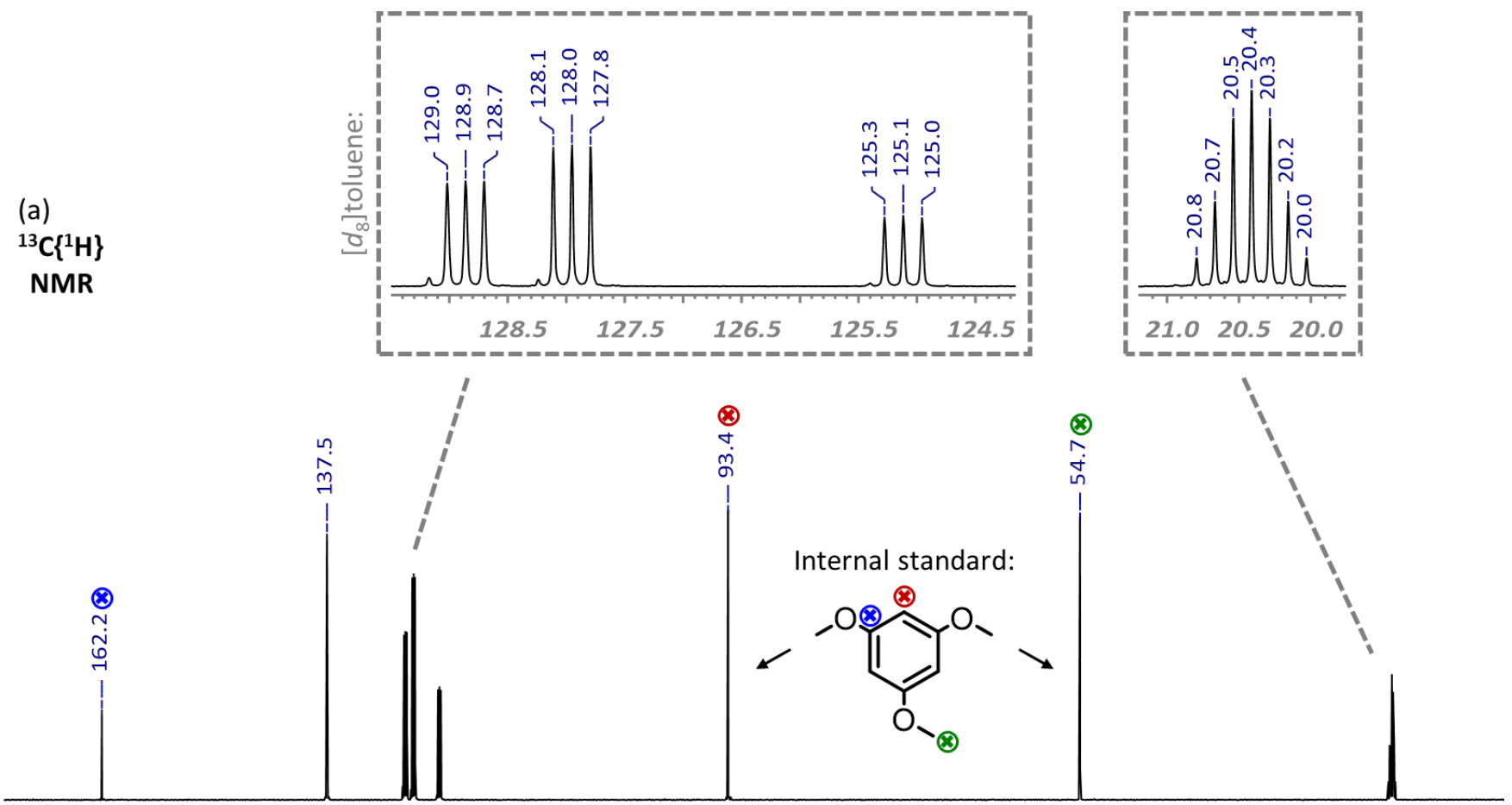

(b)
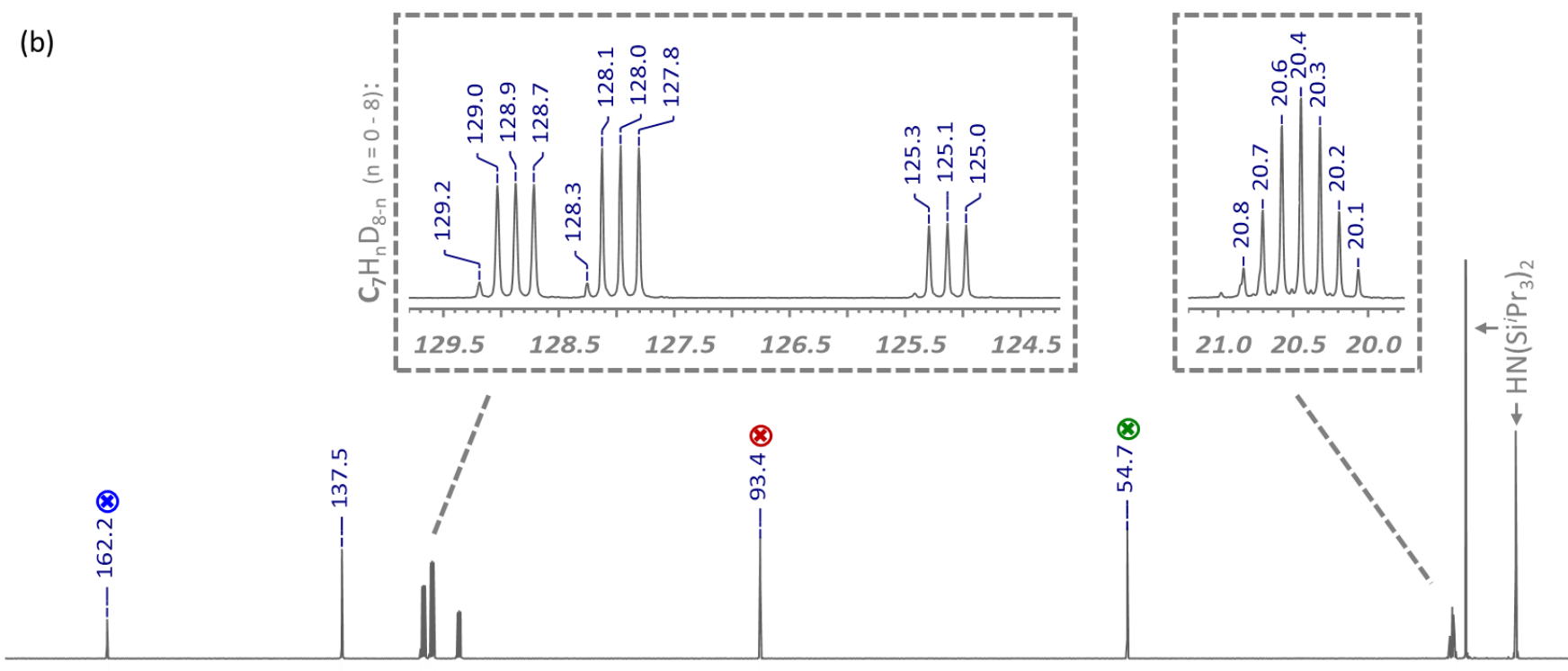

\begin{tabular}{|c|c|c|c|c|c|c|c|c|c|c|c|c|c|c|c|}
\hline 170 & 160 & 150 & 140 & 130 & 120 & 110 & 100 & 90 & 80 & 70 & 60 & 50 & 40 & 30 & 20 \\
\hline
\end{tabular}

Figure S35. Stacked ${ }^{13} \mathrm{C}\left\{{ }^{1} \mathrm{H}\right\}$ NMR spectra $\left(151 \mathrm{MHz},\left[d_{8}\right]\right.$ toluene, $\left.25^{\circ} \mathrm{C}\right)$ of $(a)$ the authentic $\left[d_{8}\right]$ toluene substrate and $(b)$ the obtained product of the catalytic deuterium for hydrogen exchange with $\mathrm{H}_{2}(50 \mathrm{bar})$ and $\mathrm{Ca}\left[\mathrm{N}\left(\mathrm{Si}^{i} \mathrm{Pr}_{3}\right)_{2}\right]_{2}(1 \mathrm{~mol} \%)$ as catalyst precursor at $120^{\circ} \mathrm{C}$ for 2 hours (Table S2, entry 1$)$. 

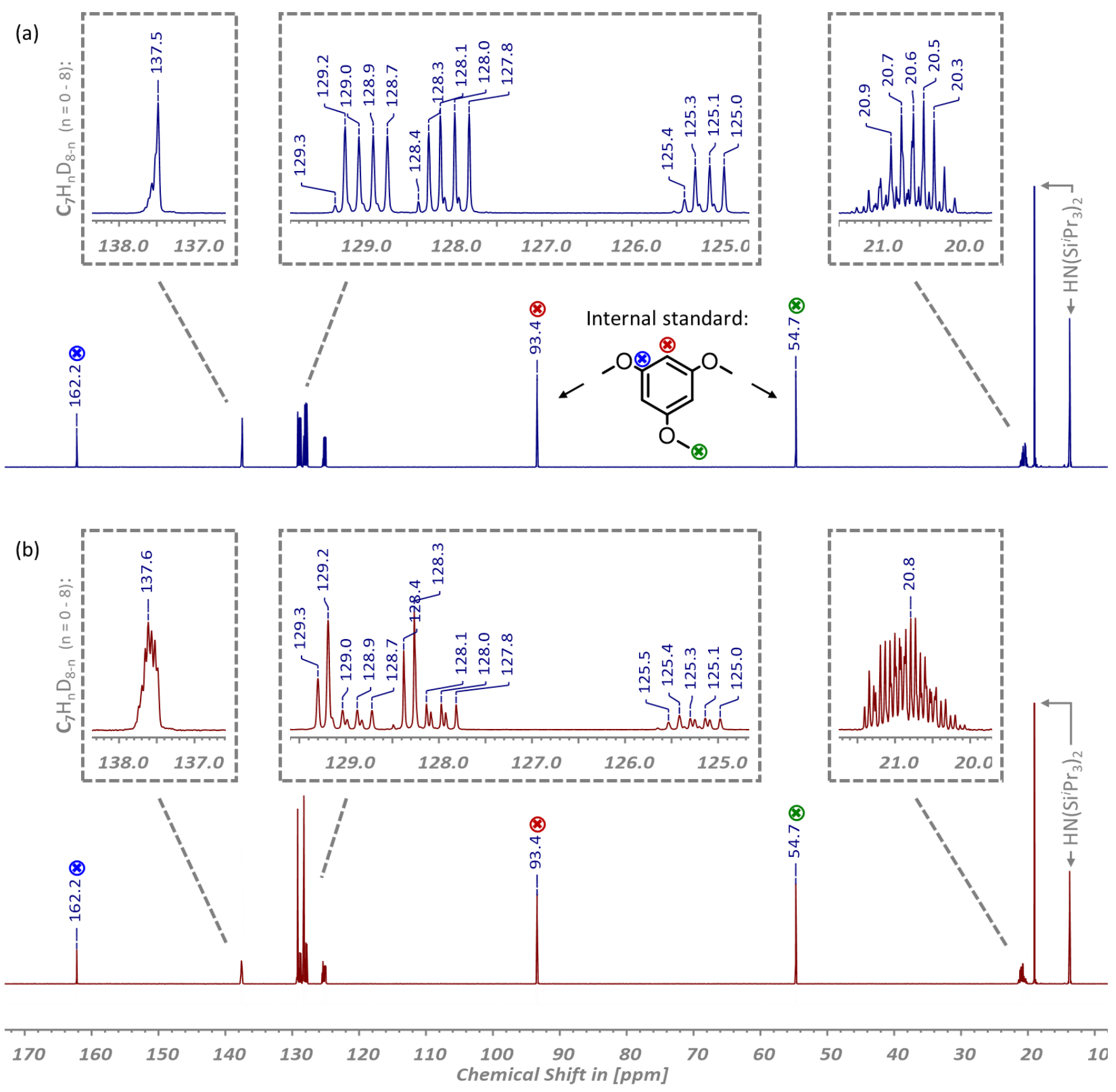

Figure S36. Stacked ${ }^{13} \mathrm{C}\left\{{ }^{1} \mathrm{H}\right\}$ NMR spectra $\left(151 \mathrm{MHz},\left[d_{8}\right]\right.$ toluene, $\left.25^{\circ} \mathrm{C}\right)$ of the products obtained after the catalytic deuterium for hydrogen exchange in $\left[d_{8}\right]$ toluene with $\mathrm{H}_{2}\left(50\right.$ bar) at $120^{\circ} \mathrm{C}$ for 2 hours using (a) $\mathrm{Sr}\left[\mathrm{N}\left(\mathrm{Si}^{i} \mathrm{Pr}_{3}\right)_{2}\right]_{2}(1 \mathrm{~mol} \%)$ and $(b) \mathrm{Ba}\left[\mathrm{N}\left(\mathrm{Si}^{\prime} \mathrm{Pr}_{3}\right)_{2}\right]_{2}(1 \mathrm{~mol} \%)$ as catalyst precursors (Table S2, entries 2 and 3 ). 

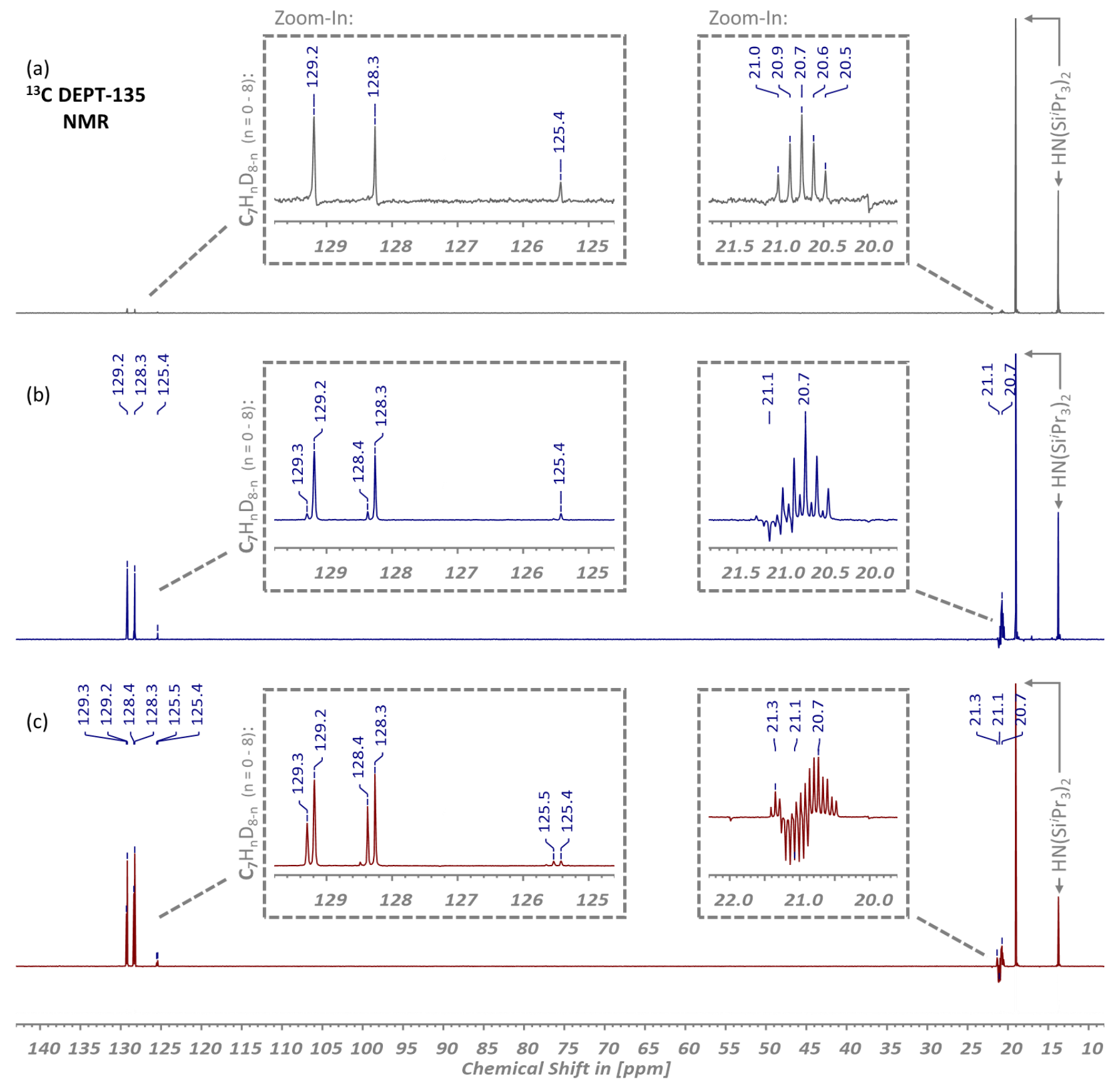

Figure S37. Stacked ${ }^{13} \mathrm{C}$ DEPT-135 NMR spectra (151 MHz, $\left[d_{8}\right]$ toluene, $25^{\circ} \mathrm{C}$ ) of the products obtained after the catalytic deuterium for hydrogen exchange in $\left[d_{8}\right]$ toluene with $\mathrm{H}_{2}\left(50\right.$ bar) at $120^{\circ} \mathrm{C}$ for 2 hours using (a) $\mathrm{Ca}\left[\mathrm{N}\left(\mathrm{Si}^{\prime} \mathrm{Pr}_{3}\right)_{2}\right]_{2}(1 \mathrm{~mol} \%),(b) \mathrm{Sr}\left[\mathrm{N}\left(\mathrm{Si}^{i} \mathrm{Pr}_{3}\right)_{2}\right]_{2}(1 \mathrm{~mol} \%)$ and $(c) \mathrm{Ba}\left[\mathrm{N}\left(\mathrm{Si}^{i} \mathrm{Pr}_{3}\right)_{2}\right]_{2}(1 \mathrm{~mol} \%)$ as pre-catalysts (Table $\mathrm{S} 2$, entries $1-3)$. 

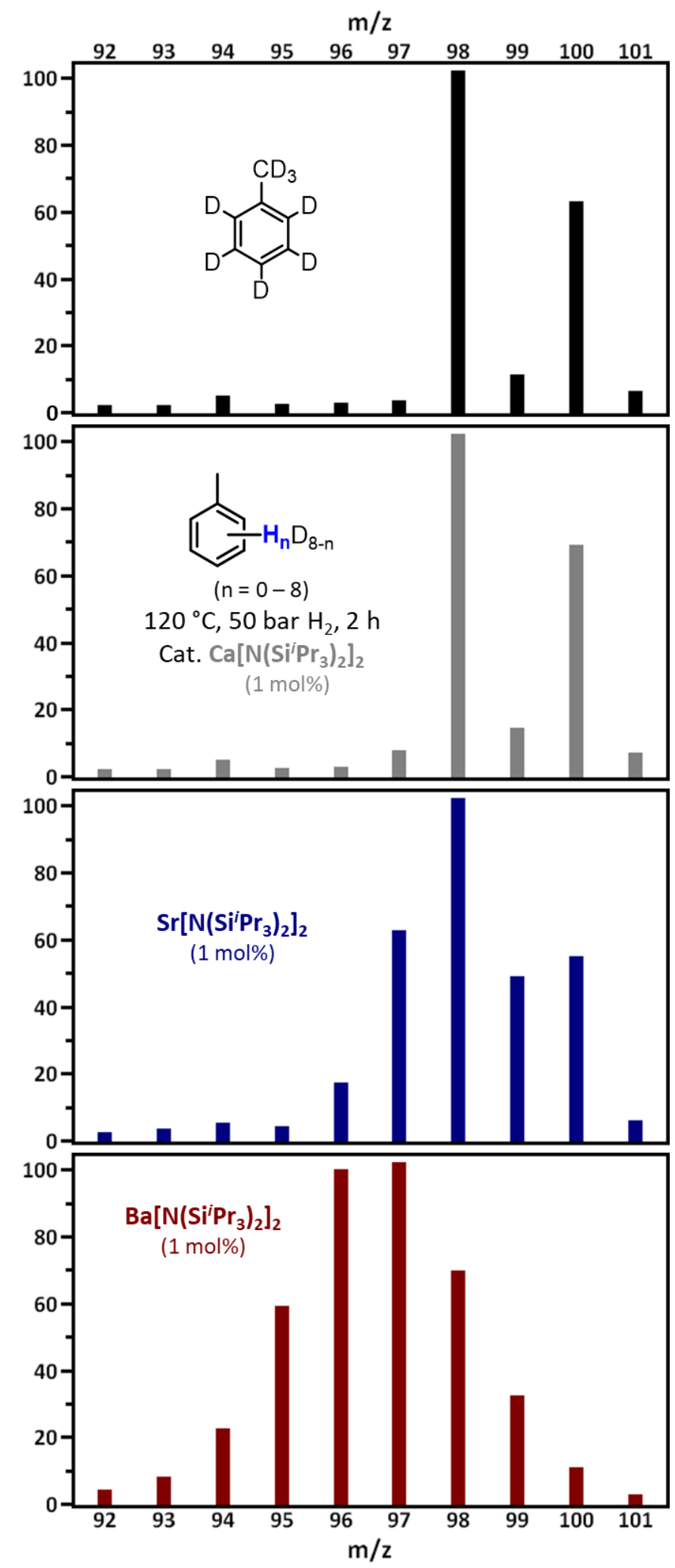

Figure S38. Stacked mass spectra of the authentic $\left[d_{8}\right]$ toluene substrate and the products obtained after the catalytic deuterium for hydrogen exchange with $\mathrm{H}_{2}(50 \mathrm{bar})$ and $\mathrm{Ae}\left[\mathrm{N}\left(\mathrm{Si}^{i} \mathrm{Pr}_{3}\right)_{2}\right]_{2}(1 \mathrm{~mol} \%)(\mathrm{Ae}=\mathrm{Ca}, \mathrm{Sr}, \mathrm{Ba})$ as catalyst precursors at $120^{\circ} \mathrm{C}$ for 2 hours (Table S2, entries $1-3$ ). 


\section{Catalytic Deuteration of Arenes}

\section{General Catalytic Procedure for the Deuteration of Benzene with $D_{2}$ :}

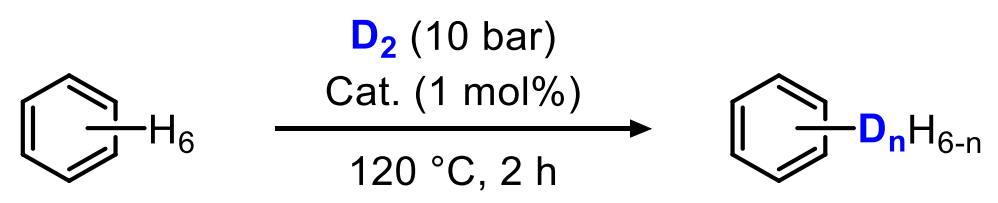

A representative deuteration experiment of benzene was performed as follows:

Under an atmosphere of $\mathrm{N}_{2}$, the appropriate crystalline alkaline earth metal pre-catalyst $(0.11 \mathrm{mmol}$, $1 \mathrm{~mol} \%), \mathrm{C}_{6} \mathrm{H}_{6}(1 \mathrm{~mL}, 874 \mathrm{mg}, 11.19 \mathrm{mmol})$ and a magnetic stir bar were added to an oven-dried miniature stainless steel autoclave $(15 \mathrm{~mL})$, which was sealed tightly and removed from the glovebox. The pressure vessel was assembled on a high vacuum Schlenk line attached to a $D_{2}$ gas cylinder. The supply line was then evacuated and purged several times with $N_{2}$, followed by three times with $D_{2}$ prior to addition of $D_{2}$ (10 bar). The reactor was re-sealed and placed in an aluminum block preheated to $120^{\circ} \mathrm{C}$ and the reaction mixture was mechanically stirred for the period of time indicated ( 2 or $24 \mathrm{~h}$ ). At the completion of the reaction, the autoclave was left to cool to room temperature and opened to air. The reaction mixture was filtered through a glass microfiber filter in a Pasteur pipette and an aliquot of the crude filtrate $(500 \mu \mathrm{L})$ was analyzed by ${ }^{2} \mathrm{H}$ NMR spectroscopy without additional purification using [ $d_{12}$ ]cyclohexane $(15 \mu \mathrm{L}, 13.4 \mathrm{mg}, 0.14 \mathrm{mmol})$ as an internal standard for determining the isotopic incorporation. The percentage of deuterium incorporated was determined experimentally by integration of the respective ${ }^{2} \mathrm{H}$ NMR resonance of the $\mathrm{C}_{6} \mathrm{D}_{n} \mathrm{H}_{6-n}(n=0-6)$ isotopologues versus the signal of the deuterated internal standard. Turnover numbers were calculated as mol of deuterium incorporated per mol of catalyst. ${ }^{5}$ In addition, ${ }^{13} \mathrm{C}\left\{{ }^{1} \mathrm{H}\right\} \mathrm{NMR}$ and GC/MS analyses were carried out to qualitatively verify the deuterium incorporation. 
Table S3. Catalytic deuteration of benzene with $D_{2}$ using representative alkaline earth metal amides as catalyst precursors. $^{a}$

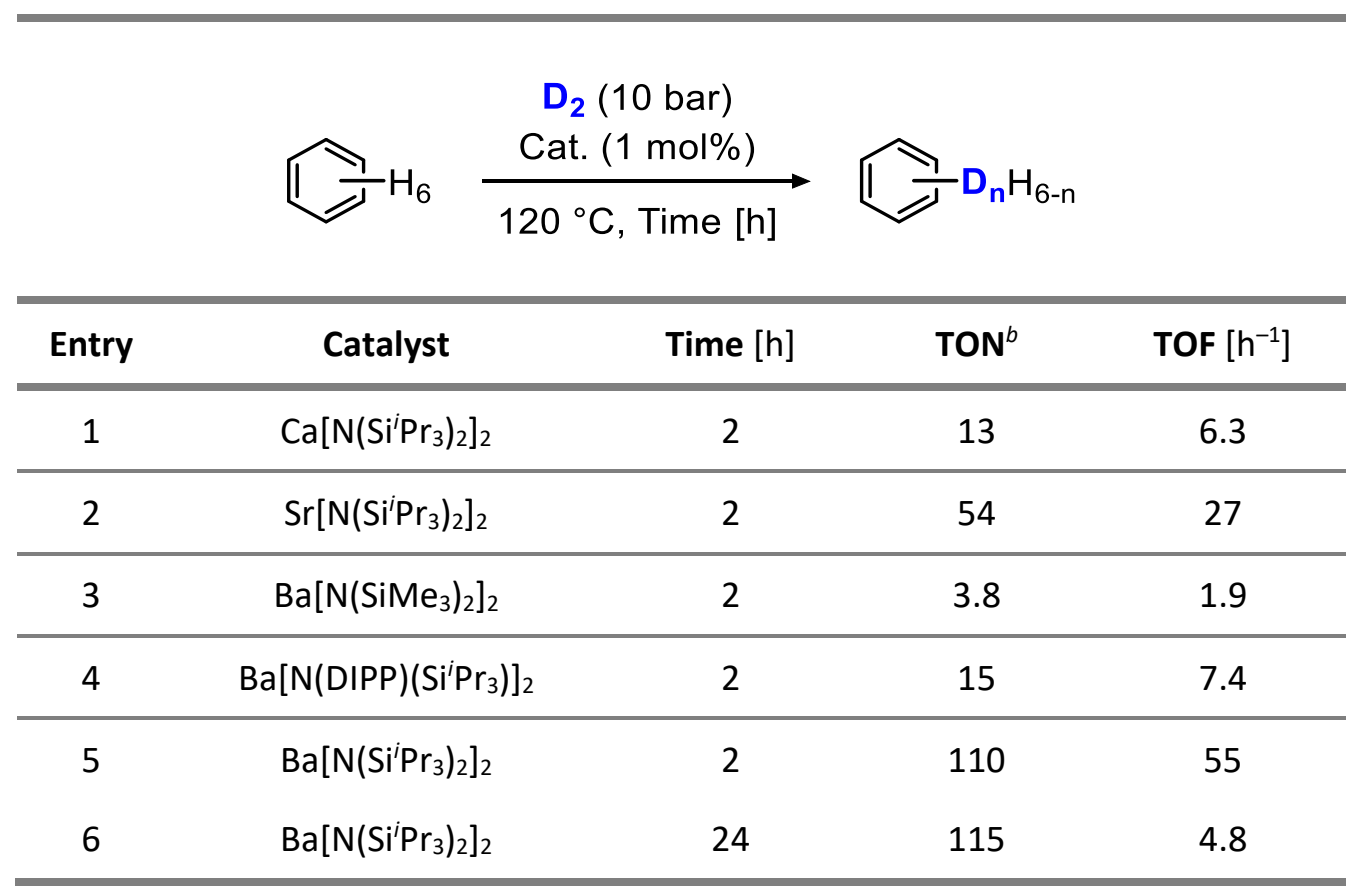

${ }^{a}$ General reaction conditions: $\mathrm{C}_{6} \mathrm{H}_{6}(1 \mathrm{~mL}, 874 \mathrm{mg}, 11.19 \mathrm{mmol})$, Ae metal pre-catalyst $(0.11 \mathrm{mmol}, 1 \mathrm{~mol} \%), \mathrm{D}_{2}(10 \mathrm{bar})$, $120^{\circ} \mathrm{C}$. ${ }^{b}$ Determined experimentally by ${ }^{2} \mathrm{H}$ NMR spectroscopy using $\left[d_{12}\right]$ cyclohexane as an internal standard. 


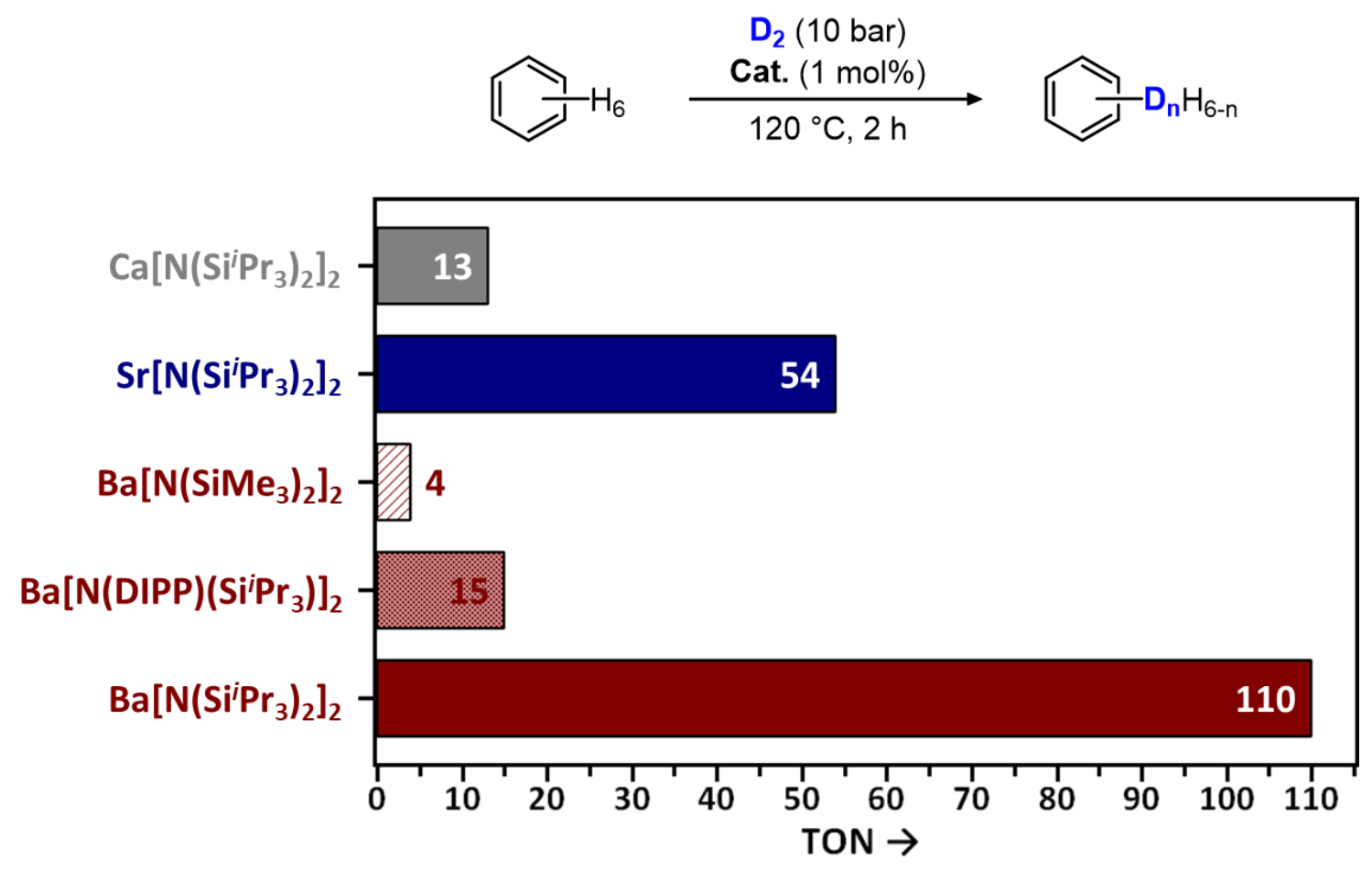

Figure S39. Turnover numbers for the catalytic deuteration of $\mathrm{C}_{6} \mathrm{H}_{6}$ using $\mathrm{D}_{2}$ as deuterium source and representative alkaline earth metal amide complexes as catalyst precursors.

Reaction conditions: $\mathrm{C}_{6} \mathrm{H}_{6}(1 \mathrm{~mL}, 874 \mathrm{mg}, 11.19 \mathrm{mmol})$, Ae metal pre-catalyst $(0.11 \mathrm{mmol}, 1 \mathrm{~mol} \%), \mathrm{D}_{2}(10 \mathrm{bar})$, $120{ }^{\circ} \mathrm{C}, 2 \mathrm{~h}$. 
(a)

Internal standard:

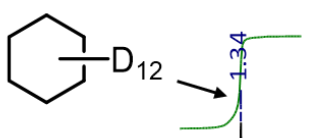

1

${ }^{2} \mathrm{H}\left\{{ }^{1} \mathrm{H}\right\}$ NMR
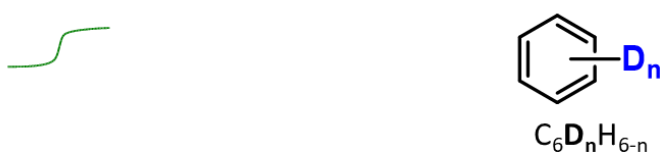

$$
(n=0-6)
$$

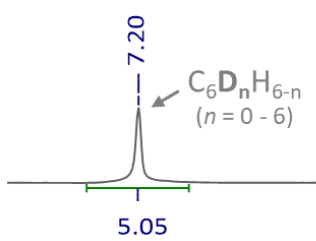

$120{ }^{\circ} \mathrm{C}, 10$ bar $\mathrm{D}_{2}, 2 \mathrm{~h}$, Cat. $\mathrm{Ca}\left[\mathrm{N}\left(\mathrm{Si}^{\prime} \mathrm{Pr}_{3}\right)_{2}\right]_{2}$

(1 mol\%)

(c)
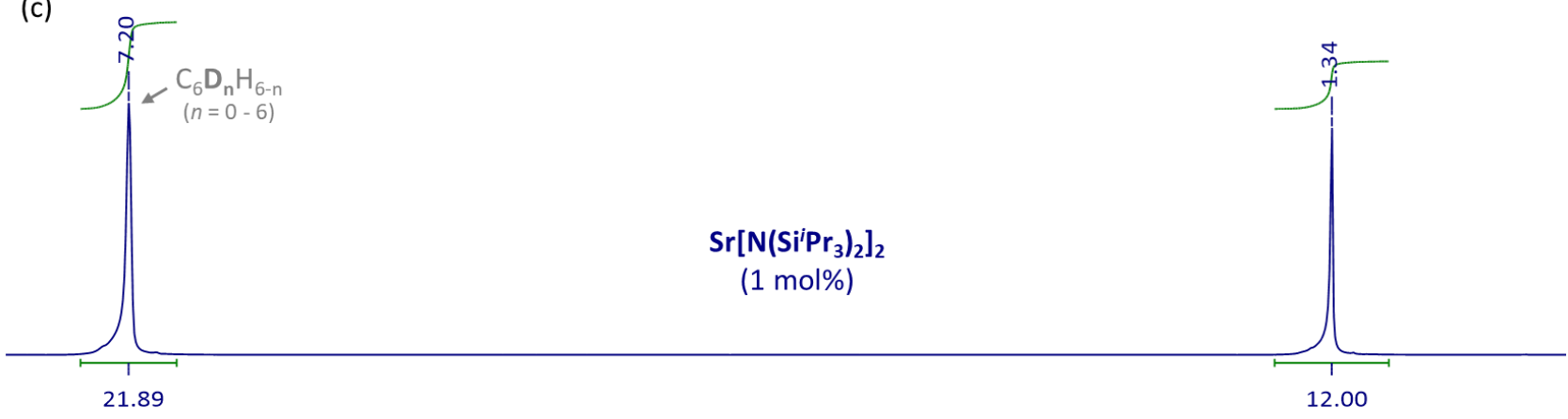

(d)

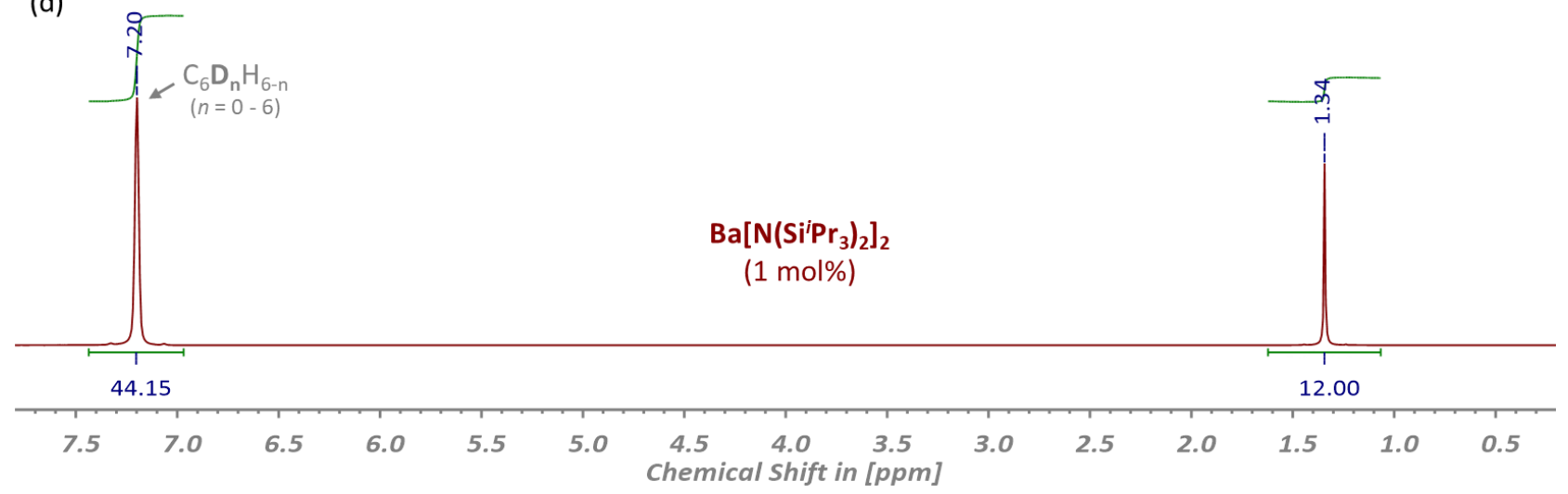

Figure S40. Stacked ${ }^{2} \mathrm{H}\left\{{ }^{1} \mathrm{H}\right\}$ NMR spectra $\left(92 \mathrm{MHz}, \mathrm{C}_{6} \mathrm{H}_{6}, 25^{\circ} \mathrm{C}\right.$ ) of $(a)$ the authentic $\mathrm{C}_{6} \mathrm{H}_{6}$ substrate and the deuterated products of the catalytic deuteration with $\mathrm{D}_{2}\left(10 \mathrm{bar}\right.$ ) at $120^{\circ} \mathrm{C}$ for 2 hours using $\mathrm{Ae}\left[\mathrm{N}\left(\mathrm{Si}^{\mathrm{i}} \mathrm{Pr}_{3}\right)_{2}\right]_{2}$ (1 mol\%) as catalyst precursors: $\mathrm{Ae}=(b) \mathrm{Ca},(c) \mathrm{Sr}$ and $(d) \mathrm{Ba}$ (Table S3, entries 1, 2 and 5).

Note: $\left[d_{12}\right]$ Cyclohexane was used as an internal standard. 

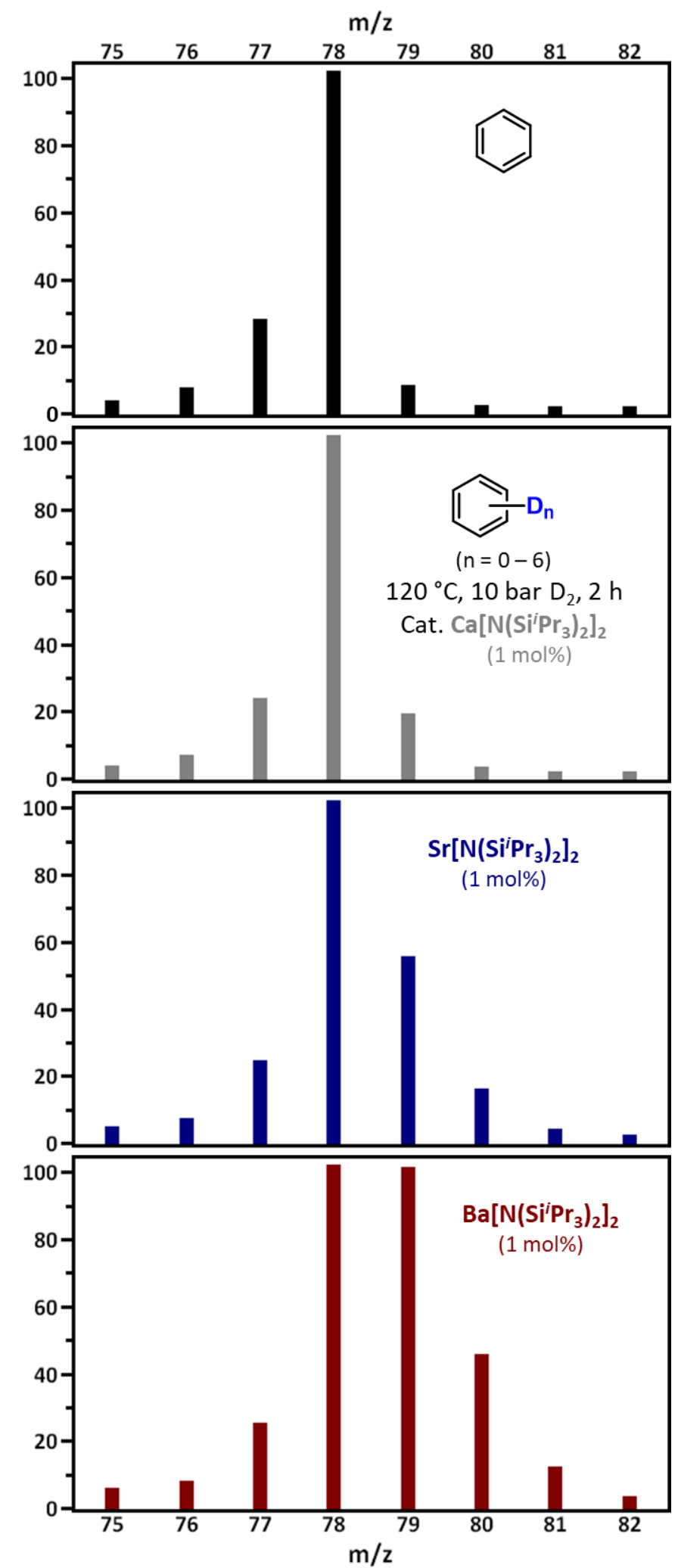

Figure S41. Stacked mass spectra of the all-protio benzene substrate and the partially deuterated products obtained after the catalytic deuteration with $\mathrm{D}_{2}(10 \mathrm{bar})$ and $\mathrm{Ae}\left[\mathrm{N}\left(\mathrm{Si}^{\mathrm{P}} \mathrm{Pr}_{3}\right)_{2}\right]_{2}(1 \mathrm{~mol} \%)(\mathrm{Ae}=\mathrm{Ca}, \mathrm{Sr}, \mathrm{Ba})$ as catalyst precursors at $120^{\circ} \mathrm{C}$ for 2 hours (Table S3, entries 1,2 and 5). 
(a)

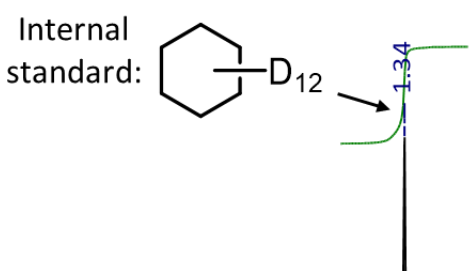

${ }^{2} \mathrm{H}\left\{{ }^{1} \mathrm{H}\right\}$ NMR

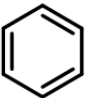

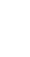


(a)

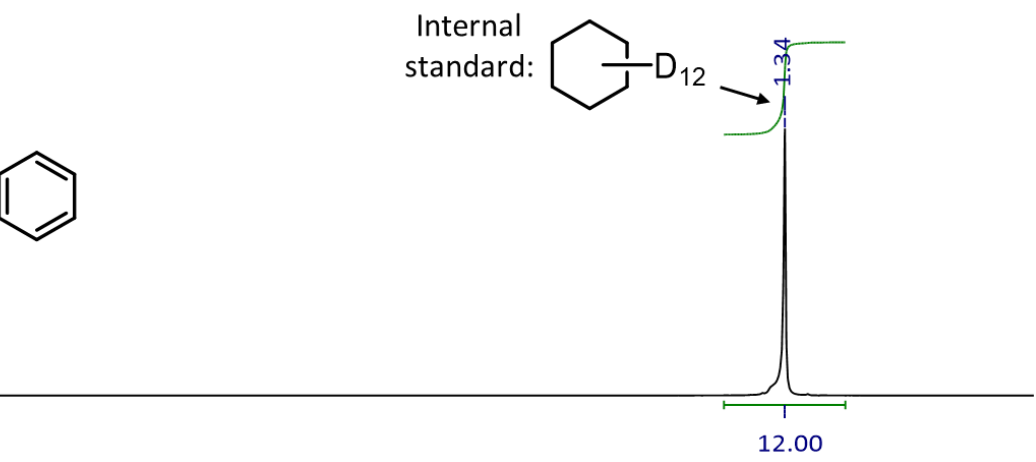

${ }^{2} \mathrm{H}\left\{{ }^{1} \mathrm{H}\right\}$ NMR

18

(b)

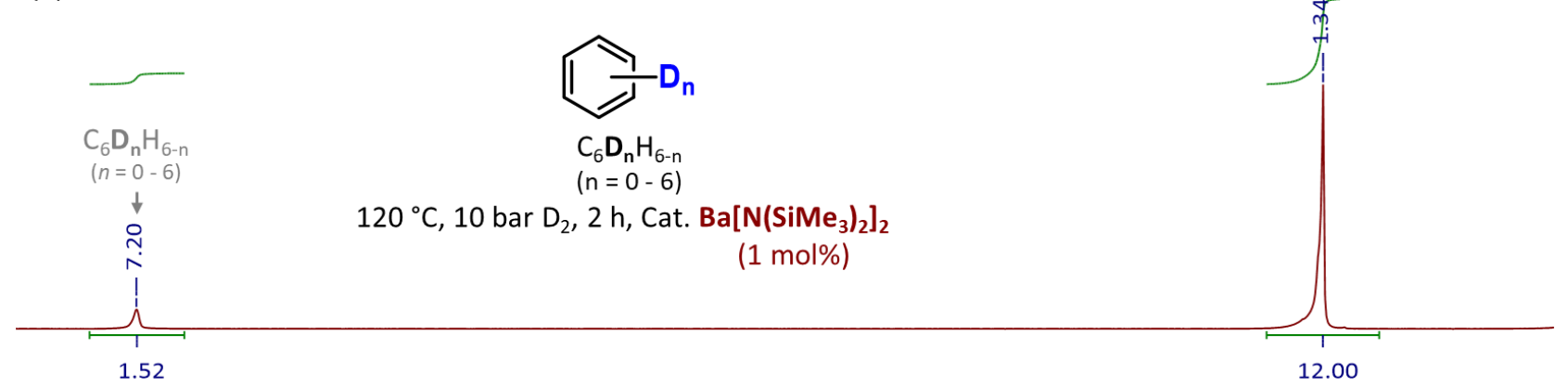

(c)
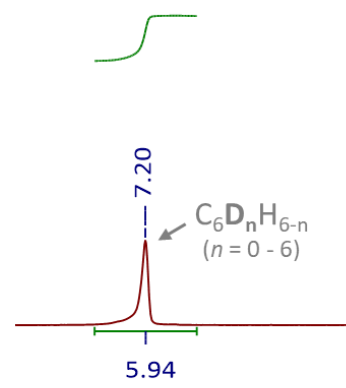

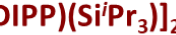

(1 mol\%)

(d)

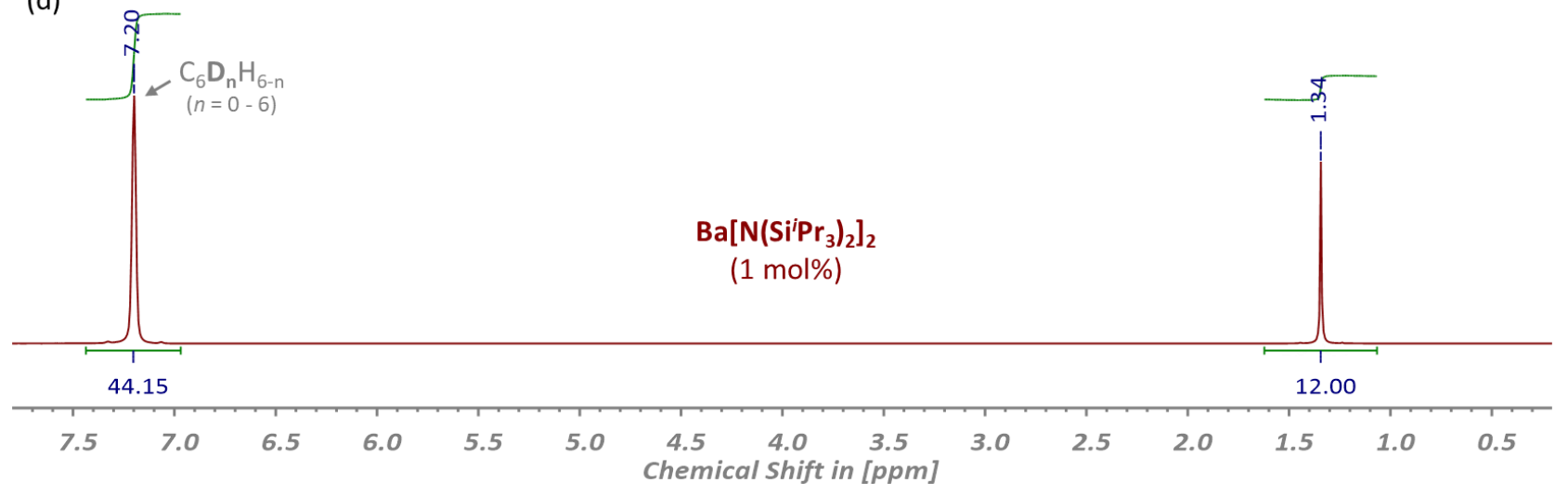

Figure S43. Stacked ${ }^{2} \mathrm{H}\left\{{ }^{1} \mathrm{H}\right\}$ NMR spectra $\left(92 \mathrm{MHz}, \mathrm{C}_{6} \mathrm{H}_{6}, 25^{\circ} \mathrm{C}\right.$ ) of $(a)$ the authentic $\mathrm{C}_{6} \mathrm{H}_{6}$ substrate and the partially deuterated products obtained after the catalytic deuteration with $\mathrm{D}_{2}\left(10 \mathrm{bar}\right.$ ) at $120^{\circ} \mathrm{C}$ for 2 hours using

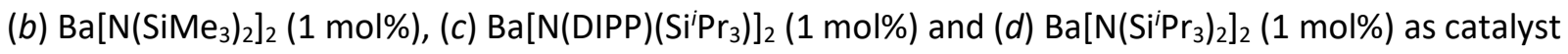
precursors (Table S3, entries $3-5)$. Note: \# denotes DN(DIPP) $\left(\mathrm{Si}^{i} \mathrm{Pr}_{3}\right)$. 

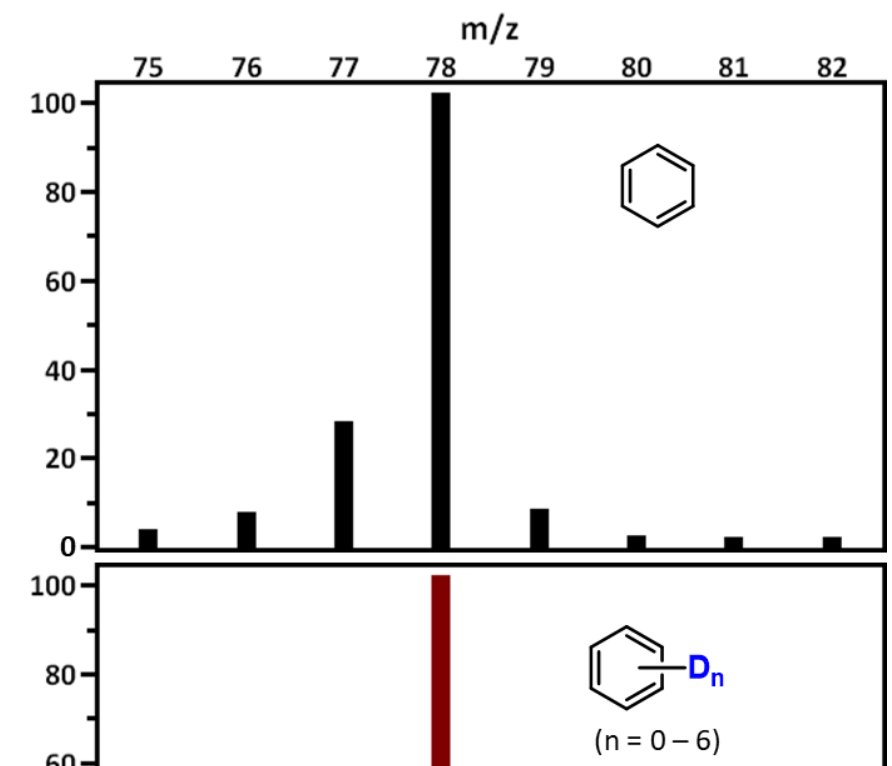

$120^{\circ} \mathrm{C}, 50$ bar $\mathrm{D}_{2}, 2 \mathrm{~h}$

Cat. $\mathrm{Ba}\left[\mathrm{N}\left(\mathrm{SiMe}_{3}\right)_{2}\right]_{2}$

(1 $\mathrm{mol} \%)$
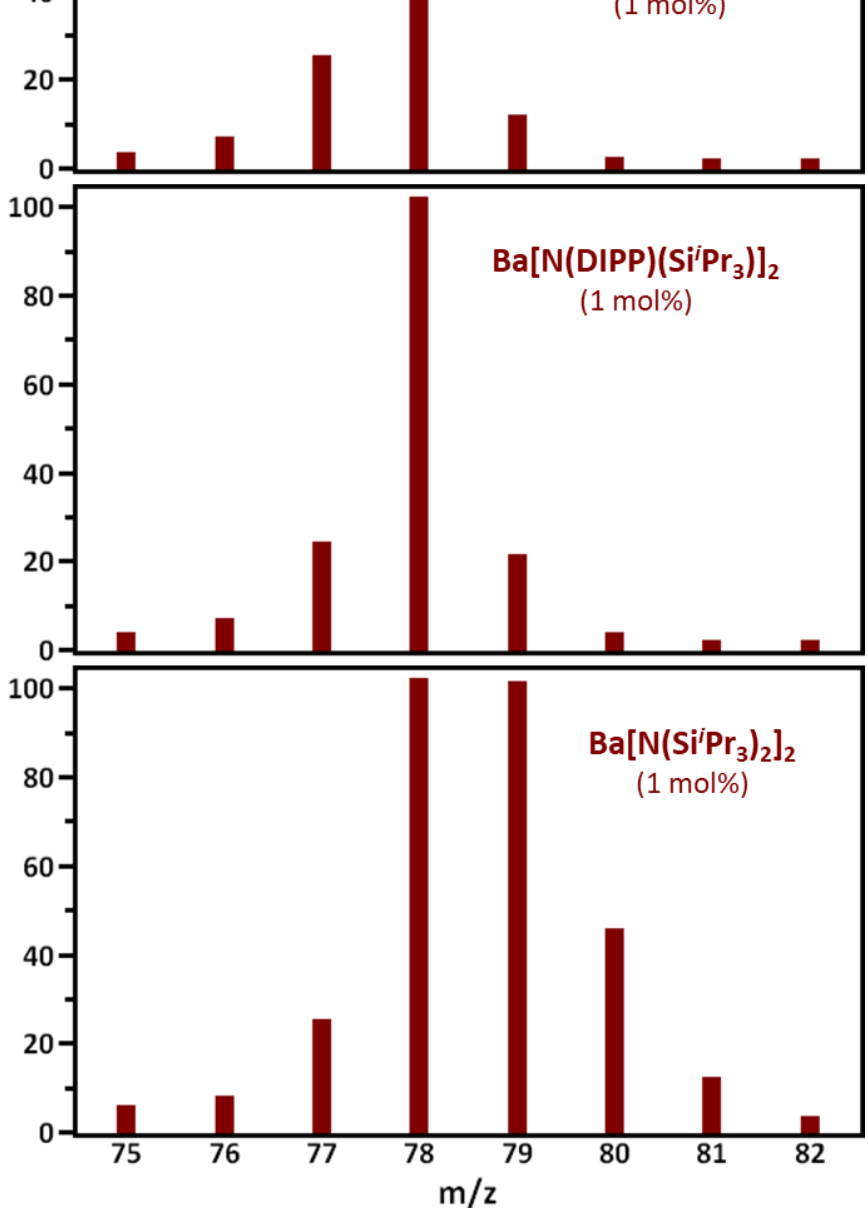

Figure S44. Stacked mass spectra of the natural abundance $\mathrm{C}_{6} \mathrm{H}_{6}$ substrate and the catalytically deuterated products obtained after the deuteration with $\mathrm{D}_{2}(10 \mathrm{bar})$ at $120{ }^{\circ} \mathrm{C}$ for 2 hours using $\mathrm{Ba}\left[\mathrm{N}\left(\mathrm{SiMe}_{3}\right)_{2}\right]_{2}(1 \mathrm{~mol} \%)$, $\mathrm{Ba}\left[\mathrm{N}(\mathrm{DIPP})\left(\mathrm{Si}^{i} \mathrm{Pr}_{3}\right)\right]_{2}(1 \mathrm{~mol} \%)$ and $\mathrm{Ba}\left[\mathrm{N}\left(\mathrm{Si}^{\prime} \mathrm{Pr}_{3}\right)_{2}\right]_{2}(1 \mathrm{~mol} \%)$ as catalyst precursors (Table S3, entries $\left.3-5\right)$. 

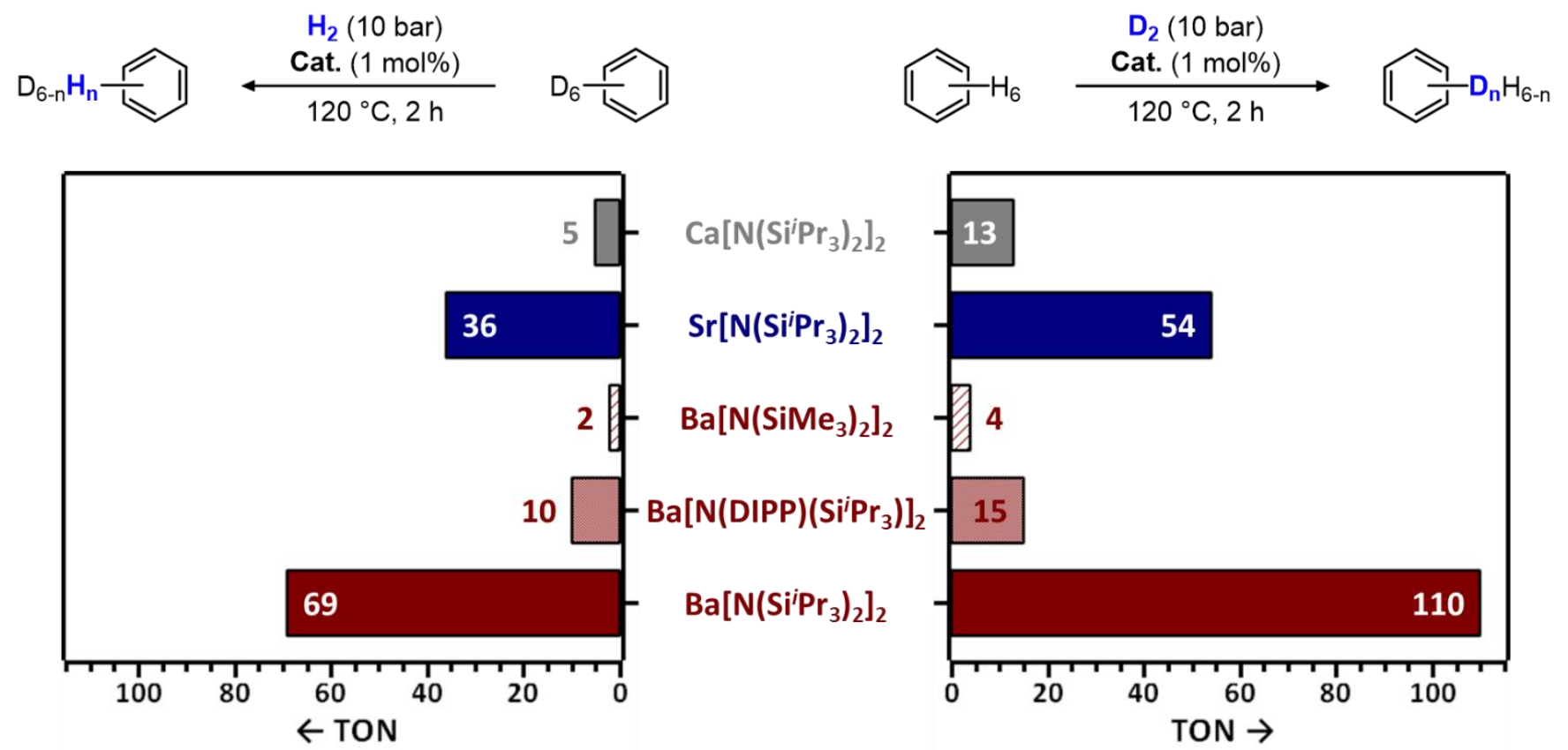

Figure S45. Comparison of the turnover numbers for the catalytic deuteration of benzene with $D_{2}$ and the deuterium for hydrogen exchange in $\mathrm{C}_{6} \mathrm{D}_{6}$ with $\mathrm{H}_{2}$ using representative alkaline earth metal amide complexes as catalyst precursors.

Reaction conditions:

- Catalytic deuteration: $\mathrm{C}_{6} \mathrm{H}_{6}(1 \mathrm{~mL}, 874 \mathrm{mg}, 11.19 \mathrm{mmol})$, Ae metal catalyst precursor $(0.11 \mathrm{mmol}, 1 \mathrm{~mol} \%)$, $\mathrm{D}_{2}$ (10 bar), $120^{\circ} \mathrm{C}, 2 \mathrm{~h}$.

- Catalytic D/H exchange: $\mathrm{C}_{6} \mathrm{D}_{6}(1 \mathrm{~mL}, 950 \mathrm{mg}, 11.29 \mathrm{mmol})$, Ae metal pre-catalyst $(0.11 \mathrm{mmol}, 1 \mathrm{~mol} \%)$, $\mathrm{H}_{2}$ (10 bar), $120^{\circ} \mathrm{C}, 2 \mathrm{~h}$. 


\section{General Procedure for the Deuteration of Arenes:}

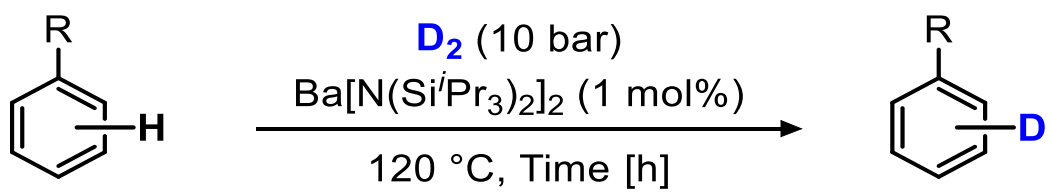

Unless otherwise stated, deuterium labeling experiments of arenes were carried out according to the following standard procedure:

In an $\mathrm{N}_{2}$-filled glovebox, a stainless steel miniature autoclave $(15 \mathrm{~mL})$ containing a magnetic stir bar was charged with $\mathrm{Ba}\left[\mathrm{N}\left(\mathrm{Si}^{i} \mathrm{Pr}_{3}\right)_{2}\right]_{2} \quad(36 \mathrm{mg}, 45 \mu \mathrm{mol}, 1 \mathrm{~mol} \%)$ and the corresponding arene substrate (4.5 mmol). Once tightly sealed, the pressure vessel was brought outside the glovebox and connected to a vacuum / $N_{2}$ manifold and a $D_{2}$ gas cylinder. Upon evacuation and refilling of the supply line several times with $N_{2}$, followed by three times with $D_{2}$, the reactor was pressurized to 10 bars $D_{2}$ atmosphere and placed in an aluminum heating block set to $120^{\circ} \mathrm{C}$. The reaction mixture was stirred at $120^{\circ} \mathrm{C}$ for 4 or 24 hours as specified before it was allowed to cool to room temperature and quenched by exposure to air. The deuterium-labeled arene products were isolated as clear, colorless liquids following trap-to-trap vacuum distillation for removal of $\left({ }^{i} \mathrm{Pr}_{3} \mathrm{Si}\right)_{2} \mathrm{ND}$ and barium metal contents, dissolved in $\mathrm{CDCl}_{3}$ and then analyzed by NMR spectroscopy to determine the extent and regioselectivity of deuterium incorporation. GC/MS was used additionally as a qualitative analysis method to confirm the isotopic incorporation.

The percentage of deuterium incorporation at each specified position was estimated by the decrease of the integral intensity of the respective ${ }^{1} \mathrm{H}$ NMR signal as compared to the integral value of the corresponding resonance in the ${ }^{1} \mathrm{H}$ NMR spectrum of the authentic, non-labeled arene starting material: ${ }^{7}$

$$
\% \mathrm{D} \text { incorporation }=100-\left[\frac{\text { residual integral value }}{\text { initial number of convertible } \mathrm{H} \text { atoms at specified position }} \cdot 100\right]
$$

The integral intensities of interest were calibrated against a proton resonance corresponding to a position that did not undergo H/D exchange under the present conditions. The locations of deuterium incorporation were confirmed by ${ }^{2} \mathrm{H}\left\{{ }^{1} \mathrm{H}\right\} \mathrm{NMR}$ spectroscopy (using $\mathrm{CHCl}_{3}$ as solvent) and by the appearance of deuterium coupled ${ }^{13} \mathrm{C}$ resonances in the ${ }^{13} \mathrm{C}\left\{{ }^{1} \mathrm{H}\right\}$ NMR spectrum, if applicable. In cases where deuterium exchange occurred in all possible positions (i.e. benzene, toluene, 
trimethylsilylbenzene and meta-xylene), an integration standard was added. The extent of deuterium incorporation was calculated from the loss of signal intensity in the ${ }^{1} \mathrm{H}$ NMR spectrum of the isolated deuterated product relative to integration of a ${ }^{1} \mathrm{H}$ NMR reference sample containing the standard and the all-protio arene substrate in an equimolar ratio. In practice, a premixed $0.3 \mathrm{M}$ stock solution of 1,3,5-trimethoxybenzene in $\mathrm{CDCl}_{3}(500 \mu \mathrm{L} ; 0.15 \mathrm{mmol})$ was added separately to an aliquot (30 $\left.\mu \mathrm{L}\right)$ of both the purified deuterated arene and non-labeled starting material prior to ${ }^{1} \mathrm{H}$ NMR analysis. 
<smiles>c1ccccc1</smiles><smiles>CC(C)c1ccccc1</smiles>

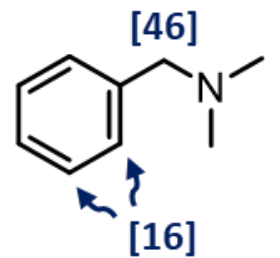

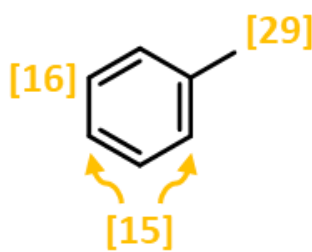<smiles>CC(C)(C)c1ccccc1[Te]</smiles>

[6]<smiles>[Bi]C1CCCc2ccc3c(c21)C3[Bi]</smiles>

[26] [7]<smiles>CCc1ccc2cc1C[Al]2</smiles>

[17]

[19]<smiles>[R11]c1cc([Si](C)(C)I)ccc1I</smiles>

[13]

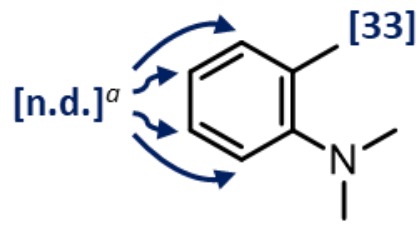

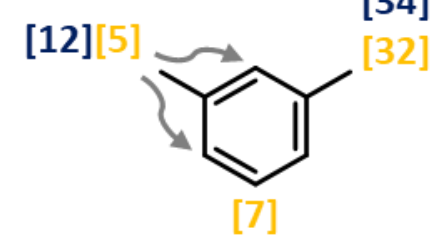

[15]

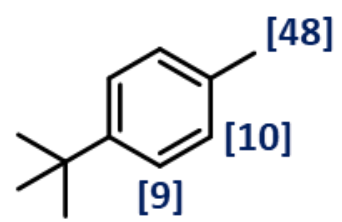

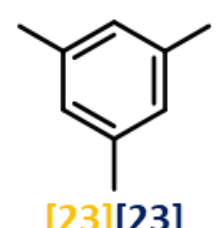

Figure S46. [Ba]-catalyzed deuteration of representative arenes with $D_{2}$.

General catalytic reaction conditions as follows: neat arene substrate $(4.5 \mathrm{mmol})$, Cat. $\mathrm{Ba}\left[\mathrm{N}\left(\mathrm{Si}^{i} \mathrm{Pr}_{3}\right)_{2}\right]_{2}(36 \mathrm{mg}$, $45 \mu \mathrm{mol}, 1 \mathrm{~mol} \%), \mathrm{D}_{2}$ (10 bar), $120^{\circ} \mathrm{C}$. The percentages of deuterium incorporation at the designated positions were estimated by ${ }^{1} \mathrm{H}$ NMR spectroscopy and given in parentheses.

Note: ${ }^{a}$ The extent of deuterium incorporated at the specified locations in the aromatic ring is less than $5 \%$ or too small to be accurately determined by ${ }^{1} \mathrm{H}$ NMR spectroscopy. 
Selected $\left({ }^{1} \mathrm{H},{ }^{13} \mathrm{C}\left\{{ }^{1} \mathrm{H}\right\}\right.$ and $\left.{ }^{2} \mathrm{H}\left\{{ }^{1} \mathrm{H}\right\}\right)$ NMR and Mass Spectra

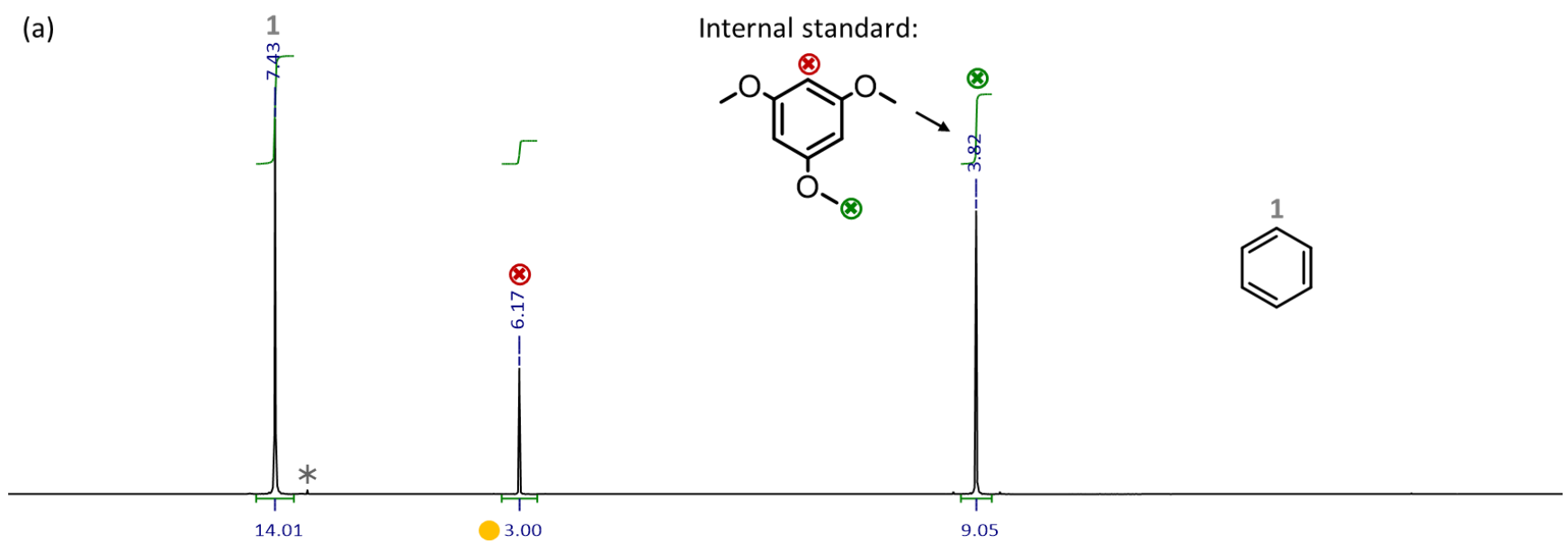

(b)

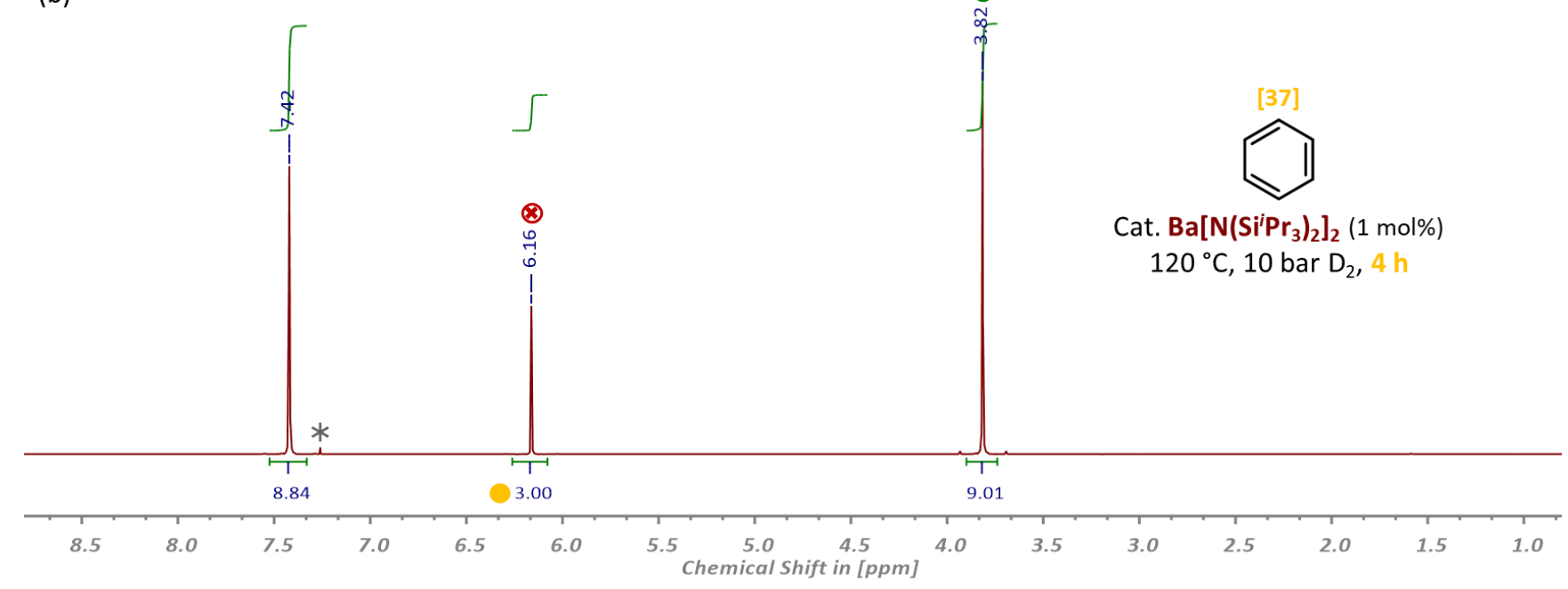

Figure S47. Stacked ${ }^{1} \mathrm{H}$ NMR spectra $\left(600 \mathrm{MHz}, \mathrm{CDCl}_{3}, 25^{\circ} \mathrm{C}\right)$ of $(a)$ an authentic sample of benzene and $(b)$ the purified partially deuterated benzene product isolated after the catalytic deuteration with $\mathrm{D}_{2}(10 \mathrm{bar})$ and $\mathrm{Ba}\left[\mathrm{N}\left(\mathrm{Si}^{i} \mathrm{Pr}_{3}\right)_{2}\right]_{2}(1 \mathrm{~mol} \%)$ as catalyst precursor at $120{ }^{\circ} \mathrm{C}$ for 4 hours. Note: $1,3,5-$ Trimethoxybenzene was used as internal standard. 

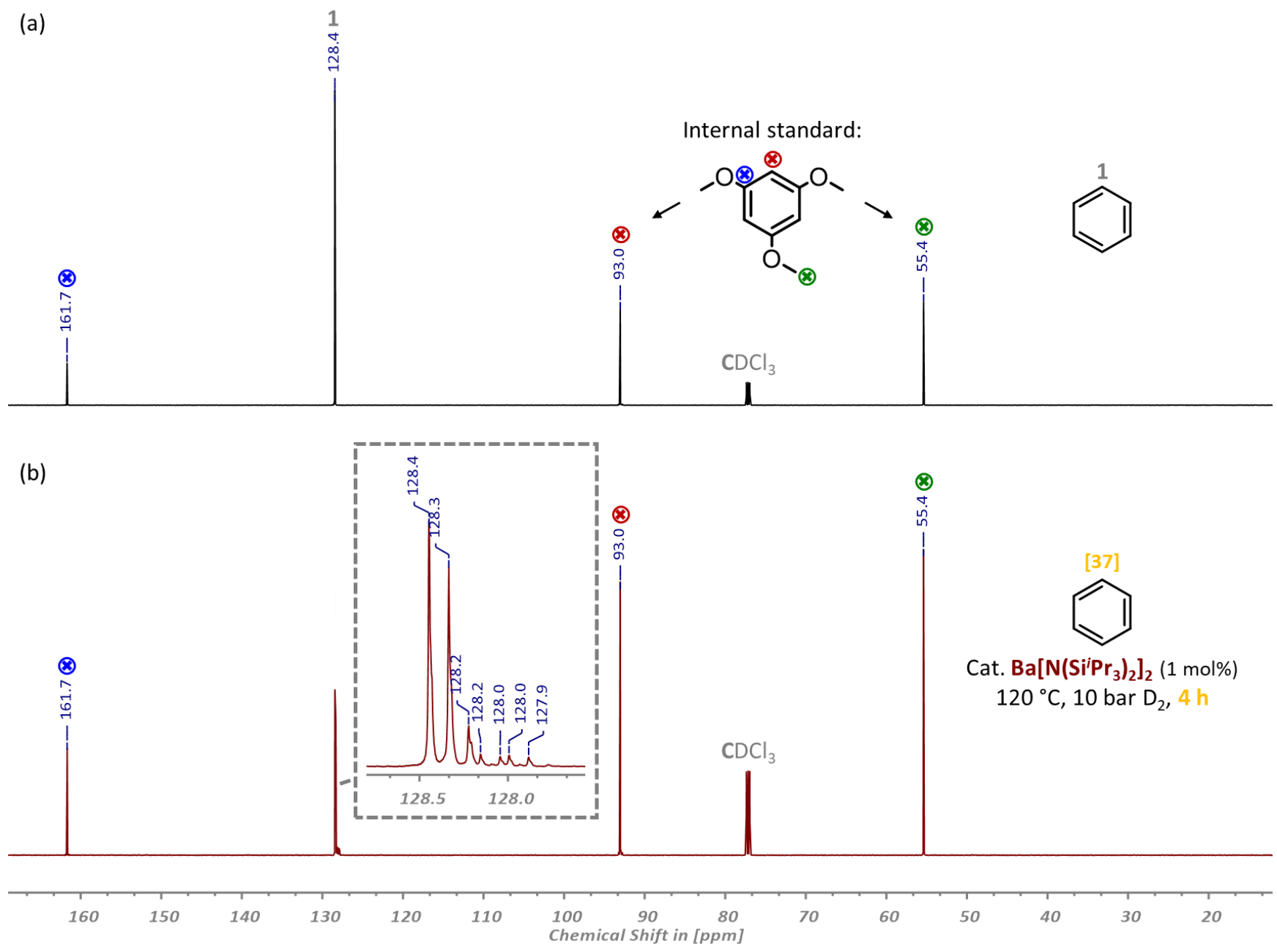

Figure S48. Stacked ${ }^{13} \mathrm{C}\left\{{ }^{1} \mathrm{H}\right\} \mathrm{NMR}$ spectra $\left(151 \mathrm{MHz}, \mathrm{CDCl}_{3}, 25^{\circ} \mathrm{C}\right.$ ) of $(a)$ the all-protio benzene starting material and $(b)$ the partially deuterated benzene isotopologues obtained after the catalytic deuteration with $D_{2}(10$ bar) at $120{ }^{\circ} \mathrm{C}$ for 4 hours using $\mathrm{Ba}\left[\mathrm{N}\left(\mathrm{Si}^{i} \mathrm{Pr}_{3}\right)_{2}\right]_{2}(1 \mathrm{~mol} \%)$ as catalyst precursor. Note: 1,3,5-Trimethoxybenzene was used as internal standard. 


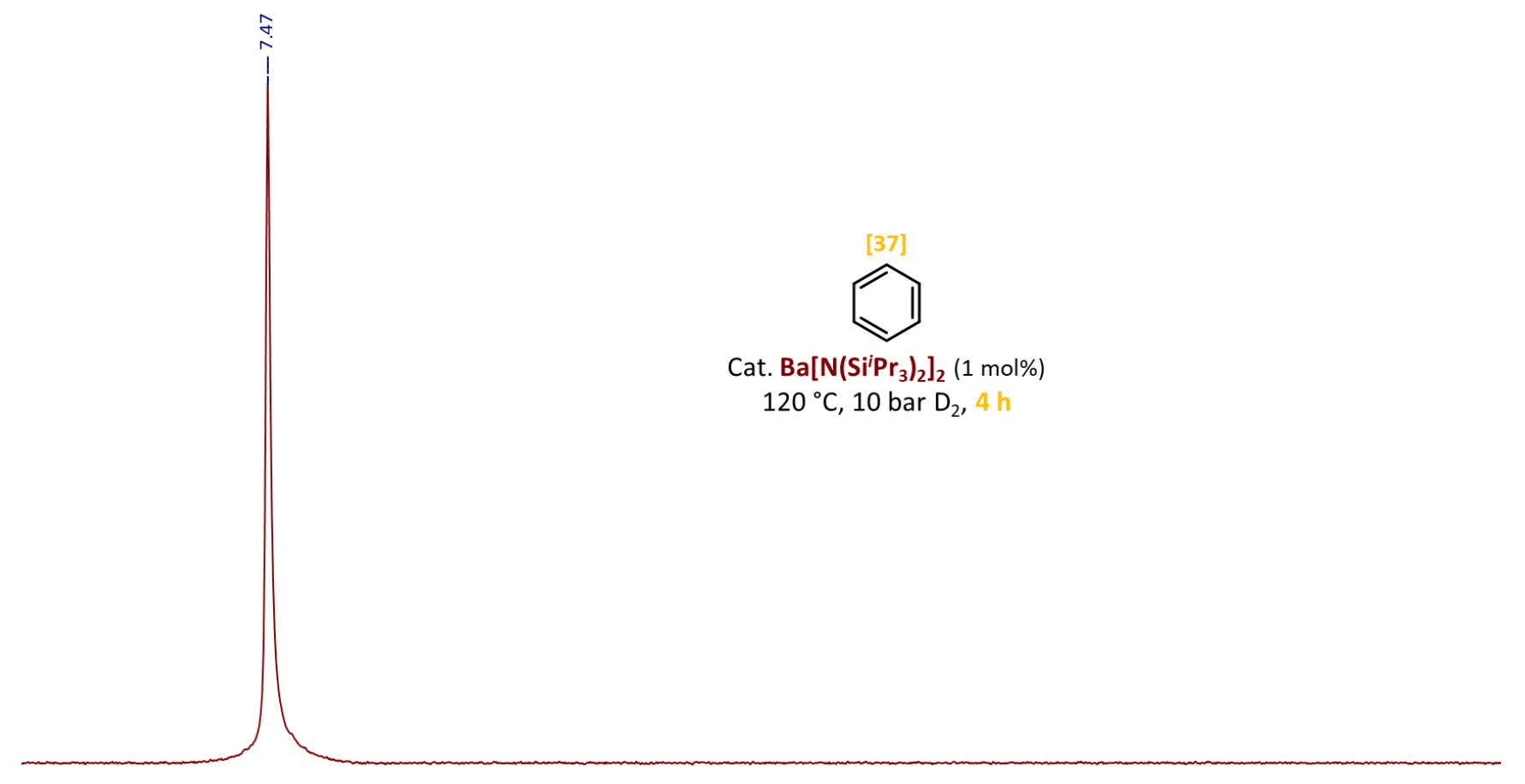

\begin{tabular}{|c|c|c|c|c|c|c|c|c|c|c|c|c|c|c|c|}
\hline 8.5 & 8.0 & 7.5 & 7.0 & 6.5 & 6.0 & 5.5 & $\begin{array}{l}5.0 \\
\text { ical St }\end{array}$ & $\begin{array}{l}4.5 \\
\text { in [ppm] }\end{array}$ & 4.0 & 3.5 & 3.0 & 2.5 & 2.0 & 1.5 & 1.0 \\
\hline
\end{tabular}

Figure S49. ${ }^{2} \mathrm{H}\left\{{ }^{1} \mathrm{H}\right\} \mathrm{NMR}$ spectrum $\left(92 \mathrm{MHz}, \mathrm{CHCl}_{3}, 25^{\circ} \mathrm{C}\right)$ of the catalytically deuterated benzene product obtained after the deuteration with $\mathrm{D}_{2}(10 \mathrm{bar})$ and $\mathrm{Ba}\left[\mathrm{N}\left(\mathrm{Si}^{i} \mathrm{Pr}_{3}\right)_{2}\right]_{2}(1 \mathrm{~mol} \%)$ as pre-catalyst at $120{ }^{\circ} \mathrm{C}$ for 4 hours. 


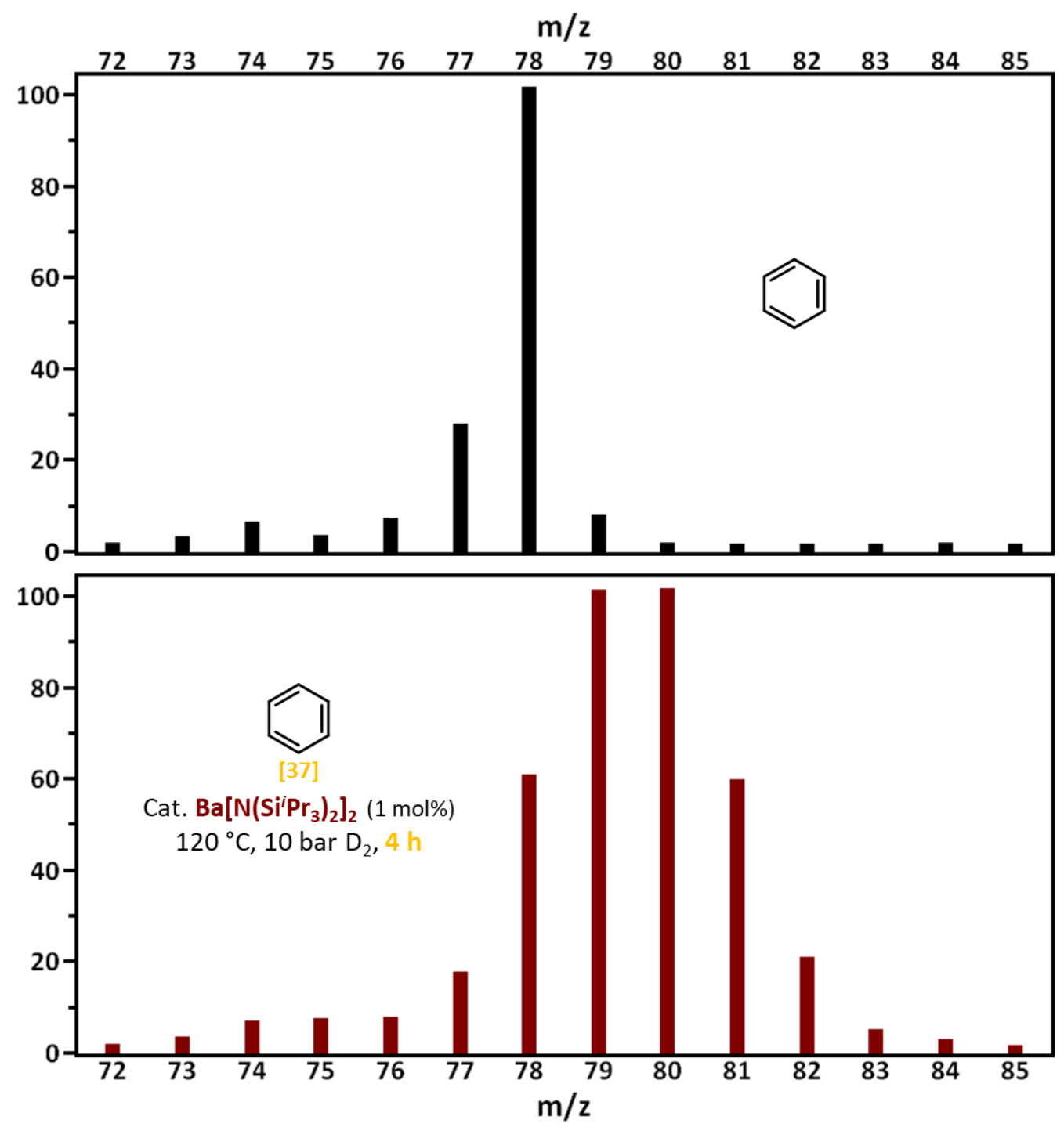

Figure S50. Stacked mass spectra of (top) authentic benzene and (bottom) the partially deuterated product isolated after the catalytic deuteration with $\mathrm{D}_{2}(10 \mathrm{bar})$ and $\mathrm{Ba}\left[\mathrm{N}\left(\mathrm{Si}^{i} \mathrm{Pr}_{3}\right)_{2}\right]_{2}(1 \mathrm{~mol} \%)$ as catalyst precursor at $120^{\circ} \mathrm{C}$ for 4 hours. 


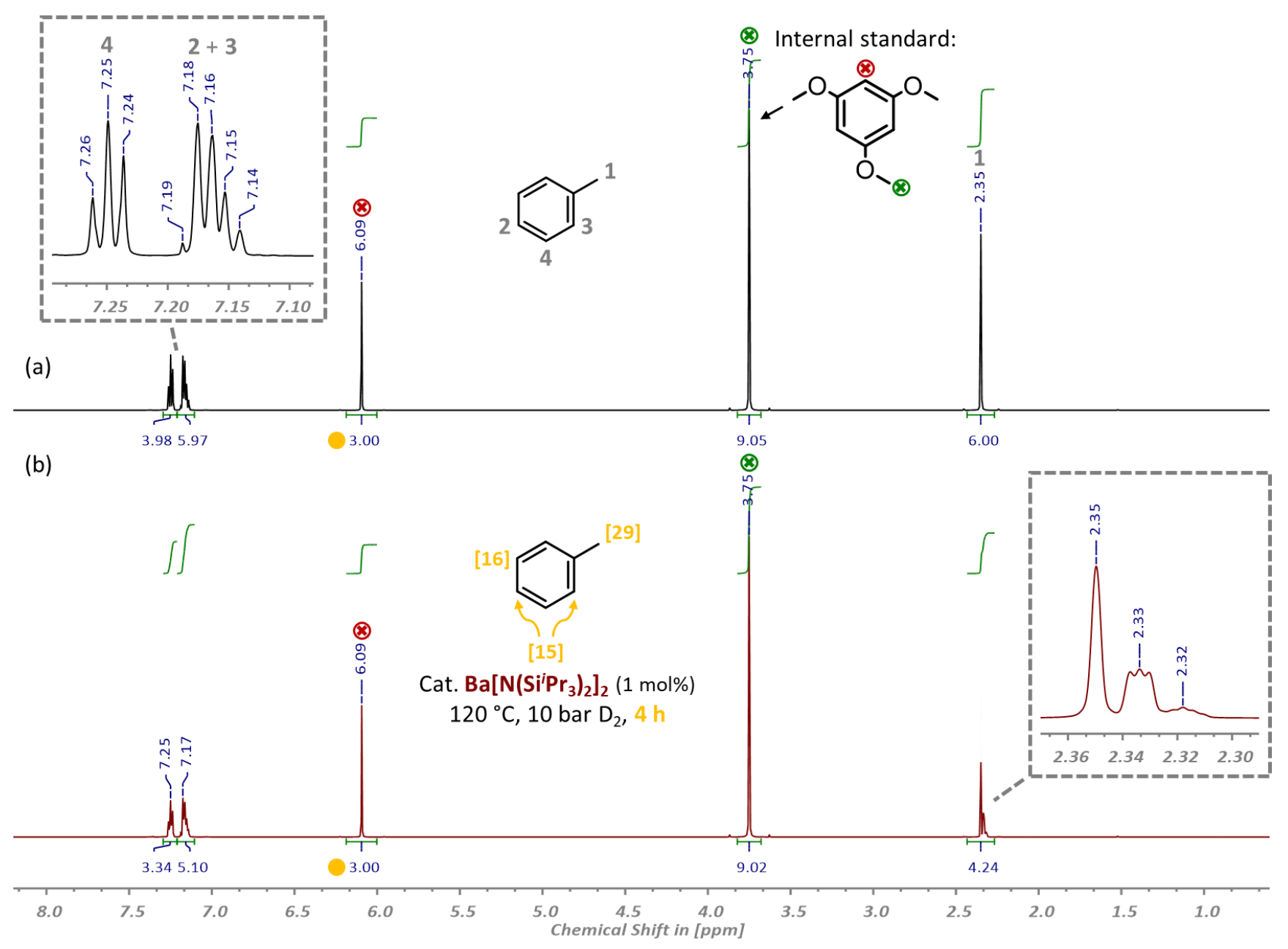

Figure S51. Stacked ${ }^{1} \mathrm{H}$ NMR spectra $\left(600 \mathrm{MHz}, \mathrm{CDCl}_{3}, 25^{\circ} \mathrm{C}\right)$ of $(a)$ the non-deuterated toluene substrate and

(b) the purified deuterium-labeled product obtained after the catalytic deuteration with $\mathrm{D}_{2}(10 \mathrm{bar})$ and $\mathrm{Ba}\left[\mathrm{N}\left(\mathrm{Si}^{i} \mathrm{Pr}_{3}\right)_{2}\right]_{2}(1 \mathrm{~mol} \%)$ as catalyst precursor at $120^{\circ} \mathrm{C}$ for 4 hours. Note: All $\mathrm{C}-\mathrm{H}$ bonds of toluene incorporate deuterium. 1,3,5-Trimethoxybenzene was therefore used as an internal standard. 


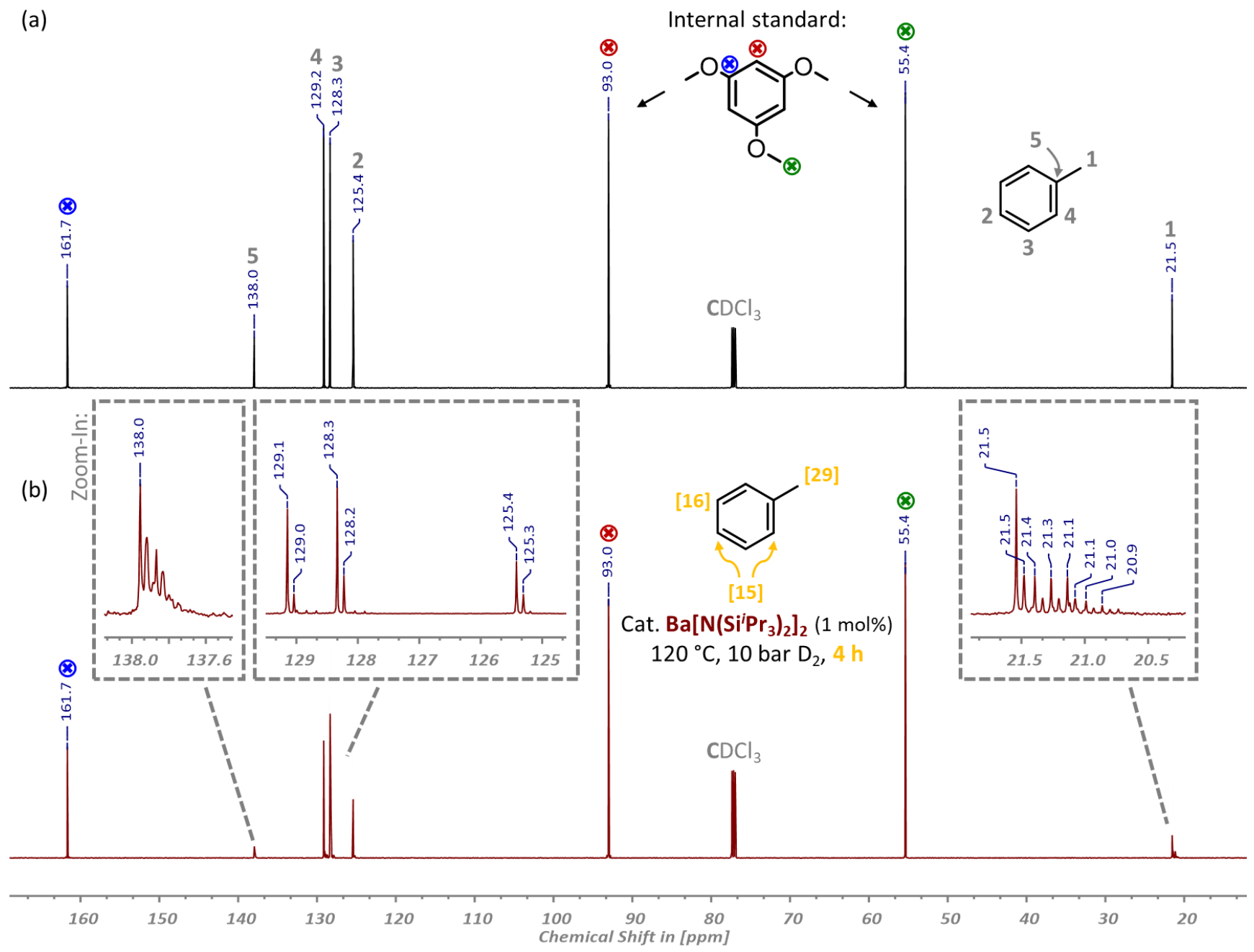

Figure S52. Stacked ${ }^{13} \mathrm{C}\left\{{ }^{1} \mathrm{H}\right\}$ NMR spectra $\left(151 \mathrm{MHz}, \mathrm{CDCl}_{3}, 25^{\circ} \mathrm{C}\right)$ of $(a)$ the natural abundance toluene substrate and $(b)$ the deuterium-labeled product isolated after the catalytic deuteration with $\mathrm{D}_{2}\left(10 \mathrm{bar}\right.$ ) at $120^{\circ} \mathrm{C}$ for 4 hours using $\mathrm{Ba}\left[\mathrm{N}\left(\mathrm{Si}^{i} \mathrm{Pr}_{3}\right)_{2}\right]_{2}(1 \mathrm{~mol} \%)$ as catalyst precursor. Note: 1,3,5-Trimethoxybenzene was used as internal standard. 
(a)

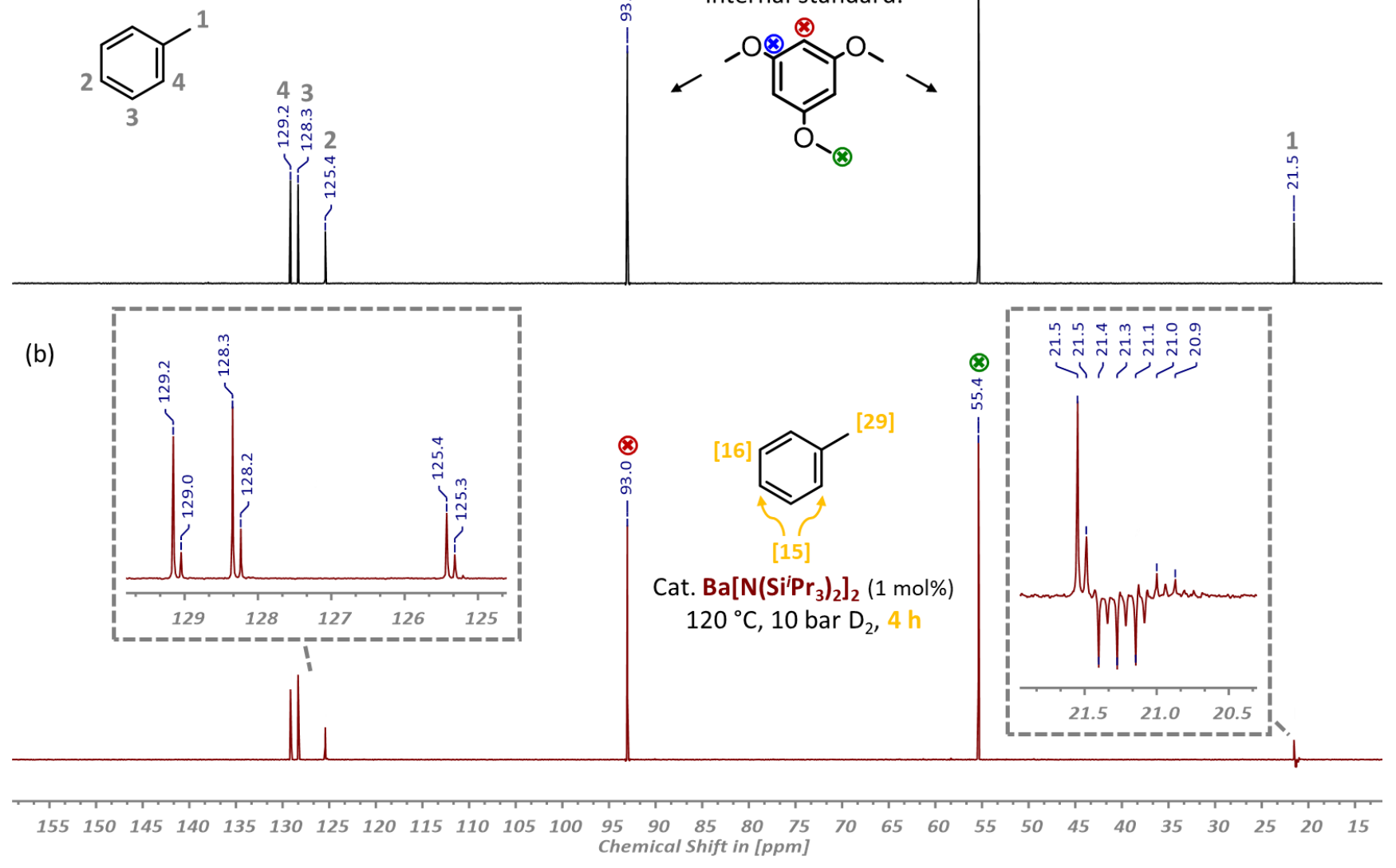

Figure S53. Stacked ${ }^{13} \mathrm{C}$ DEPT-135 NMR spectra $\left(151 \mathrm{MHz}, \mathrm{CDCl}_{3}, 25^{\circ} \mathrm{C}\right)$ of $(a)$ the unlabeled toluene starting material and $(b)$ the partially deuterated product obtained after the catalytic deuteration with $\mathrm{D}_{2}(10$ bar) and $\mathrm{Ba}\left[\mathrm{N}\left(\mathrm{Si}^{i} \mathrm{Pr}_{3}\right)_{2}\right]_{2}(1 \mathrm{~mol} \%)$ as catalyst precursor at $120^{\circ} \mathrm{C}$ for 4 hours. Note: $1,3,5$-Trimethoxybenzene was added as internal standard. 


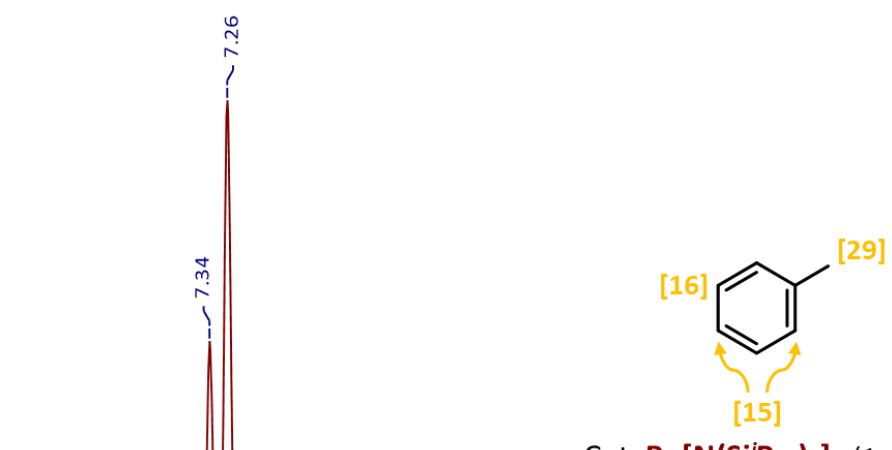

Cat. $\mathrm{Ba}\left[\mathrm{N}\left(\mathrm{Si}^{\mathrm{P}} \mathrm{Pr}_{3}\right)_{2}\right]_{2}(1 \mathrm{~mol} \%)$ $120^{\circ} \mathrm{C}, 10$ bar $\mathrm{D}_{2}, 4 \mathrm{~h}$

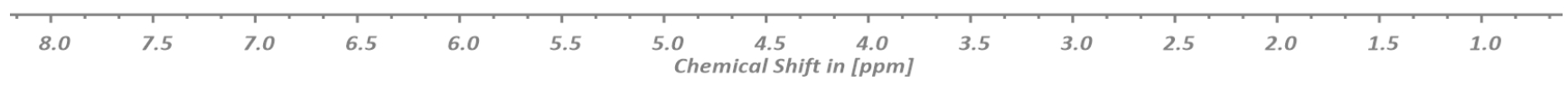

Figure S54. ${ }^{2} \mathrm{H}\left\{{ }^{1} \mathrm{H}\right\} \mathrm{NMR}$ spectrum $\left(92 \mathrm{MHz}, \mathrm{CHCl}_{3}, 25^{\circ} \mathrm{C}\right)$ of the deuterium-labeled product isolated after the catalytic deuteration of toluene with $\mathrm{D}_{2}(10 \mathrm{bar})$ and $\mathrm{Ba}\left[\mathrm{N}\left(\mathrm{Si}^{i} \mathrm{Pr}_{3}\right)_{2}\right]_{2}(1 \mathrm{~mol} \%)$ as catalyst precursor at $120^{\circ} \mathrm{C}$ for 4 hours. 


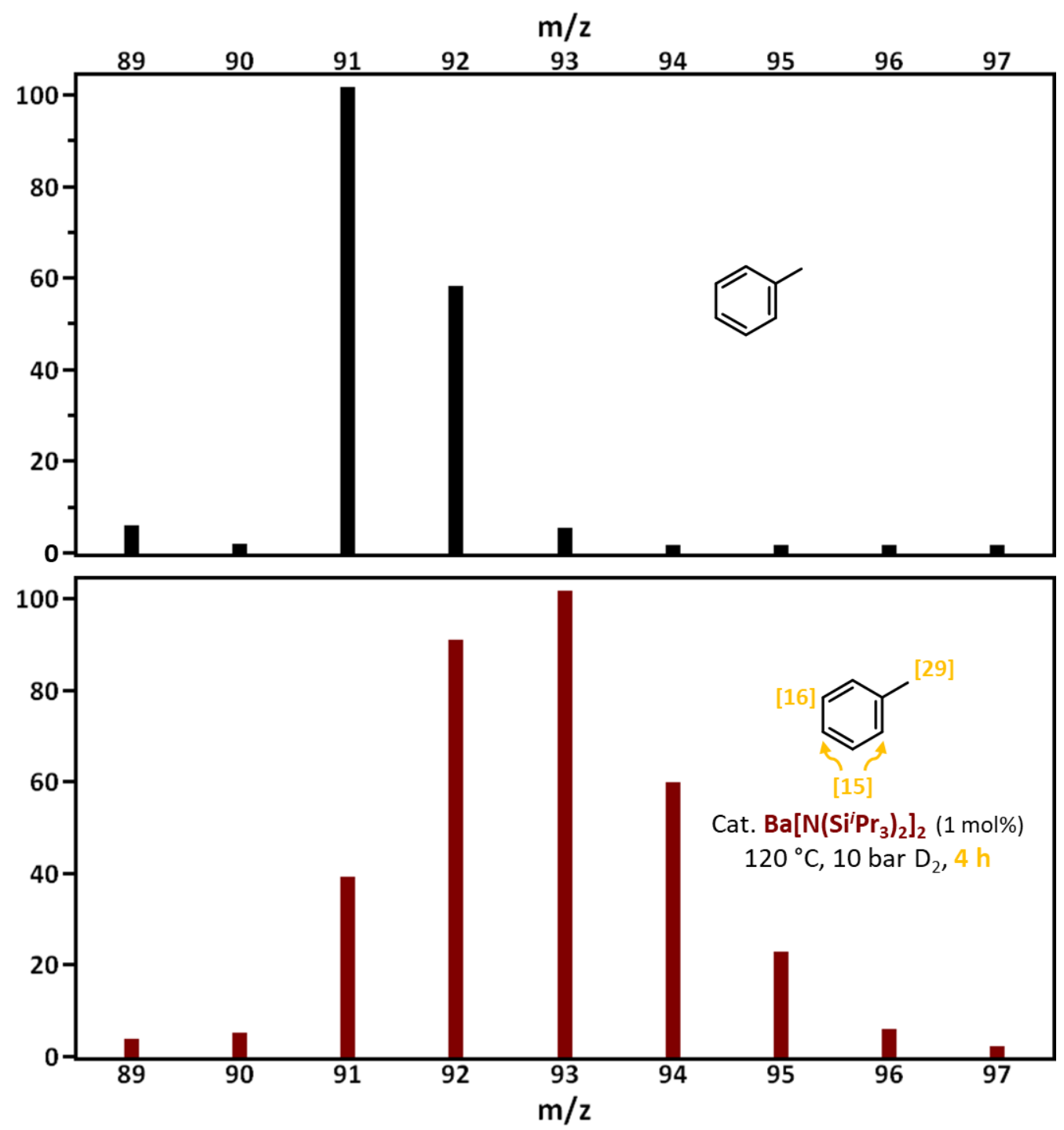

Figure S55. Stacked mass spectra of (top) the authentic toluene substrate and (bottom) the distilled deuterated product after the catalytic deuteration with $\mathrm{D}_{2}(10 \mathrm{bar})$ and $\mathrm{Ba}\left[\mathrm{N}\left(\mathrm{Si}^{i} \mathrm{Pr}_{3}\right)_{2}\right]_{2}(1 \mathrm{~mol} \%)$ as catalyst precursor at $120^{\circ} \mathrm{C}$ for 4 hours. 

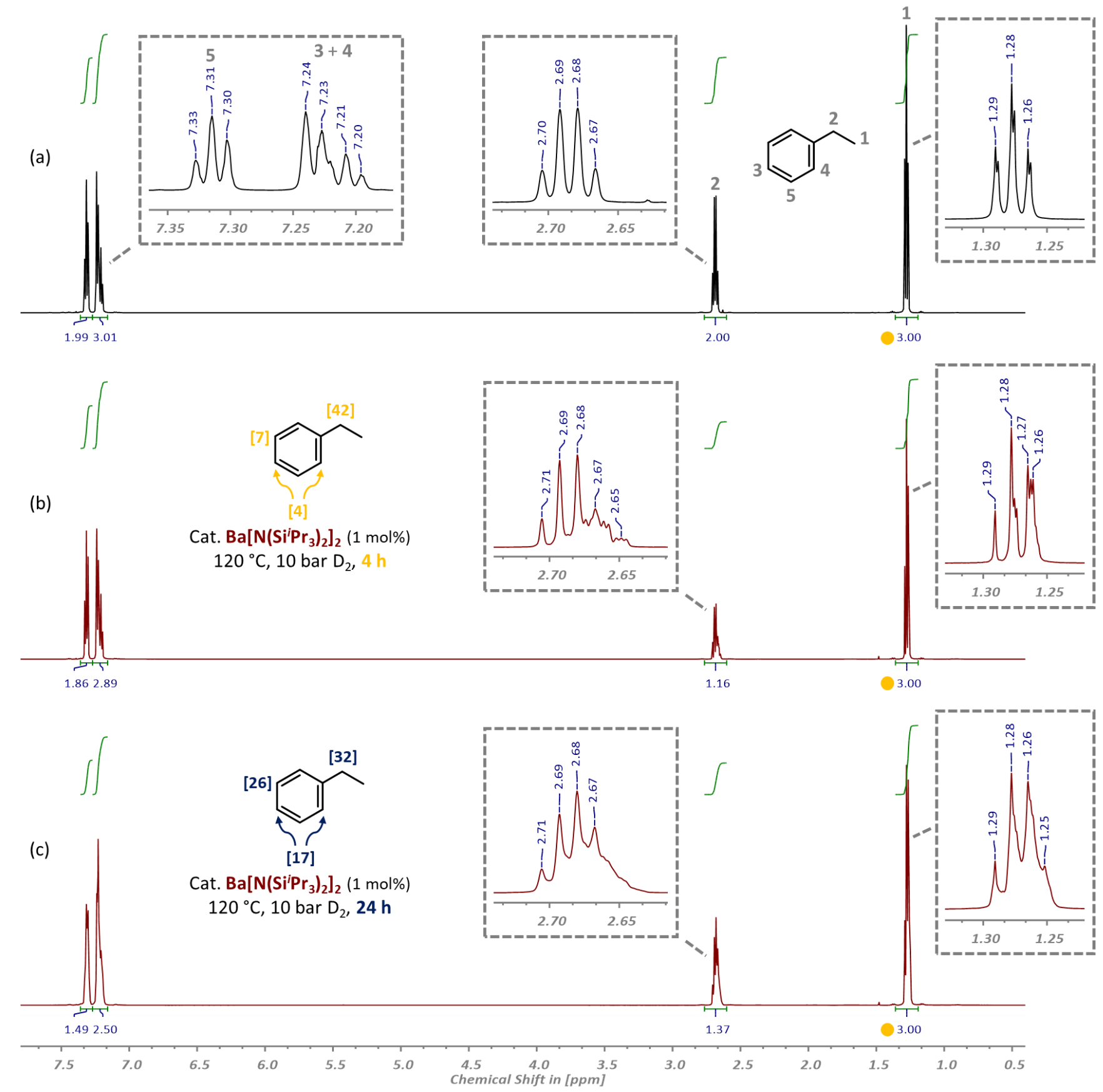

Figure S56. Stacked ${ }^{1} \mathrm{H}$ NMR spectra $\left(600 \mathrm{MHz} \mathrm{CDCl}_{3}, 25^{\circ} \mathrm{C}\right)$ of $(a)$ the authentic ethylbenzene substrate and the deuterium-labeled products obtained after the catalytic deuteration with $\mathrm{D}_{2}(10 \mathrm{bar})$ and $\mathrm{Ba}\left[\mathrm{N}\left(\mathrm{Si}^{i} \operatorname{Pr}_{3}\right)_{2}\right]_{2}(1 \mathrm{~mol} \%)$ as catalyst precursor at $120^{\circ} \mathrm{C}$ for (b) 4 and (c) 24 hours, respectively. 

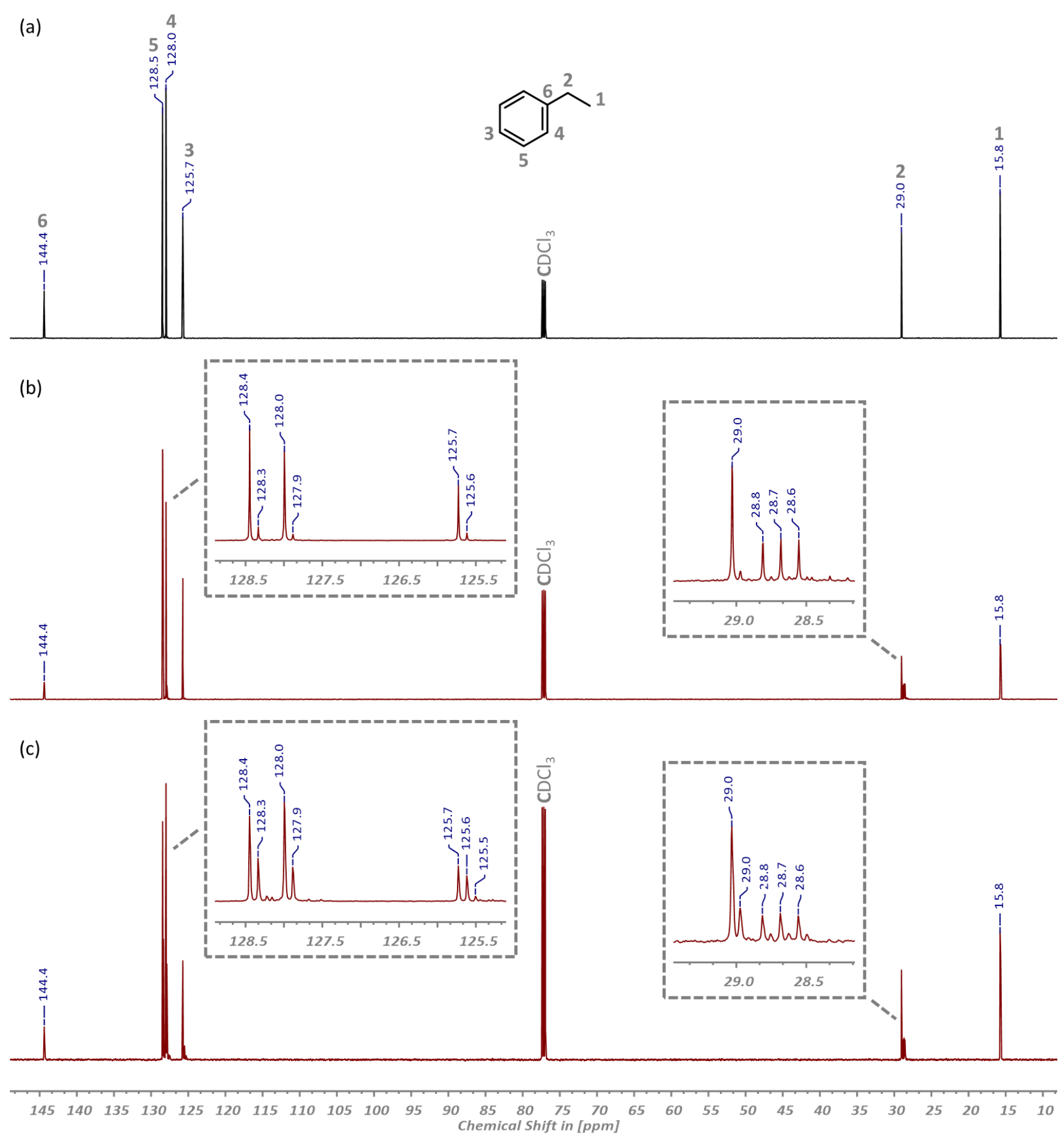

Figure S57. Stacked ${ }^{13} \mathrm{C}\left\{{ }^{1} \mathrm{H}\right\}$ NMR spectra $\left(151 \mathrm{MHz}, \mathrm{CDCl}_{3}, 25^{\circ} \mathrm{C}\right)$ of $(a)$ the all-protio ethylbenzene substrate and the deuterated products obtained after the catalytic deuteration with $\mathrm{D}_{2}(10 \mathrm{bar})$ and $\mathrm{Ba}\left[\mathrm{N}\left(\mathrm{Si}^{\mathrm{i}} \mathrm{Pr}_{3}\right)_{2}\right]_{2}(1 \mathrm{~mol} \%)$ as pre-catalyst at $120^{\circ} \mathrm{C}$ for (b) 4 and (c) 24 hours, respectively. 


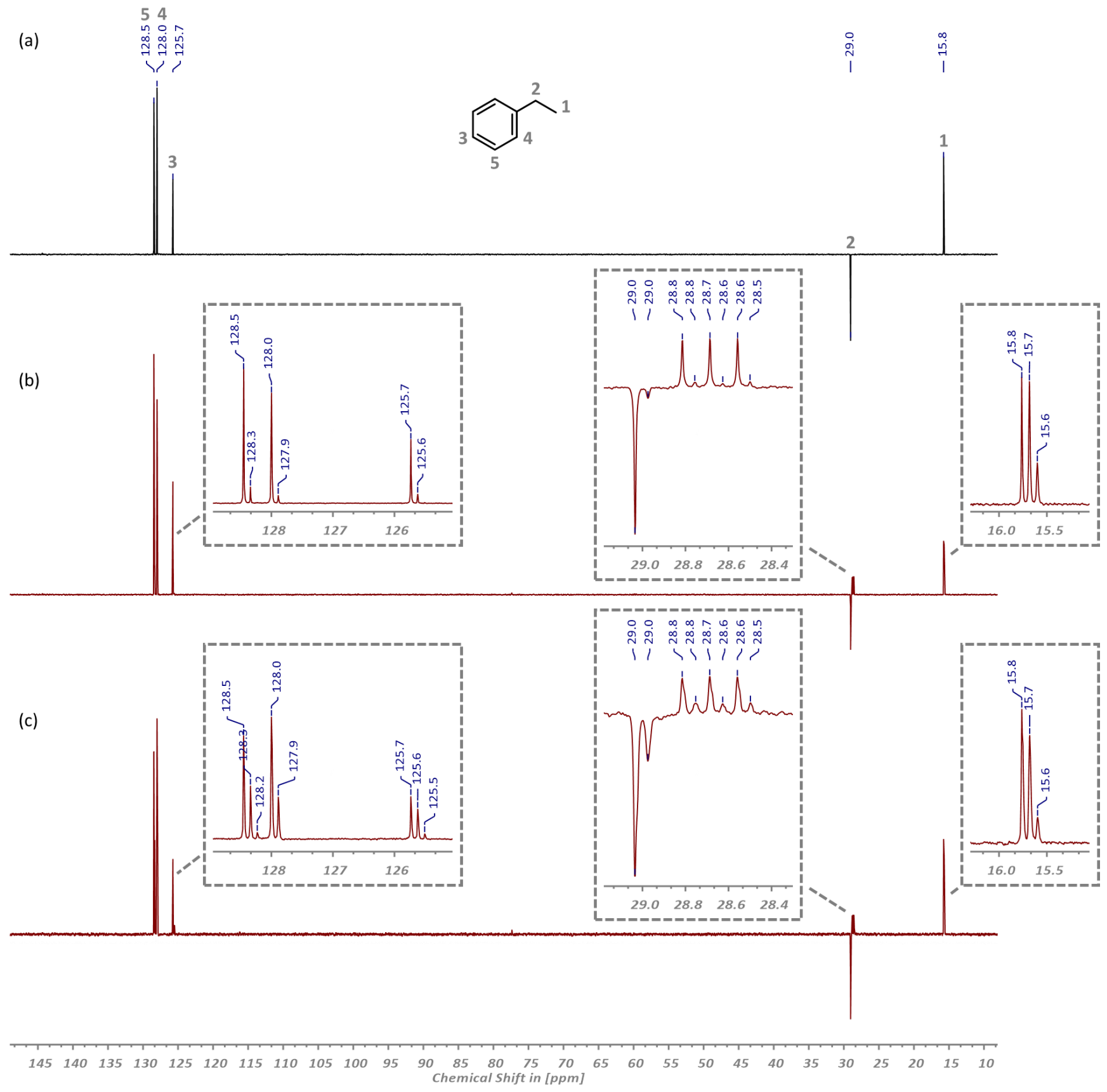

Figure S58. Stacked ${ }^{13} \mathrm{C}$ DEPT-135 NMR spectra $\left(151 \mathrm{MHz}, \mathrm{CDCl}_{3}, 25^{\circ} \mathrm{C}\right)$ of $(a)$ the commercial ethylbenzene starting material and the distilled deuterium-labeled products after the catalytic deuteration with $\mathrm{D}_{2}$ (10 bar) and $\mathrm{Ba}\left[\mathrm{N}\left(\mathrm{Si}^{i} \mathrm{Pr}_{3}\right)_{2}\right]_{2}(1 \mathrm{~mol} \%)$ as catalyst precursor at $120^{\circ} \mathrm{C}$ for $(b) 4$ and $(c) 24$ hours, respectively. 
(a)

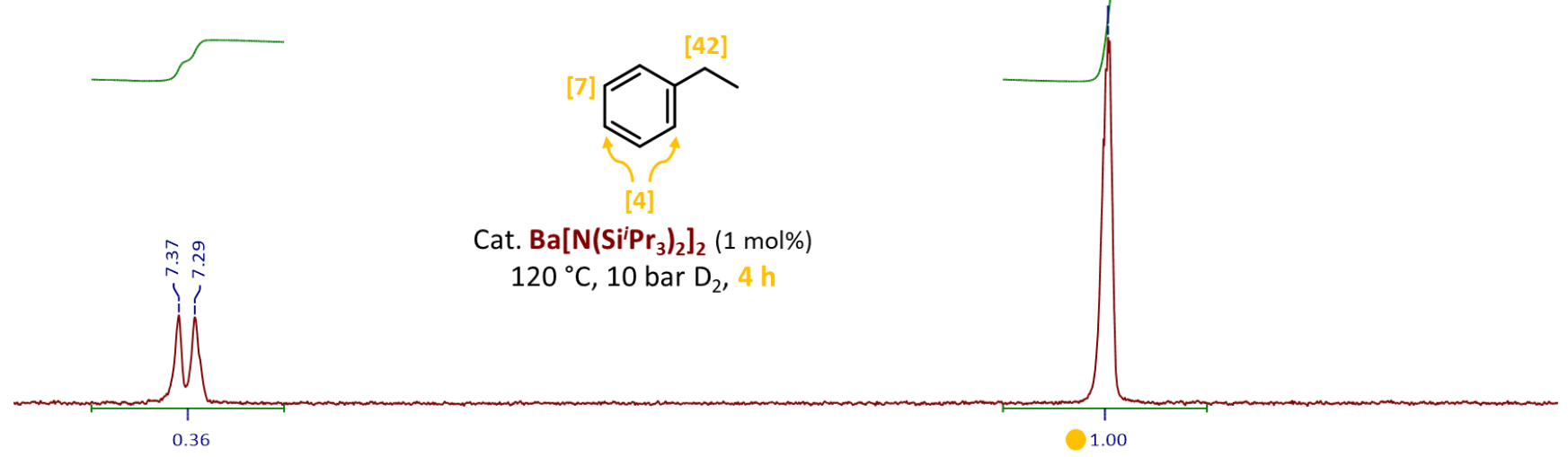

(b)

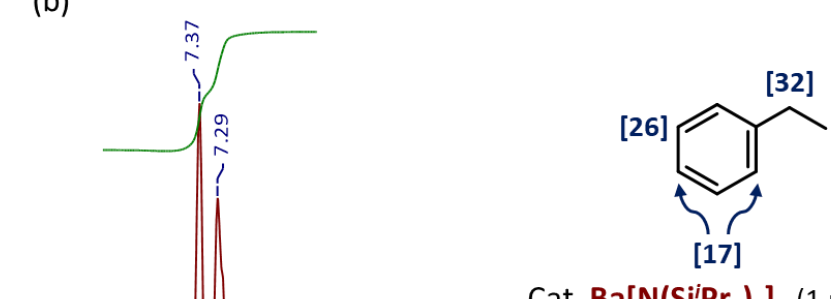

Cat. $\mathrm{Ba}\left[\mathrm{N}\left(\mathrm{Si}^{\mathrm{P} P \mathrm{Pr}_{3}}\right)_{2}\right]_{2}(1 \mathrm{~mol} \%)$

$120^{\circ} \mathrm{C}, 10$ bar $\mathrm{D}_{2}, 24 \mathrm{~h}$

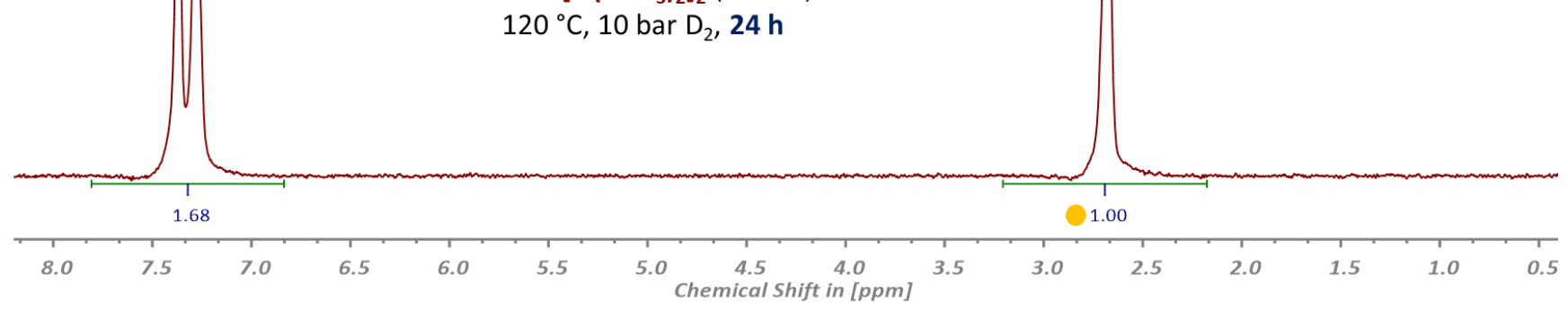

Figure S59. Stacked ${ }^{2} \mathrm{H}\left\{{ }^{1} \mathrm{H}\right\}$ NMR spectra $\left(92 \mathrm{MHz} \mathrm{CHCl}_{3}, 25^{\circ} \mathrm{C}\right.$ ) of the purified deuterium-labeled products after the catalytic deuteration of ethylbenzene with $\mathrm{D}_{2}(10 \mathrm{bar})$ and $\mathrm{Ba}\left[\mathrm{N}\left(\mathrm{Si}^{i} \mathrm{Pr}_{3}\right)_{2}\right]_{2}(1 \mathrm{~mol} \%)$ as catalyst precursor at $120{ }^{\circ} \mathrm{C}$ for $(a) 4$ and $(b) 24$ hours, respectively. 

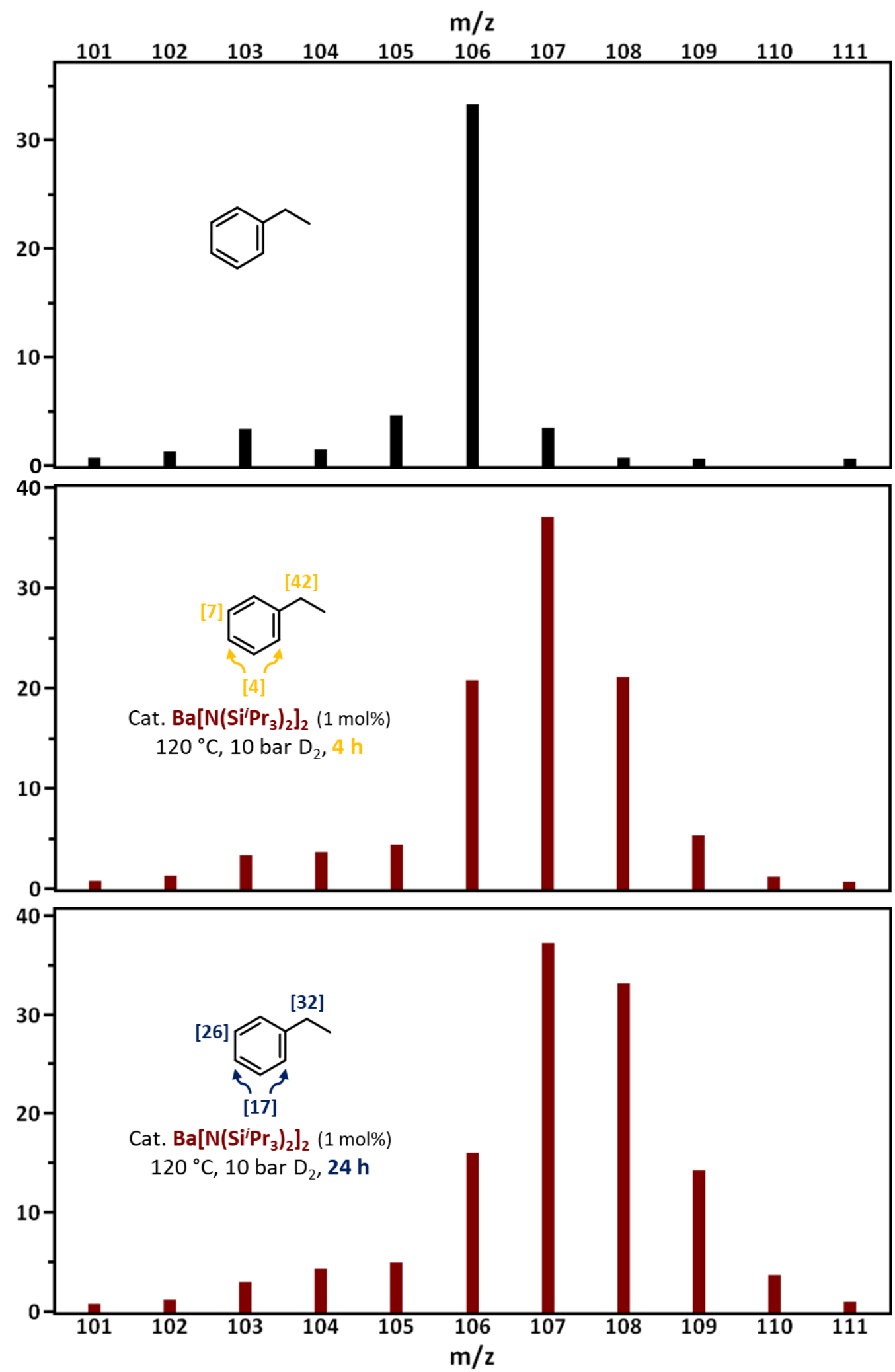

Figure S60. Stacked mass spectra of (top) the non-labeled ethylbenzene substrate and the catalytically deuterated products obtained after the deuteration with $\mathrm{D}_{2}(10 \mathrm{bar})$ and $\mathrm{Ba}\left[\mathrm{N}\left(\mathrm{Si}^{i} \mathrm{Pr}_{3}\right)_{2}\right]_{2}(1 \mathrm{~mol} \%)$ as catalyst precursor at $120^{\circ} \mathrm{C}$ for (center) 4 and (bottom) 24 hours, respectively. 
(a)

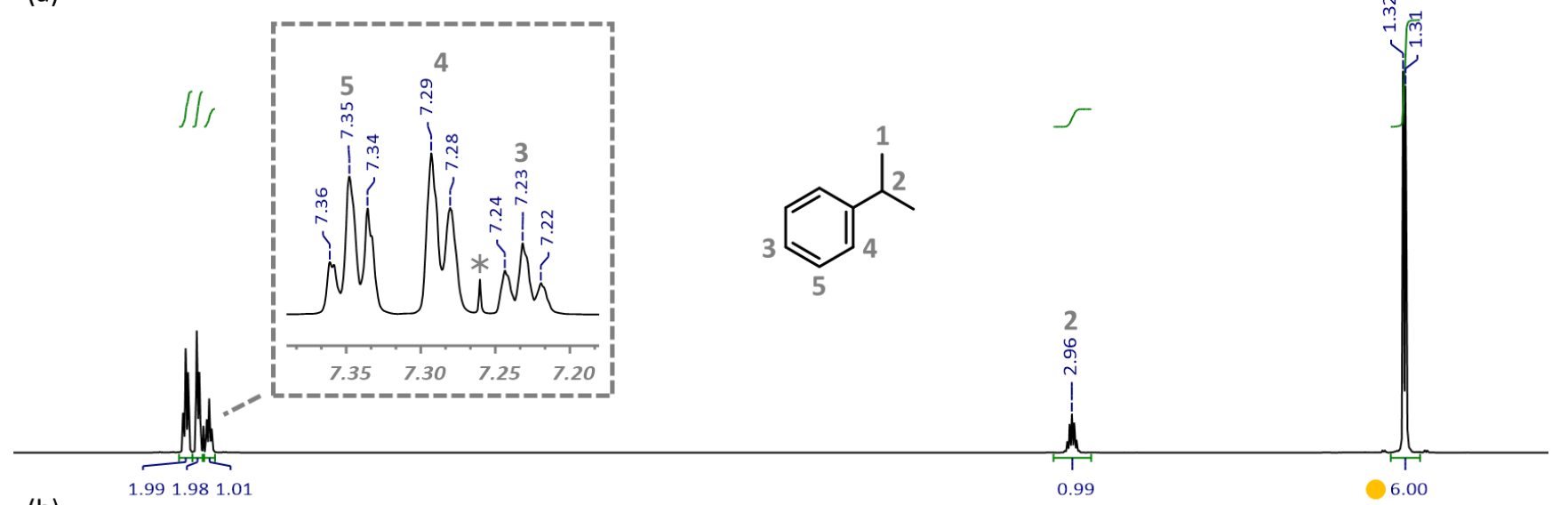

(b)

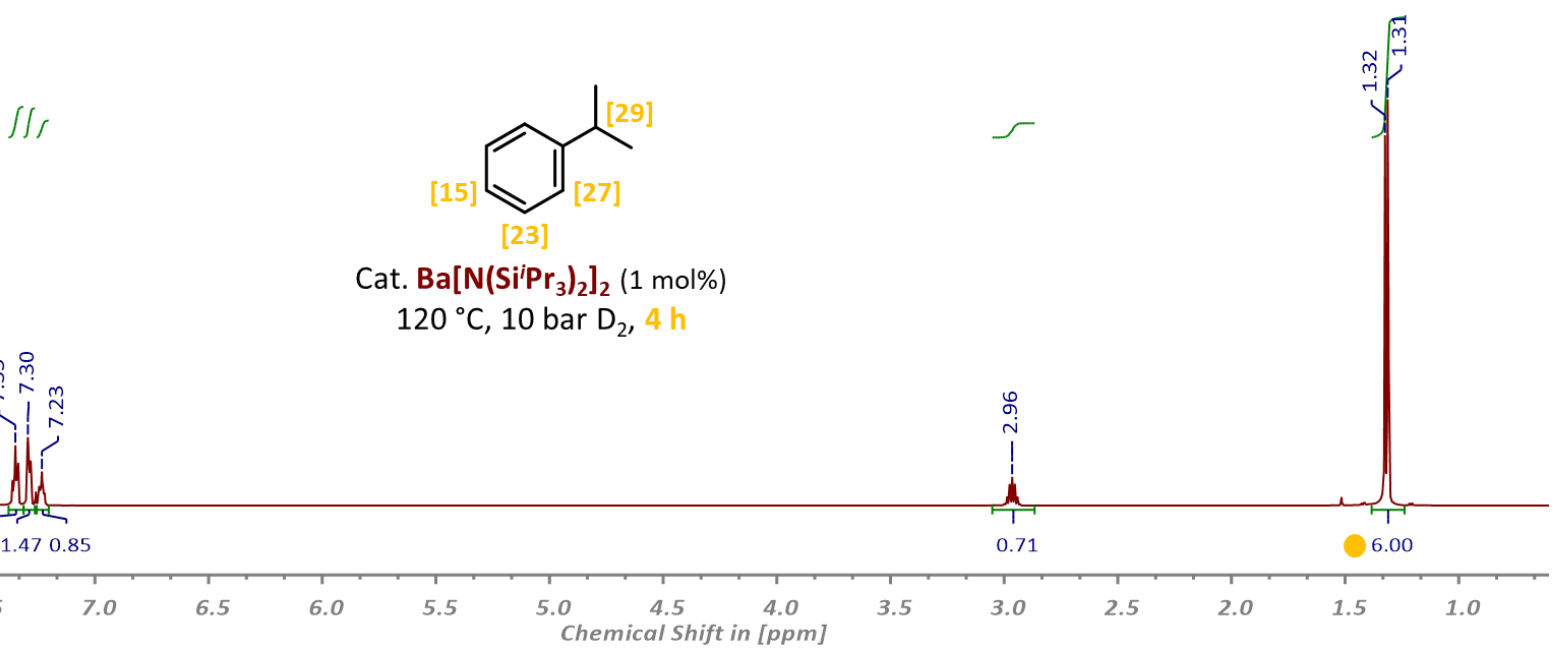

Figure S61. Stacked ${ }^{1} \mathrm{H}$ NMR spectra $\left(600 \mathrm{MHz}, \mathrm{CDCl}_{3}, 25^{\circ} \mathrm{C}\right)$ of $(a)$ the natural abundance isopropylbenzene substrate and $(b)$ the deuterium-labeled product obtained after the catalytic deuteration with $\mathrm{D}_{2}(10$ bar) and $\mathrm{Ba}\left[\mathrm{N}\left(\mathrm{Si}^{i} \mathrm{Pr}_{3}\right)_{2}\right]_{2}(1 \mathrm{~mol} \%)$ as catalyst precursor at $120^{\circ} \mathrm{C}$ for 4 hours. 
(a)

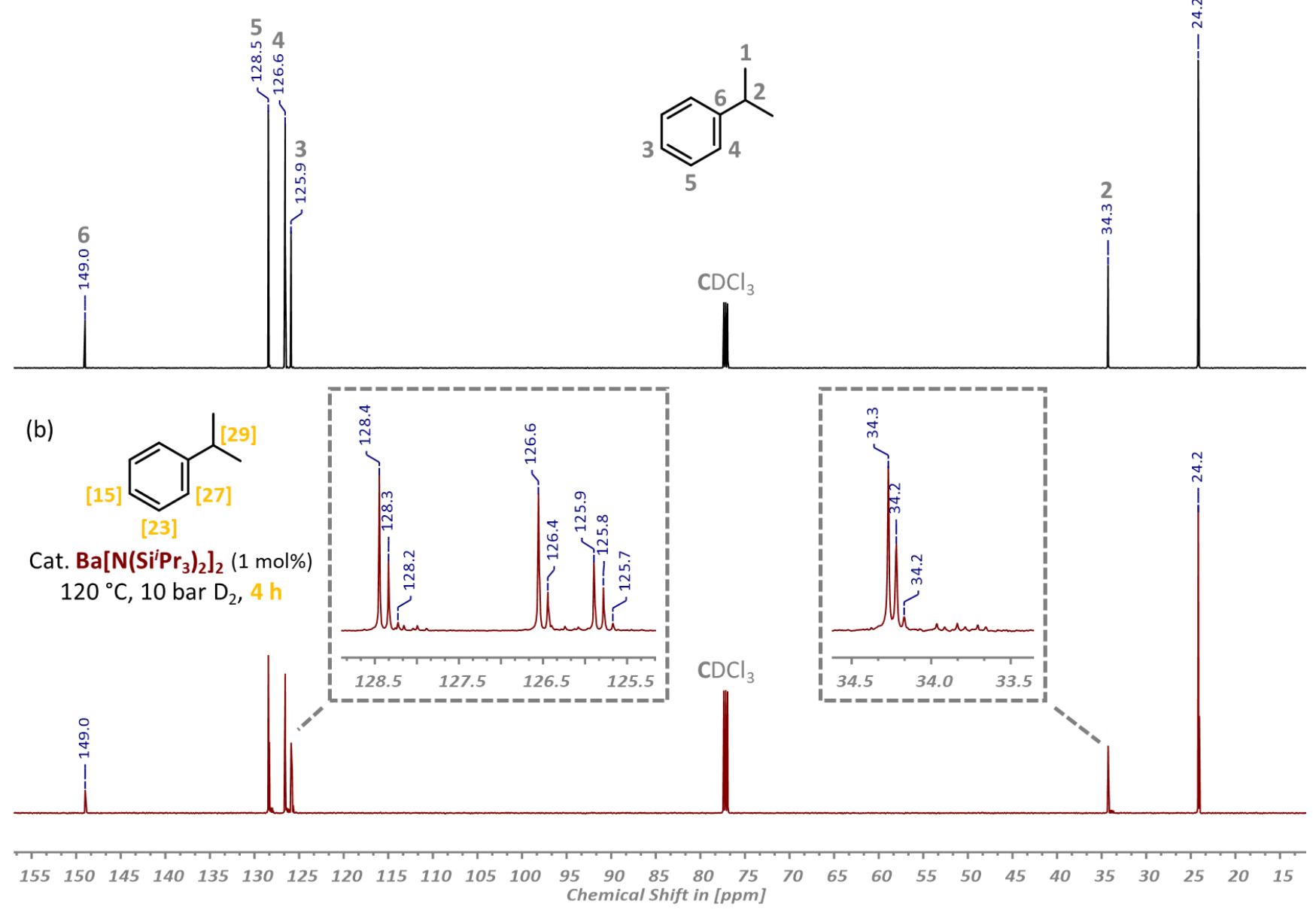

Figure S62. Stacked ${ }^{13} \mathrm{C}\left\{{ }^{1} \mathrm{H}\right\} \mathrm{NMR}$ spectra $\left(151 \mathrm{MHz}, \mathrm{CDCl}_{3}, 25^{\circ} \mathrm{C}\right)$ of $(a)$ the non-labeled cumene substrate and (b) the partially deuterated product isolated after the catalytic deuteration with $\mathrm{D}_{2}\left(10\right.$ bar) and $\mathrm{Ba}\left[\mathrm{N}\left(\mathrm{Si}^{i} \mathrm{Pr}_{3}\right)_{2}\right]_{2}$ (1 mol\%) as catalyst precursor at $120^{\circ} \mathrm{C}$ for 4 hours. 


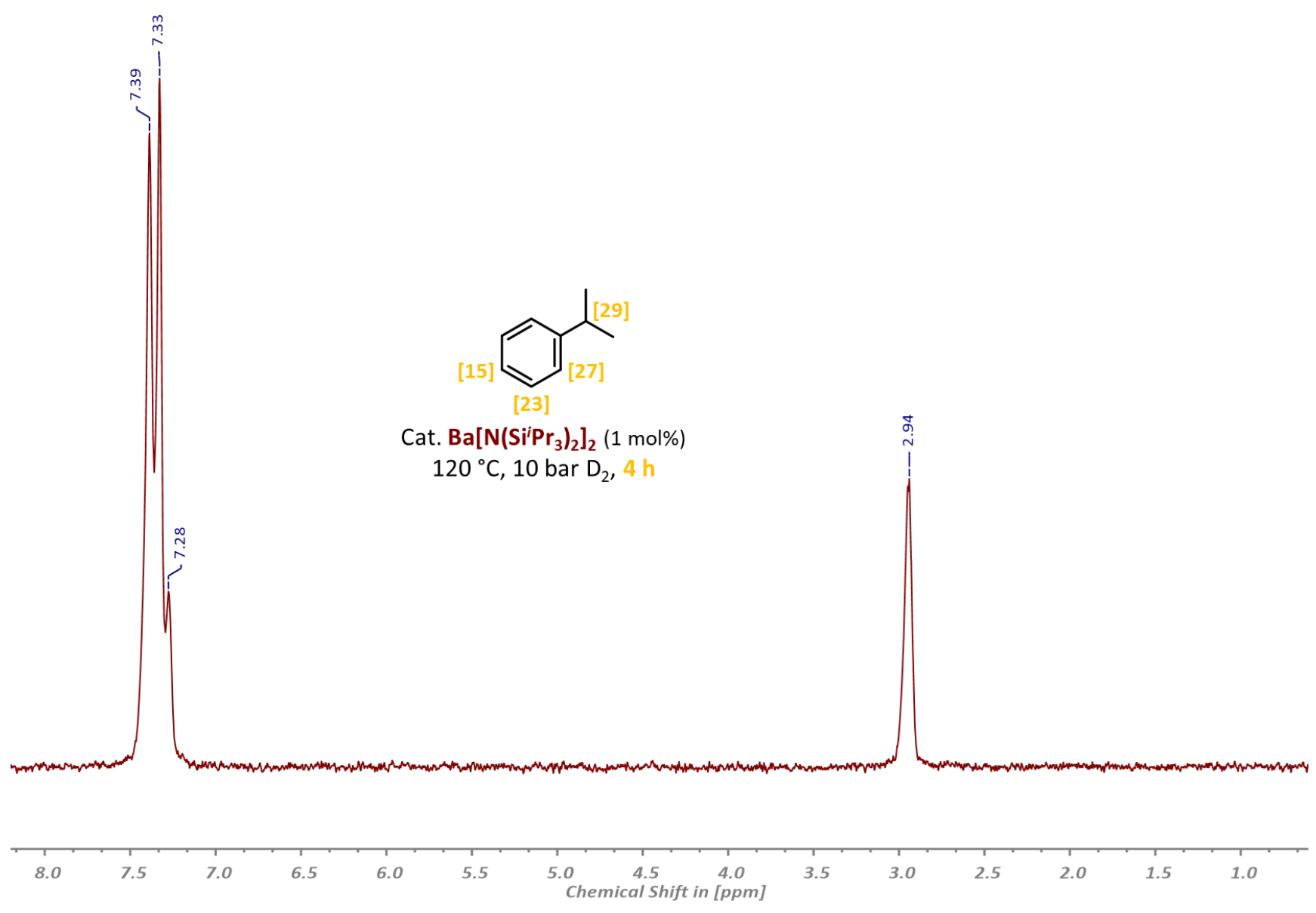

Figure S63. ${ }^{2} \mathrm{H}\left\{{ }^{1} \mathrm{H}\right\} \mathrm{NMR}$ spectrum $\left(92 \mathrm{MHz}, \mathrm{CHCl}_{3}, 25^{\circ} \mathrm{C}\right.$ ) of the deuterium-enriched product isolated after the catalytic deuteration of isopropylbenzene with $\mathrm{D}_{2}(10 \mathrm{bar})$ and $\mathrm{Ba}\left[\mathrm{N}\left(\mathrm{Si}^{i} \mathrm{Pr}_{3}\right)_{2}\right]_{2}(1 \mathrm{~mol} \%)$ as catalyst precursor at $120^{\circ} \mathrm{C}$ for 4 hours. 


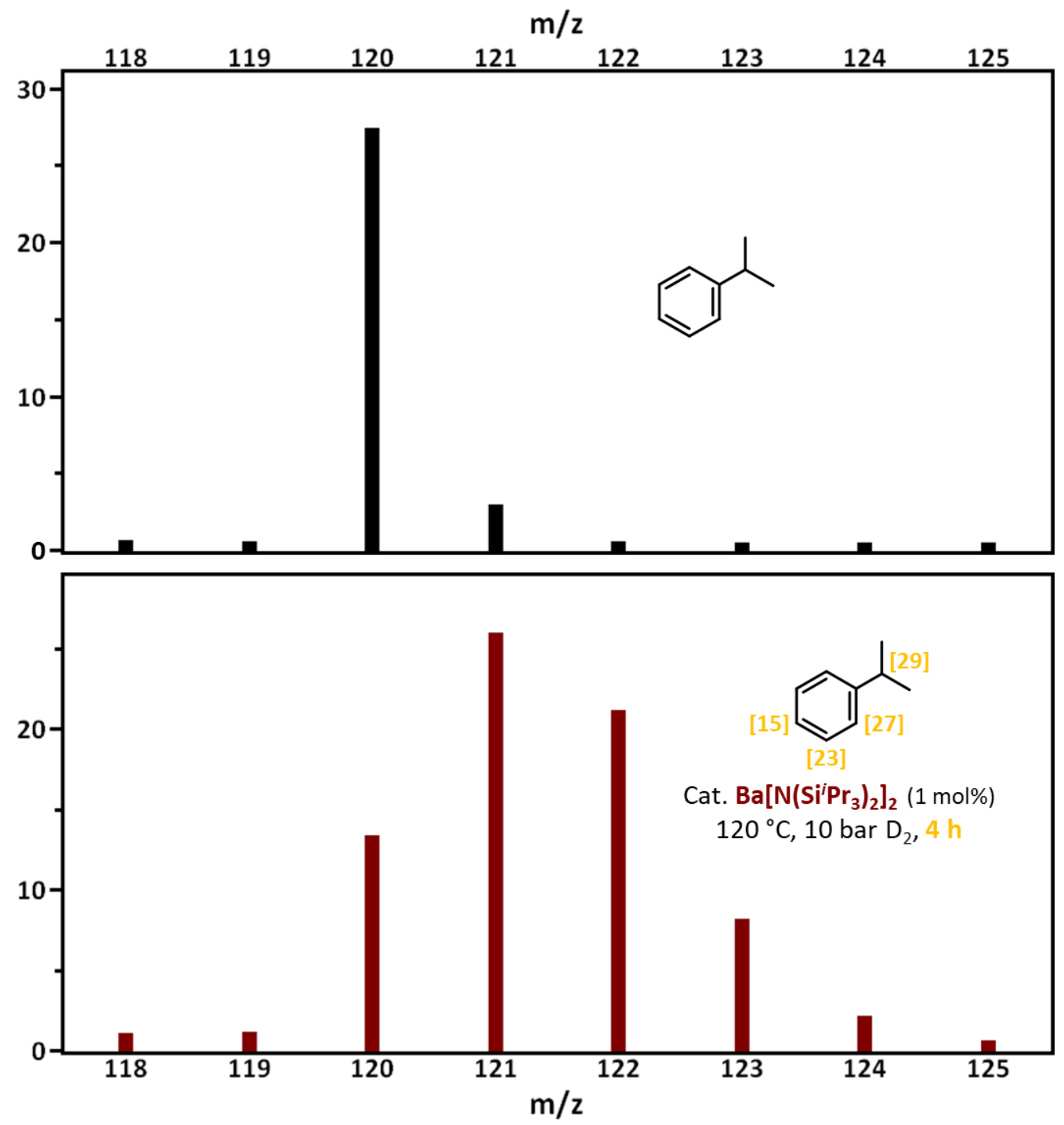

Figure S64. Stacked mass spectra of (top) the reference isopropylbenzene starting material and (bottom) the deuterated product obtained after the catalytic deuteration with $\mathrm{D}_{2}(10 \mathrm{bar})$ and $\mathrm{Ba}\left[\mathrm{N}\left(\mathrm{Si}^{i} \mathrm{Pr}_{3}\right)_{2}\right]_{2}(1 \mathrm{~mol} \%)$ as pre-catalyst at $120^{\circ} \mathrm{C}$ for 4 hours. 


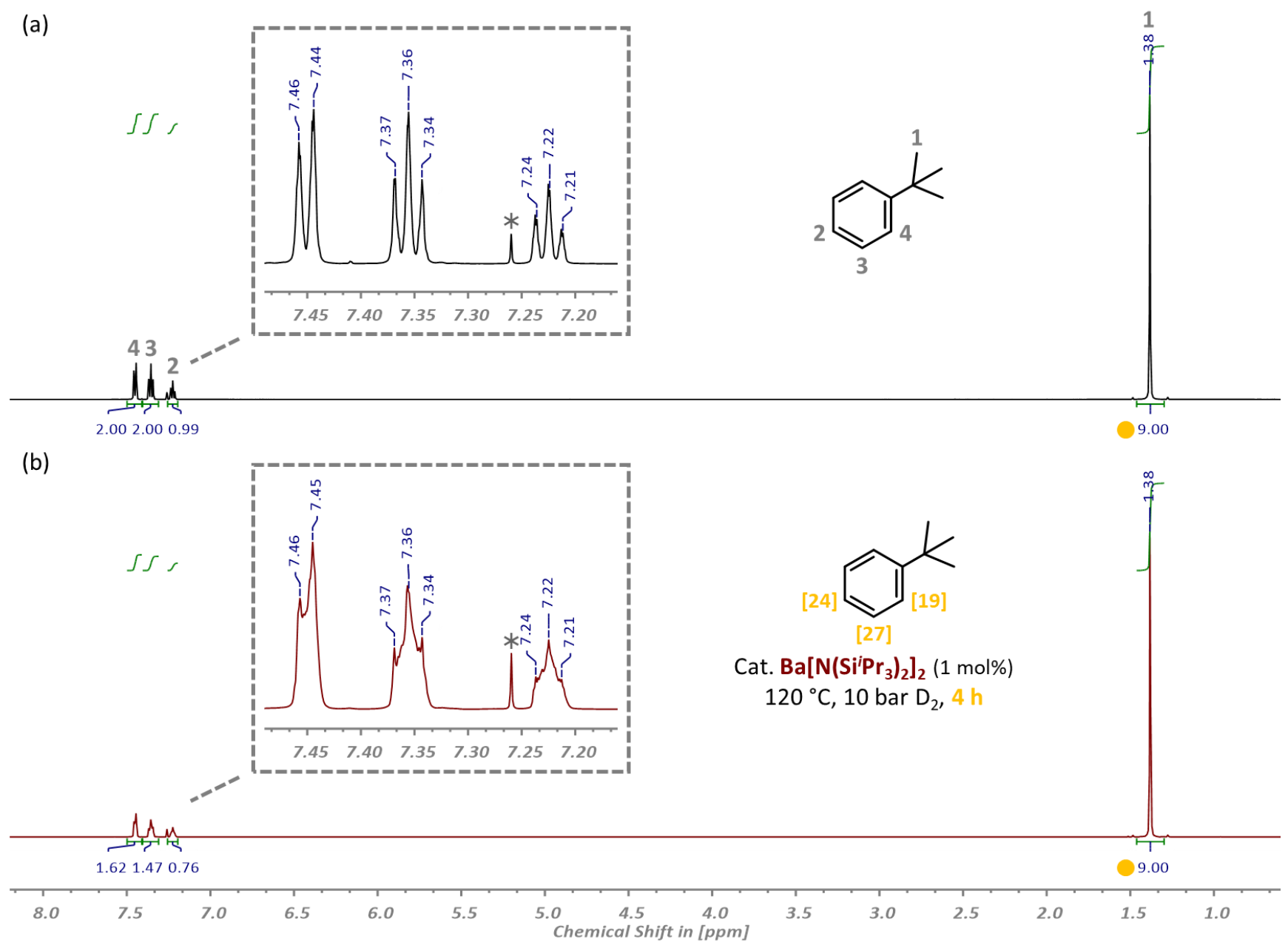

Figure S65. Stacked ${ }^{1} \mathrm{H}$ NMR spectra $\left(600 \mathrm{MHz}, \mathrm{CDCl}_{3}, 25^{\circ} \mathrm{C}\right)$ of $(a)$ an authentic sample of the tert-butylbenzene substrate and $(b)$ the resulting deuterium labeling product after the catalytic deuteration with $\mathrm{D}_{2}(10$ bar) and $\mathrm{Ba}\left[\mathrm{N}\left(\mathrm{Si}^{i} \mathrm{Pr}_{3}\right)_{2}\right]_{2}(1 \mathrm{~mol} \%)$ as pre-catalyst at $120{ }^{\circ} \mathrm{C}$ for 4 hours. 


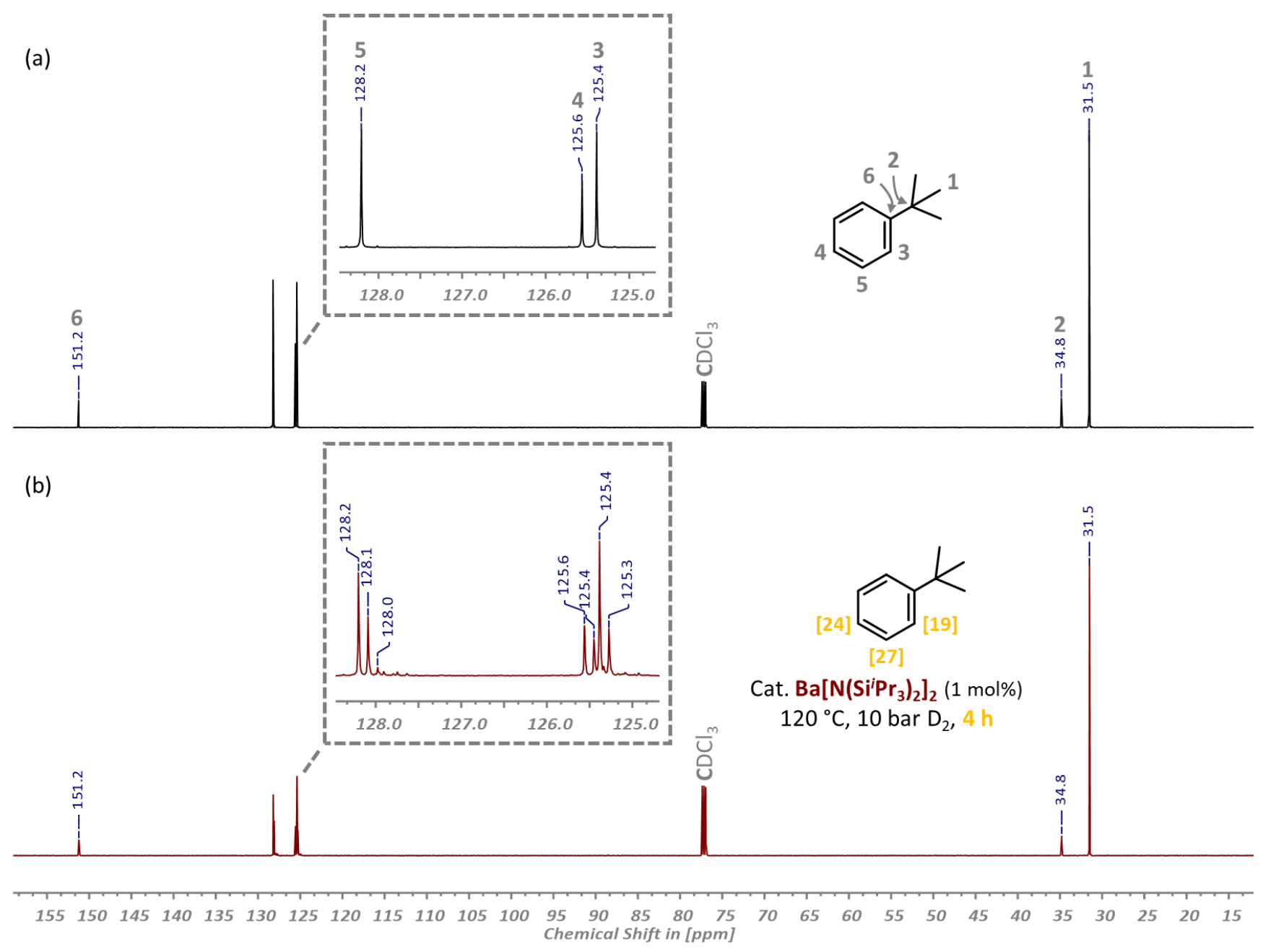

Figure S66. Stacked ${ }^{13} \mathrm{C}\left\{{ }^{1} \mathrm{H}\right\} \mathrm{NMR}$ spectra $\left(151 \mathrm{MHz}, \mathrm{CDCl}_{3}, 25^{\circ} \mathrm{C}\right)$ of $(a)$ the all-protio tert-butylbenzene substrate and $(b)$ the partially deuterated product obtained after the catalytic $H / D$ exchange with $D_{2}(10$ bar $)$ and $\mathrm{Ba}\left[\mathrm{N}\left(\mathrm{Si}^{i} \mathrm{Pr}_{3}\right)_{2}\right]_{2}(1 \mathrm{~mol} \%)$ as catalyst precursor at $120^{\circ} \mathrm{C}$ for 4 hours. 

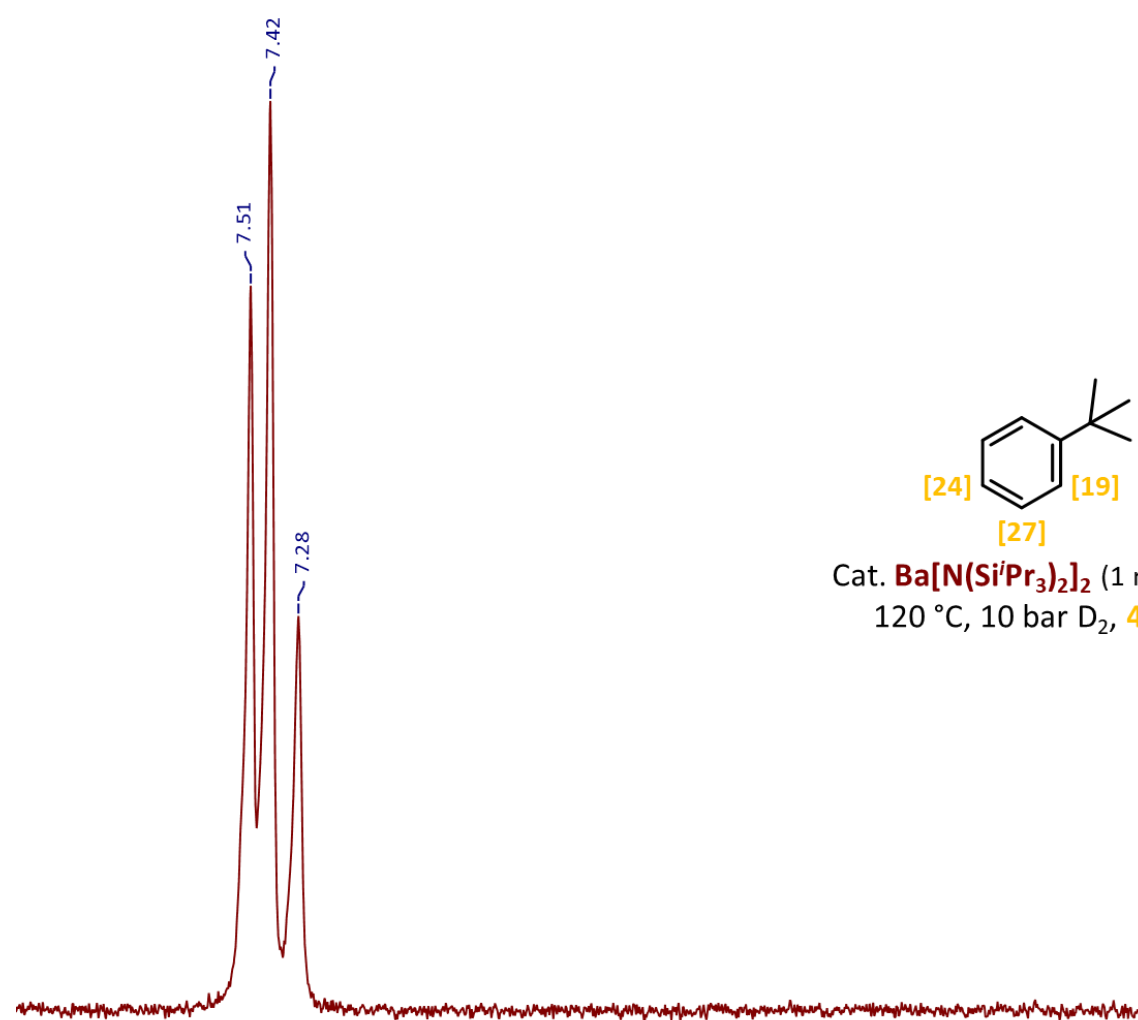

Cat. $\mathrm{Ba}\left[\mathrm{N}\left(\mathrm{Si}^{\mathrm{i}} \mathrm{Pr}_{3}\right)_{2}\right]_{2}(1 \mathrm{~mol} \%)$ $120^{\circ} \mathrm{C}, 10$ bar $\mathrm{D}_{2}, 4 \mathrm{~h}$

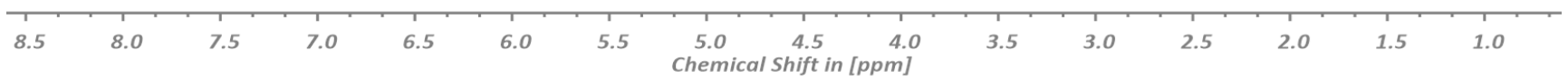

Figure S67. ${ }^{2} \mathrm{H}\left\{{ }^{1} \mathrm{H}\right\} \mathrm{NMR}$ spectrum $\left(92 \mathrm{MHz}, \mathrm{CHCl}_{3}, 25^{\circ} \mathrm{C}\right)$ of the catalytically deuterium-labeled product isolated after the deuteration of tert-butylbenzene with $\mathrm{D}_{2}(10 \mathrm{bar})$ and $\mathrm{Ba}\left[\mathrm{N}\left(\mathrm{Si}^{i} \mathrm{Pr}_{3}\right)_{2}\right]_{2}(1 \mathrm{~mol} \%)$ as catalyst precursor at $120^{\circ} \mathrm{C}$ for 4 hours. 


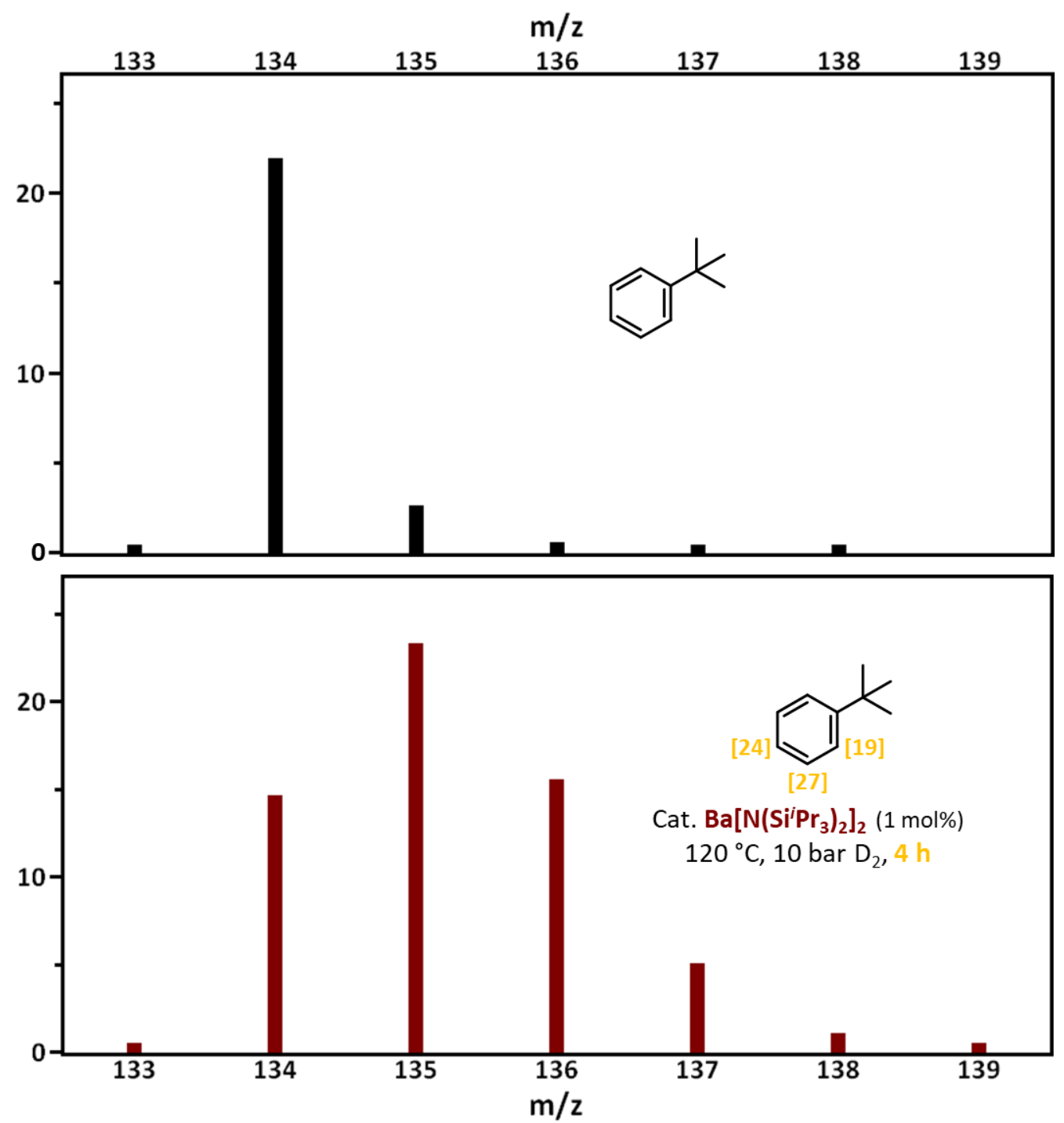

Figure S68. Stacked mass spectra of (top) the unlabeled tert-butylbenzene substrate and (bottom) the deuterated product isolated after the catalytic deuteration with $\mathrm{D}_{2}(10 \mathrm{bar})$ and $\mathrm{Ba}\left[\mathrm{N}\left(\mathrm{Si}^{i} \mathrm{Pr}_{3}\right)_{2}\right]_{2}(1 \mathrm{~mol} \%)$ as catalyst precursor at $120^{\circ} \mathrm{C}$ for 4 hours. 
(a)

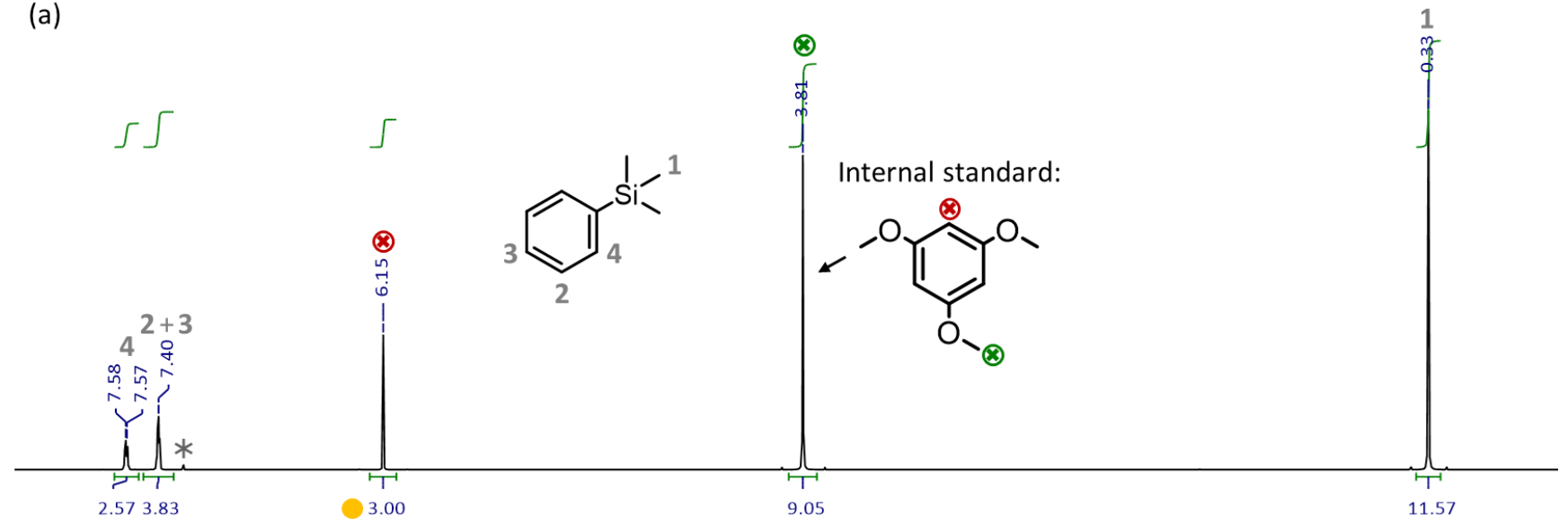

(b)
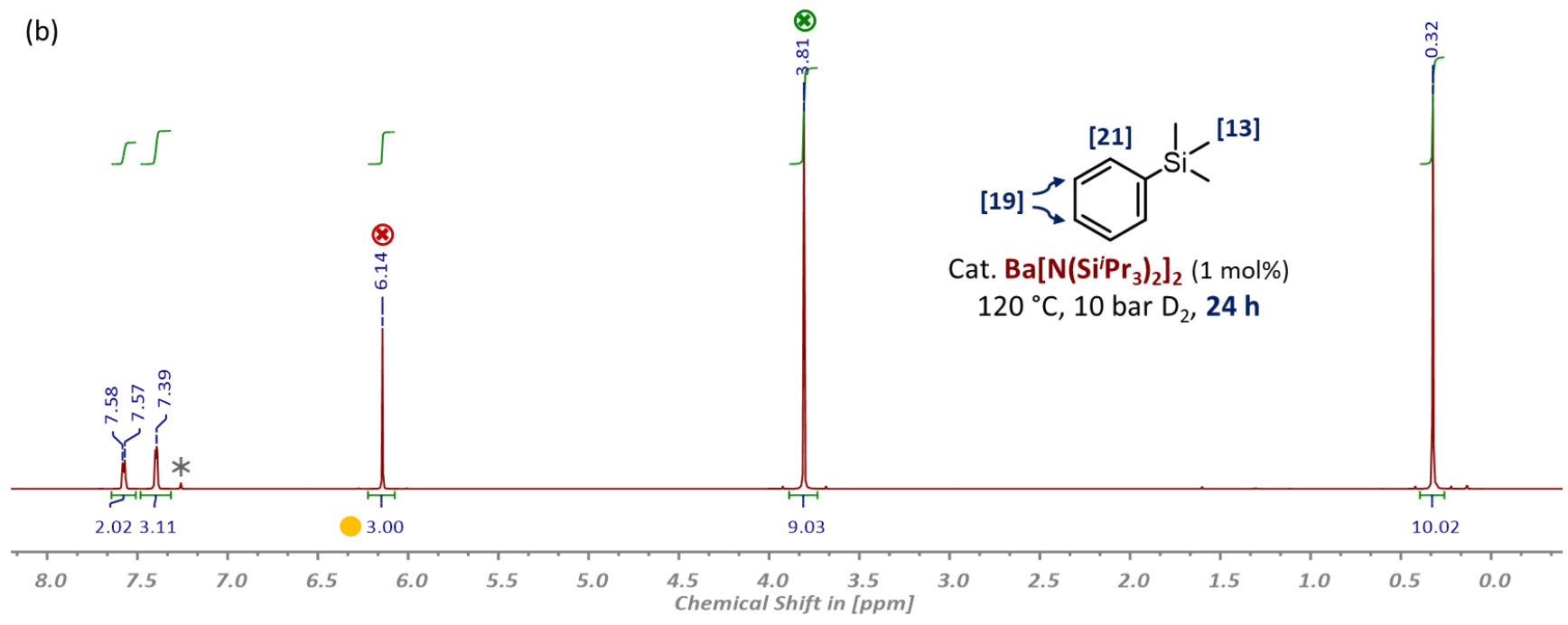

Figure S69. Stacked ${ }^{1} \mathrm{H}$ NMR spectra $\left(600 \mathrm{MHz}, \mathrm{CDCl}_{3}, 25^{\circ} \mathrm{C}\right)$ of $(a)$ the reference trimethylsilylbenzene starting material and $(b)$ the distilled deuterium-labeled product after the catalytic deuteration with $\mathrm{D}_{2}(10$ bar) and $\mathrm{Ba}\left[\mathrm{N}\left(\mathrm{Si}^{\mathrm{i}} \mathrm{Pr}_{3}\right)_{2}\right]_{2}(1 \mathrm{~mol} \%)$ as pre-catalyst at $120{ }^{\circ} \mathrm{C}$ for 24 hours. Note: $1,3,5$-Trimethoxybenzene was added as internal standard. 
(a)

$$
\text { Internal standard: }
$$
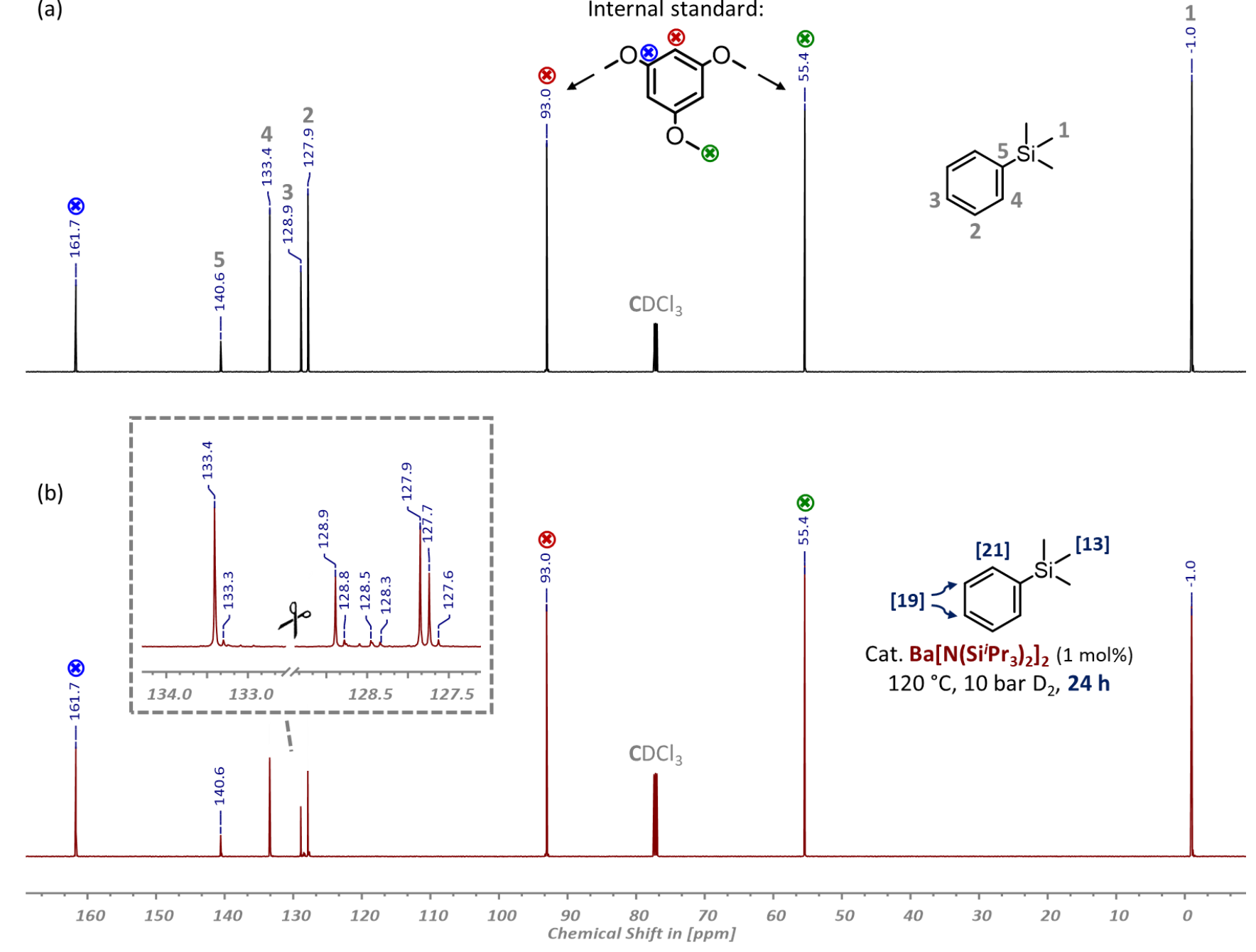

Figure S70. Stacked ${ }^{13} \mathrm{C}\left\{{ }^{1} \mathrm{H}\right\}$ NMR spectra $\left(151 \mathrm{MHz}, \mathrm{CDCl}_{3}, 25^{\circ} \mathrm{C}\right)$ of $(a)$ the natural abundance trimethyl(phenyl)silane substrate and $(b)$ the partially deuterium-labeled product obtained after the catalytic deuteration with $\mathrm{D}_{2}(10 \mathrm{bar})$ and $\mathrm{Ba}\left[\mathrm{N}\left(\mathrm{Si}^{i} \mathrm{Pr}_{3}\right)_{2}\right]_{2}(1 \mathrm{~mol} \%)$ as catalyst precursor at $120{ }^{\circ} \mathrm{C}$ for 24 hours. Note: 1,3,5-Trimethoxybenzene was added as internal standard. 


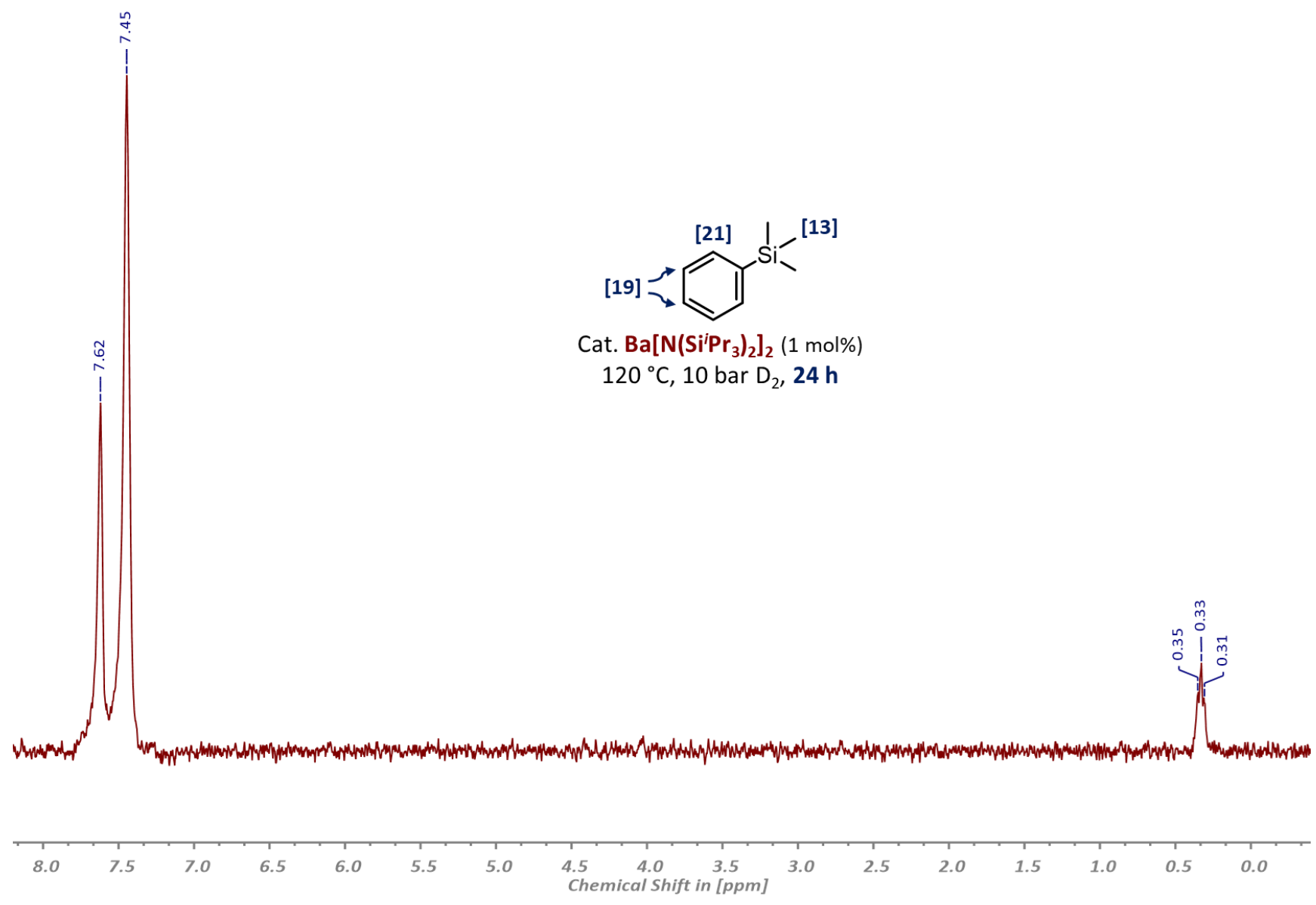

Figure S71. ${ }^{2} \mathrm{H}\left\{{ }^{1} \mathrm{H}\right\} \mathrm{NMR}$ spectrum $\left(92 \mathrm{MHz}, \mathrm{CHCl}_{3}, 25^{\circ} \mathrm{C}\right)$ of the partially deuterated trimethylsilylbenzene product isolated after the catalytic deuteration with $\mathrm{D}_{2}(10 \mathrm{bar})$ and $\mathrm{Ba}\left[\mathrm{N}\left(\mathrm{Si}^{i} \mathrm{Pr}_{3}\right)_{2}\right]_{2}(1 \mathrm{~mol} \%)$ as catalyst precursor at $120^{\circ} \mathrm{C}$ for 24 hours. 


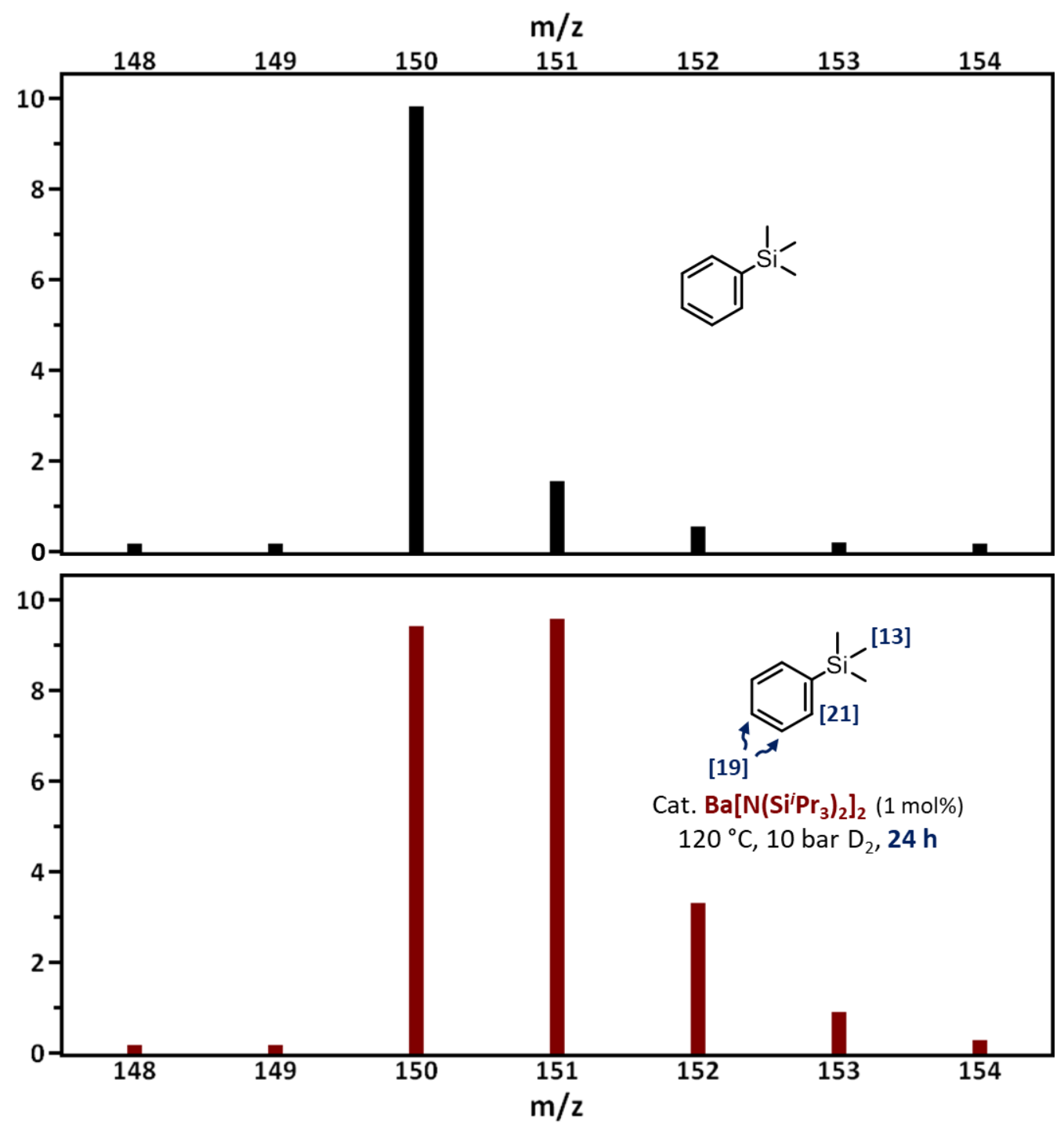

Figure S72. Stacked mass spectra of (top) the all-protio trimethylsilylbenzene substrate and (bottom) the deuterium-labeled product obtained after the catalytic deuteration with $\mathrm{D}_{2}$ (10 bar) and $\mathrm{Ba}\left[\mathrm{N}\left(\mathrm{Si}^{\mathrm{i}} \mathrm{Pr}_{3}\right)_{2}\right]_{2}(1 \mathrm{~mol} \%)$ as catalyst precursor at $120^{\circ} \mathrm{C}$ for 24 hours. 
(a)

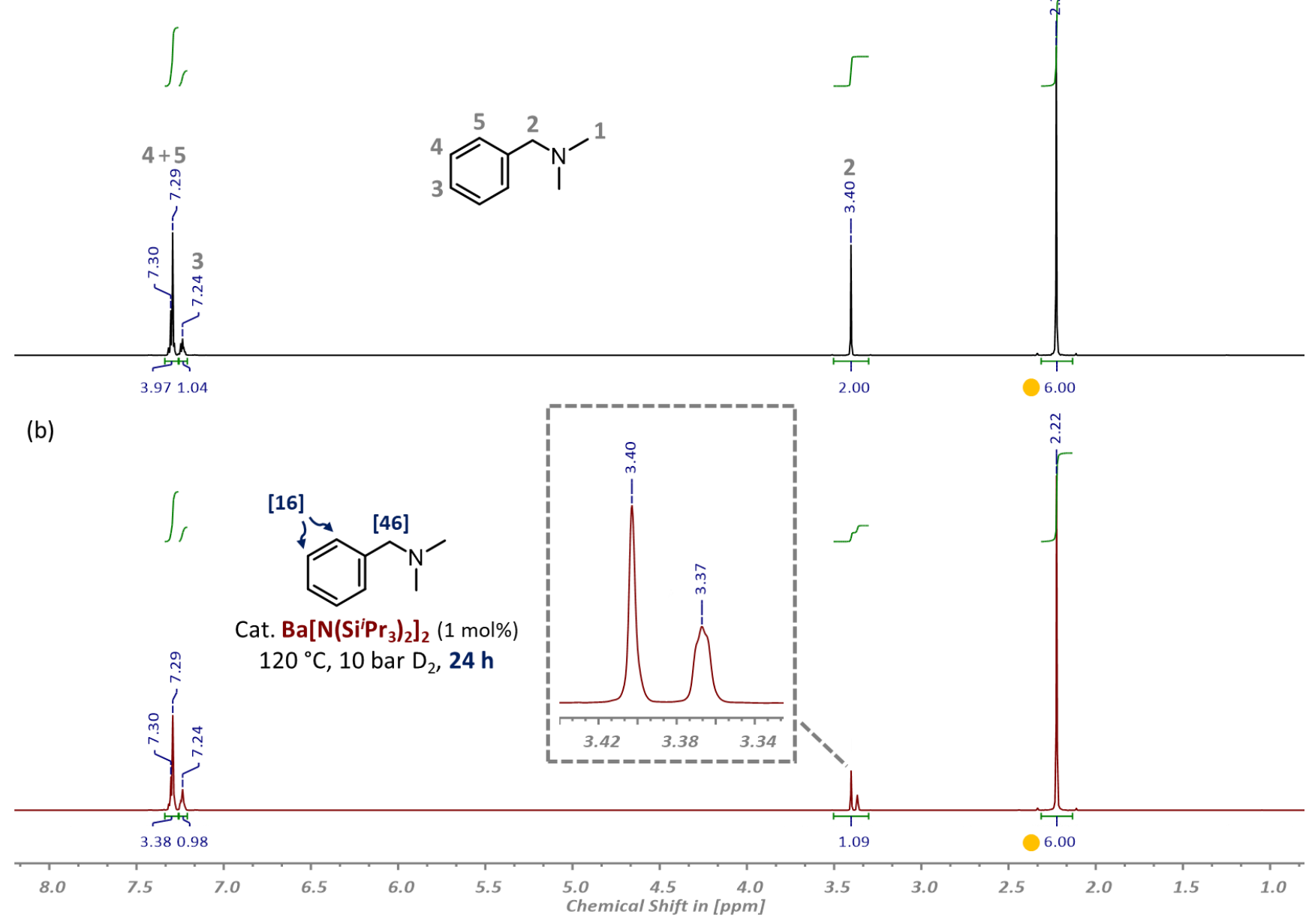

Figure S73. Stacked ${ }^{1} \mathrm{H}$ NMR spectra $\left(600 \mathrm{MHz}, \mathrm{CDCl}_{3}, 25^{\circ} \mathrm{C}\right)$ of $(a)$ a sample of non-deuterated $\mathrm{N}, \mathrm{N}$-dimethylbenzylamine and $(b)$ the deuterium-labeled product obtained after the catalytic deuteration with $\mathrm{D}_{2}$ (10 bar) and $\mathrm{Ba}\left[\mathrm{N}\left(\mathrm{Si}^{\mathrm{i}} \mathrm{Pr}_{3}\right)_{2}\right]_{2}(1 \mathrm{~mol} \%)$ as pre-catalyst at $120{ }^{\circ} \mathrm{C}$ for 24 hours. 
(a)

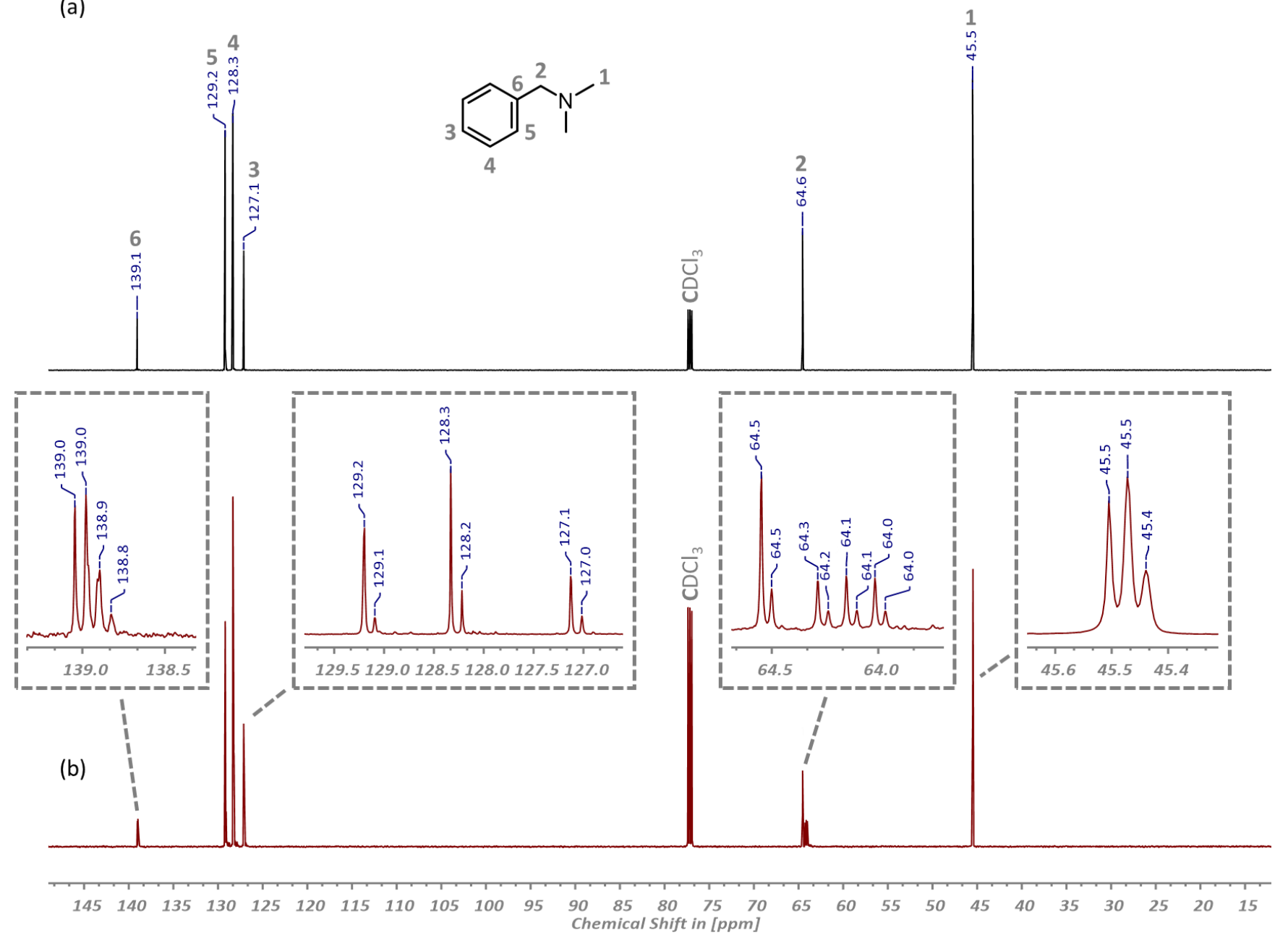

Figure S74. Stacked ${ }^{13} \mathrm{C}\left\{{ }^{1} \mathrm{H}\right\} \mathrm{NMR}$ spectra $\left(151 \mathrm{MHz}, \mathrm{CDCl}_{3}, 25^{\circ} \mathrm{C}\right)$ of $(a)$ authentic $N, N$-dimethylbenzylamine and

(b) the purified deuterium-enriched product isolated after the catalytic deuteration with $\mathrm{D}_{2}$ (10 bar) and $\mathrm{Ba}\left[\mathrm{N}\left(\mathrm{Si}^{\mathrm{i}} \mathrm{Pr}_{3}\right)_{2}\right]_{2}(1 \mathrm{~mol} \%)$ as catalyst precursor at $120{ }^{\circ} \mathrm{C}$ for 24 hours. 


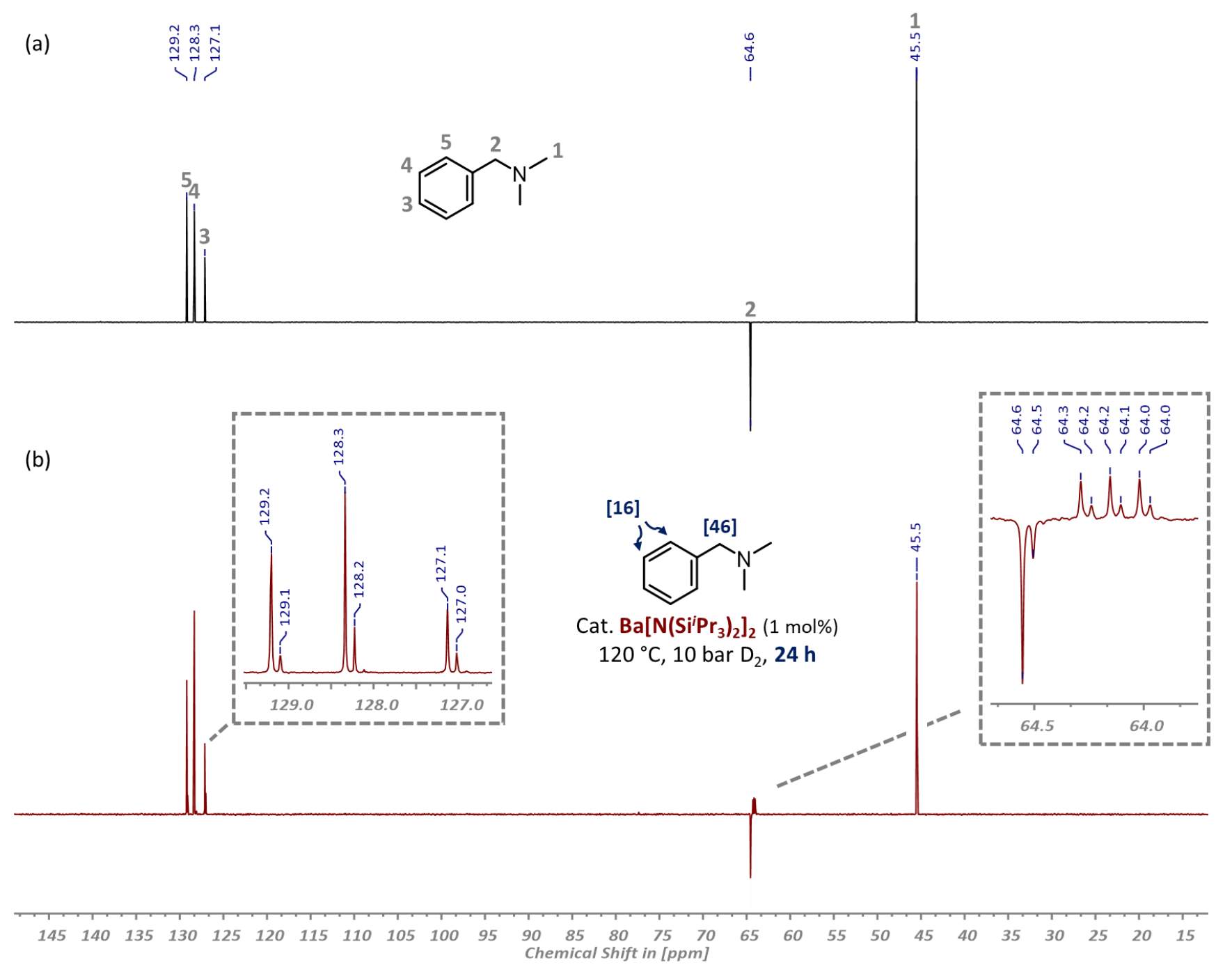

Figure S75. Stacked ${ }^{13} \mathrm{C}$ DEPT-135 NMR spectra $\left(151 \mathrm{MHz}, \mathrm{CDCl}_{3}, 25^{\circ} \mathrm{C}\right)$ of $(a)$ the non-labeled $\mathrm{N}, \mathrm{N}$-dimethylbenzylamine starting material and $(b)$ the partially deuterated product obtained after the catalytic deuteration with $\mathrm{D}_{2}(10 \mathrm{bar})$ and $\mathrm{Ba}\left[\mathrm{N}\left(\mathrm{Si}^{i} \mathrm{Pr}_{3}\right)_{2}\right]_{2}(1 \mathrm{~mol} \%)$ as catalyst precursor at $120^{\circ} \mathrm{C}$ for 24 hours. 


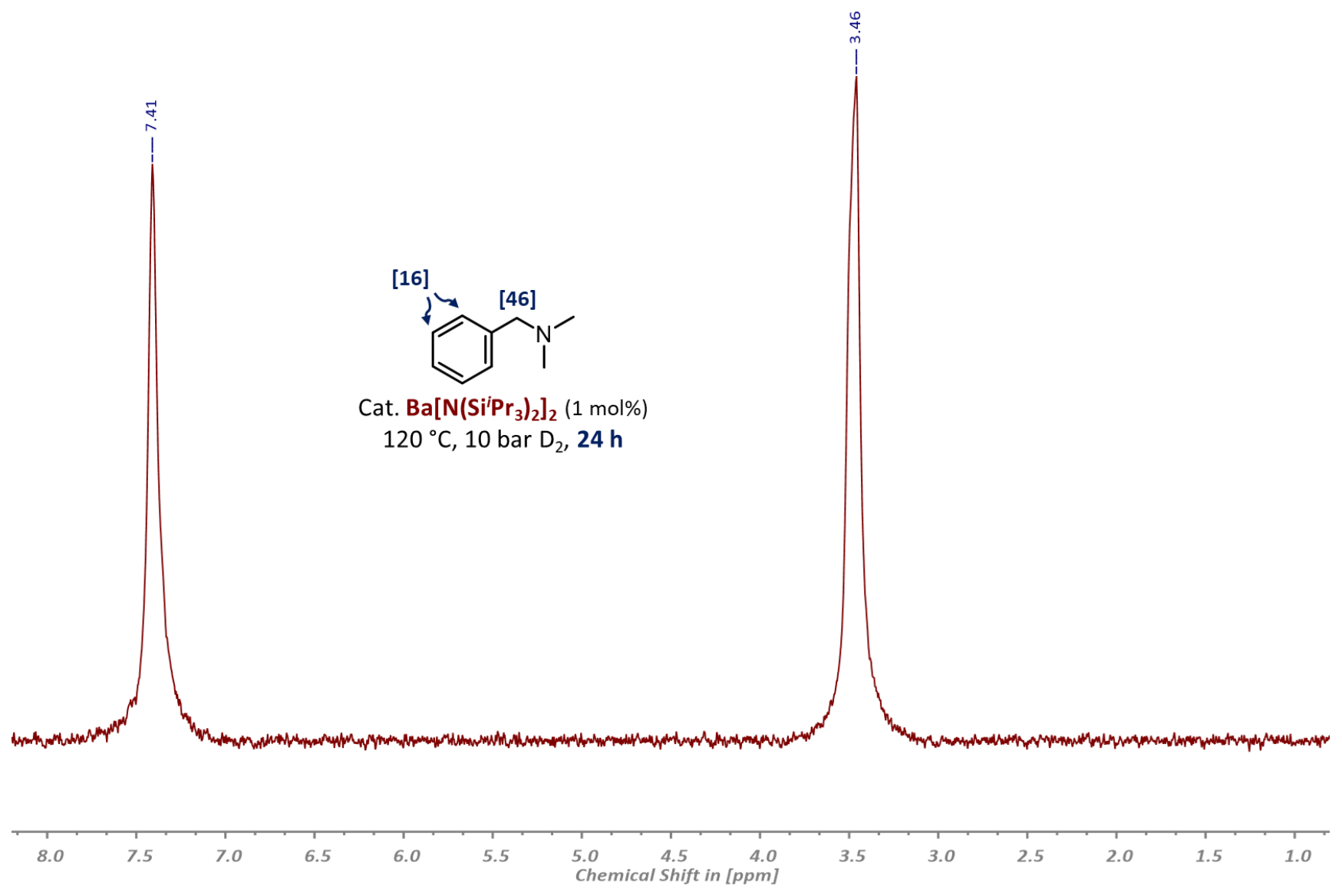

Figure S76. ${ }^{2} \mathrm{H}\left\{{ }^{1} \mathrm{H}\right\} \mathrm{NMR}$ spectrum $\left(92 \mathrm{MHz}, \mathrm{CHCl}_{3}, 25^{\circ} \mathrm{C}\right)$ of the purified deuterium-labeled $\mathrm{N}, \mathrm{N}$-dimethylbenzylamine product after the catalytic deuteration with $\mathrm{D}_{2}(10 \mathrm{bar})$ and $\mathrm{Ba}\left[\mathrm{N}\left(\mathrm{Si}^{i} \mathrm{Pr}_{3}\right)_{2}\right]_{2}(1 \mathrm{~mol} \%)$ as catalyst precursor at $120^{\circ} \mathrm{C}$ for 24 hours. 


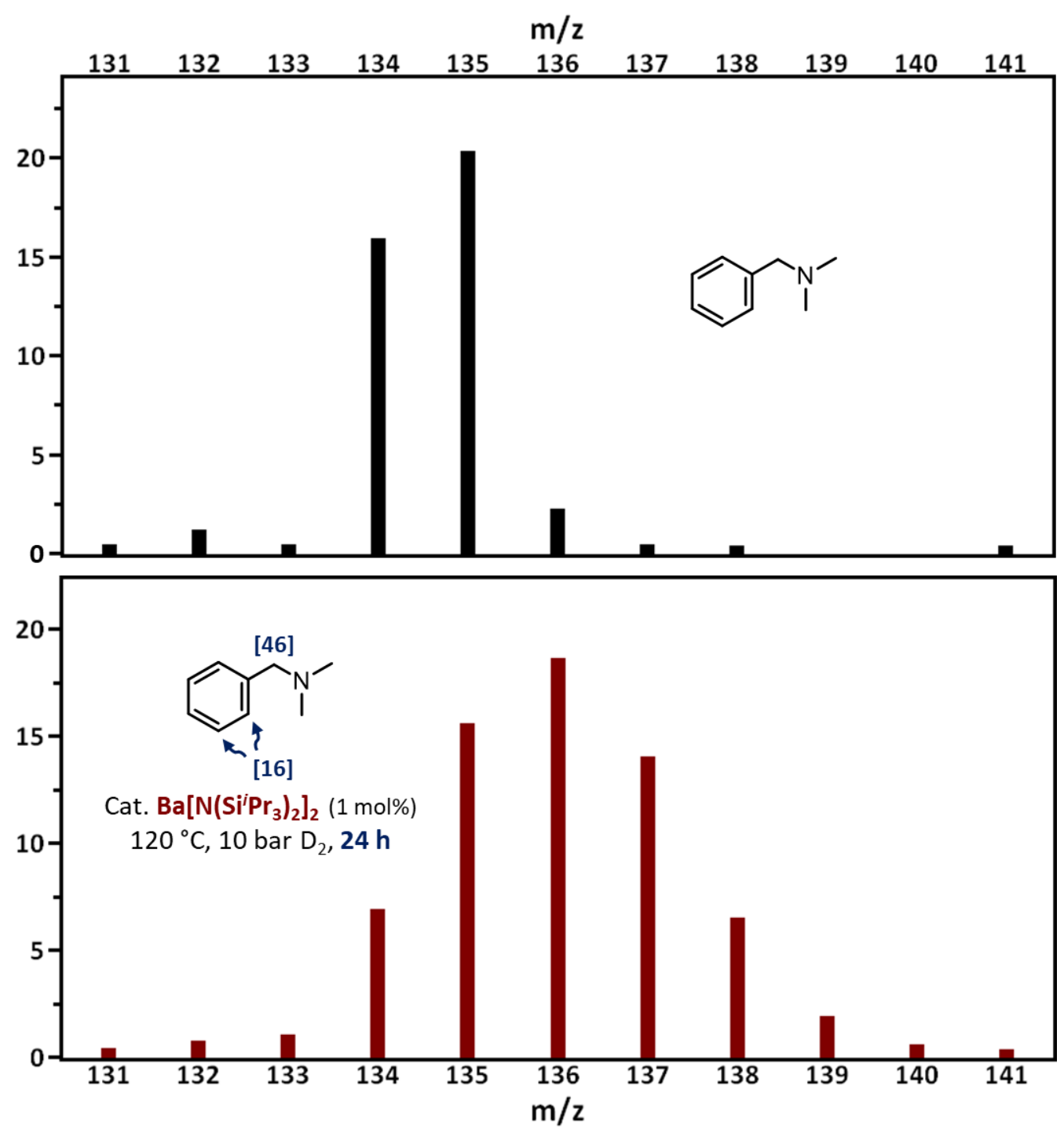

Figure S77. Stacked mass spectra of (top) the authentic $N, N$-dimethylbenzylamine substrate and (bottom) the catalytically deuterated product obtained after the deuteration with $\mathrm{D}_{2}(10 \mathrm{bar})$ and $\mathrm{Ba}\left[\mathrm{N}\left(\mathrm{Si}^{i} \mathrm{Pr}_{3}\right)_{2}\right]_{2}(1 \mathrm{~mol} \%)$ as catalyst precursor at $120^{\circ} \mathrm{C}$ for 24 hours. 


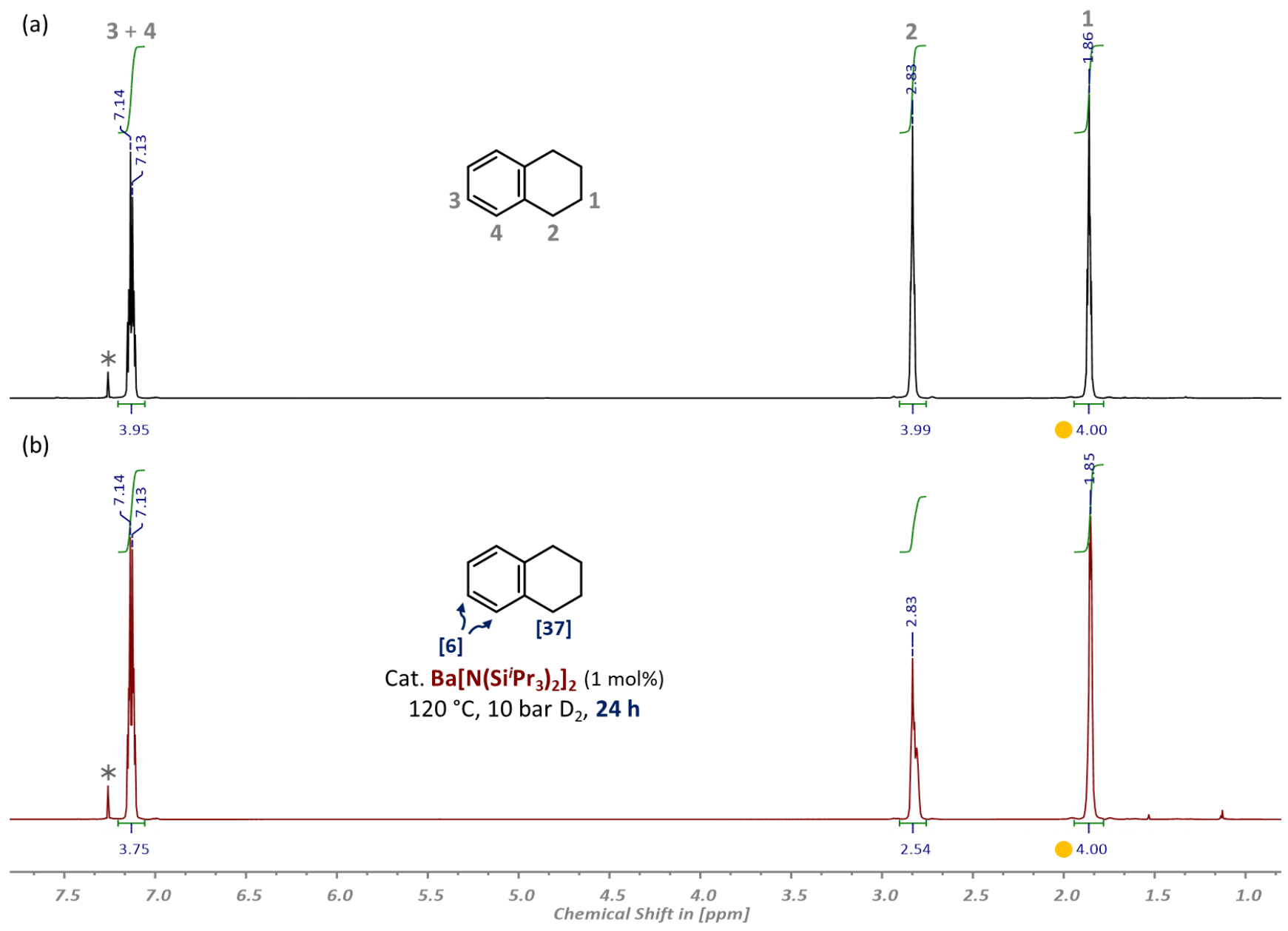

Figure S78. Stacked ${ }^{1} \mathrm{H}$ NMR spectra $\left(600 \mathrm{MHz}, \mathrm{CDCl}_{3}, 25^{\circ} \mathrm{C}\right)$ of $(a)$ an authentic sample of the tetralin substrate and $(b)$ the deuterium labeling product obtained after the catalytic deuteration with $\mathrm{D}_{2}(10 \mathrm{bar})$ and $\mathrm{Ba}\left[\mathrm{N}\left(\mathrm{Si}^{\mathrm{P}} \mathrm{Pr}_{3}\right)_{2}\right]_{2}(1 \mathrm{~mol} \%)$ as pre-catalyst at $120^{\circ} \mathrm{C}$ for 24 hours. 
(a)

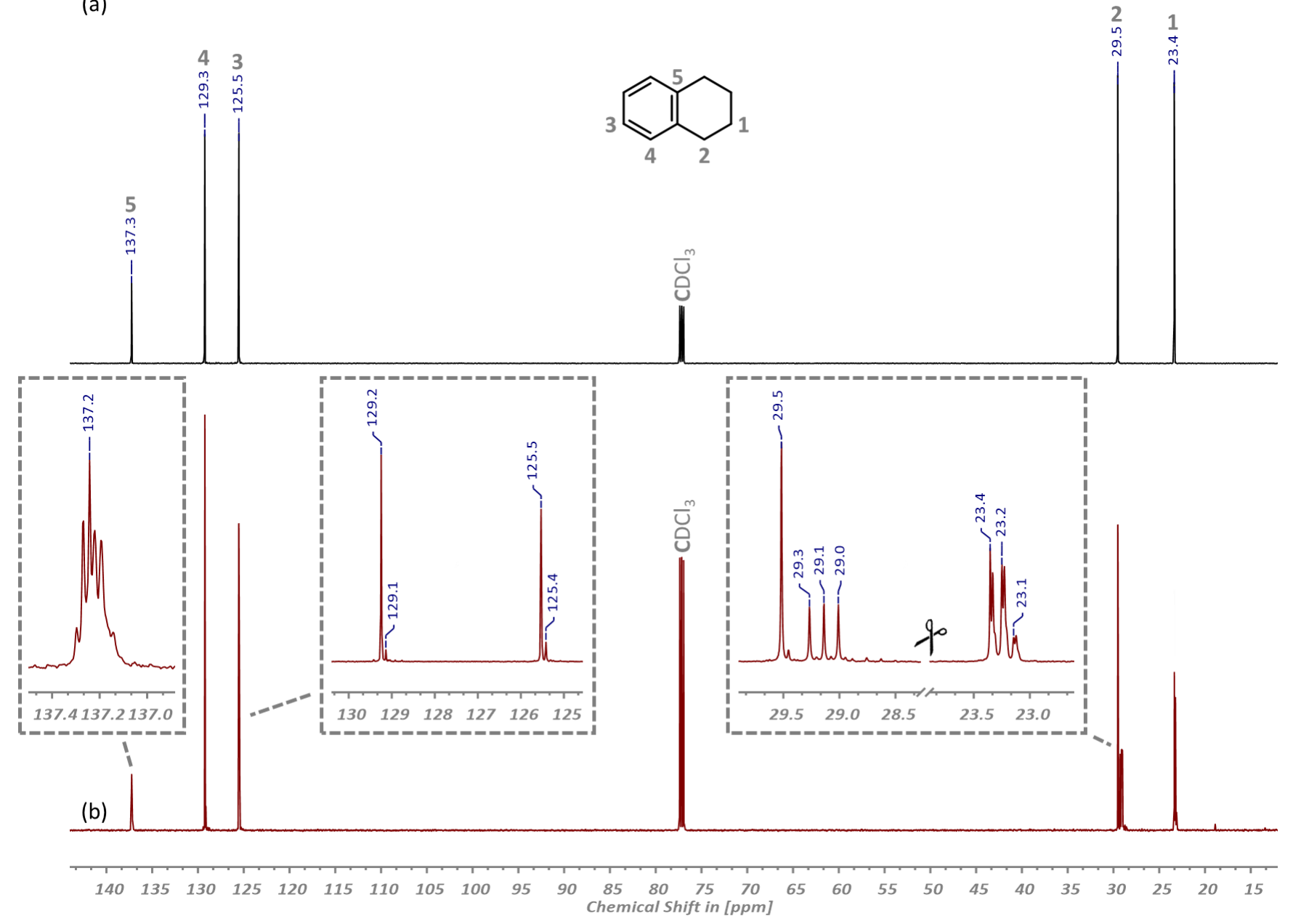

Figure S79. Stacked ${ }^{13} \mathrm{C}\left\{{ }^{1} \mathrm{H}\right\}$ NMR spectra $\left(151 \mathrm{MHz}, \mathrm{CDCl}_{3}, 25^{\circ} \mathrm{C}\right)$ of $($ a) the all-protio 1,2,3,4-tetrahydronaphthalene substrate and $(b)$ the catalytically deuterium-labeled product isolated after the deuteration with $\mathrm{D}_{2}$ (10 bar) and $\mathrm{Ba}\left[\mathrm{N}\left(\mathrm{Si}^{\mathrm{i}} \mathrm{Pr}_{3}\right)_{2}\right]_{2}(1 \mathrm{~mol} \%)$ as catalyst precursor at $120^{\circ} \mathrm{C}$ for 24 hours. 


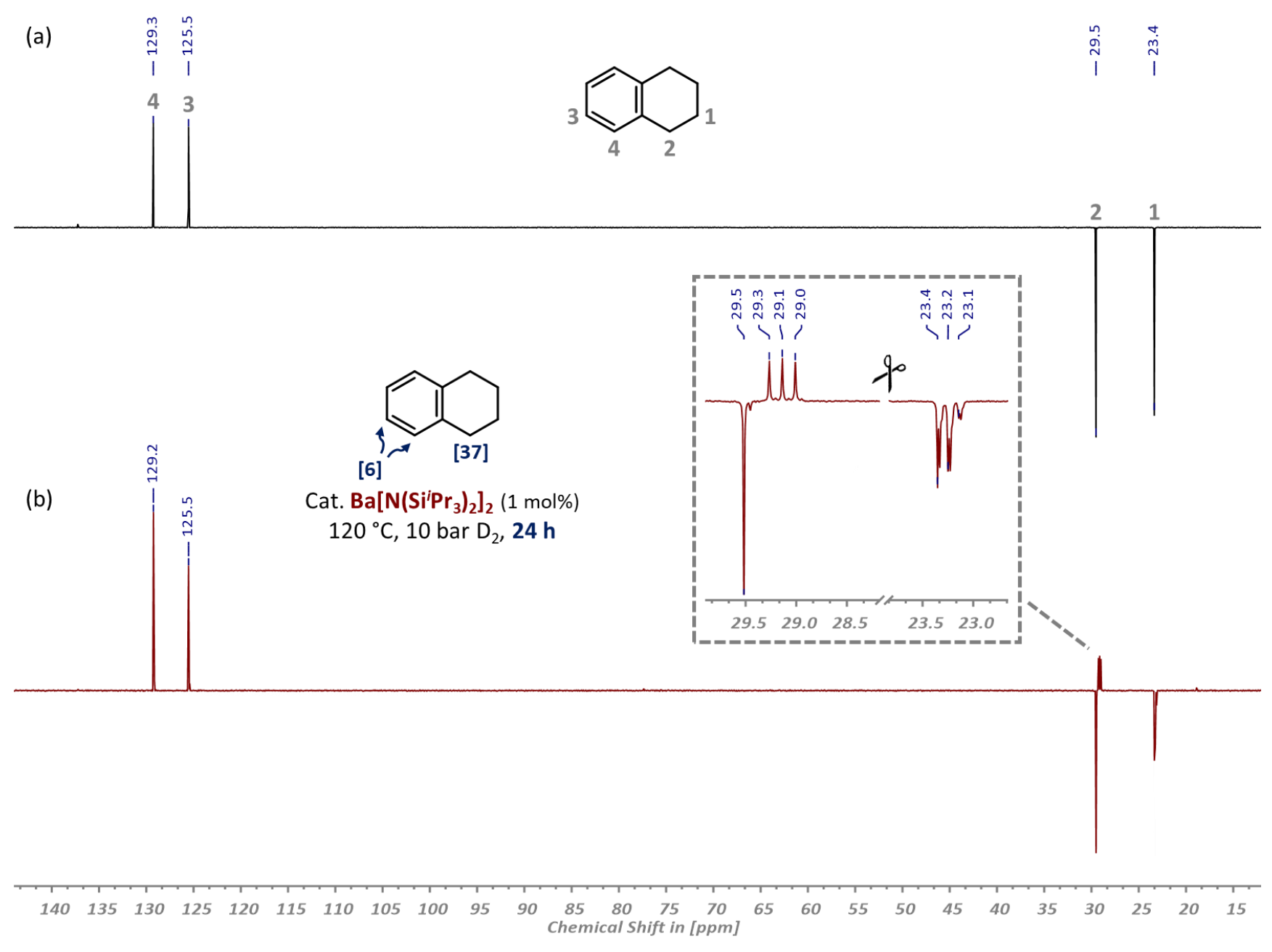

Figure S80. Stacked ${ }^{13} \mathrm{C}$ DEPT-135 NMR spectra $\left(151 \mathrm{MHz}, \mathrm{CDCl}_{3}, 25^{\circ} \mathrm{C}\right)$ of $(a)$ the non-deuterated tetralin substrate and $(b)$ the purified deuterium-labeled product isolated after the catalytic deuteration with $\mathrm{D}_{2}(10$ bar) and $\mathrm{Ba}\left[\mathrm{N}\left(\mathrm{Si}^{i} \mathrm{Pr}_{3}\right)_{2}\right]_{2}(1 \mathrm{~mol} \%)$ as catalyst precursor at $120^{\circ} \mathrm{C}$ for 24 hours. 


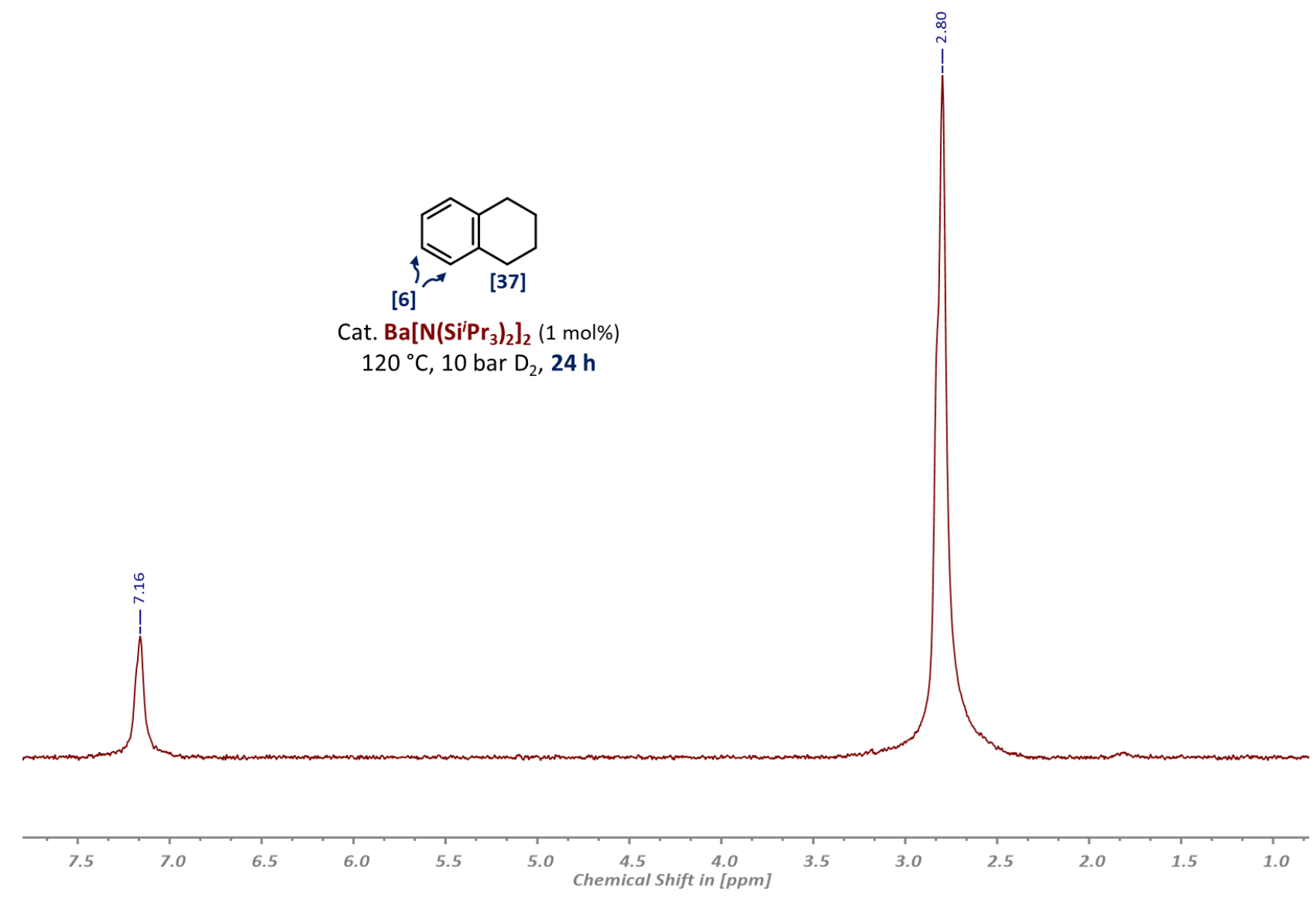

Figure S81. ${ }^{2} \mathrm{H}\left\{{ }^{1} \mathrm{H}\right\} \mathrm{NMR}$ spectrum $\left(92 \mathrm{MHz}, \mathrm{CHCl}_{3}, 25^{\circ} \mathrm{C}\right)$ of the partially deuterium-labeled product obtained after the catalytic deuteration of 1,2,3,4-tetrahydronaphthalene with $\mathrm{D}_{2}(10 \mathrm{bar})$ and $\mathrm{Ba}\left[\mathrm{N}\left(\mathrm{Si}^{i} \mathrm{Pr}_{3}\right)_{2}\right]_{2}(1 \mathrm{~mol} \%)$ as catalyst precursor at $120{ }^{\circ} \mathrm{C}$ for 24 hours. 

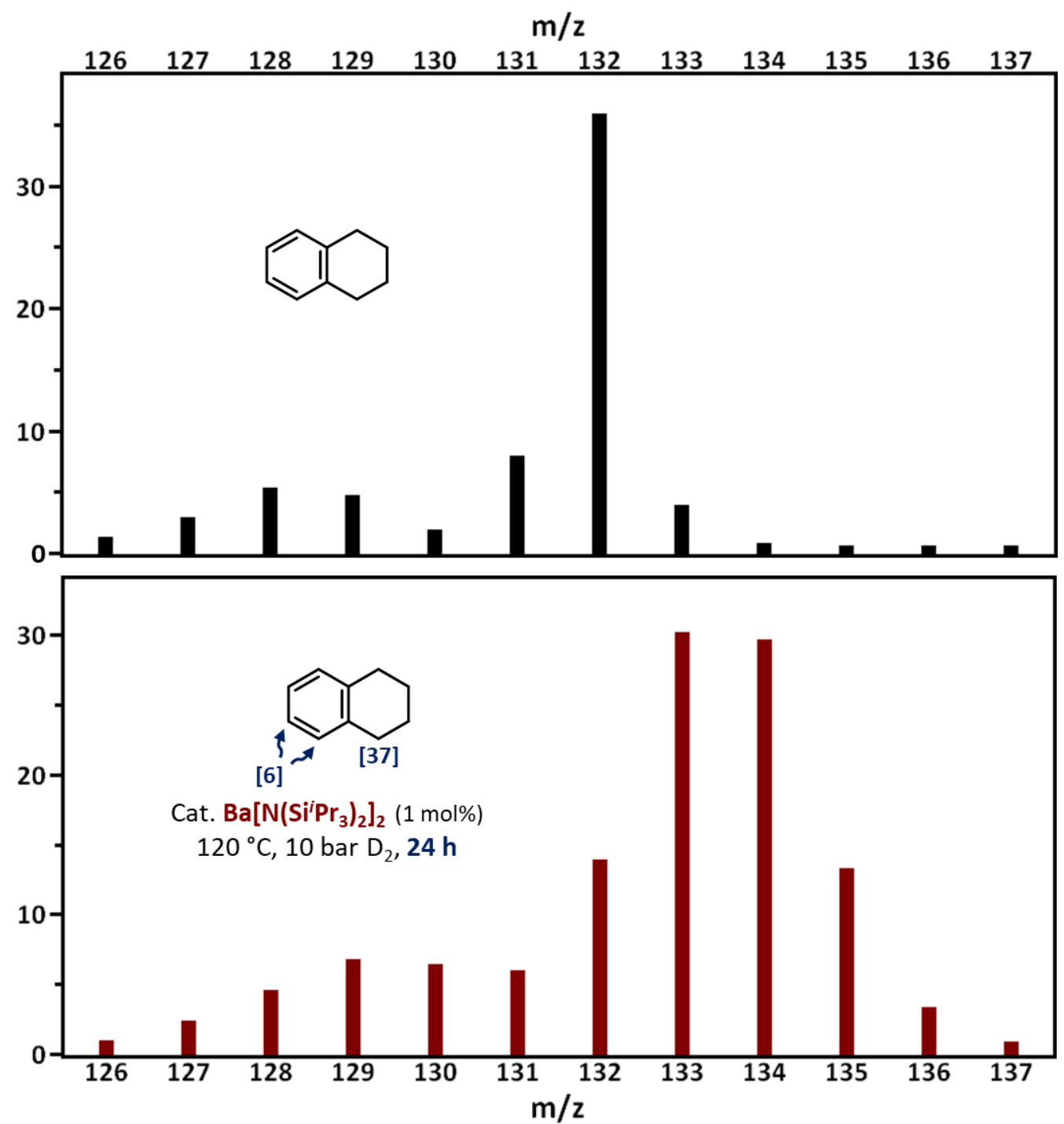

Figure S82. Stacked mass spectra of (top) the original tetralin starting material and (bottom) the deuterium-labeled product isolated after the catalytic deuteration with $\mathrm{D}_{2}(10 \mathrm{bar})$ and $\mathrm{Ba}\left[\mathrm{N}\left(\mathrm{Si}^{i} \mathrm{Pr}_{3}\right)_{2}\right]_{2}(1 \mathrm{~mol} \%)$ as catalyst precursor at $120^{\circ} \mathrm{C}$ for 24 hours. 
(a)

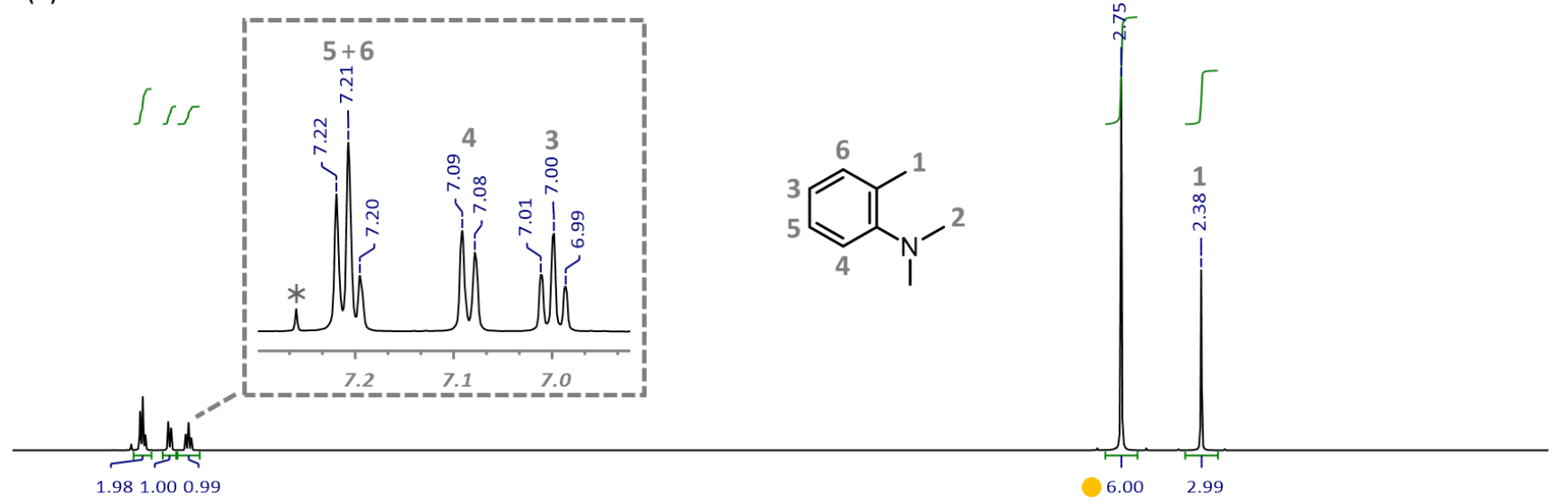

(b)

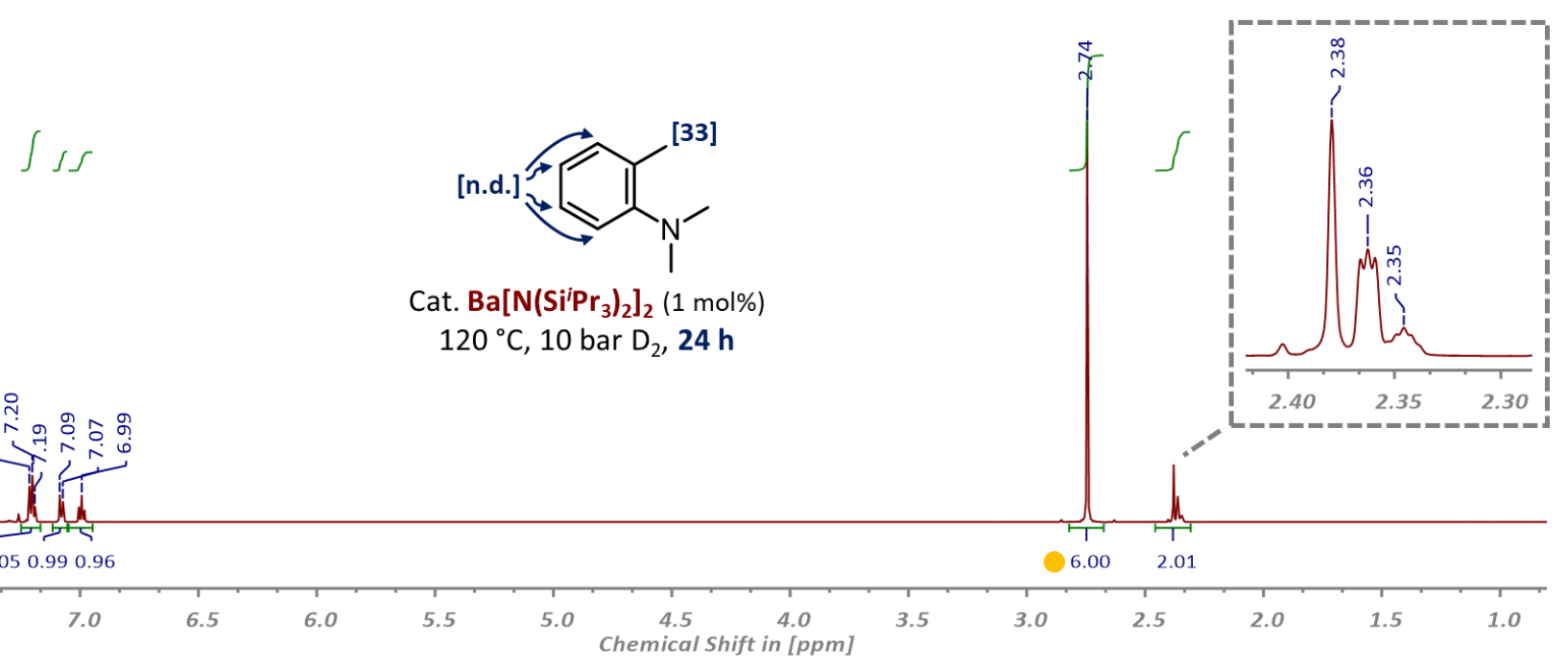

Figure S83. Stacked ${ }^{1} \mathrm{H}$ NMR spectra $\left(600 \mathrm{MHz}, \mathrm{CDCl}_{3}, 25^{\circ} \mathrm{C}\right)$ of $(a)$ the natural abundance

$\mathrm{N}, \mathrm{N}$-dimethyl-o-toluidine substrate and $(b)$ the catalytically deuterated product obtained after the deuteration with $\mathrm{D}_{2}(10 \mathrm{bar})$ and $\mathrm{Ba}\left[\mathrm{N}\left(\mathrm{Si}^{i} \mathrm{Pr}_{3}\right)_{2}\right]_{2}(1 \mathrm{~mol} \%)$ as catalyst precursor at $120^{\circ} \mathrm{C}$ for 24 hours.

Note: The extent of deuterium incorporated at the specified locations in the aromatic ring is less than $5 \%$ or too small to be accurately determined by ${ }^{1} \mathrm{H}$ NMR spectroscopy. 
(a)

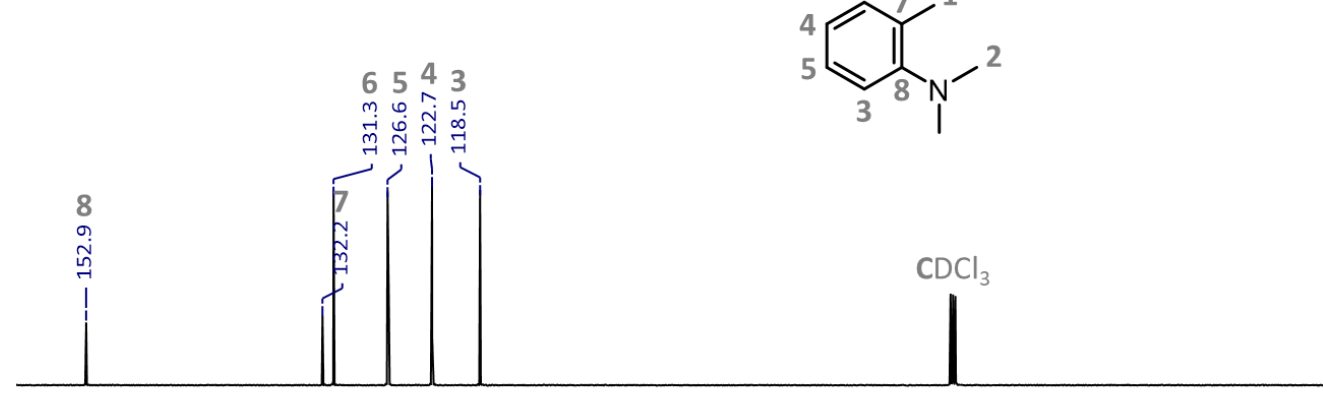

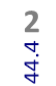

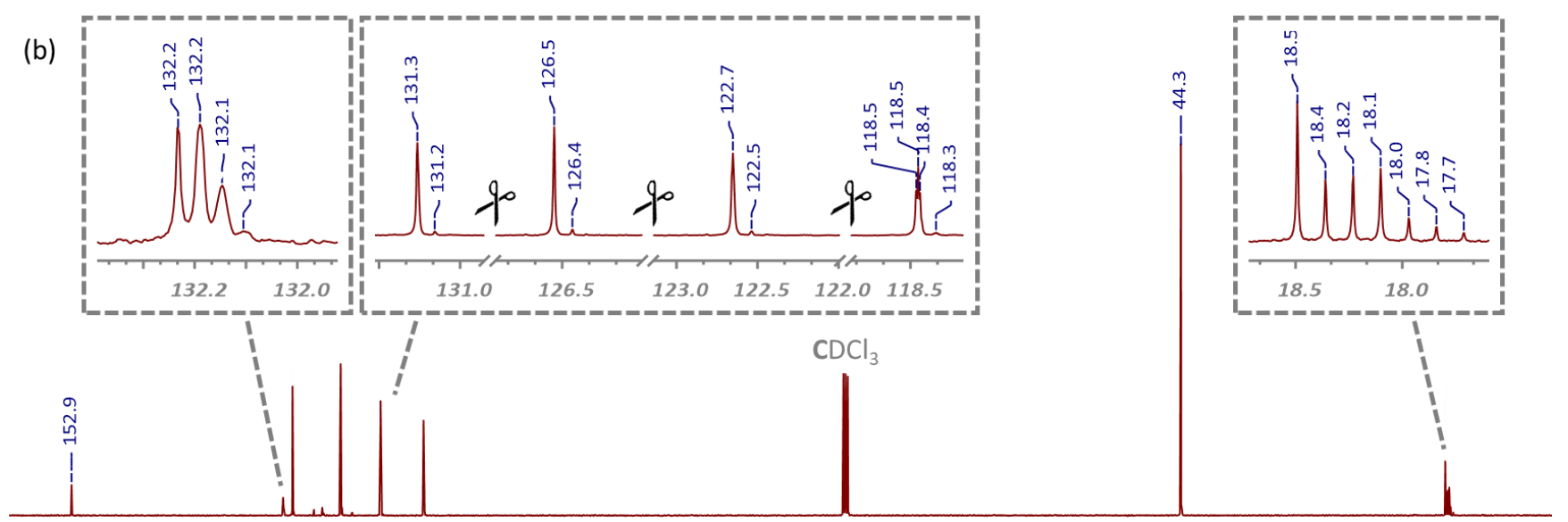

$\begin{array}{llllllllllllllllllllllllllllllllll}155 & 150 & 145 & 140 & 135 & 130 & 125 & 120 & 115 & 110 & 105 & 100 & 95 & 90 & 85 & 80 & 75 & 70 & 65 & 60 & 55 & 50 & 45 & 40 & 35 & 30 & 25 & 20 & 15 & 10 & 10\end{array}$

Figure S84. Stacked ${ }^{13} \mathrm{C}\left\{{ }^{1} \mathrm{H}\right\} \mathrm{NMR}$ spectra $\left(151 \mathrm{MHz}, \mathrm{CDCl}_{3}, 25^{\circ} \mathrm{C}\right.$ ) of $(a)$ the authentic $N, N$-dimethyl-o-toluidine starting material and $(b)$ the distilled deuterium-enriched product after the catalytic deuteration with $\mathrm{D}_{2}(10$ bar) and $\mathrm{Ba}\left[\mathrm{N}\left(\mathrm{Si}^{i} \mathrm{Pr}_{3}\right)_{2}\right]_{2}(1 \mathrm{~mol} \%)$ as catalyst precursor at $120^{\circ} \mathrm{C}$ for 24 hours. 
(a)

$65 \stackrel{4}{3}$

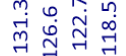

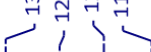

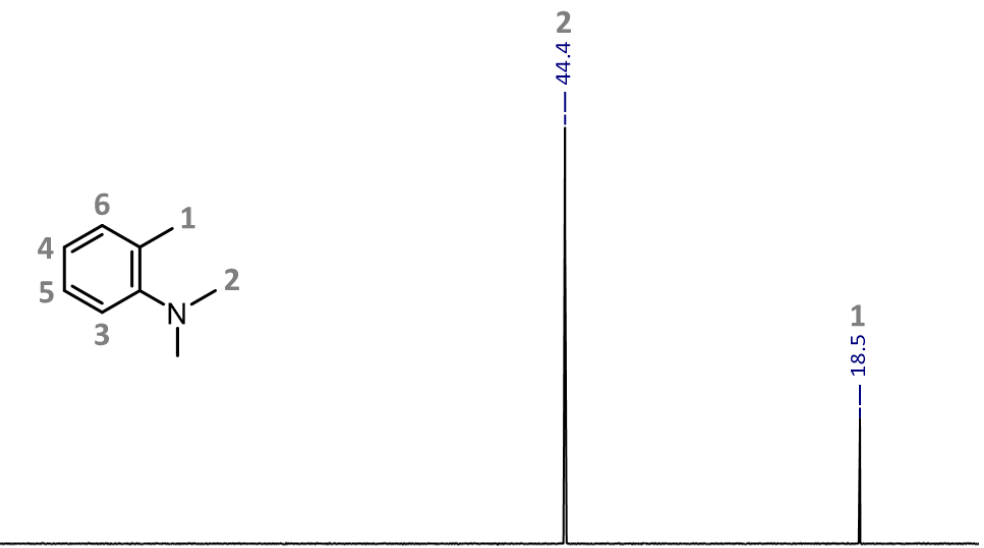

$\int_{+}^{2}$

(b)

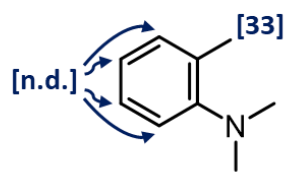

Cat. Ba[N(Si'Pr $\left.)_{3}\right]_{2}(1 \mathrm{~mol} \%)$ $120^{\circ} \mathrm{C}, 10$ bar $\mathrm{D}_{2}, 24 \mathrm{~h}$
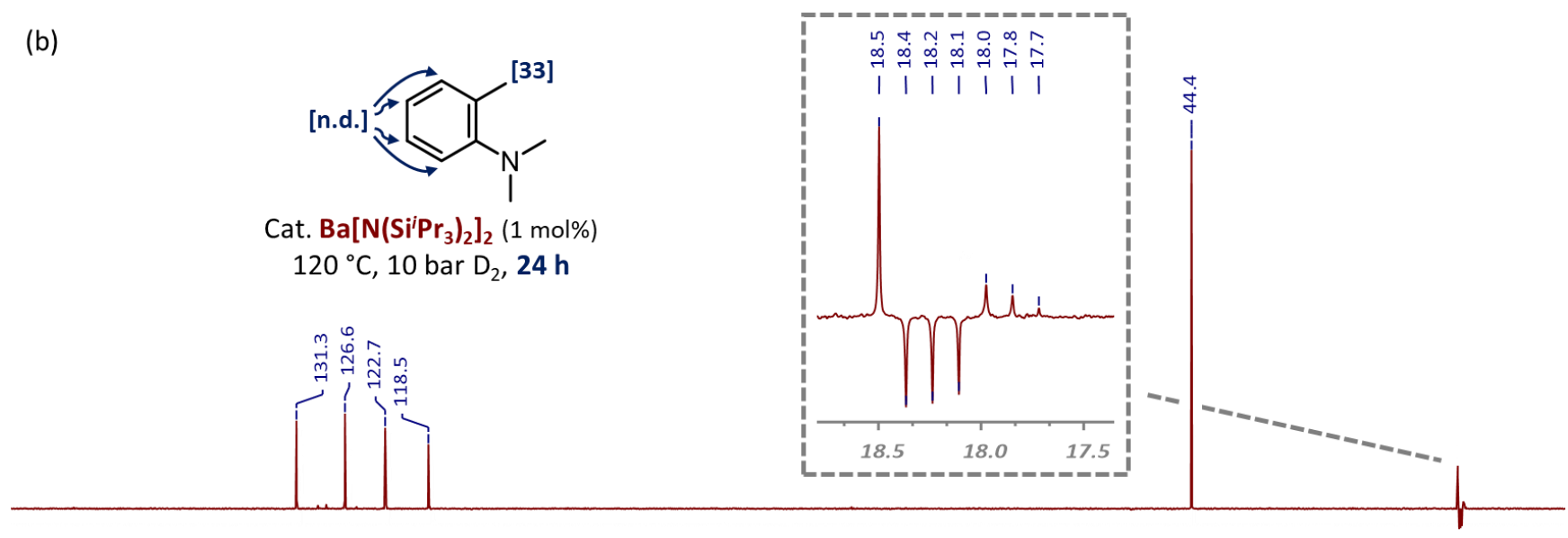

$\begin{array}{lllllllllllllllllllllllllllllllllllll}155 & 150 & 145 & 140 & 135 & 130 & 125 & 120 & 115 & 110 & 105 & 100 & 95 & 90 & 85 & 80 & 75 & 70 & 65 & 60 & 55 & 50 & 45 & 40 & 35 & 30 & 25 & 20 & 15 & 10\end{array}$

Figure S85. Stacked ${ }^{13} \mathrm{C}$ DEPT-135 NMR spectra $\left(151 \mathrm{MHz}, \mathrm{CDCl}_{3}, 25^{\circ} \mathrm{C}\right)$ of $($ a) the all-protio $\mathrm{N}, \mathrm{N}$-dimethyl-o-toluidine substrate and $(b)$ the catalytically deuterated product isolated after the deuteration with $\mathrm{D}_{2}(10 \mathrm{bar})$ and $\mathrm{Ba}\left[\mathrm{N}\left(\mathrm{Si}^{\prime} \mathrm{Pr}_{3}\right)_{2}\right]_{2}(1 \mathrm{~mol} \%)$ as pre-catalyst at $120^{\circ} \mathrm{C}$ for 24 hours. Note: The extent of deuterium incorporated at the specified locations in the aromatic ring is less than $5 \%$ or too small to be accurately determined by ${ }^{1} \mathrm{H}$ NMR spectroscopy. 


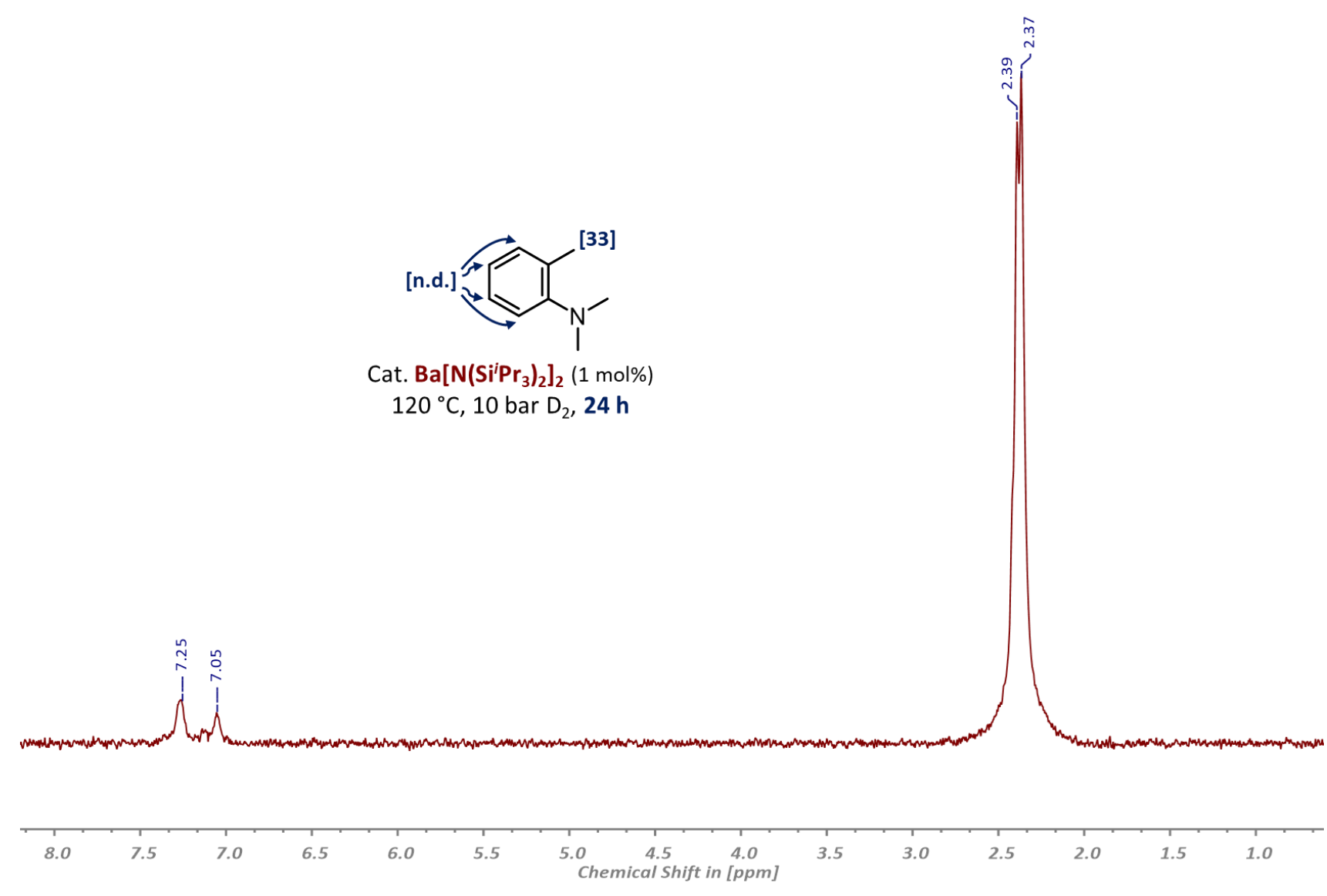

Figure S86. ${ }^{2} \mathrm{H}\left\{{ }^{1} \mathrm{H}\right\} \mathrm{NMR}$ spectrum $\left(92 \mathrm{MHz}, \mathrm{CHCl}_{3}, 25^{\circ} \mathrm{C}\right.$ ) of the partially deuterium-labeled $\mathrm{N}, \mathrm{N}$-dimethyl-o-toluidine product obtained after the catalytic deuteration with $\mathrm{D}_{2}$ (10 bar) and $\mathrm{Ba}\left[\mathrm{N}\left(\mathrm{Si}^{i} \mathrm{Pr}_{3}\right)_{2}\right]_{2}$ ( $1 \mathrm{~mol} \%$ ) as catalyst precursor at $120^{\circ} \mathrm{C}$ for 24 hours. Note: The extent of deuterium incorporated at the specified locations in the aromatic ring is less than $5 \%$ or too small to be accurately determined by ${ }^{1} \mathrm{H}$ NMR spectroscopy. 


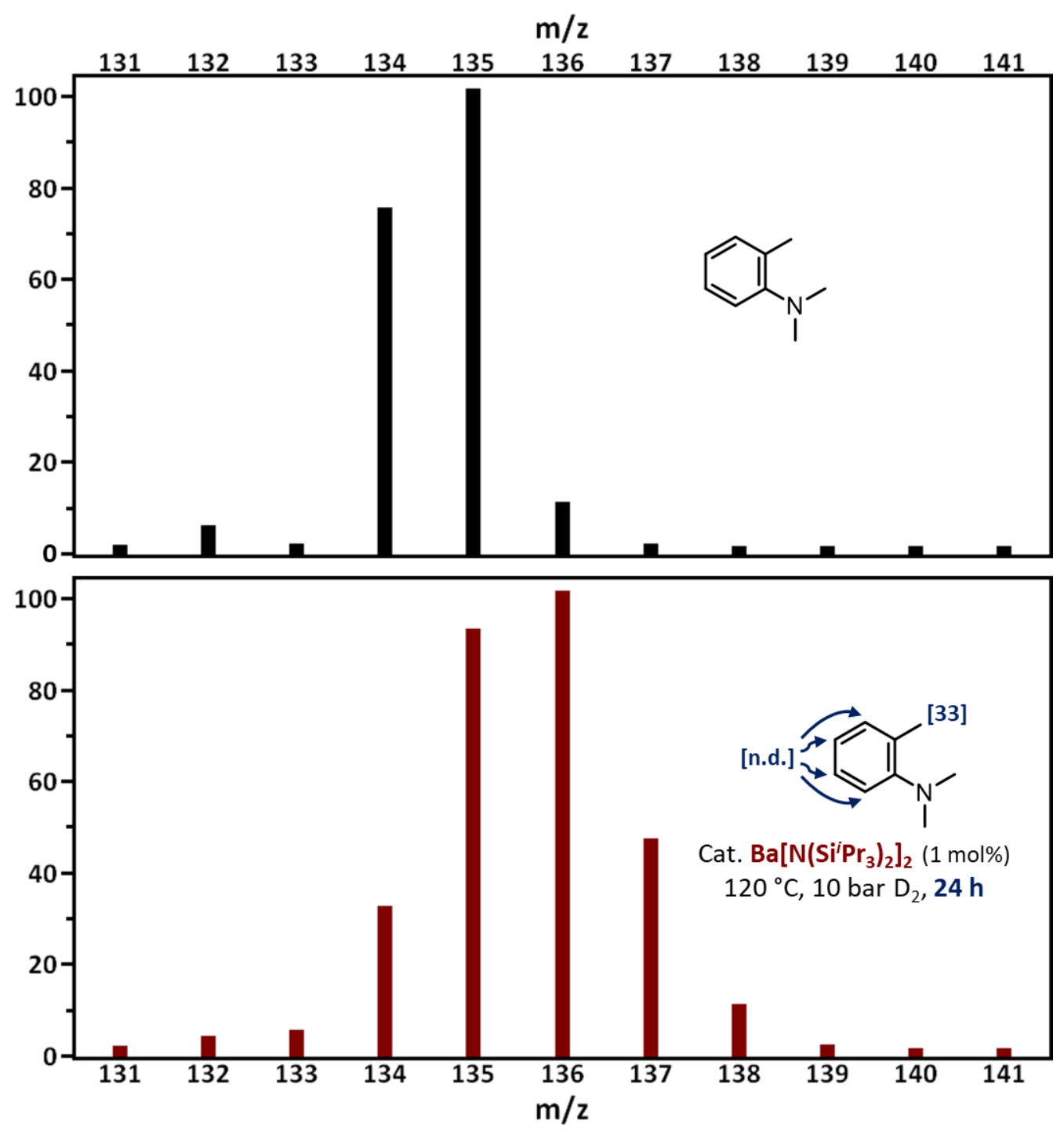

Figure S87. Stacked mass spectra of (top) the natural abundance $N, N$-dimethyl-o-toluidine substrate and

(bottom) the deuterium-labeled product isolated after the catalytic deuteration with $D_{2}(10$ bar) and $\mathrm{Ba}\left[\mathrm{N}\left(\mathrm{Si}^{i} \mathrm{Pr}_{3}\right)_{2}\right]_{2}(1 \mathrm{~mol} \%)$ as catalyst precursor at $120{ }^{\circ} \mathrm{C}$ for 24 hours. Note: The extent of deuterium incorporated at the specified locations in the aromatic ring is less than $5 \%$ or too small to be accurately determined by ${ }^{1} \mathrm{H}$ NMR spectroscopy. 


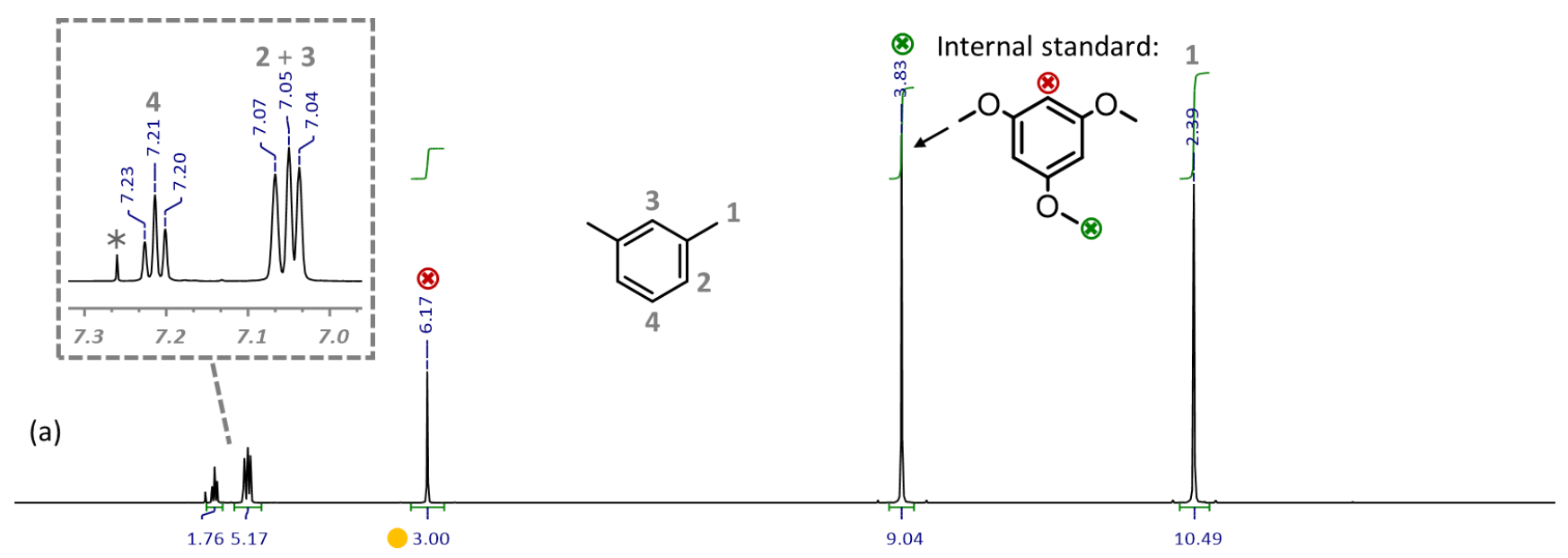

(b)

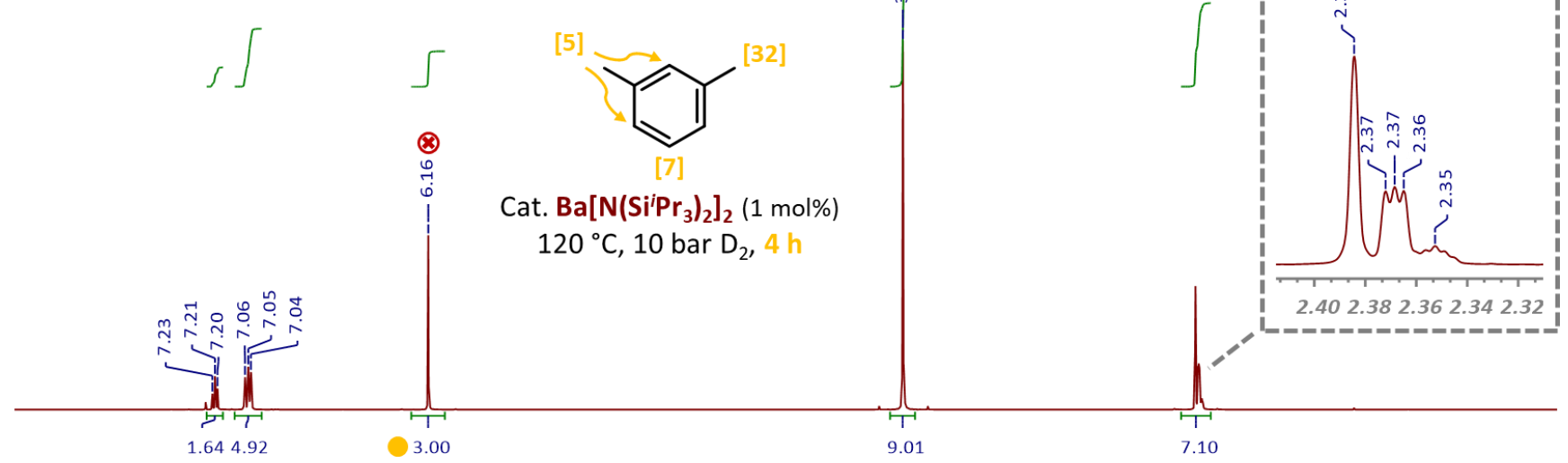

(c)

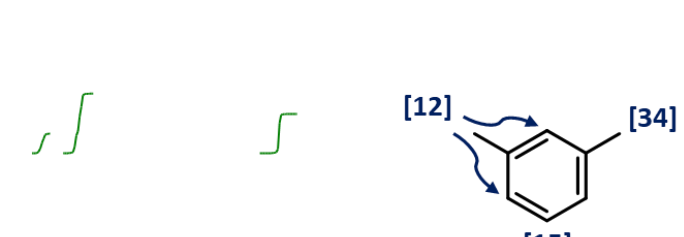

[15]

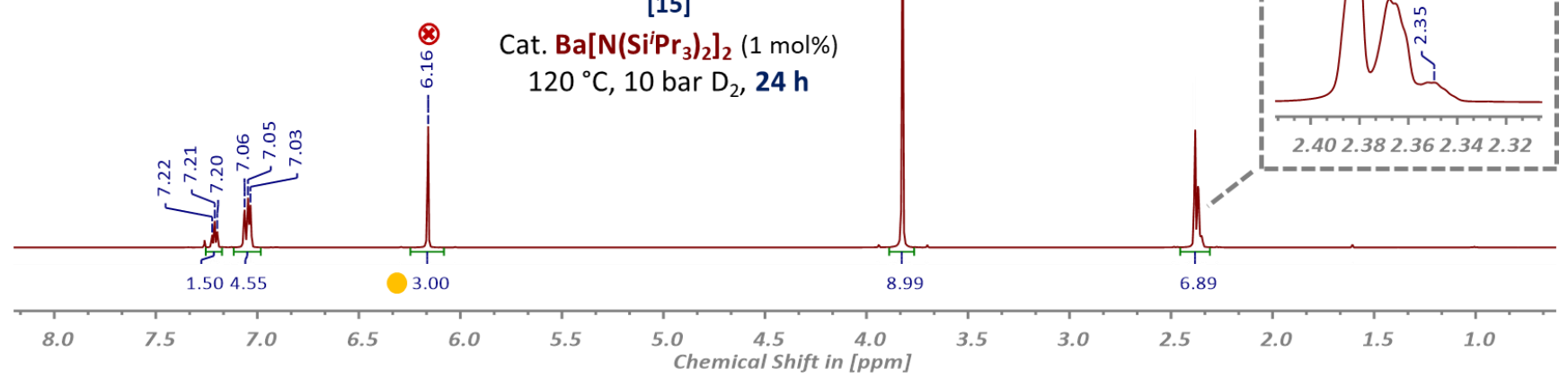

Figure S88. Stacked ${ }^{1} \mathrm{H}$ NMR spectra $\left(600 \mathrm{MHz}, \mathrm{CDCl}_{3}, 25^{\circ} \mathrm{C}\right)$ of $(a)$ the authentic meta-xylene substrate and the purified deuterium-labeled products obtained after the catalytic deuteration with $\mathrm{D}_{2}(10 \mathrm{bar})$ and $\mathrm{Ba}\left[\mathrm{N}\left(\mathrm{Si}^{i} \mathrm{Pr}_{3}\right)_{2}\right]_{2}$

( $1 \mathrm{~mol} \%$ ) as catalyst precursor at $120^{\circ} \mathrm{C}$ for $(b) 4$ and $(c) 24$ hours, respectively. Note: All $\mathrm{C}-\mathrm{H}$ positions are labeled. 1,3,5-Trimethoxybenzene was therefore used as an internal standard. 

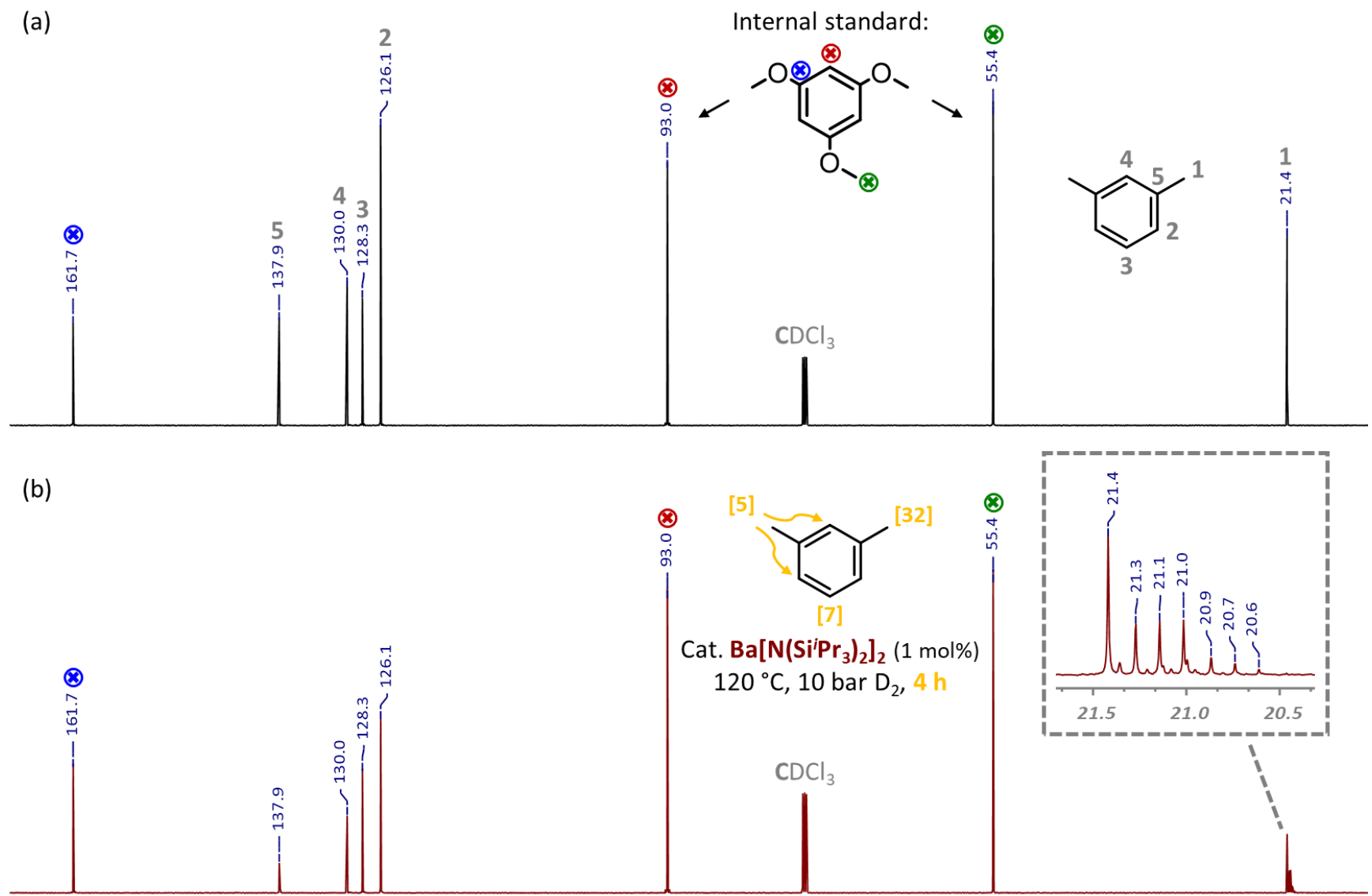

(c)

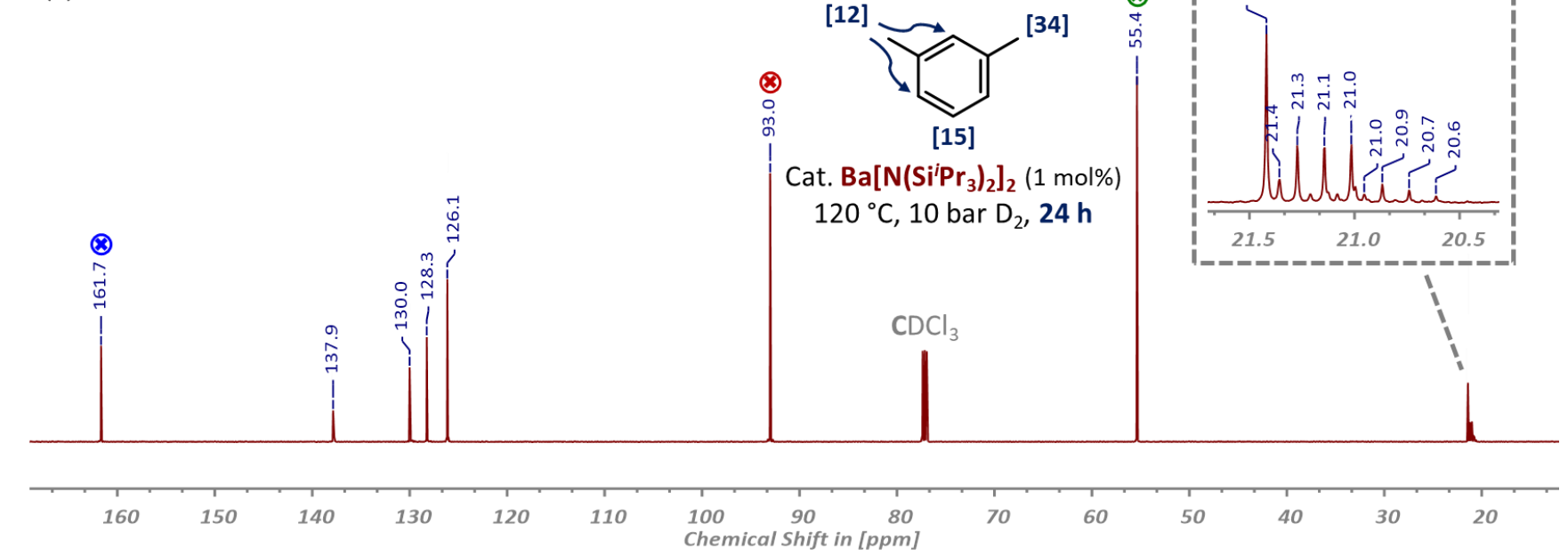

Figure S89. Stacked ${ }^{13} \mathrm{C}\left\{{ }^{1} \mathrm{H}\right\} \mathrm{NMR}$ spectra $\left(151 \mathrm{MHz}, \mathrm{CDCl}_{3}, 25^{\circ} \mathrm{C}\right)$ of $(a)$ a sample of the unlabeled meta-xylene substrate and $(b)$ the partially deuterated products isolated after the catalytic deuteration with $\mathrm{D}_{2}(10$ bar) and $\mathrm{Ba}\left[\mathrm{N}\left(\mathrm{Si}^{\mathrm{P}} \mathrm{Pr}_{3}\right)_{2}\right]_{2}(1 \mathrm{~mol} \%)$ as pre-catalyst at $120^{\circ} \mathrm{C}$ for $(b) 4$ and $(c) 24$ hours, respectively. Note: 1,3,5-Trimethoxybenzene was added as internal standard. 
(a)

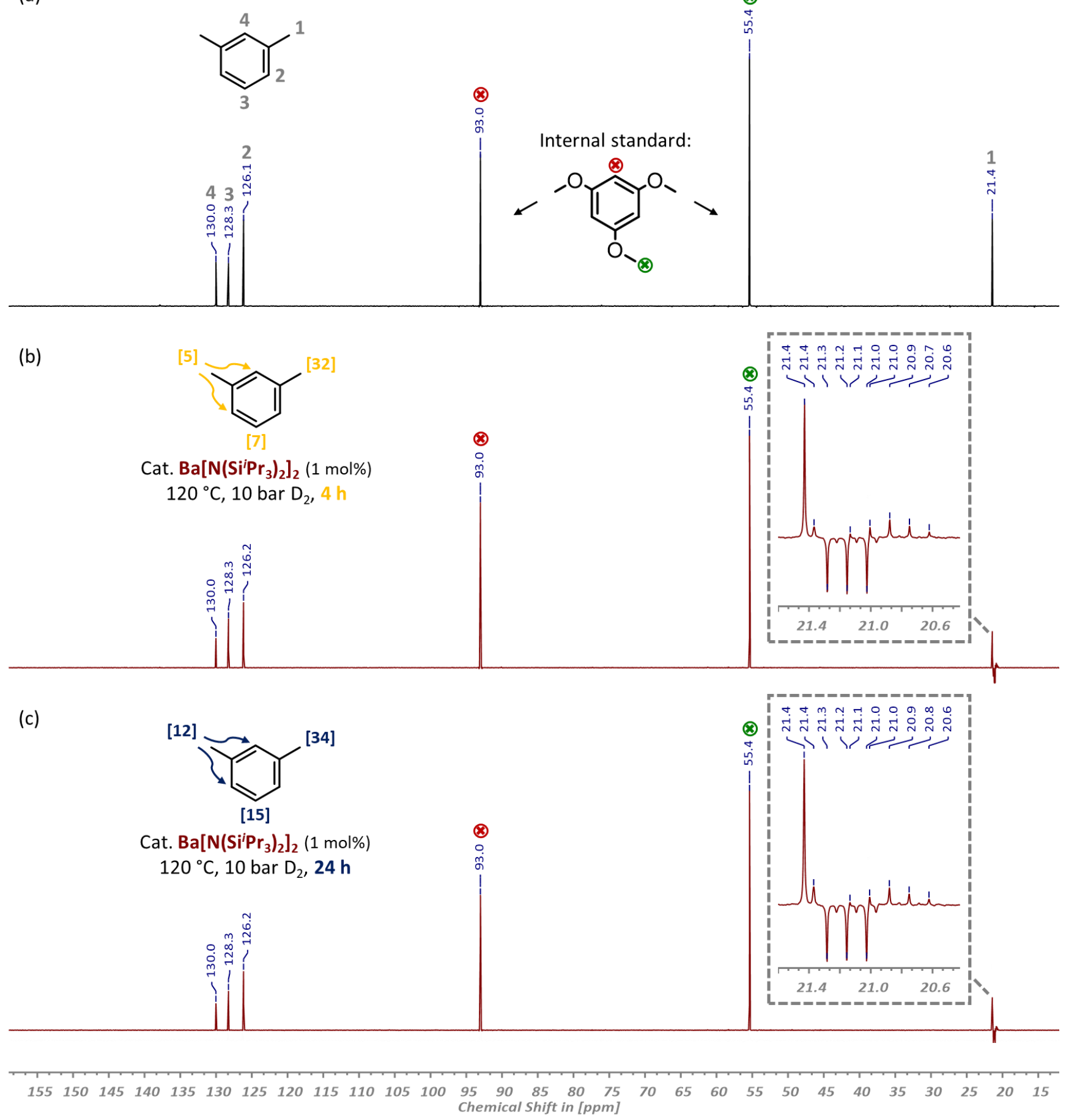

Figure S90. Stacked ${ }^{13} \mathrm{C}$ DEPT-135 NMR spectra $\left(151 \mathrm{MHz}, \mathrm{CDCl}_{3}, 25{ }^{\circ} \mathrm{C}\right)$ of $(a)$ the all-protio meta-xylene starting material and the deuterium-labeled products obtained after the catalytic deuteration with $\mathrm{D}_{2}(10 \mathrm{bar})$ and $\mathrm{Ba}\left[\mathrm{N}\left(\mathrm{Si}^{i} \mathrm{Pr}_{3}\right)_{2}\right]_{2}(1 \mathrm{~mol} \%)$ as catalyst precursor at $120{ }^{\circ} \mathrm{C}$ for $(b) 4$ and $(c) 24$ hours, respectively. Note: 1,3,5-Trimethoxybenzene was added as internal standard. 
(a)

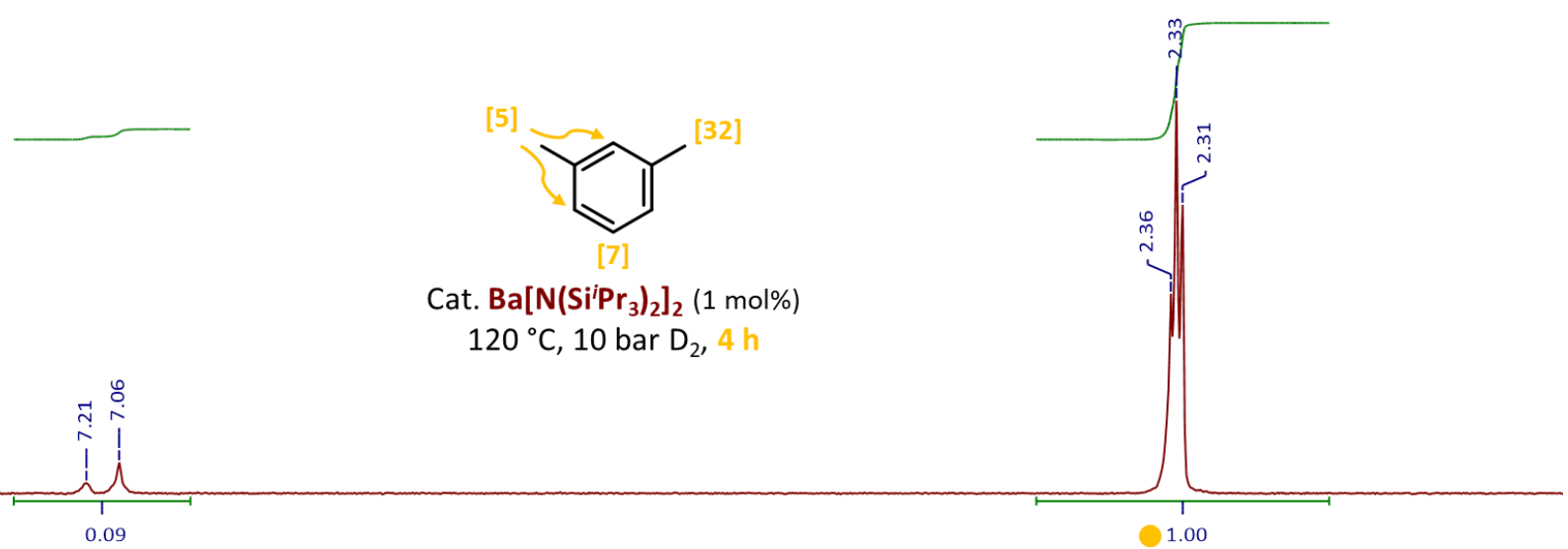

(b)

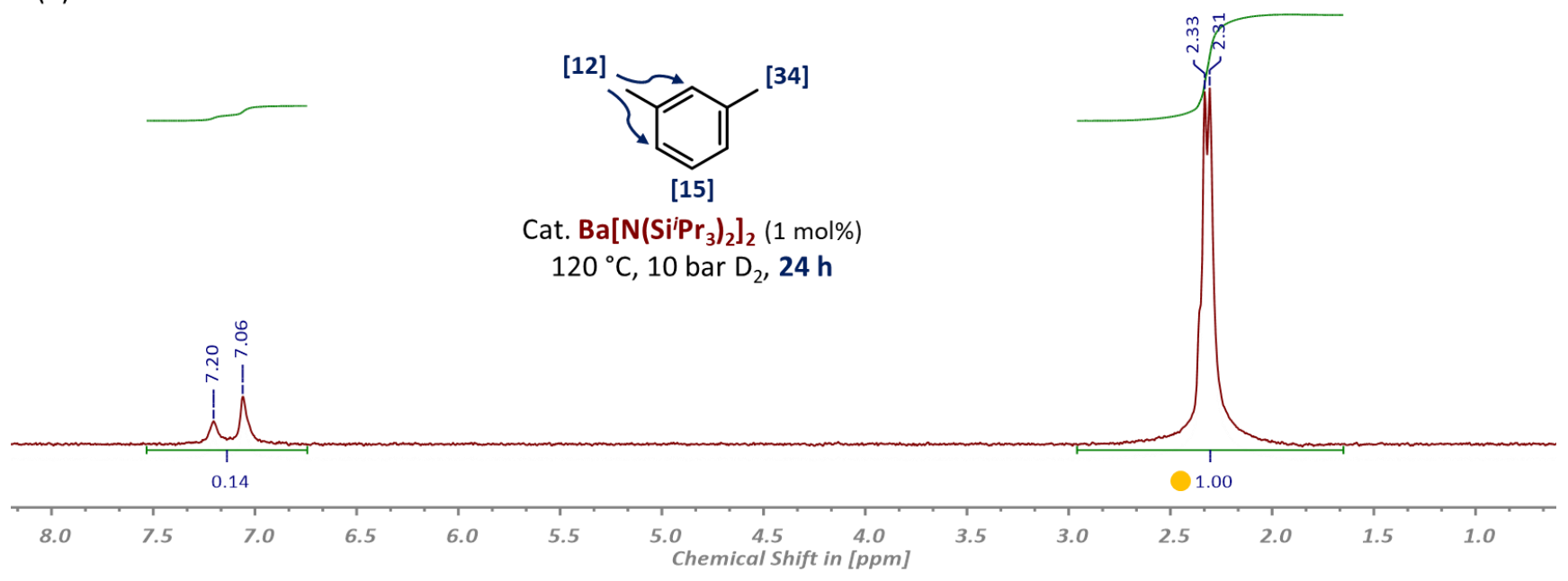

Figure S91. Stacked ${ }^{2} \mathrm{H}\left\{{ }^{1} \mathrm{H}\right\}$ NMR spectra $\left(92 \mathrm{MHz}, \mathrm{CHCl}_{3}, 25^{\circ} \mathrm{C}\right)$ of the catalytically deuterium-labeled products isolated after the deuteration of meta-xylene with $\mathrm{D}_{2}(10 \mathrm{bar})$ and $\mathrm{Ba}\left[\mathrm{N}\left(\mathrm{Si}^{i} \mathrm{Pr}_{3}\right)_{2}\right]_{2}(1 \mathrm{~mol} \%)$ as promoter at $120^{\circ} \mathrm{C}$ for $(a) 4$ and $(b) 24$ hours, respectively. 

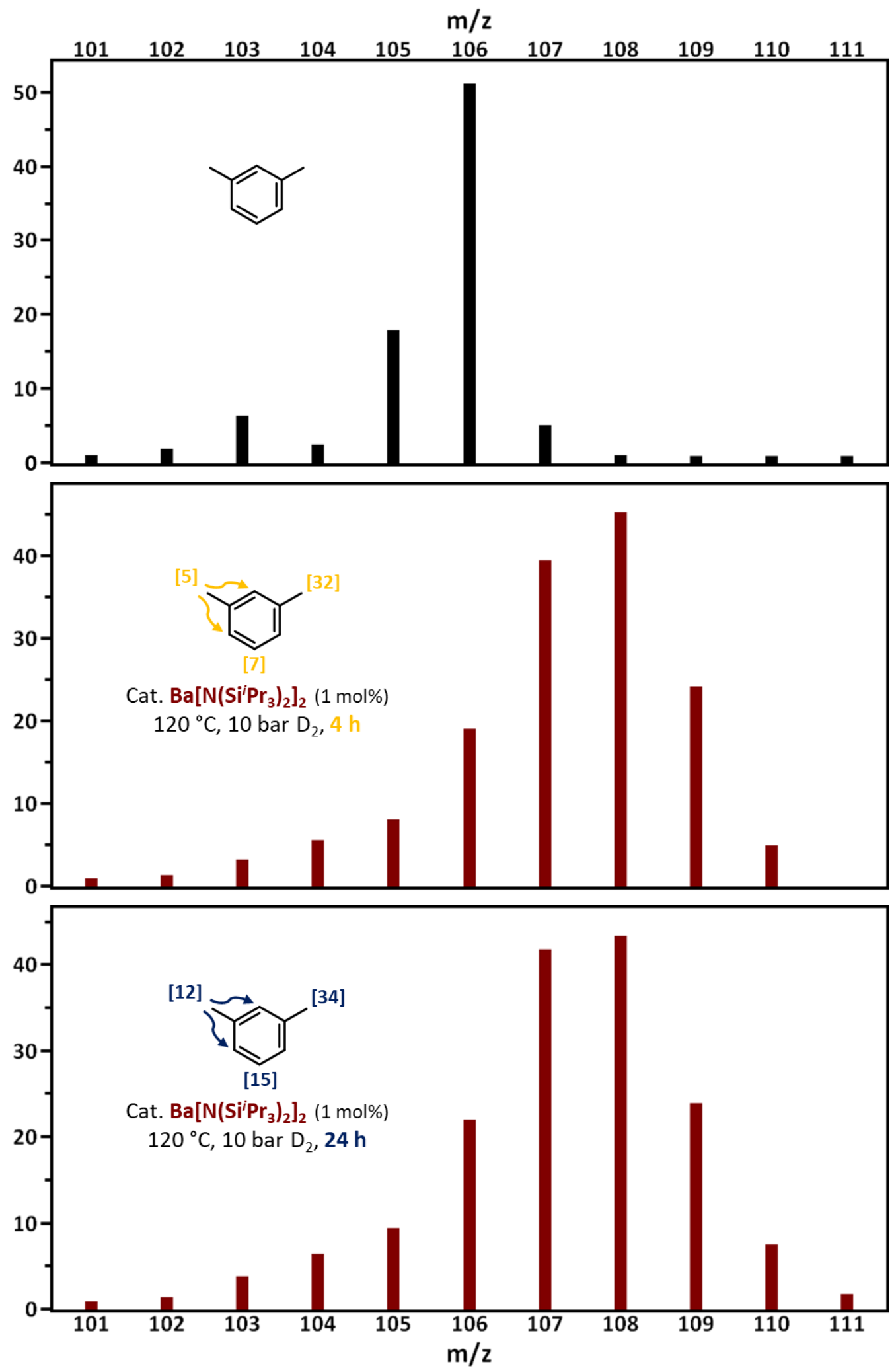

Figure S92. Stacked mass spectra of (top) the non-labeled meta-xylene substrate and the partially deuterated products obtained after the catalytic deuteration with $\mathrm{D}_{2}(10 \mathrm{bar})$ and $\mathrm{Ba}\left[\mathrm{N}\left(\mathrm{Si}^{i} \mathrm{Pr}_{3}\right)_{2}\right]_{2}(1 \mathrm{~mol} \%)$ as catalyst precursor at $120^{\circ} \mathrm{C}$ for (middle) 4 and (bottom) 24 hours, respectively. 


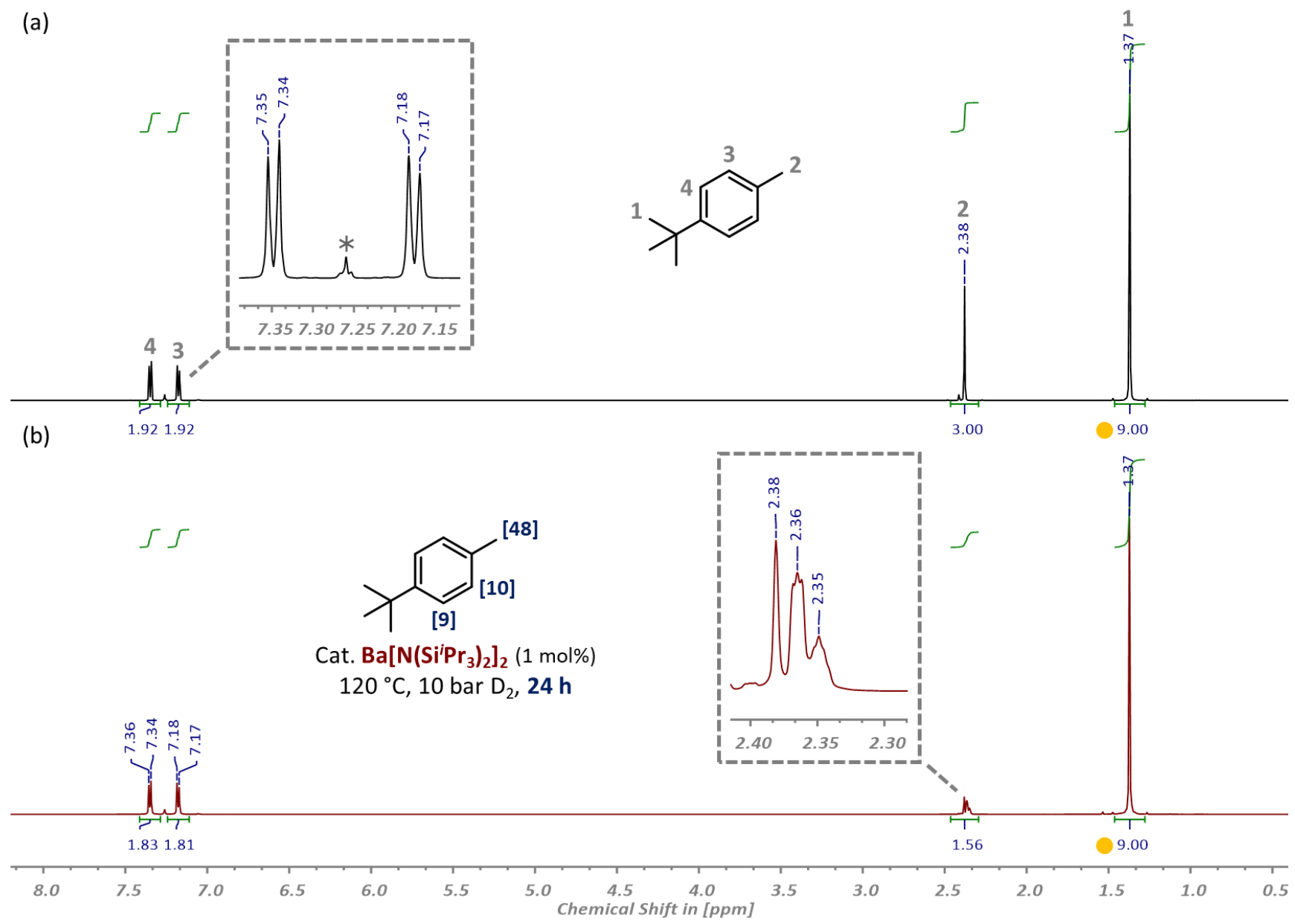

Figure S93. Stacked ${ }^{1} \mathrm{H}$ NMR spectra $\left(600 \mathrm{MHz} \mathrm{CDCl}_{3}, 25^{\circ} \mathrm{C}\right)$ of $(a)$ an authentic sample of 4-tert-butyltoluene and $(b)$ the deuterium-labeled product isolated after the catalytic deuteration with $\mathrm{D}_{2}\left(10 \mathrm{bar}\right.$ ) at $120{ }^{\circ} \mathrm{C}$ for 24 hours using $\mathrm{Ba}\left[\mathrm{N}\left(\mathrm{Si}^{i} \mathrm{Pr}_{3}\right)_{2}\right]_{2}$ (1 mol\%) as catalyst precursor. 
(a)

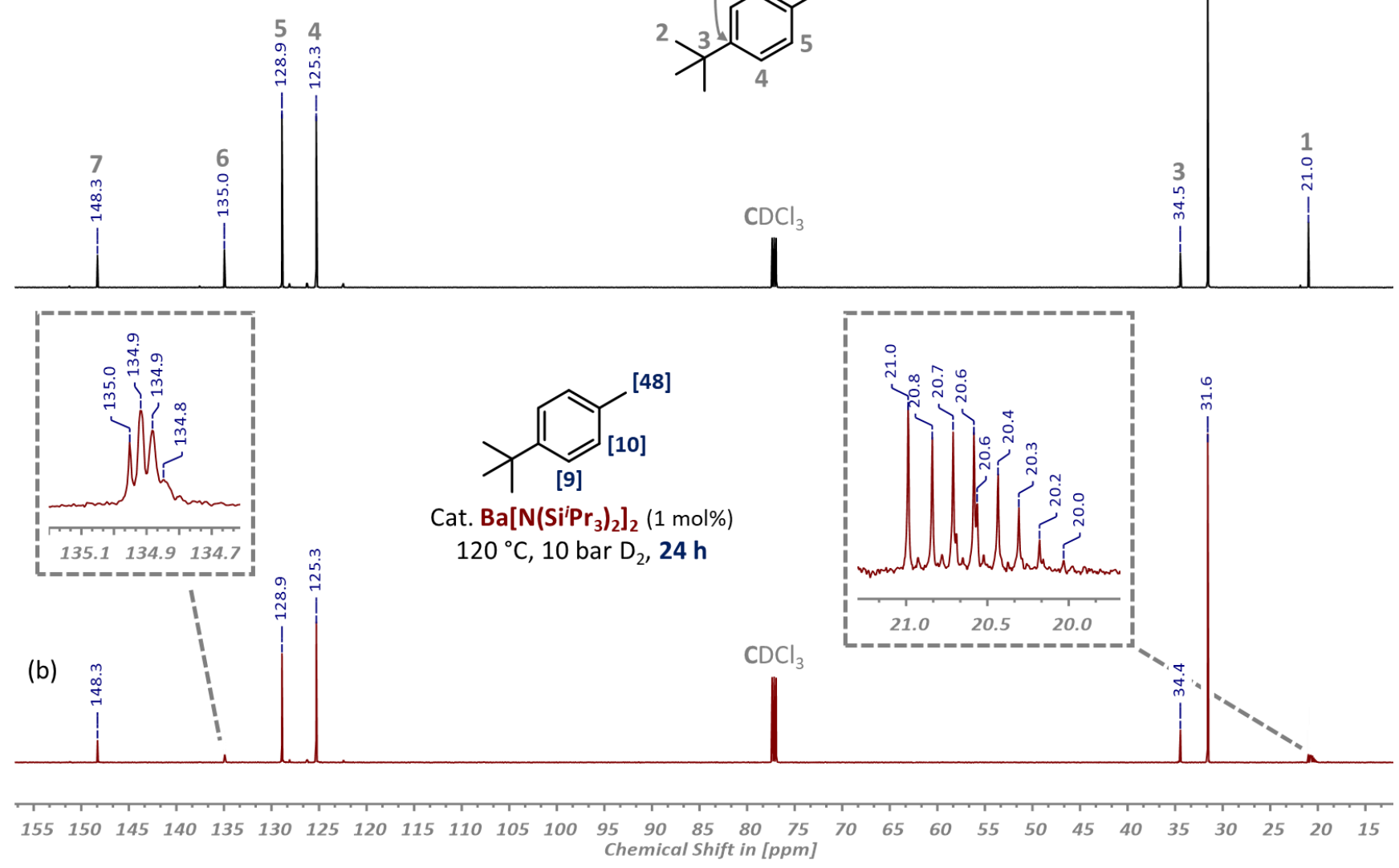

Figure S94. Stacked ${ }^{13} \mathrm{C}\left\{{ }^{1} \mathrm{H}\right\}$ NMR spectra $\left(151 \mathrm{MHz}, \mathrm{CDCl}_{3}, 25^{\circ} \mathrm{C}\right)$ of $(a)$ the natural abundance 4-tert-butyltoluene substrate and $(b)$ the deuterium labeling product obtained after the catalytic deuteration with $\mathrm{D}_{2}(10 \mathrm{bar})$ and $\mathrm{Ba}\left[\mathrm{N}\left(\mathrm{Si}^{i} \mathrm{Pr}_{3}\right)_{2}\right]_{2}(1 \mathrm{~mol} \%)$ as catalyst precursor at $120^{\circ} \mathrm{C}$ for 24 hours. 
(a)
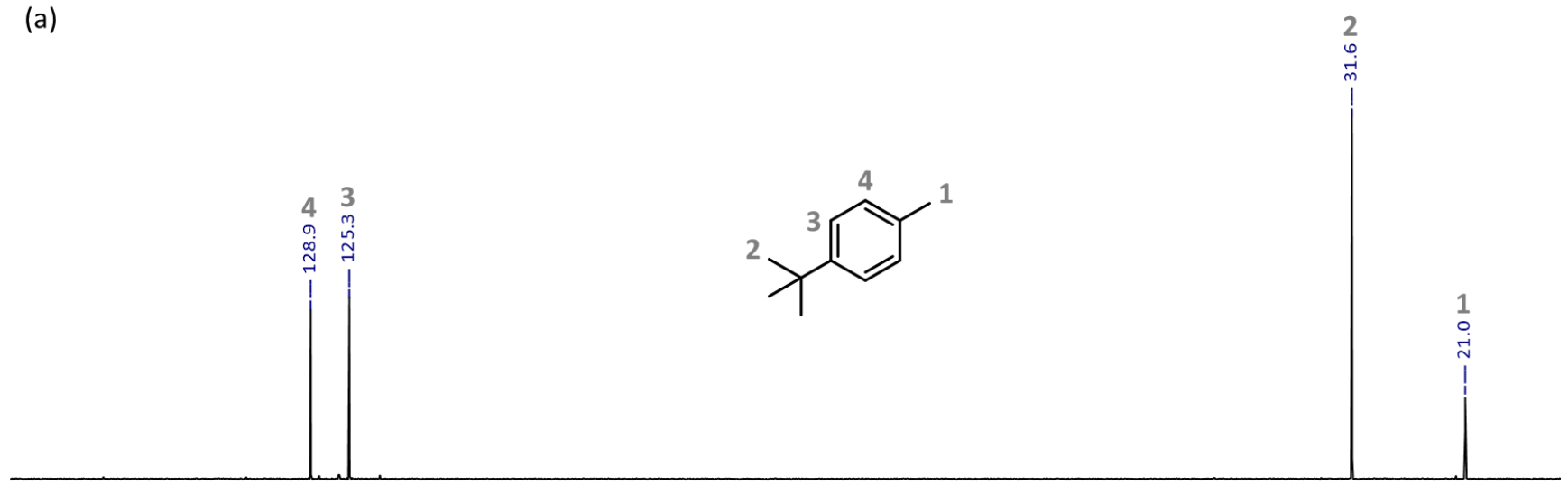

(b)

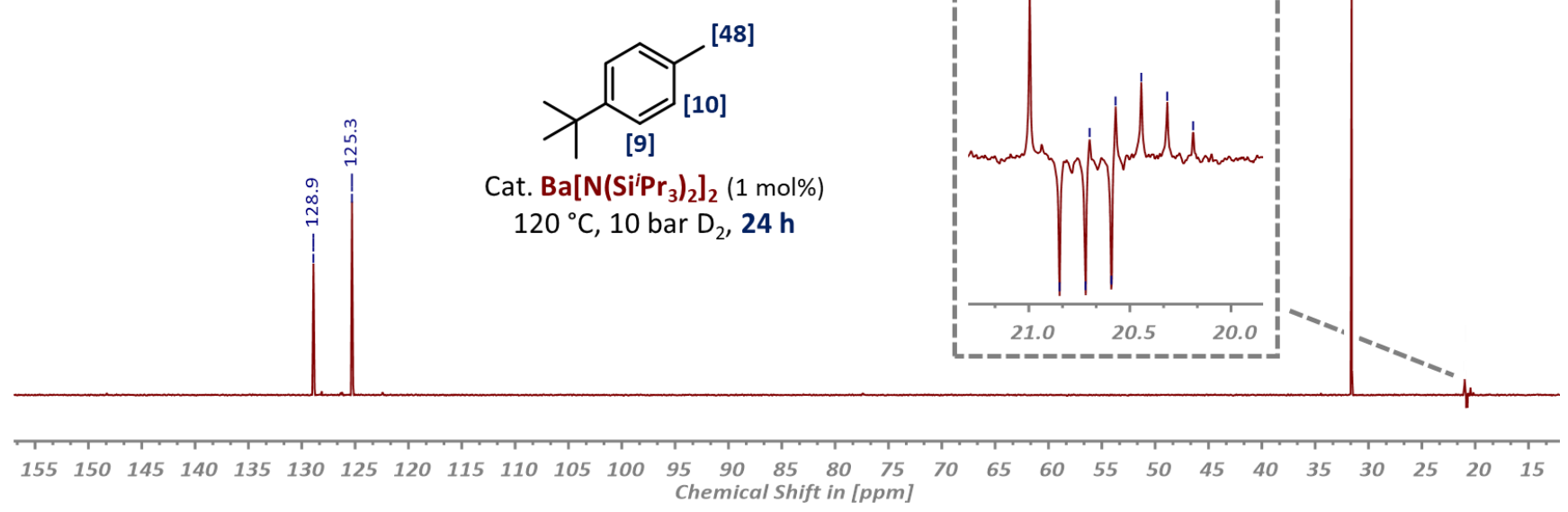

Figure S95. Stacked ${ }^{13} \mathrm{C}$ DEPT-135 NMR spectra $\left(151 \mathrm{MHz}, \mathrm{CDCl}_{3}, 25^{\circ} \mathrm{C}\right)$ of $(a)$ the non-labeled 4-tert-butyltoluene starting material and $(b)$ the partially deuterated product isolated after the catalytic deuteration with $\mathrm{D}_{2}(10 \mathrm{bar})$ and $\mathrm{Ba}\left[\mathrm{N}\left(\mathrm{Si}^{i} \mathrm{Pr}_{3}\right)_{2}\right]_{2}(1 \mathrm{~mol} \%)$ as catalyst precursor at $120{ }^{\circ} \mathrm{C}$ for 24 hours. 


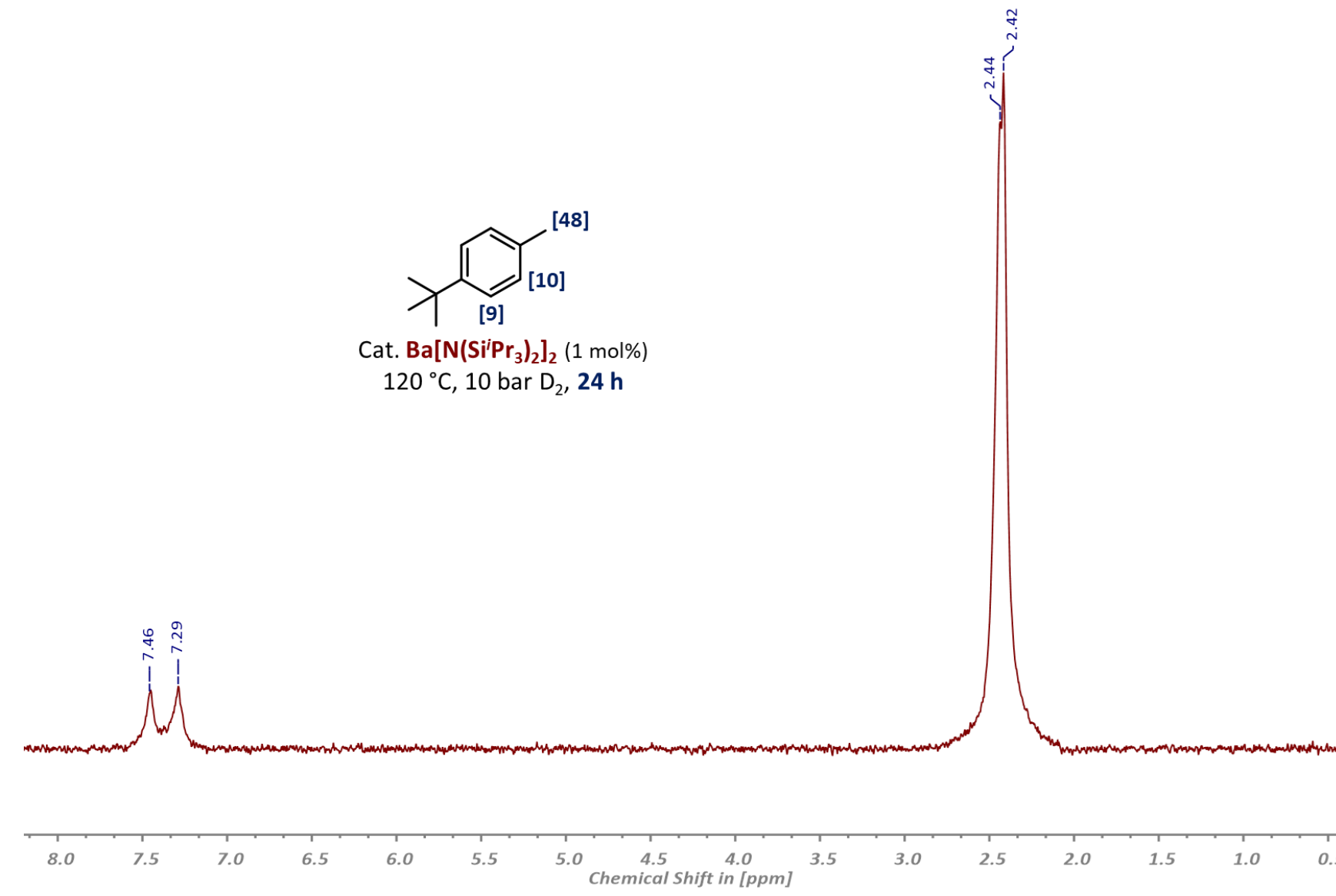

Figure S96. ${ }^{2} \mathrm{H}\left\{{ }^{1} \mathrm{H}\right\}$ NMR spectrum $\left(92 \mathrm{MHz}, \mathrm{CHCl}_{3}, 25^{\circ} \mathrm{C}\right.$ ) of the catalytically deuterated 4-tert-butyltoluene product obtained after the deuteration with $\mathrm{D}_{2}(10 \mathrm{bar})$ and $\mathrm{Ba}\left[\mathrm{N}\left(\mathrm{Si}^{i} \mathrm{Pr}_{3}\right)_{2}\right]_{2}(1 \mathrm{~mol} \%)$ as catalyst precursor at $120{ }^{\circ} \mathrm{C}$ for 24 hours. 

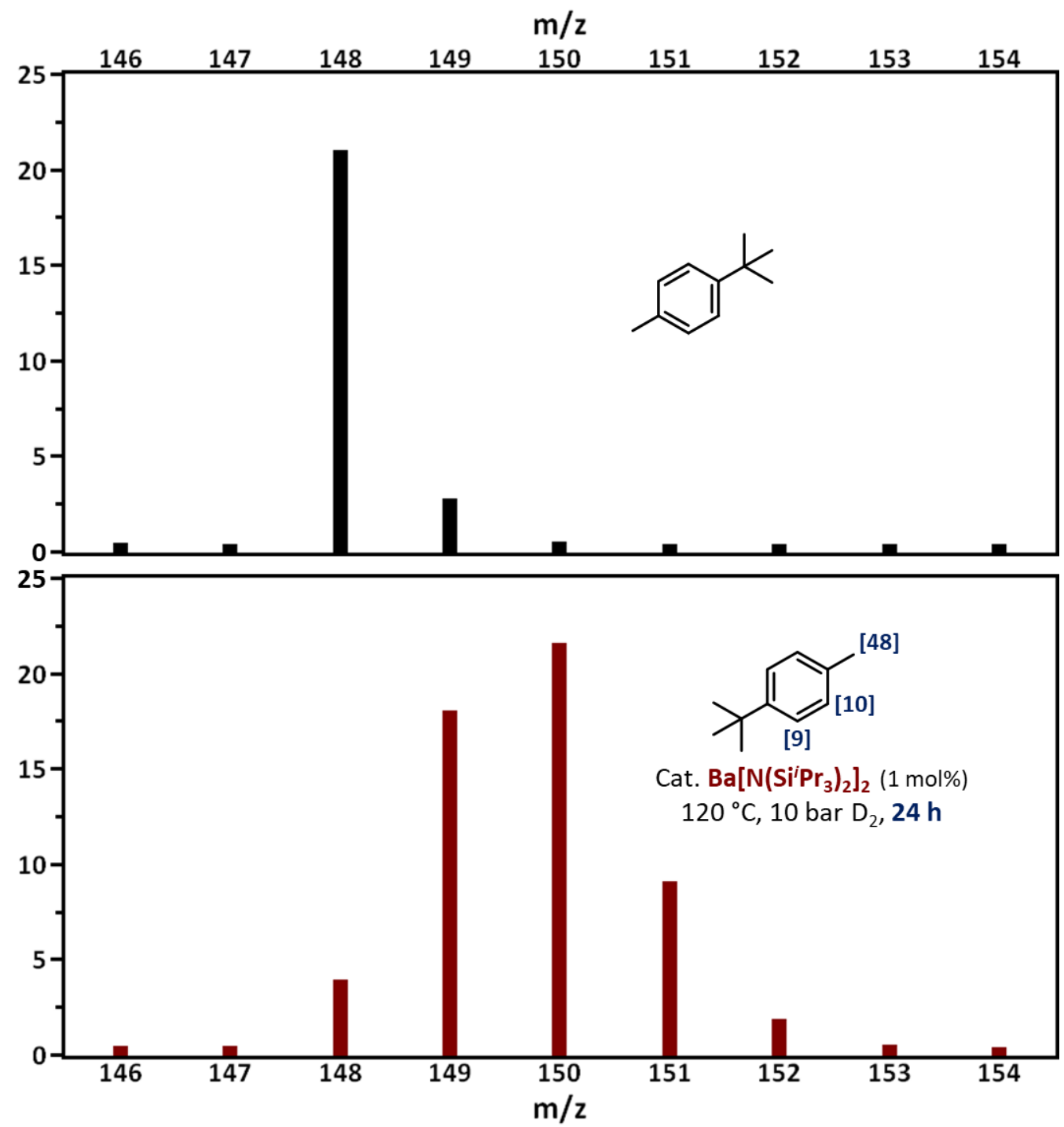

Figure S97. Stacked mass spectra of (top) the authentic 4-tert-butyltoluene substrate and (bottom) the distilled deuterium-labeled product after the catalytic deuteration using $D_{2}$ (10 bar) as deuterium source and $\mathrm{Ba}\left[\mathrm{N}\left(\mathrm{Si}^{\mathrm{i}} \mathrm{Pr}_{3}\right)_{2}\right]_{2}(1 \mathrm{~mol} \%)$ as catalyst precursor at $120{ }^{\circ} \mathrm{C}$ for 24 hours. 
(a)

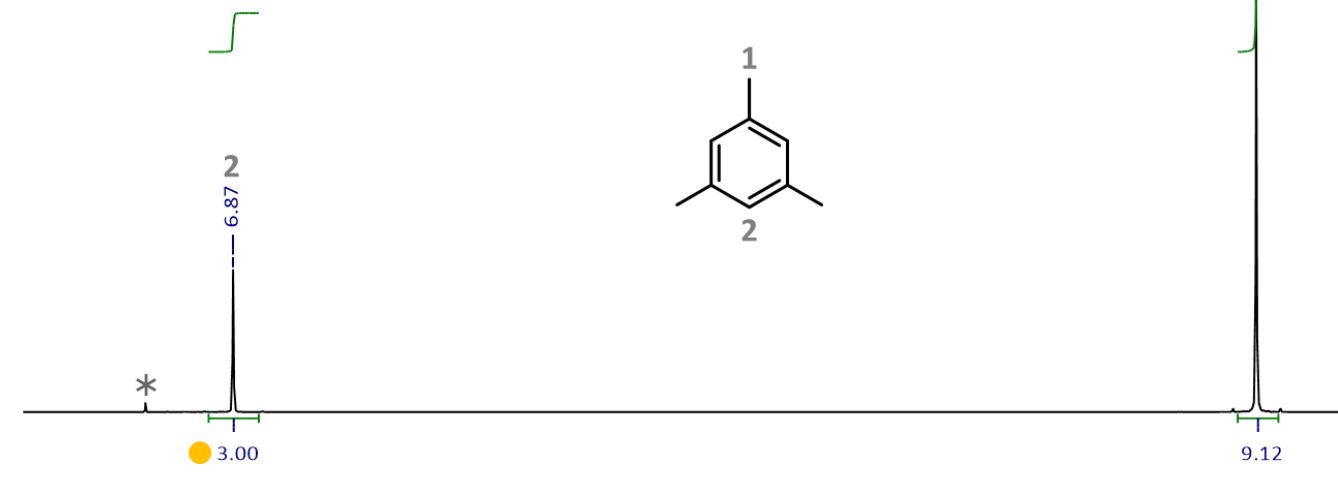

(b)

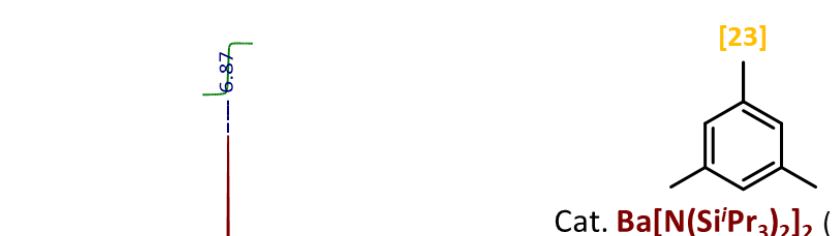

$120^{\circ} \mathrm{C}, 10$ bar $\mathrm{D}_{2}, 4 \mathrm{~h}$

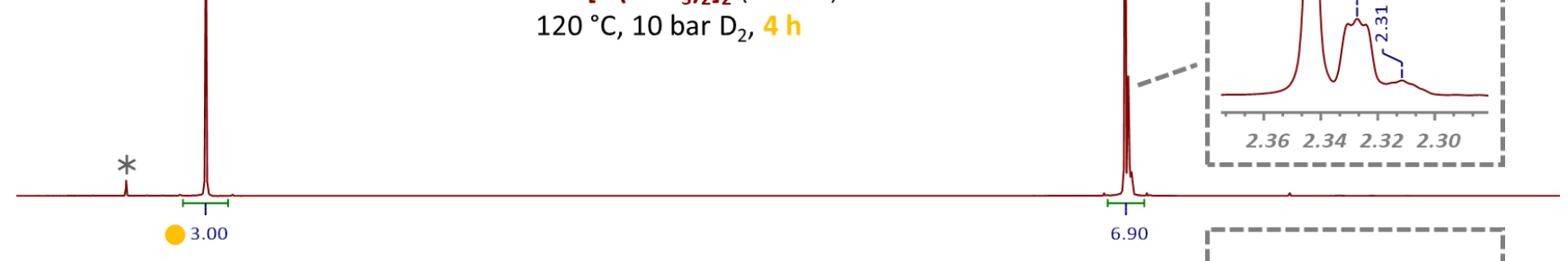

(c)

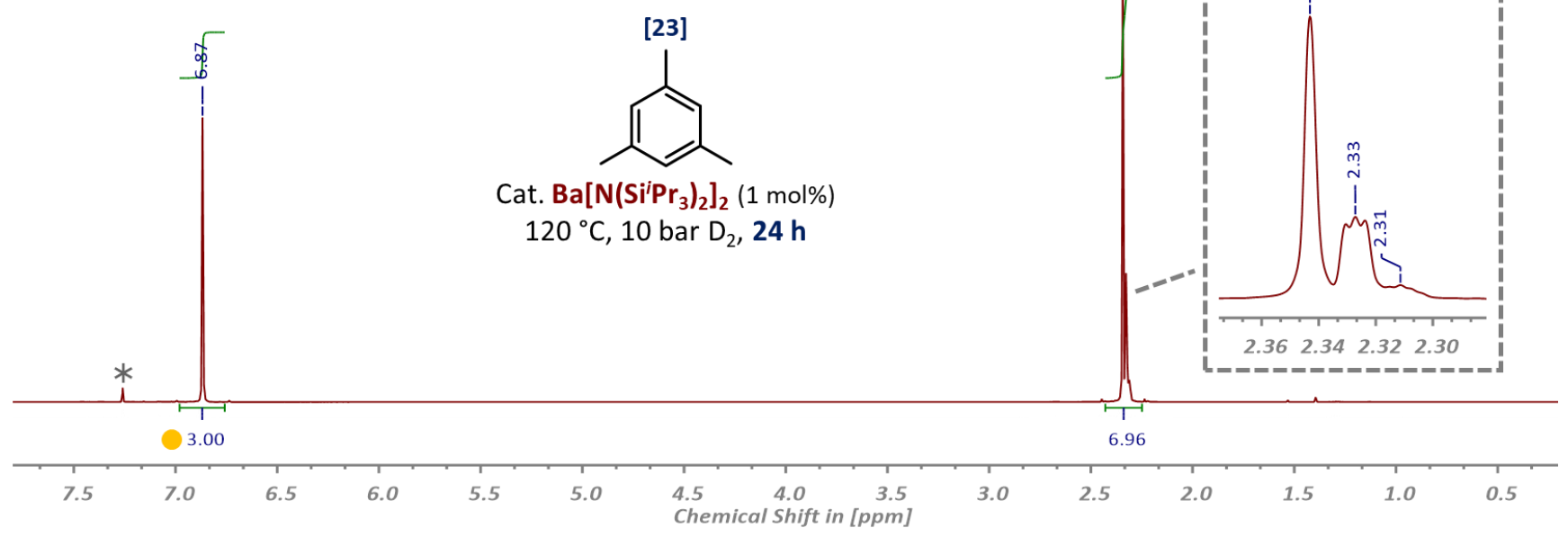

Figure S98. Stacked ${ }^{1} \mathrm{H}$ NMR spectra $\left(600 \mathrm{MHz}, \mathrm{CDCl}_{3}, 25^{\circ} \mathrm{C}\right)$ of $(a)$ the authentic mesitylene substrate and the purified deuterium-labeled products obtained after the catalytic deuteration with $\mathrm{D}_{2}\left(10 \mathrm{bar}\right.$ ) and $\mathrm{Ba}\left[\mathrm{N}\left(\mathrm{Si}^{i} \mathrm{Pr}_{3}\right)_{2}\right]_{2}$ ( 1 mol\%) as catalyst precursor at $120^{\circ} \mathrm{C}$ for $(b) 4$ and $(c) 24$ hours, respectively. 

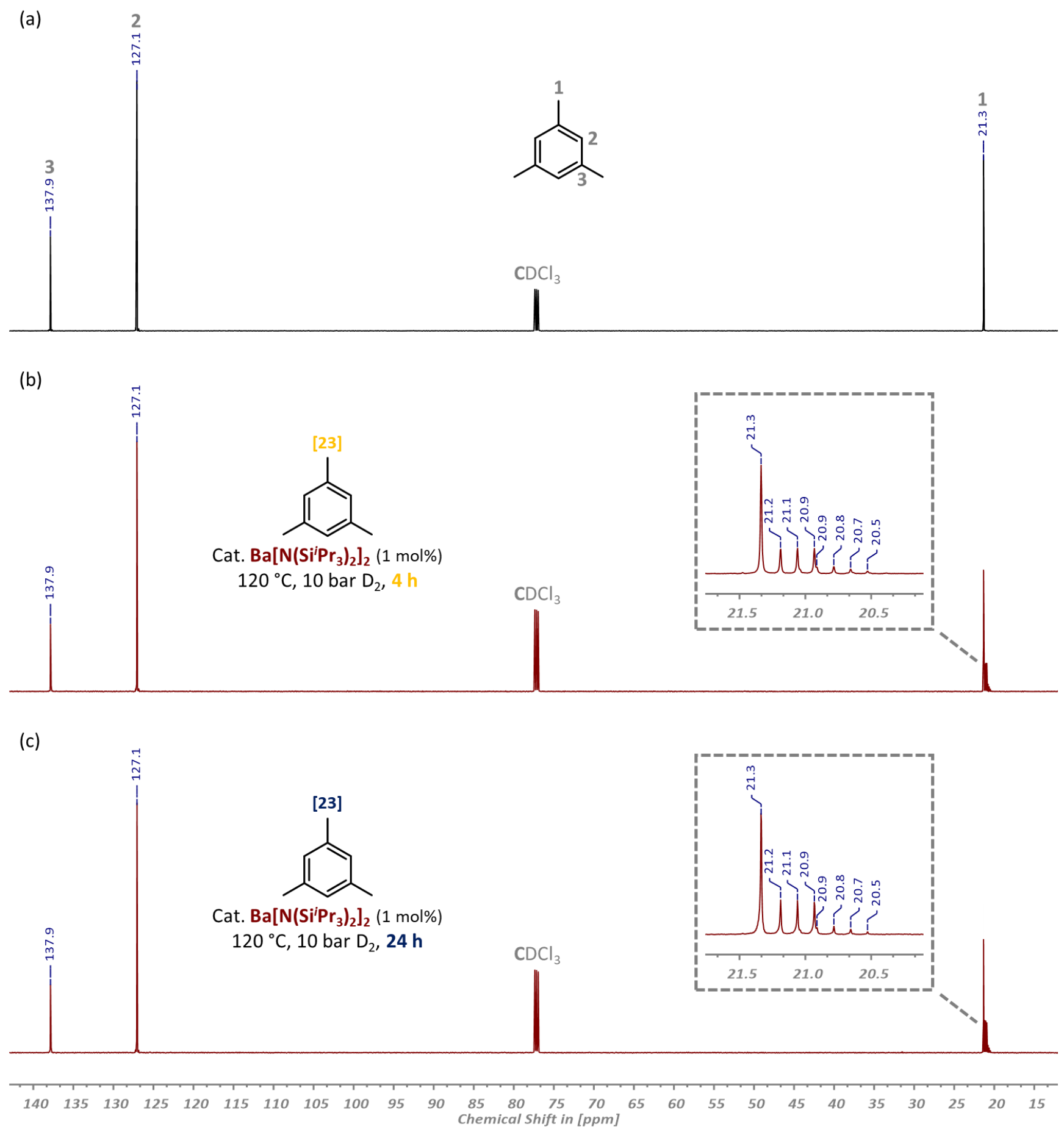

Figure 599. Stacked ${ }^{13} \mathrm{C}\left\{{ }^{1} \mathrm{H}\right\}$ NMR spectra $\left(151 \mathrm{MHz}, \mathrm{CDCl}_{3}, 25^{\circ} \mathrm{C}\right)$ of $(a)$ the unlabeled mesitylene substrate and the purified deuterated products isolated after the catalytic deuteration with $\mathrm{D}_{2}\left(10\right.$ bar) and $\mathrm{Ba}\left[\mathrm{N}\left(\mathrm{Si}^{i} \mathrm{Pr}_{3}\right)_{2}\right]_{2}$ ( $1 \mathrm{~mol} \%$ ) as catalyst precursor at $120^{\circ} \mathrm{C}$ for $(b) 4$ and $(c) 24$ hours, respectively. 
(a)

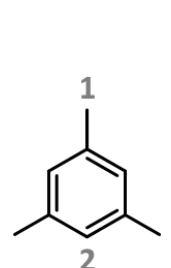

กั

(b)

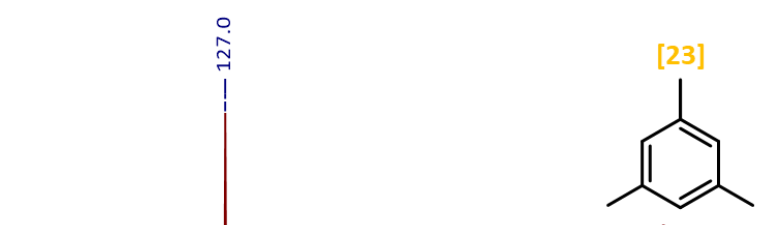

Cat. $\mathrm{Ba}\left[\mathrm{N}\left(\mathrm{Si}^{\mathrm{P}} \mathrm{Pr}_{3}\right)_{2}\right]_{2}(1 \mathrm{~mol} \%)$

$120^{\circ} \mathrm{C}, 10$ bar $\mathrm{D}_{2}, 4 \mathrm{~h}$

(c)

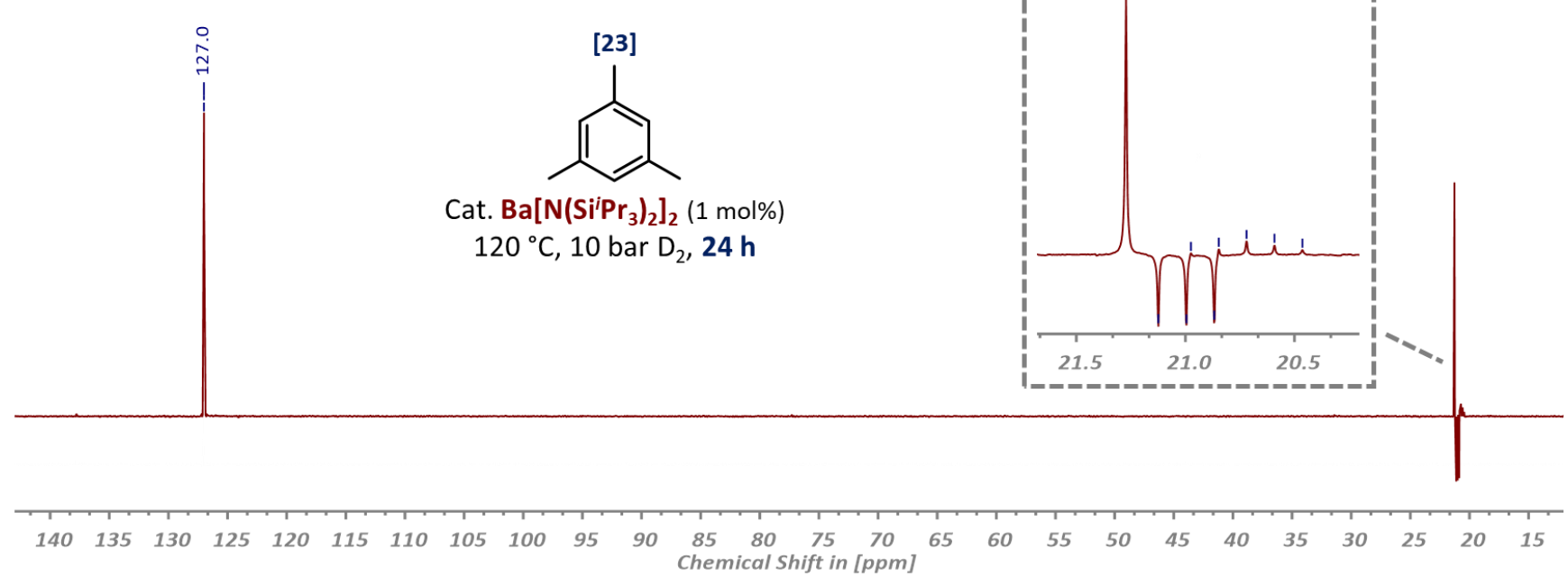

Figure S100. Stacked ${ }^{13} \mathrm{C}$ DEPT-135 NMR spectra $\left(151 \mathrm{MHz}, \mathrm{CDCl}_{3}, 25^{\circ} \mathrm{C}\right)$ of $(a)$ the commercial mesitylene starting material and the deuterium-labeled products obtained after the catalytic deuteration with $\mathrm{D}_{2}(10$ bar) and $\mathrm{Ba}\left[\mathrm{N}\left(\mathrm{Si}^{i} \mathrm{Pr}_{3}\right)_{2}\right]_{2}(1 \mathrm{~mol} \%)$ as pre-catalyst at $120^{\circ} \mathrm{C}$ for $(b) 4$ and $(c) 24$ hours, respectively. 


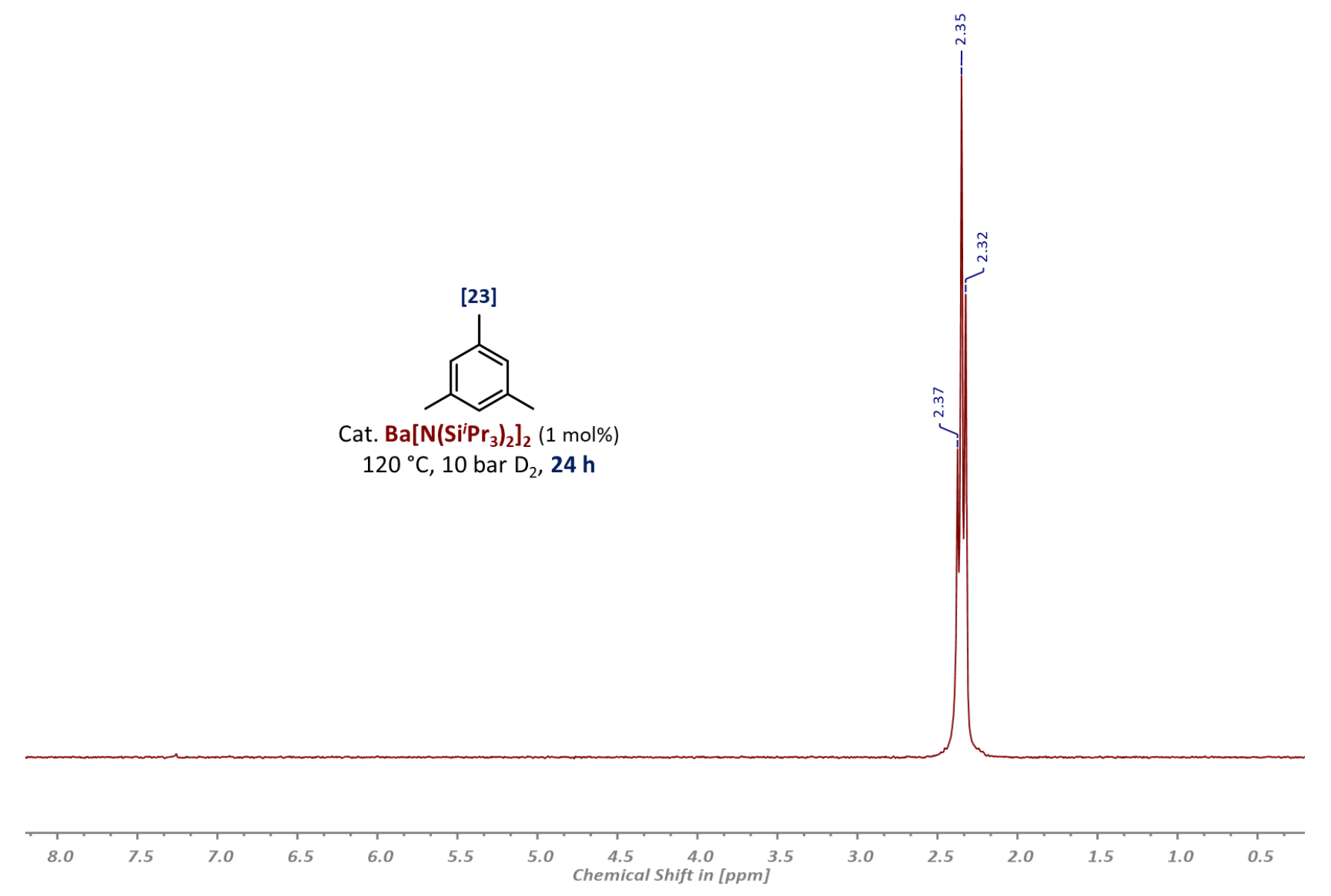

Figure $\mathrm{S} 101 .{ }^{2} \mathrm{H}\left\{{ }^{1} \mathrm{H}\right\} \mathrm{NMR}$ spectrum $\left(92 \mathrm{MHz}, \mathrm{CHCl}_{3}, 25^{\circ} \mathrm{C}\right)$ of the catalytically deuterated product isolated after the deuteration of 1,3,5-trimethylbenzene with $\mathrm{D}_{2}(10 \mathrm{bar})$ and $\mathrm{Ba}\left[\mathrm{N}\left(\mathrm{Si}^{i} \mathrm{Pr}_{3}\right)_{2}\right]_{2}(1 \mathrm{~mol} \%)$ as catalyst precursor at $120^{\circ} \mathrm{C}$ for 24 hours. 

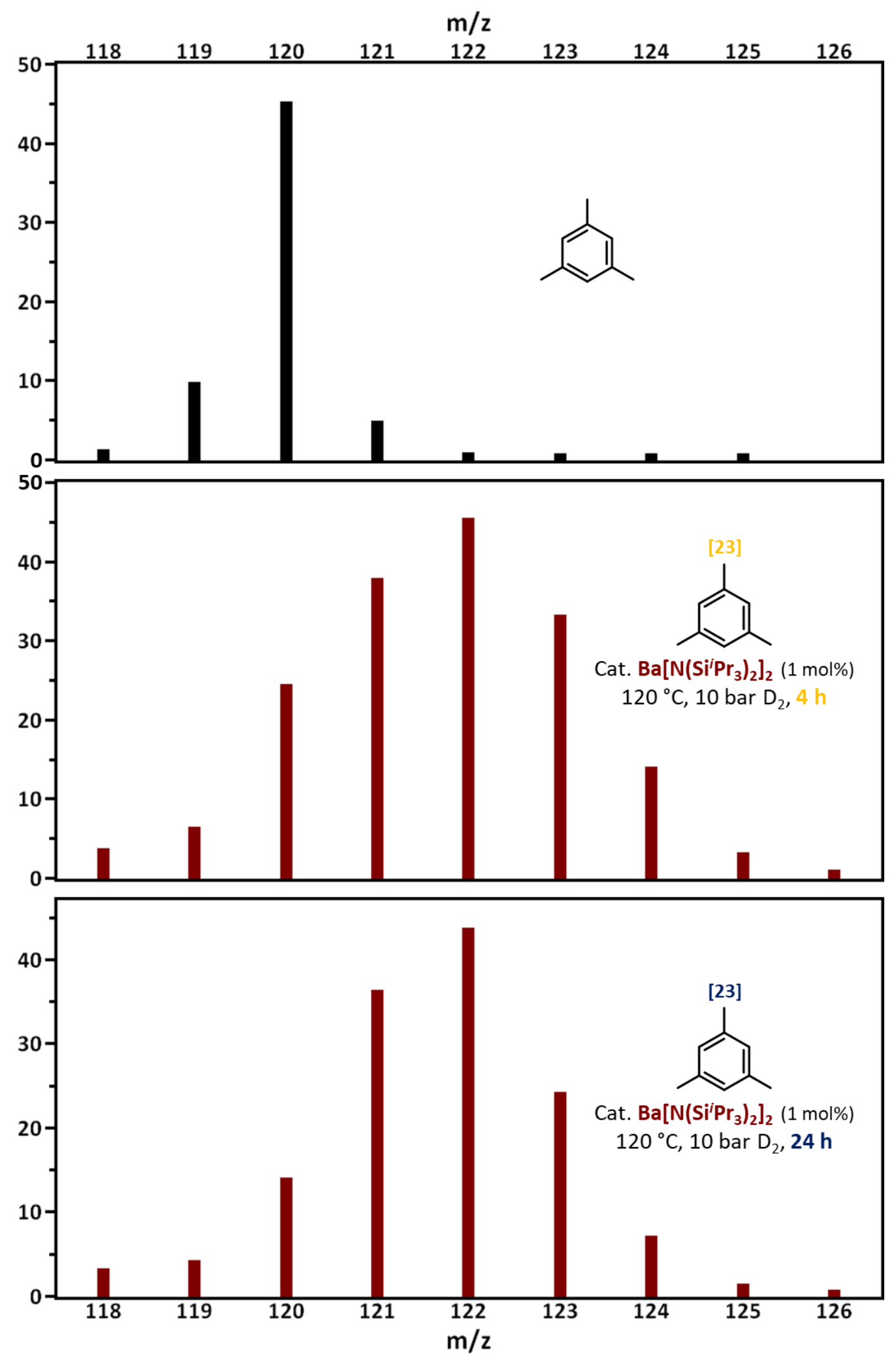

Figure S102. Stacked mass spectra of (top) the all-protio mesitylene substrate and the partially deuterated products isolated after the catalytic deuteration with $\mathrm{D}_{2}(10 \mathrm{bar})$ and $\mathrm{Ba}\left[\mathrm{N}\left(\mathrm{Si}^{i} \mathrm{Pr}_{3}\right)_{2}\right]_{2}(1 \mathrm{~mol} \%)$ as pre-catalyst at $120^{\circ} \mathrm{C}$ for (center) 4 and (bottom) 24 hours, respectively. 


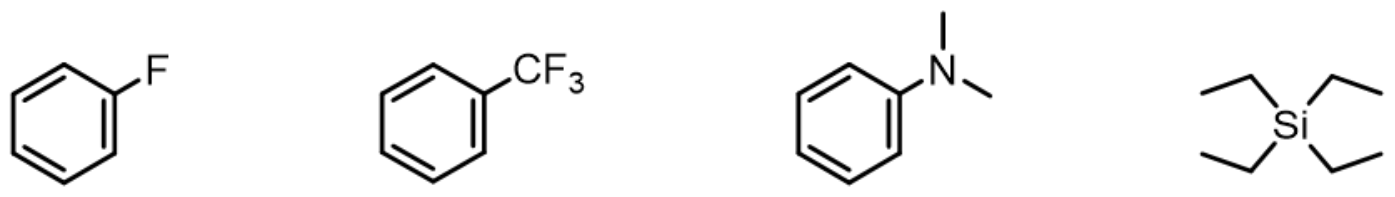

Figure S103. Inefficient substrates for [Ba]-catalyzed H/D exchange. 


\section{Hydrogen Isotope Exchange in Ferrocene}

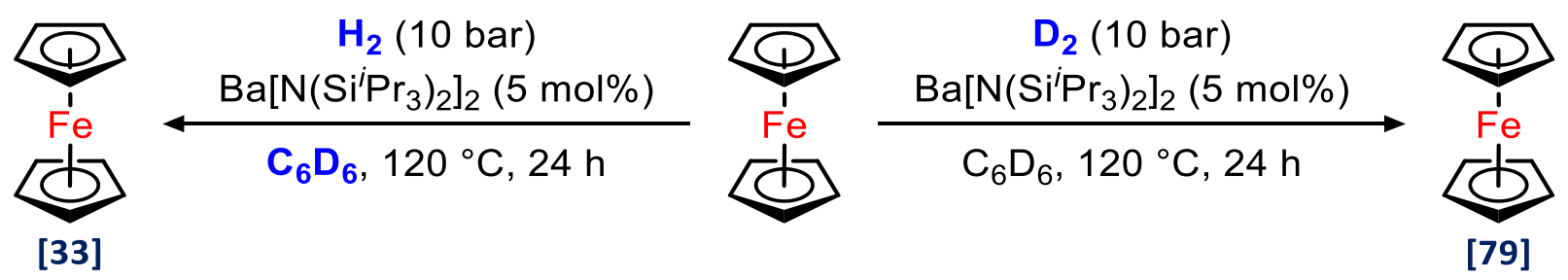

Under an atmosphere of $\mathrm{N}_{2}$, ferrocene $\left(93 \mathrm{mg}, 0.5 \mathrm{mmol}\right.$ ) and crystalline $\mathrm{Ba}\left[\mathrm{N}\left(\mathrm{Si}^{i} \mathrm{Pr}_{3}\right)_{2}\right]_{2}(20 \mathrm{mg}, 25 \mu \mathrm{mol}$, 5 mol\%) were dissolved in $\mathrm{C}_{6} \mathrm{D}_{6}(1 \mathrm{~mL})$ in an oven-dried miniature stainless steel autoclave $(15 \mathrm{~mL})$ containing a magnetic stir bar. The sealed reactor was then removed from the glovebox and attached to a vacuum / $N_{2}$ manifold and a $D_{2}$ gas cylinder. After evacuating and refilling the supply line successively with $N_{2}$ and $D_{2}$ three times each, $D_{2}$ (10 bar) was administered into the pressure vessel, which was re-sealed and heated at $120^{\circ} \mathrm{C}$ in a preheated aluminum block. The reaction mixture was then stirred at $120^{\circ} \mathrm{C}$ for 24 hours, after which time the autoclave was left to cool to room temperature and vented. Upon dilution with dichloromethane $(4 \mathrm{~mL})$ and filtration through a glass microfiber filter in a Pasteur pipette, the reaction mixture was treated with a concentrated hydrochloric acid solution (1.5 $\mathrm{mL})$ in order to remove ( $\left.{ }^{2} \mathrm{Pr}_{3} \mathrm{Si}\right)_{2} \mathrm{ND}$ as byproduct of the catalyst initiation and decomposition. The organic layer was separated from the aqueous phase, washed with water $(2 \times 3 \mathrm{~mL})$, dried over $\mathrm{MgSO}_{4}$ and filtered. Following solvent evaporation under reduced pressure, the orange solid residue obtained was purified by vacuum sublimation to afford the pure partially deuterated ferrocene product (68 $\mathrm{mg}$ ) as orange crystals. For determination of the deuterium content by ${ }^{1} \mathrm{H}$ NMR spectroscopy, cyclohexane $(15 \mu \mathrm{L}$, $11.7 \mathrm{mg}, 0.14 \mathrm{mmol}$ ) as internal standard was added to a solution of the resulting ferrocene- $\mathrm{D}_{n} \mathrm{H}_{10-n}$ $(n=0-10)$ product $(15 \mathrm{mg})$ in $\mathrm{CDCl}_{3}(500 \mu \mathrm{L})$. The deuteration level was calculated by comparison of the intensity ratio of the ${ }^{1} \mathrm{H}$ NMR signals of the partially deuterated ferrocene product and the internal cyclohexane standard with the corresponding intensity ratio of the all-protio ferrocene substrate. In addition, GC/MS analysis was carried out to qualitatively verify the deuterium incorporation.

The $\mathrm{H} / \mathrm{D}$ scrambling reaction between ferrocene $\left(93 \mathrm{mg}, 0.5 \mathrm{mmol}, 1\right.$ equiv.) and $\mathrm{C}_{6} \mathrm{D}_{6}(1 \mathrm{~mL}, 950 \mathrm{mg}$, $11.29 \mathrm{mmol}, 22.6$ equiv.) was carried out with $\mathrm{Ba}\left[\mathrm{N}\left(\mathrm{Si}^{i} \mathrm{Pr}_{3}\right)_{2}\right]_{2}(20 \mathrm{mg}, 25 \mu \mathrm{mol}, 5 \mathrm{~mol} \%)$ as catalyst precursor by the aforementioned procedure except that $\mathrm{H}_{2}$ gas (10 bar) was used in place of $\mathrm{D}_{2}$ gas. The experiment revealed that deuterium from $C_{6} D_{6}$ was incorporated into ferrocene. The reaction product (72 mg) was purified and isolated in the same manner and sampled for NMR analysis as stated above. 
${ }^{1} \mathrm{H}$ NMR integration based on the internal standard established an average percentage of deuterium incorporation at ferrocene of $33 \%$. 


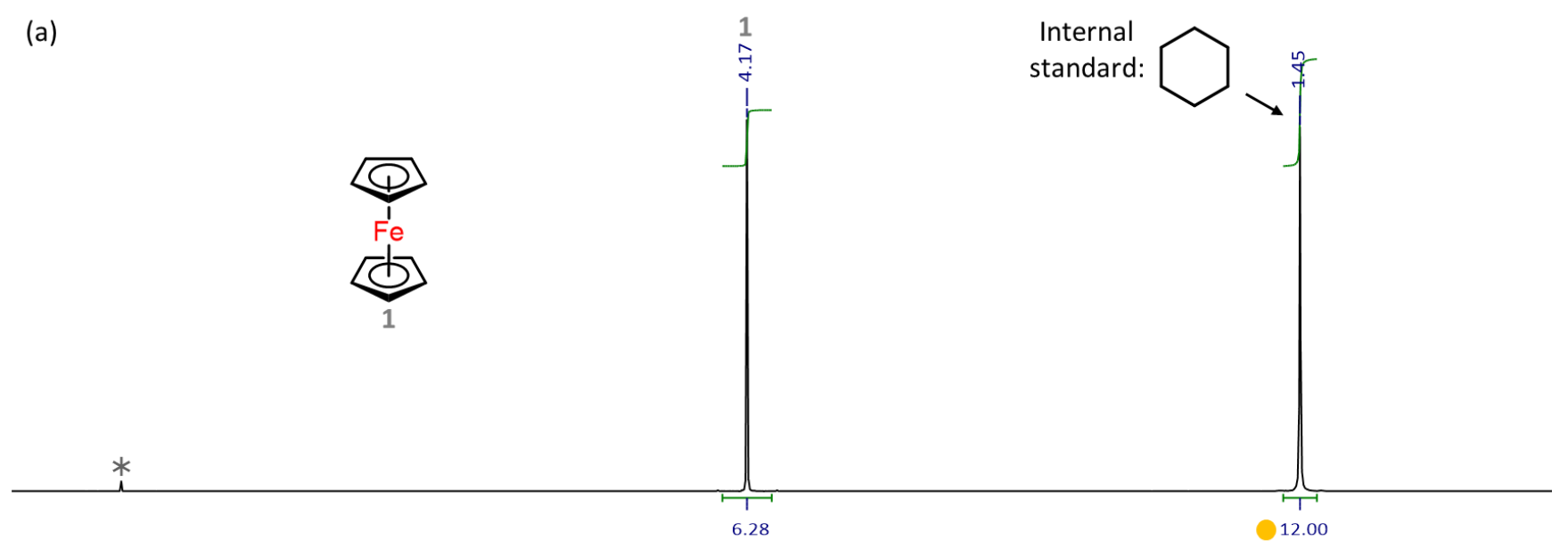

(b)

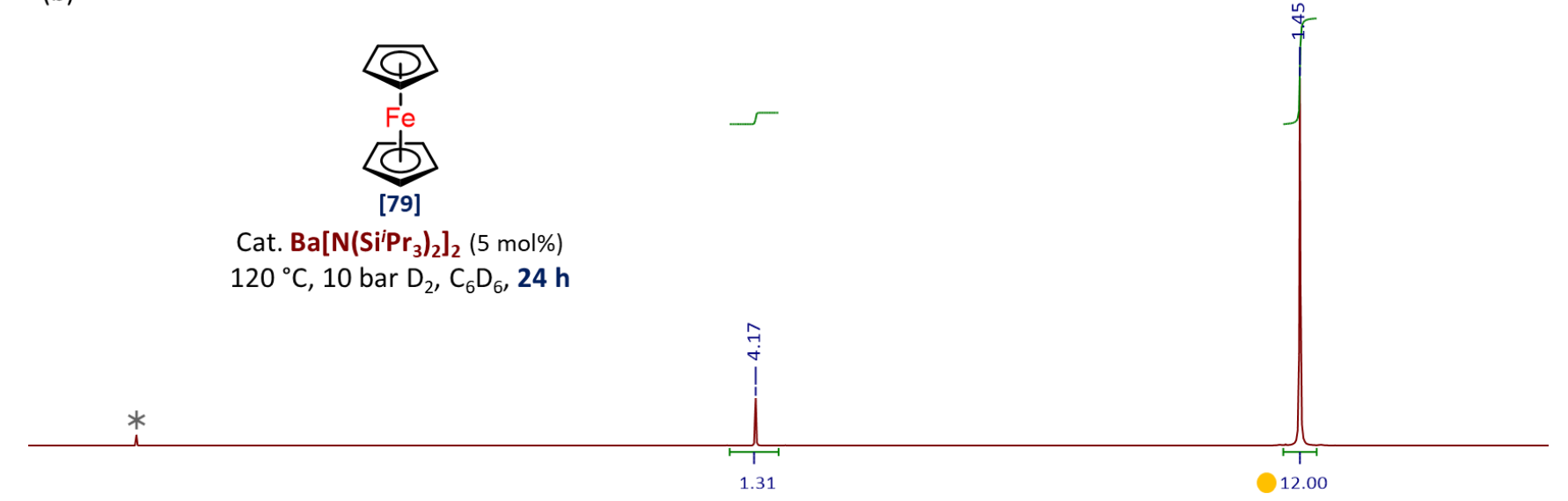

(c)

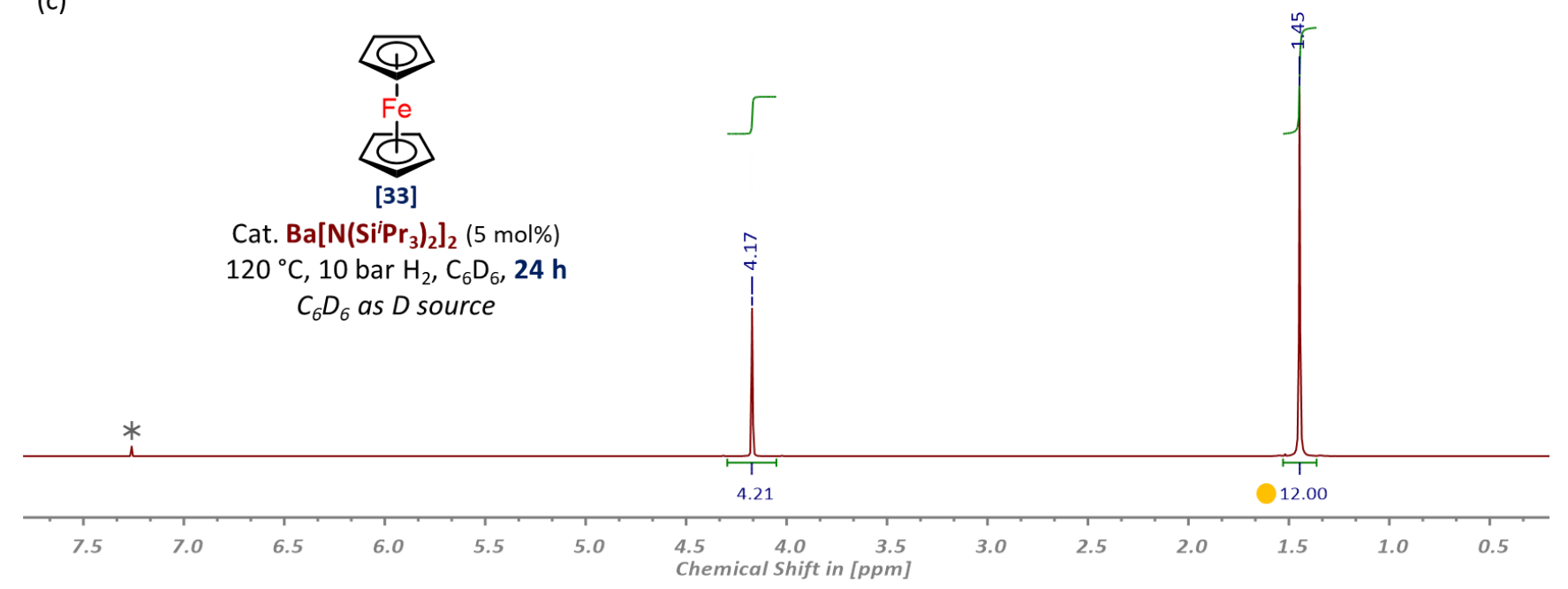

Figure S104. Stacked ${ }^{1} \mathrm{H}$ NMR spectra $\left(600 \mathrm{MHz}, \mathrm{CDCl}_{3}, 25^{\circ} \mathrm{C}\right)$ of $(a)$ the all-protio ferrocene substrate and the purified deuterium-labeled products isolated after $(b)$ the catalytic deuteration with $\mathrm{D}_{2}(10 \mathrm{bar})$ and $(c)$ the H/D scrambling reaction with $\mathrm{C}_{6} \mathrm{D}_{6}$ and $\mathrm{H}_{2}(10 \mathrm{bar})$ at $120{ }^{\circ} \mathrm{C}$ for 24 hours using $\mathrm{Ba}\left[\mathrm{N}\left(\mathrm{Si}^{i} \mathrm{Pr}_{3}\right)_{2}\right]_{2}(1 \mathrm{~mol} \%)$ as catalyst precursor in each case. 


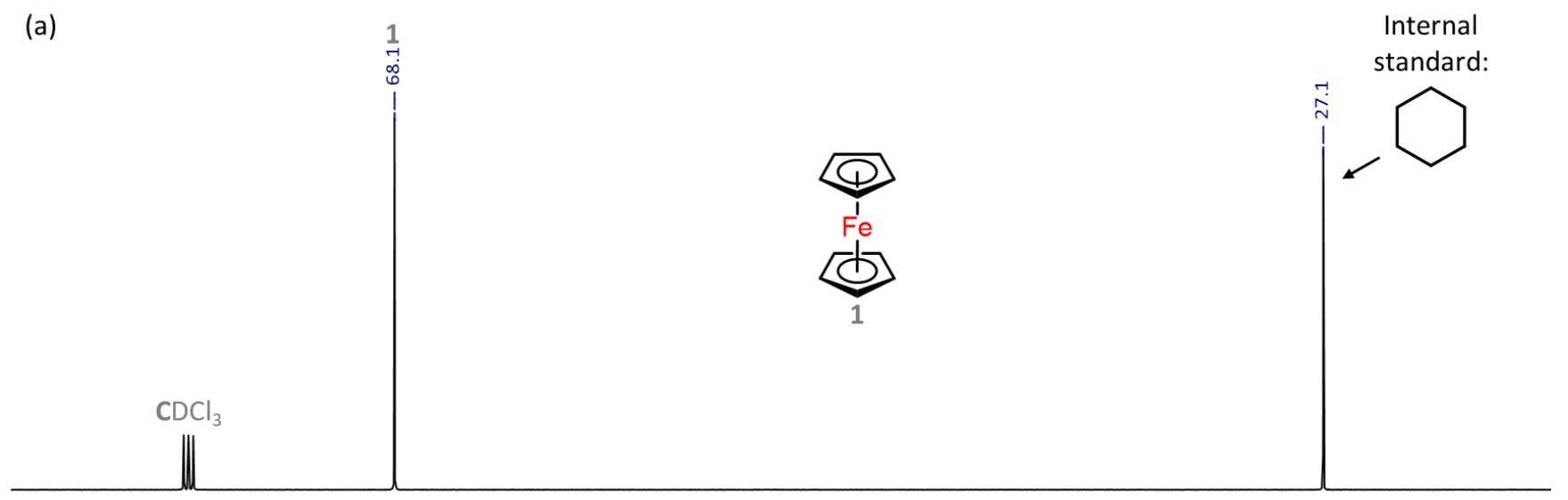

(b)
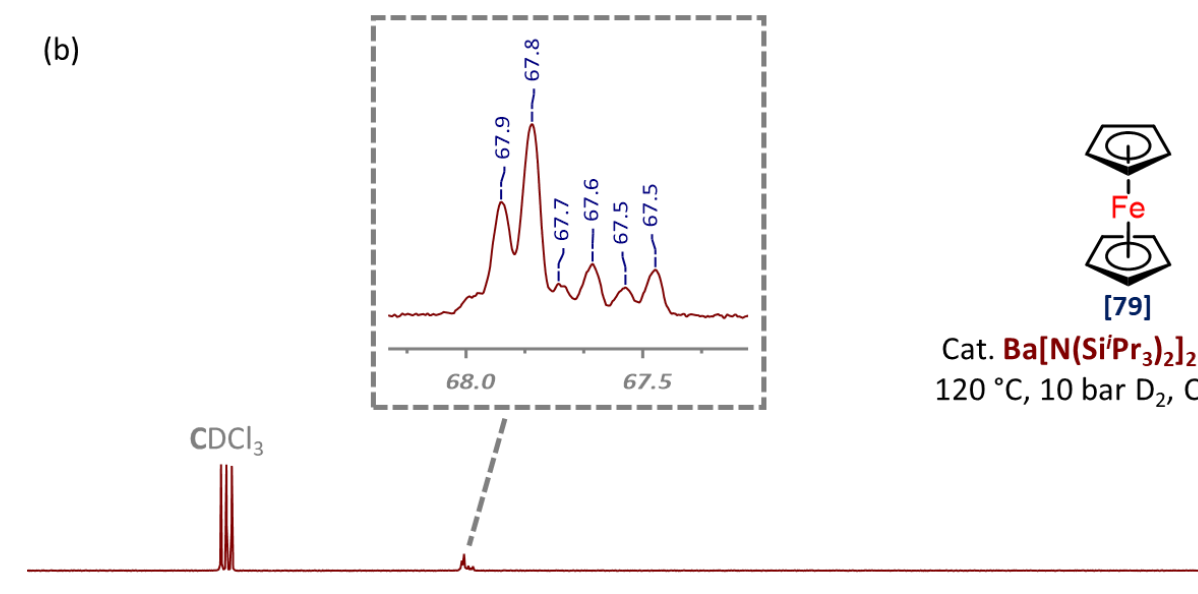

Cat. $\mathrm{Ba}\left[\mathrm{N}\left(\mathrm{Si}^{\mathrm{i} P \mathrm{Pr}_{3}}\right)_{2}\right]_{2}(5 \mathrm{~mol} \%)$ $120^{\circ} \mathrm{C}, 10$ bar $\mathrm{D}_{2}, \mathrm{C}_{6} \mathrm{D}_{6}, 24 \mathrm{~h}$

(c)
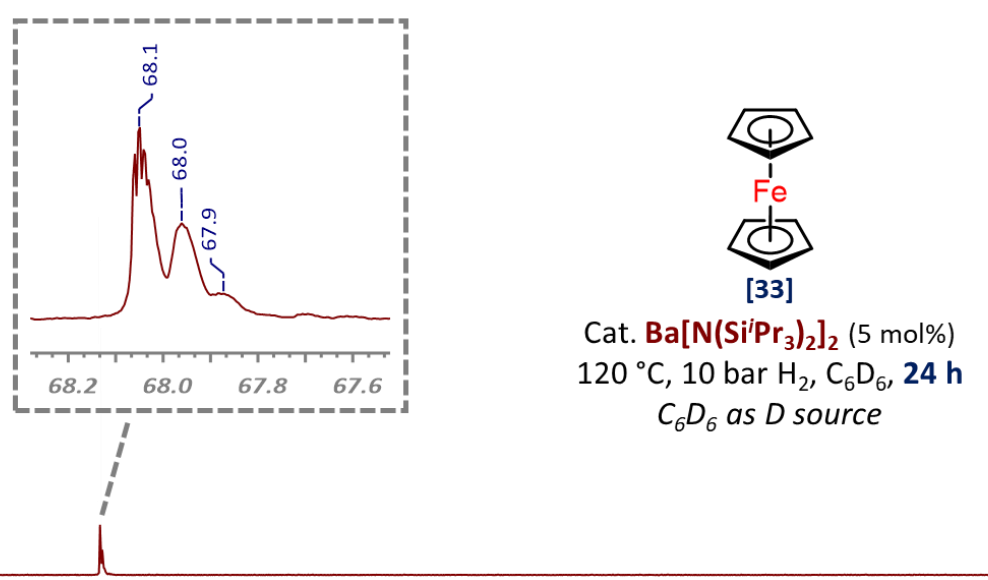

Cat. $\mathrm{Ba}\left[\mathrm{N}\left(\mathrm{Si}^{\mathrm{i} P \mathrm{Pr}_{3}}\right)_{2}\right]_{2}(5 \mathrm{~mol} \%)$ $120^{\circ} \mathrm{C}, 10$ bar $\mathrm{H}_{2}, \mathrm{C}_{6} \mathrm{D}_{6}, 24 \mathrm{~h}$ $C_{6} D_{6}$ as $D$ source
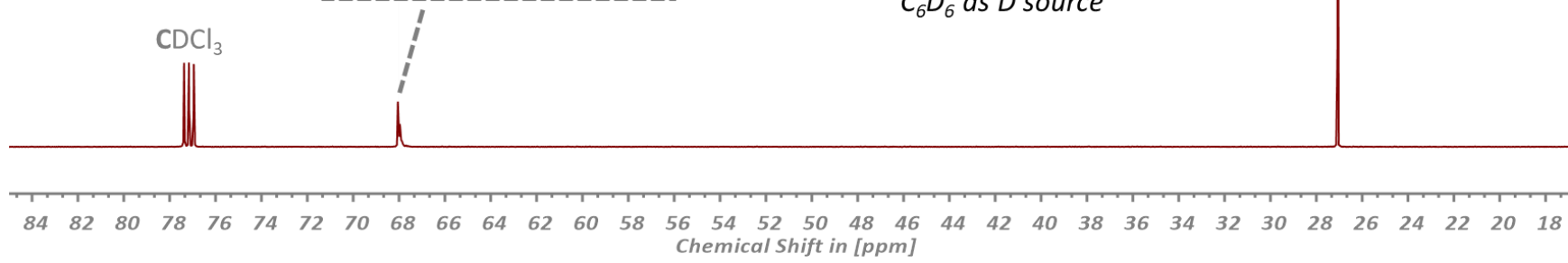

Figure S105. Stacked ${ }^{13} \mathrm{C}\left\{{ }^{1} \mathrm{H}\right\} \mathrm{NMR}$ spectra $\left(151 \mathrm{MHz}, \mathrm{CDCl}_{3}, 25{ }^{\circ} \mathrm{C}\right)$ of $(a)$ the authentic ferrocene substrate and the catalytically deuterated products obtained after $(b)$ the deuteration with $\mathrm{D}_{2}(10 \mathrm{bar})$ and $(c)$ the H/D scrambling reaction with $\mathrm{C}_{6} \mathrm{D}_{6}$ and $\mathrm{H}_{2}(10 \mathrm{bar})$ at $120{ }^{\circ} \mathrm{C}$ for 24 hours using $\mathrm{Ba}\left[\mathrm{N}\left(\mathrm{Si}^{i} \mathrm{Pr}_{3}\right)_{2}\right]_{2}(1 \mathrm{~mol} \%)$ as catalyst precursor in each case. 
(a)

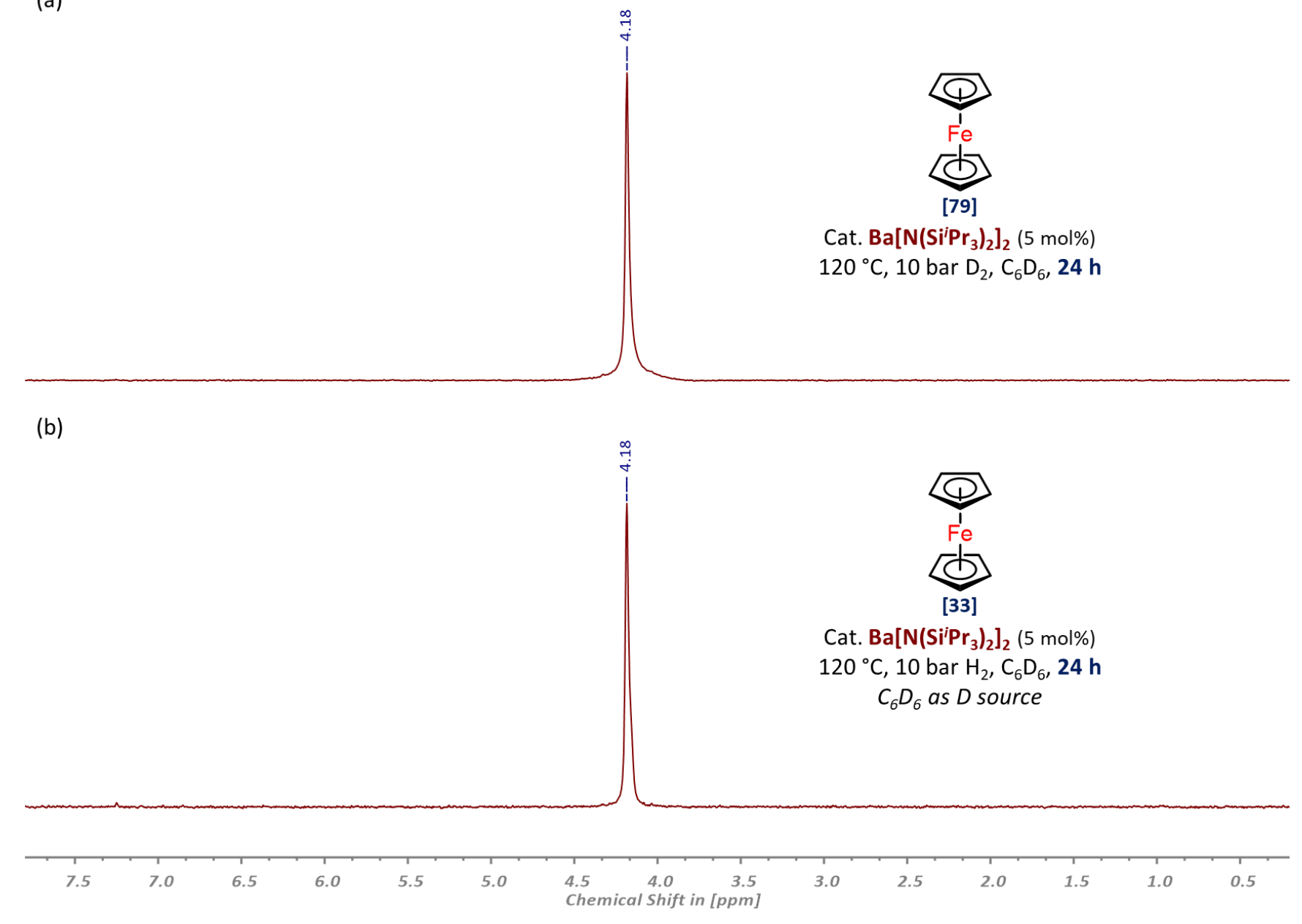

Figure S106. Stacked ${ }^{2} \mathrm{H}\left\{{ }^{1} \mathrm{H}\right\}$ NMR spectra $\left(92 \mathrm{MHz}, \mathrm{CHCl}_{3}, 25^{\circ} \mathrm{C}\right)$ of the purified deuterium-labeled ferrocene products after $(a)$ the catalytic deuteration with $\mathrm{D}_{2}(10 \mathrm{bar})$ and $(b)$ the $\mathrm{H} / \mathrm{D}$ scrambling reaction with $\mathrm{C}_{6} \mathrm{D}_{6}$ and $\mathrm{H}_{2}(10 \mathrm{bar})$ at $120^{\circ} \mathrm{C}$ for 24 hours using $\mathrm{Ba}\left[\mathrm{N}\left(\mathrm{Si}^{\mathrm{i}} \mathrm{Pr}_{3}\right)_{2}\right]_{2}(1 \mathrm{~mol} \%)$ as catalyst precursor in each case. 

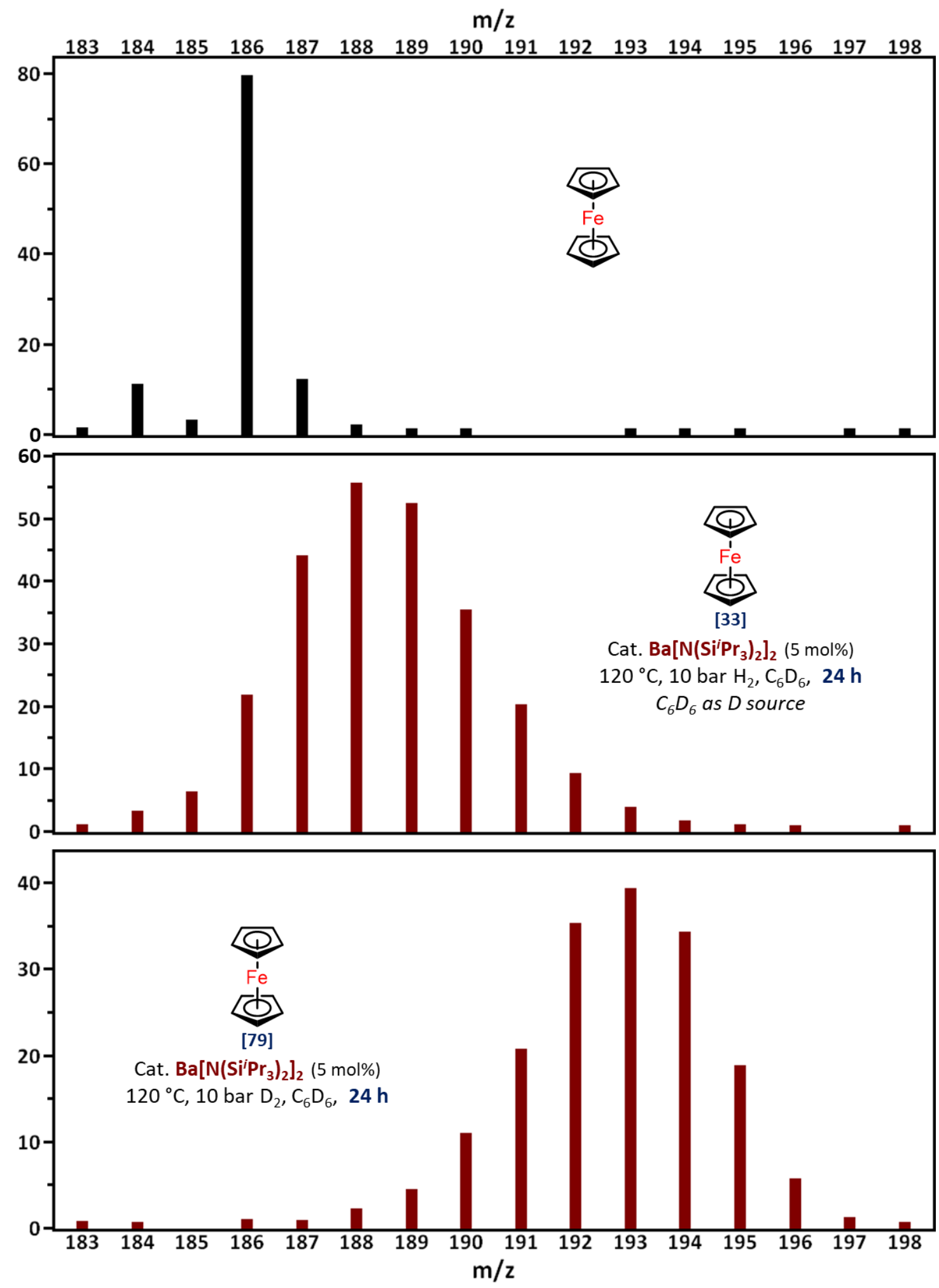

Figure S107. Stacked mass spectra of (top) the natural abundance ferrocene substrate and the sublimed deuterium-labeled products after (center) the $\mathrm{H} / \mathrm{D}$ scrambling reaction with $\mathrm{C}_{6} \mathrm{D}_{6}$ and $\mathrm{H}_{2}(10 \mathrm{bar}$ ) and (bottom) the catalytic deuteration with $\mathrm{D}_{2}(10 \mathrm{bar})$ at $120^{\circ} \mathrm{C}$ for 24 hours using $\mathrm{Ba}\left[\mathrm{N}\left(\mathrm{Si}^{i} \mathrm{Pr}_{3}\right)_{2}\right]_{2}(1 \mathrm{~mol} \%)$ as catalyst precursor in each case. 


\section{Catalytic Deuteration of Silanes}

\section{General Procedure for the Deuteration of Hydrosilanes:}

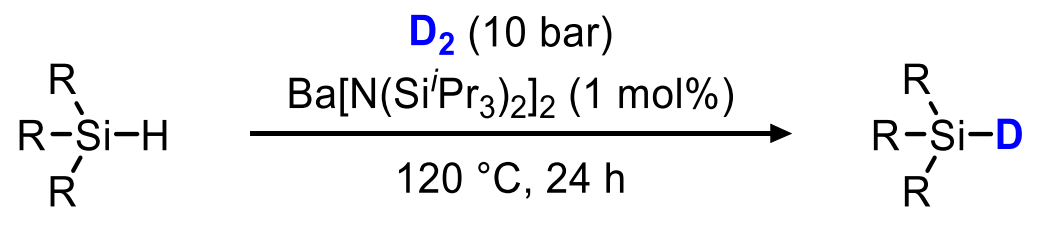

Isotopic exchange reactions in organosilanes were all carried out by the same general procedure. A typical experiment was performed as follows:

In an $\mathrm{N}_{2}$-filled glovebox, an oven-dried miniature stainless steel autoclave $(15 \mathrm{~mL})$ containing a magnetic stir bar was charged with crystalline $\mathrm{Ba}\left[\mathrm{N}\left(\mathrm{Si}^{i} \mathrm{Pr}_{3}\right)_{2}\right]_{2}(36 \mathrm{mg}, 45 \mu \mathrm{mol}, 1 \mathrm{~mol} \%$ ) and the desired hydrosilane $(4.5 \mathrm{mmol})$ was added. The tightly sealed reactor was transferred out of the glovebox and connected to vacuum $/ N_{2}$ manifold and a $D_{2}$ gas cylinder. After the supply line was repeatedly evacuated and refilled several times with $\mathrm{N}_{2}$ and subsequently purged three times with $D_{2}$, the autoclave was pressurized to 10 bars with $D_{2}$ gas. The reaction mixture was then stirred for 24 hours at $120^{\circ} \mathrm{C}$ in a preheated aluminum heating block. At the end of the reaction, the pressure vessel was cooled to room temperature and the reaction quenched by exposure to air. The deuterosilane products were obtained as clear, colorless liquids following trap-to-trap distillation under reduced pressure. The deuteration of $\mathrm{Si}-\mathrm{H}$ bonds was evidenced by ${ }^{1} \mathrm{H},{ }^{2} \mathrm{H}\left\{{ }^{1} \mathrm{H}\right\}$ and ${ }^{29} \mathrm{Si}\left\{{ }^{1} \mathrm{H}\right\}$ NMR spectroscopy, FT-IR spectroscopy and GC/MS analysis. The identities of the deuterated silanes were confirmed by comparison of the obtained spectroscopic data with corresponding data previously reported in the literature. ${ }^{8,9}$ The extent of isotopic incorporation was in each case determined by the decrease of the corresponding ${ }^{1} \mathrm{H} \mathrm{NMR} \mathrm{Si-H}$ signal intensity relative to the resonance signal of the methyl group(s) of the silane alkyl substituent(s), which do not experience any H/D exchange under the present conditions. The deuterium incorporation was further confirmed qualitatively by the appearance of deuterium coupled ${ }^{29} \mathrm{Si}$ resonances in the ${ }^{29} \mathrm{Si}\left\{{ }^{1} \mathrm{H}\right\} \mathrm{NMR}$ spectrum as well as a strong band for $v(\mathrm{Si}-\mathrm{D})$ at around $\tilde{v}=1500 \mathrm{~cm}^{-1}$ in the IR spectrum of the respective silane isotopologues mixture. ${ }^{9}$ 

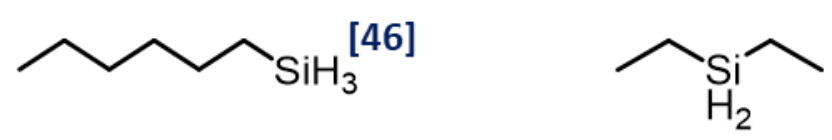

[56]
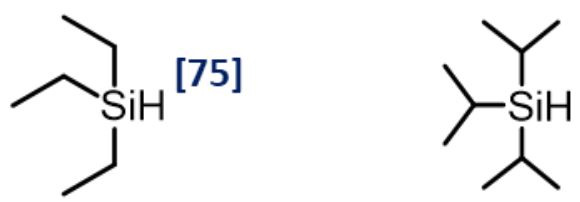

Figure S108. Deuterium labeling of representative hydrosilanes with $\mathrm{D}_{2}$ as deuterium source and $\mathrm{Ba}\left[\mathrm{N}\left(\mathrm{Si}^{i} \mathrm{Pr}_{3}\right)_{2}\right]_{2}$ as catalyst precursor.

General catalytic reaction conditions: neat silane $(4.5 \mathrm{mmol})$, Cat. $\mathrm{Ba}\left[\mathrm{N}\left(\mathrm{Si}^{i} \mathrm{Pr}_{3}\right)_{2}\right]_{2}(36 \mathrm{mg}, 45 \mu \mathrm{mol}, 1 \mathrm{~mol} \%)$, $D_{2}$ (10 bar), $120^{\circ} \mathrm{C}, 24 \mathrm{~h}$. The percentages in parentheses correspond to the extent of deuterium incorporation and were estimated by ${ }^{1} \mathrm{H}$ NMR spectroscopy.

Selected $\left({ }^{1} \mathrm{H},{ }^{29} \mathrm{Si}\left\{{ }^{1} \mathrm{H}\right\}\right.$ and $\left.{ }^{2} \mathrm{H}\left\{{ }^{1} \mathrm{H}\right\}\right)$ NMR, IR, and Mass Spectra 
(a)
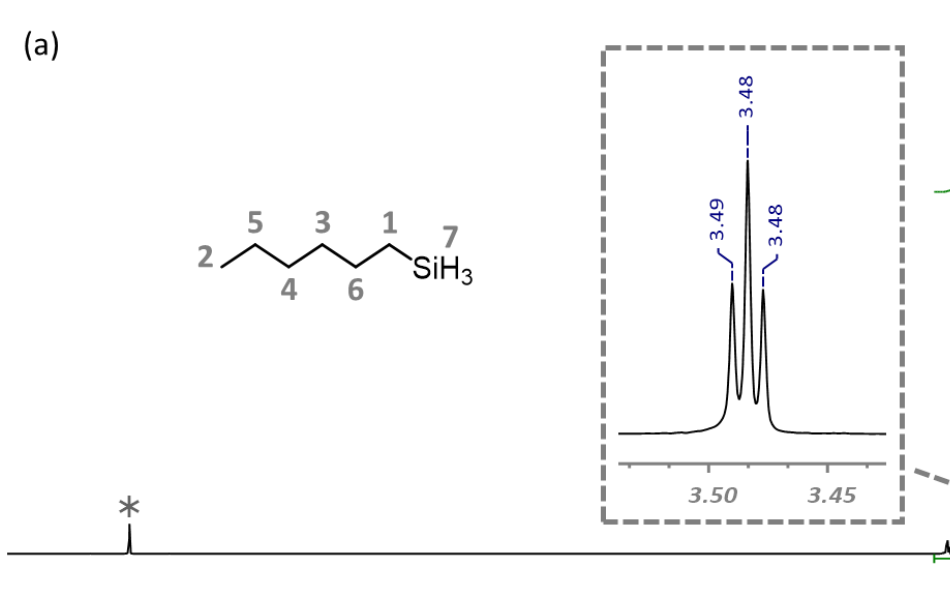

(b)
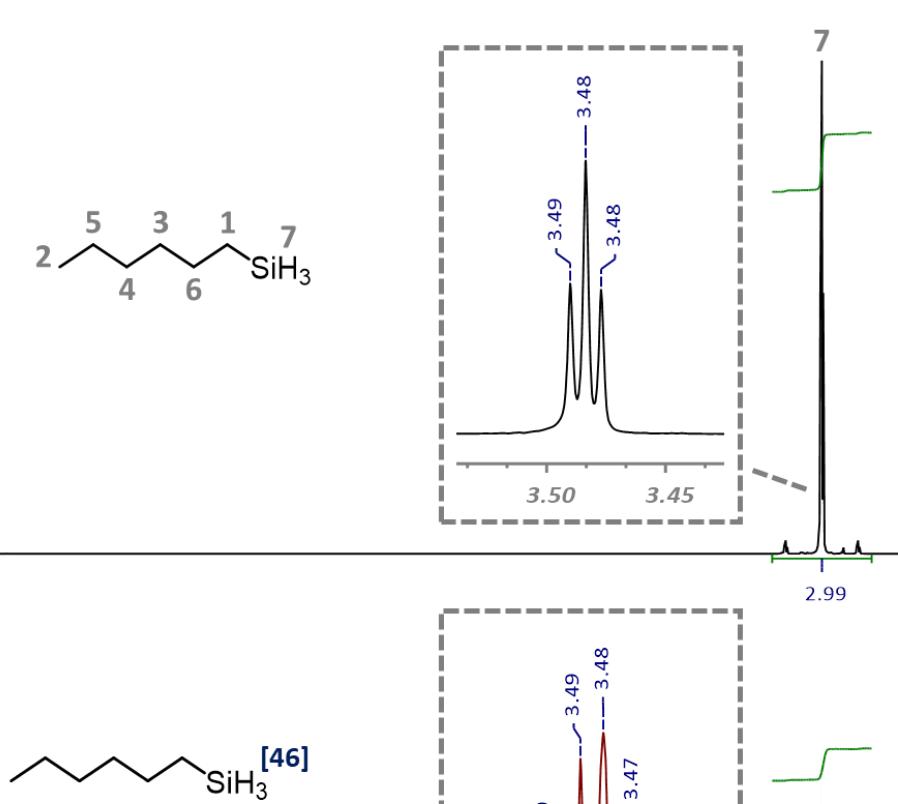

Cat. $\mathrm{Ba}\left[\mathrm{N}\left(\mathrm{Si}^{\mathrm{P}} \mathrm{Pr}_{3}\right)_{2}\right]_{2}(1 \mathrm{~mol} \%)$ $120^{\circ} \mathrm{C}, 10$ bar $\mathrm{D}_{2}, \mathbf{2 4} \mathrm{h}$
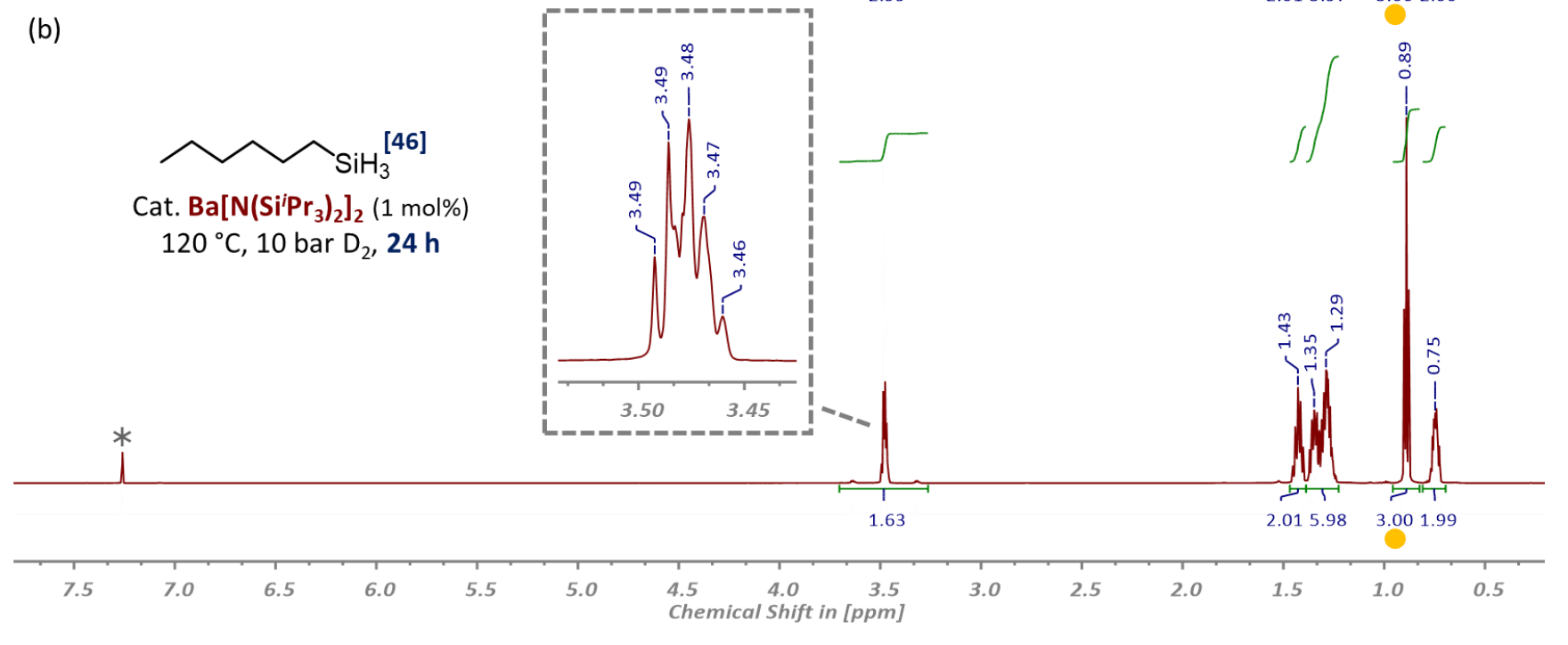

Figure S109. Stacked ${ }^{1} \mathrm{H}$ NMR spectra $\left(600 \mathrm{MHz}, \mathrm{CDCl}_{3}, 25^{\circ} \mathrm{C}\right)$ of $(a)$ the authentic $n$-hexylsilane substrate and (b) the purified deuterated product obtained after the catalytic deuteration with $\mathrm{D}_{2}$ (10 bar) and $\mathrm{Ba}\left[\mathrm{N}\left(\mathrm{Si}^{\mathrm{i}} \mathrm{Pr}_{3}\right)_{2}\right]_{2}$ (1 mol\%) as catalyst precursor at $120^{\circ} \mathrm{C}$ for 24 hours. 
(a)

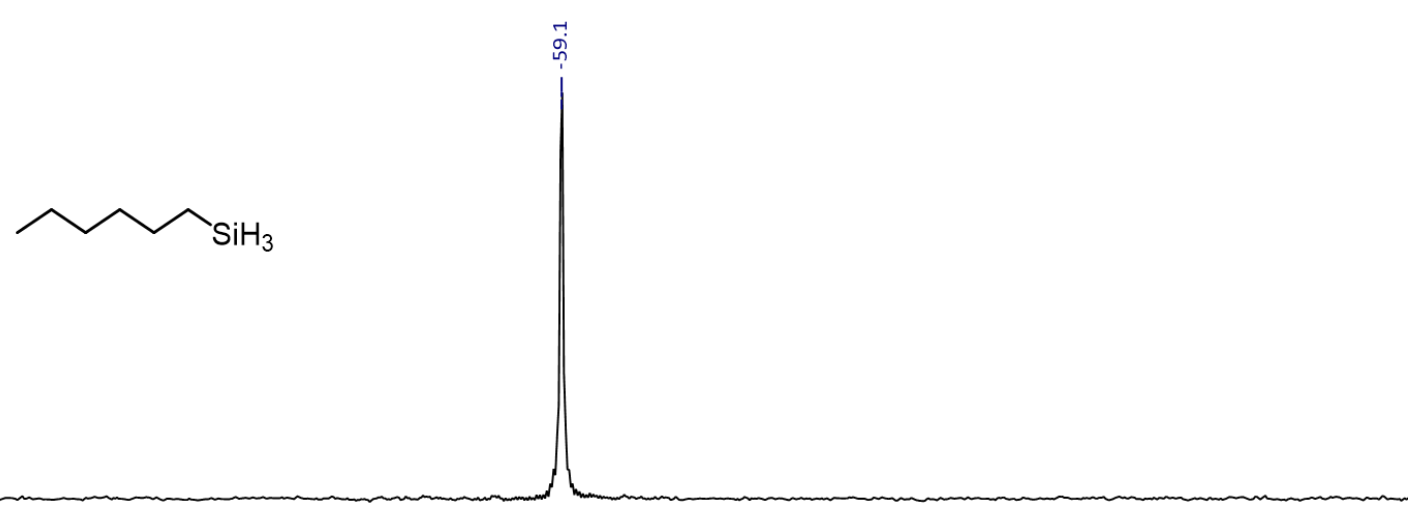

(b)

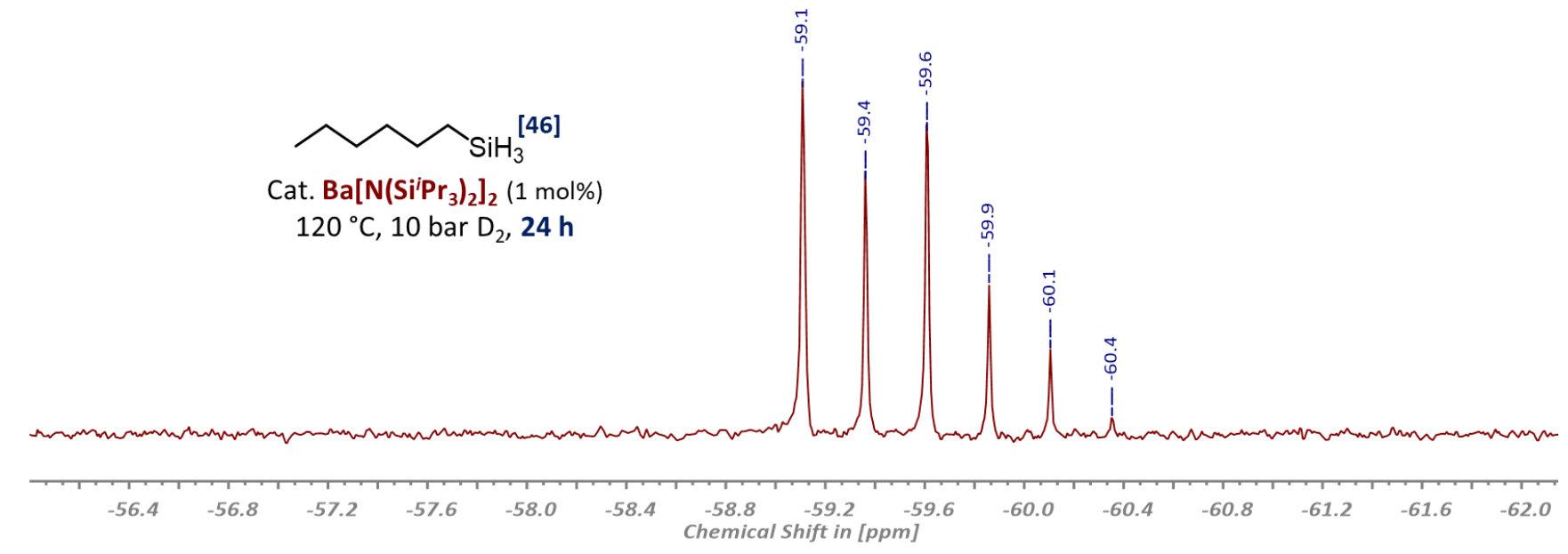

Figure S110. Stacked ${ }^{29} \mathrm{Si}\left\{{ }^{1} \mathrm{H}\right\}$ NMR spectra $\left(119 \mathrm{MHz}, \mathrm{CDCl}_{3}, 25{ }^{\circ} \mathrm{C}\right)$ of $(a)$ an authentic sample of the $n$-hexylsilane substrate and $(b)$ the distilled deuterium-labeled product after the catalytic deuteration with $\mathrm{D}_{2}(10 \mathrm{bar})$ and $\mathrm{Ba}\left[\mathrm{N}\left(\mathrm{Si}^{i} \mathrm{Pr}_{3}\right)_{2}\right]_{2}(1 \mathrm{~mol} \%)$ as catalyst precursor at $120^{\circ} \mathrm{C}$ for 24 hours. 


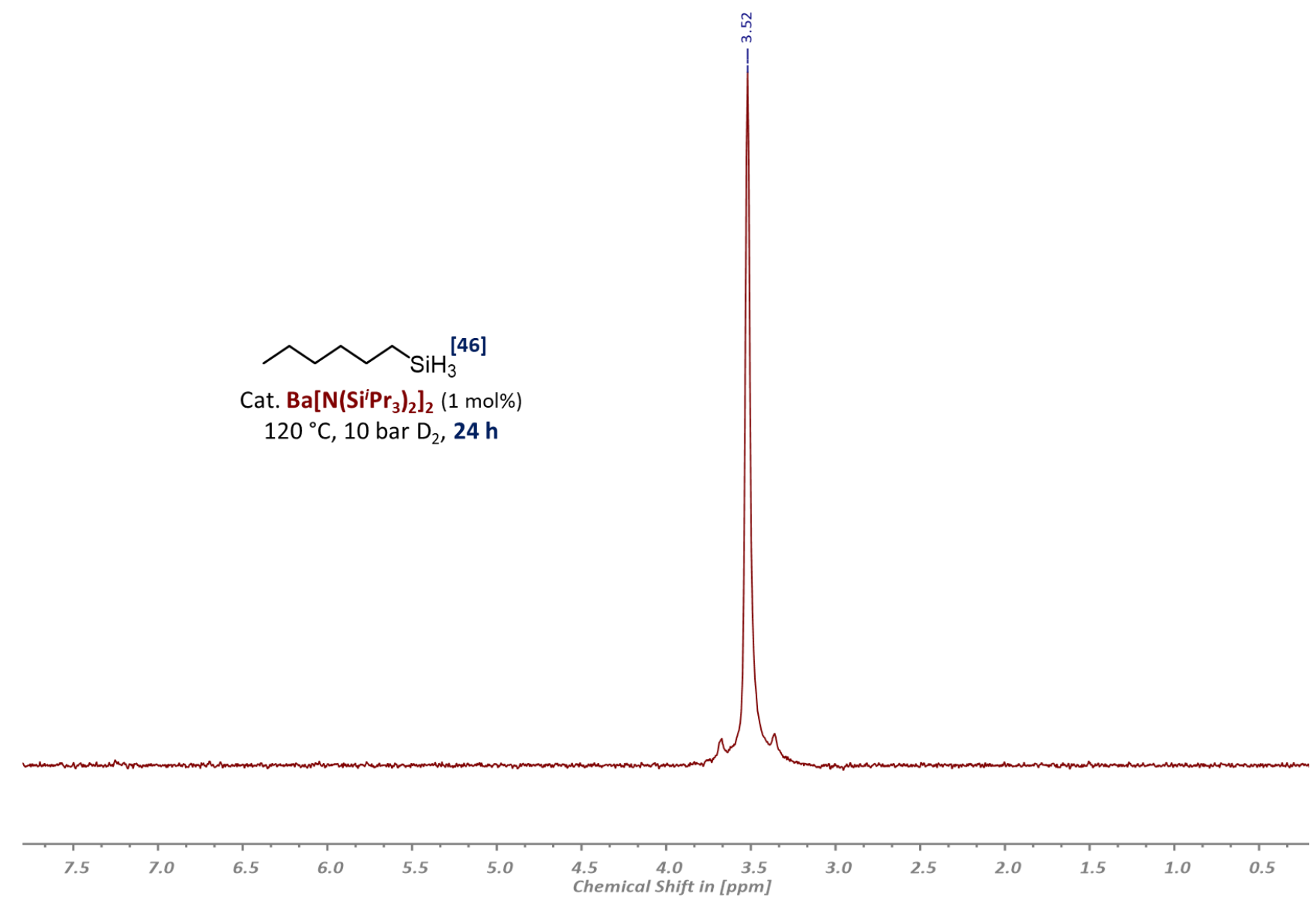

Figure S111. ${ }^{2} \mathrm{H}\left\{{ }^{1} \mathrm{H}\right\} \mathrm{NMR}$ spectrum $\left(92 \mathrm{MHz}, \mathrm{CHCl}_{3}, 25^{\circ} \mathrm{C}\right)$ of catalytically deuterium-labeled $n$-hexylsilane after the deuteration with $\mathrm{D}_{2}(10 \mathrm{bar})$ and $\mathrm{Ba}\left[\mathrm{N}\left(\mathrm{Si}^{\mathrm{i}} \mathrm{Pr}_{3}\right)_{2}\right]_{2}(1 \mathrm{~mol} \%)$ as pre-catalyst at $120^{\circ} \mathrm{C}$ for 24 hours. 


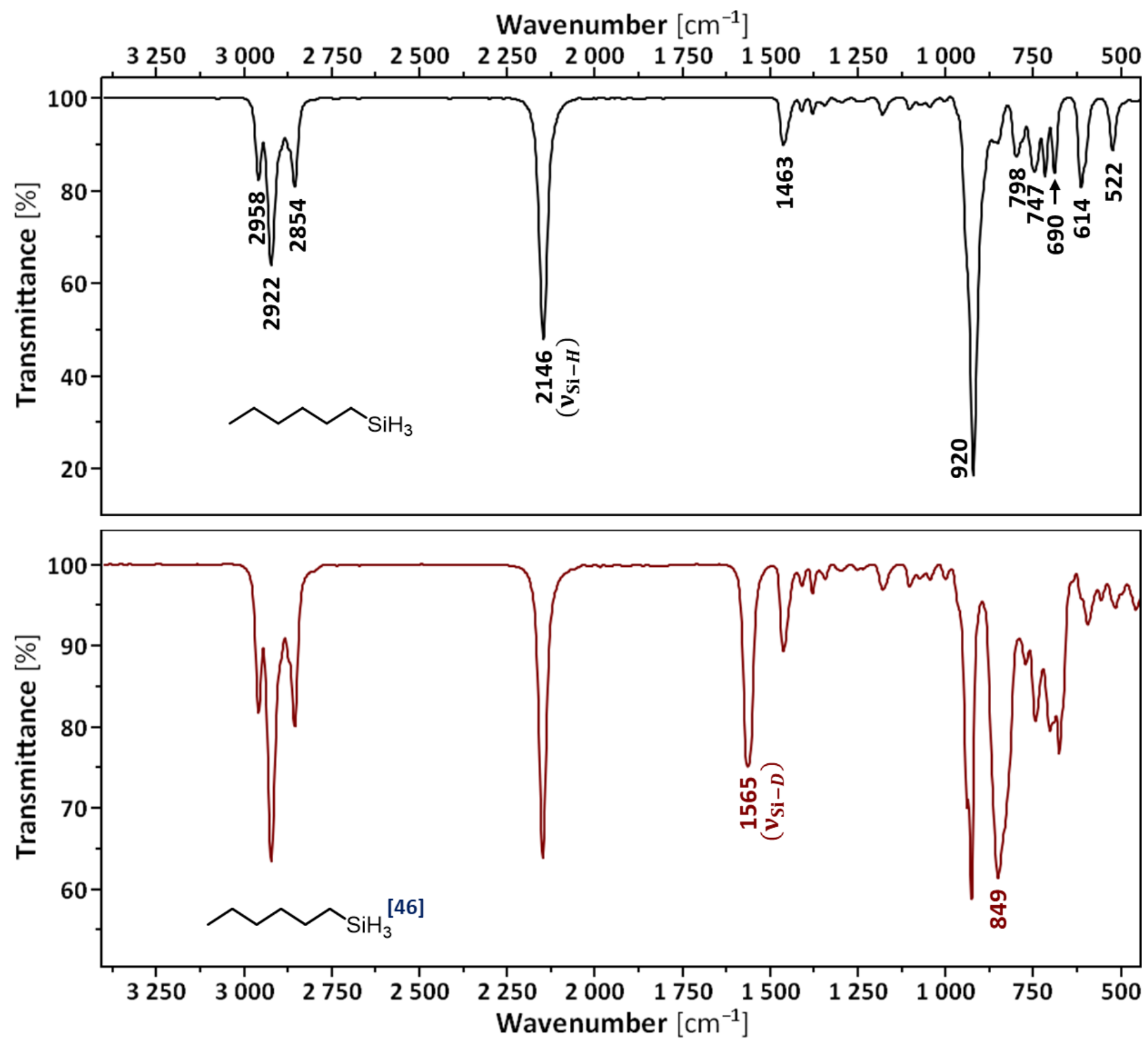

Figure S112. Stacked FT-IR spectra of $(a)$ the authentic $n$-hexylsilane substrate and $(b)$ the isolated deuterium-labeled product after the catalytic deuteration with $\mathrm{D}_{2}(10 \mathrm{bar})$ and $\mathrm{Ba}\left[\mathrm{N}\left(\mathrm{Si}^{i} \mathrm{Pr}_{3}\right)_{2}\right]_{2}(1 \mathrm{~mol} \%)$ as catalyst precursor at $120^{\circ} \mathrm{C}$ for 24 hours. 


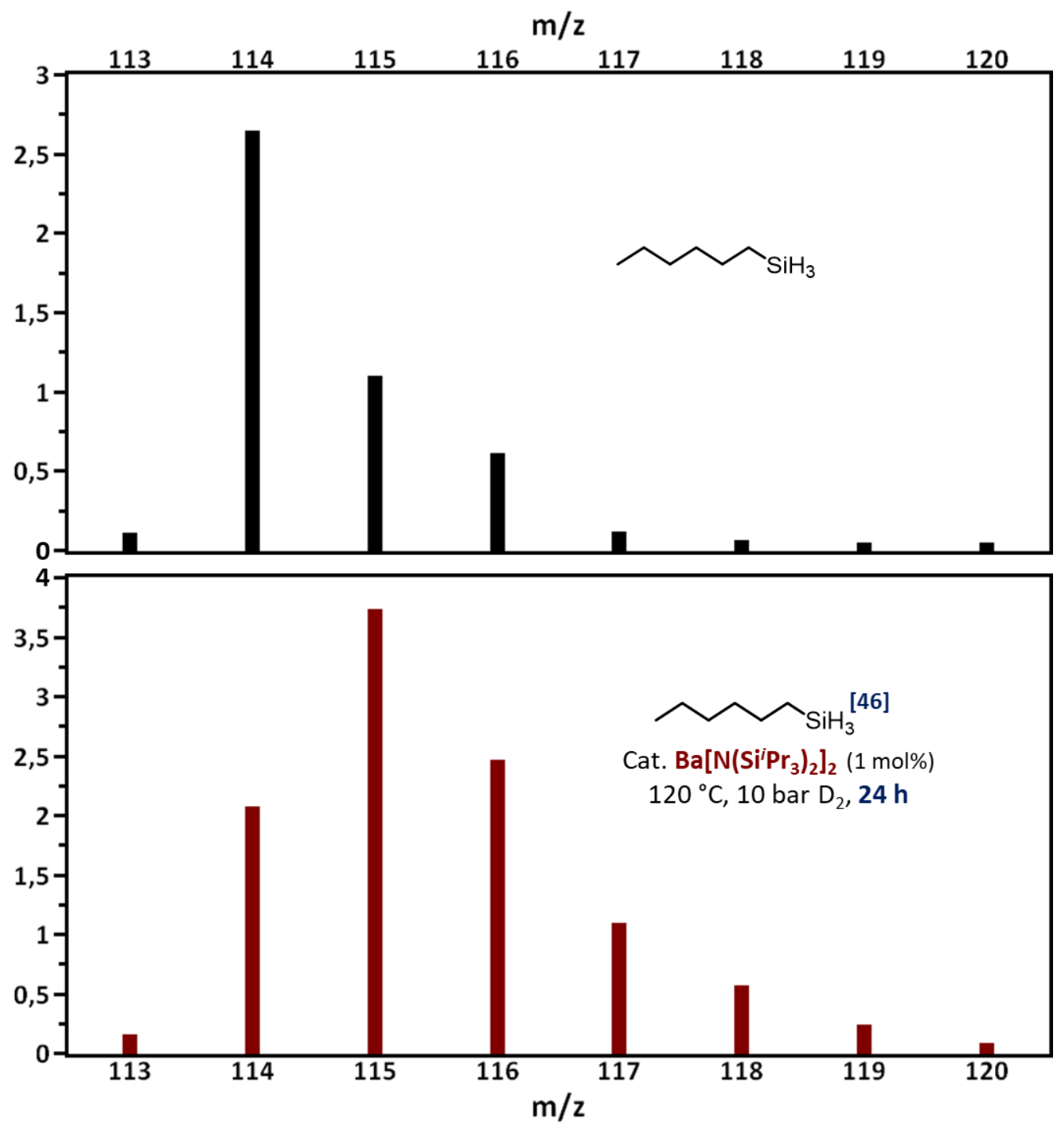

Figure S113. Stacked mass spectra of (top) the authentic $n$-hexylsilane substrate and (bottom) the deuterium-labeled product obtained after the catalytic deuteration with $\mathrm{D}_{2}$ (10 bar) and $\mathrm{Ba}\left[\mathrm{N}\left(\mathrm{Si}^{\mathrm{i}} \mathrm{Pr}_{3}\right)_{2}\right]_{2}(1 \mathrm{~mol} \%)$ as catalyst precursor at $120^{\circ} \mathrm{C}$ for 24 hours. 
(a)

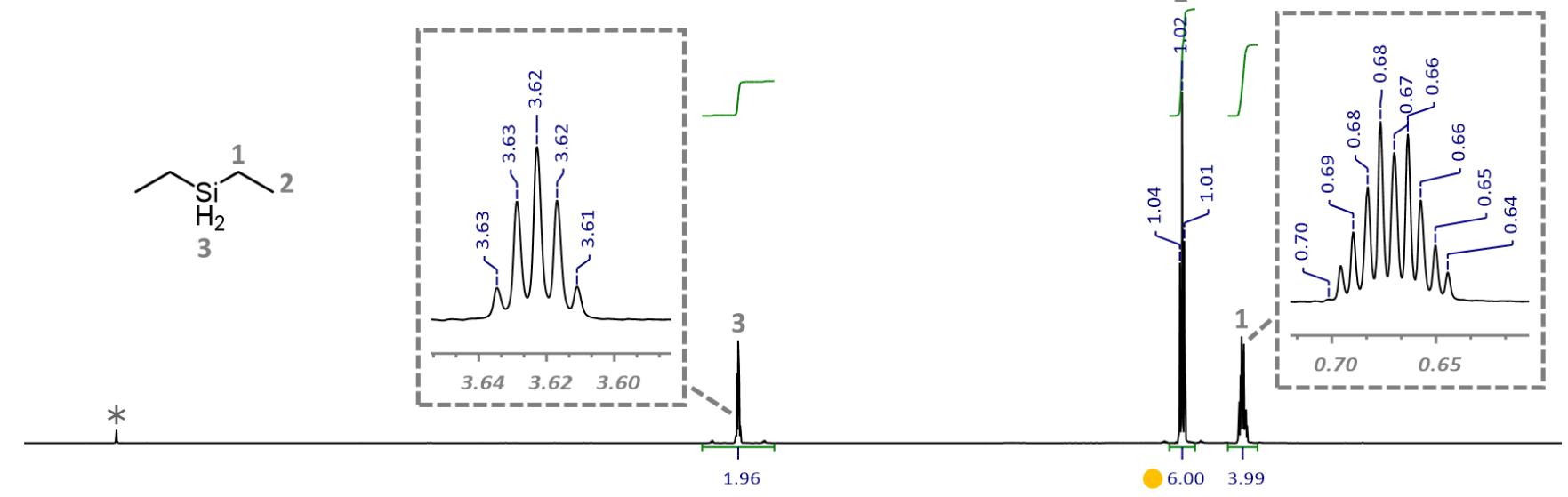

(b)

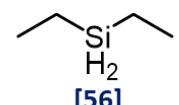

[56]

Cat. $\mathrm{Ba}\left[\mathrm{N}\left(\mathrm{Si}^{\mathrm{i} P \mathrm{Pr}_{3}}\right)_{2}\right]_{2}(1 \mathrm{~mol} \%)$

$120^{\circ} \mathrm{C}, 10$ bar $\mathrm{D}_{2}, 24 \mathrm{~h}$

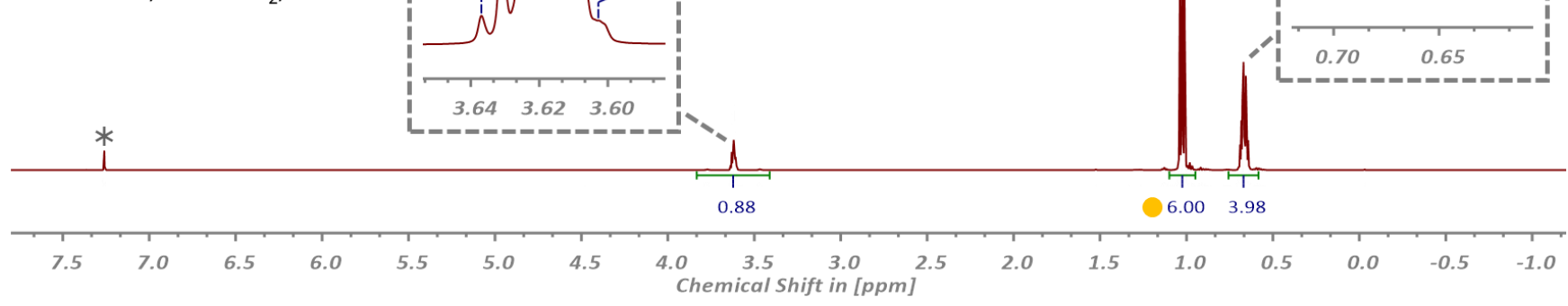

Figure S114. Stacked ${ }^{1} \mathrm{H}$ NMR spectra $\left(600 \mathrm{MHz}, \mathrm{CDCl}_{3}, 25^{\circ} \mathrm{C}\right)$ of $(a)$ a sample of the natural abundance diethylsilane substrate and $(b)$ the catalytically deuterium-labeled product isolated after the deuteration with $\mathrm{D}_{2}$ (10 bar) and $\mathrm{Ba}\left[\mathrm{N}\left(\mathrm{Si}^{i} \mathrm{Pr}_{3}\right)_{2}\right]_{2}(1 \mathrm{~mol} \%)$ as catalyst precursor at $120^{\circ} \mathrm{C}$ for 24 hours. 
(a)

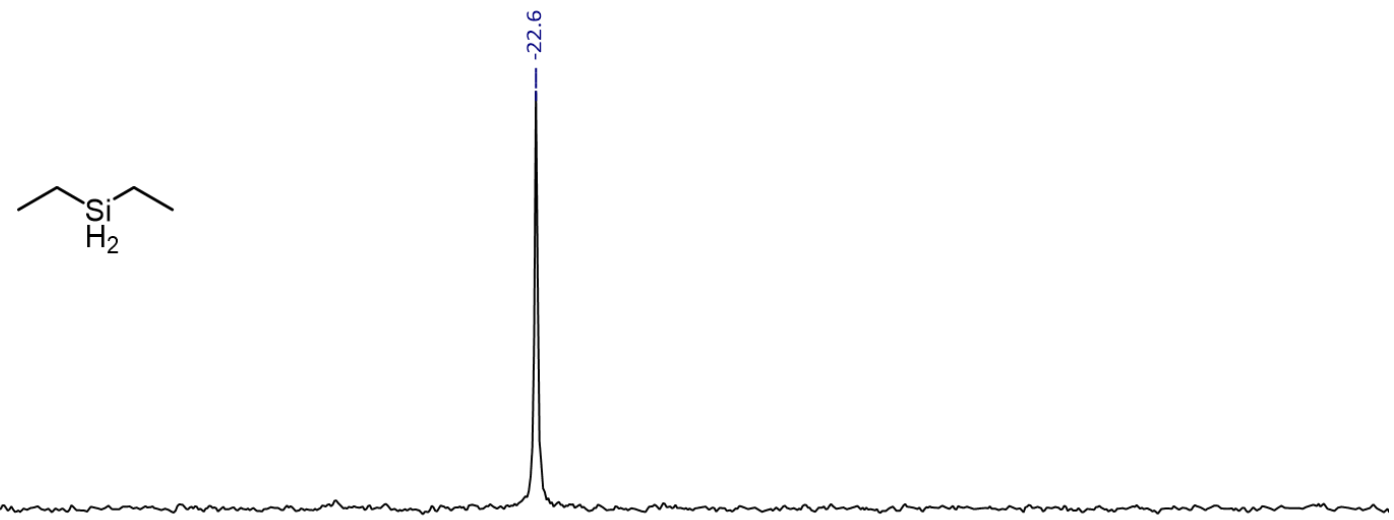

(b)

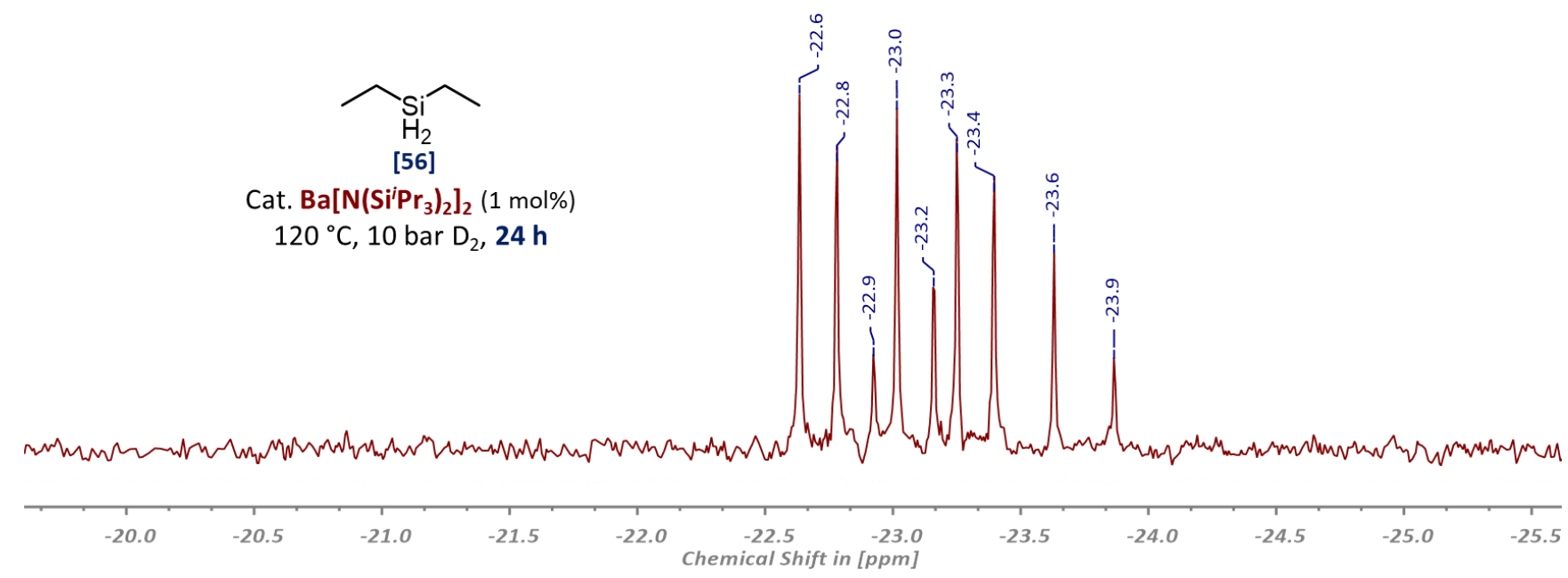

Figure S115. Stacked ${ }^{29} \mathrm{Si}\left\{{ }^{1} \mathrm{H}\right\}$ NMR spectra $\left(119 \mathrm{MHz}, \mathrm{CDCl}_{3}, 25^{\circ} \mathrm{C}\right)$ of $(a)$ the non-labeled diethylsilane substrate and $(b)$ the partially deuterated product obtained after the catalytic deuteration with $\mathrm{D}_{2}(10 \mathrm{bar})$ and $\mathrm{Ba}\left[\mathrm{N}\left(\mathrm{Si}^{i} \mathrm{Pr}_{3}\right)_{2}\right]_{2}(1 \mathrm{~mol} \%)$ as catalyst precursor at $120{ }^{\circ} \mathrm{C}$ for 24 hours. 


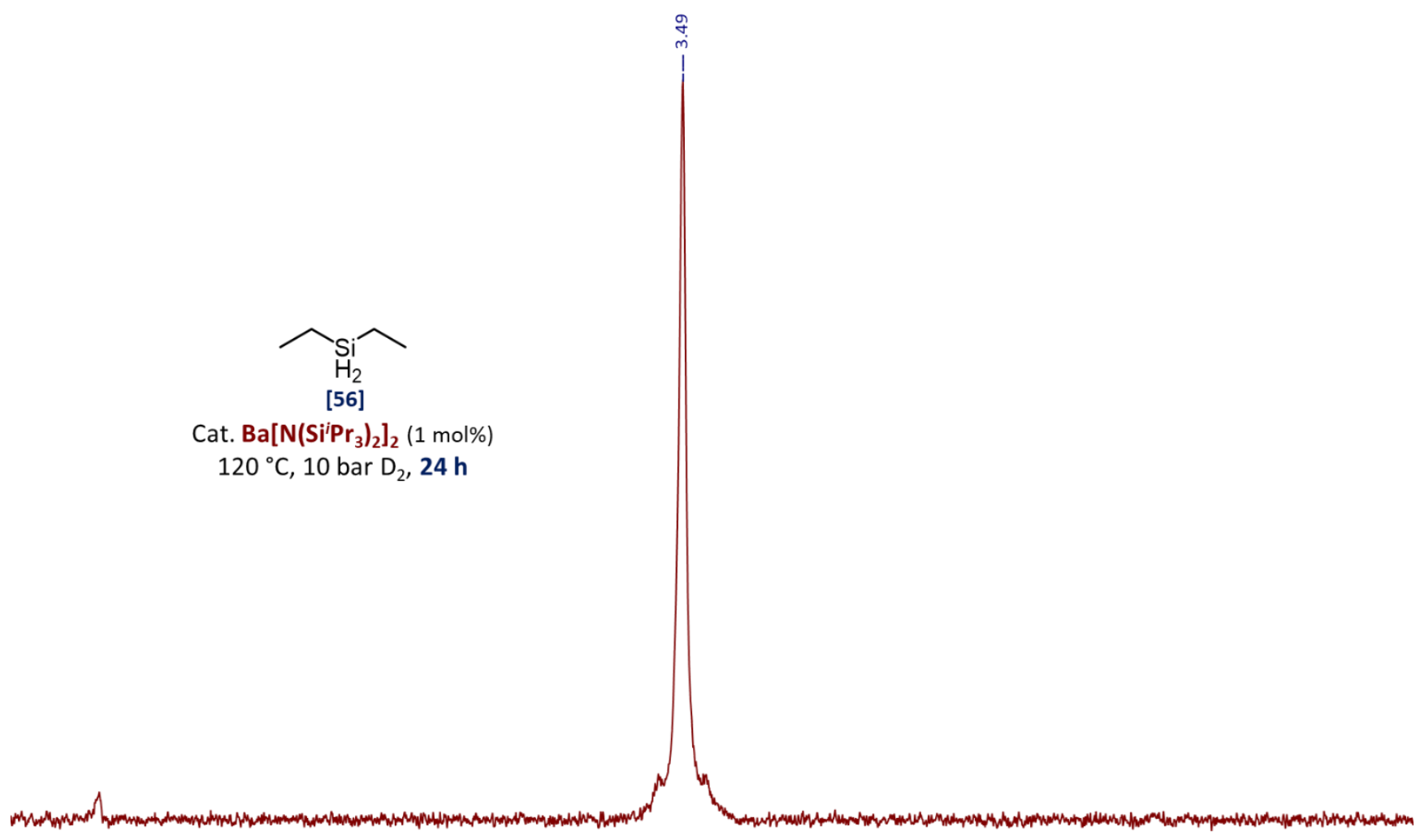

Cat. Ba[N( $\left.\left.\left(\mathrm{Si}^{\mathrm{i} P r}\right)_{3}\right)_{2}\right]_{2}(1 \mathrm{~mol} \%)$ $120^{\circ} \mathrm{C}, 10$ bar $\mathrm{D}_{2}, 24 \mathrm{~h}$

\begin{tabular}{|c|c|c|c|c|c|c|c|c|c|c|c|c|c|c|c|c|c|}
\hline 7.5 & 7.0 & 6.5 & 6.0 & 5.5 & 5.0 & 4.5 & $\stackrel{4.0}{C h}$ & $\begin{array}{c}3.5 \\
\text { mical si }\end{array}$ & $\begin{array}{l}3.0 \\
f t \text { in }[p p\end{array}$ & 2.5 & 2.0 & 1.5 & 1.0 & 0.5 & 0.0 & -0.5 & -1.0 \\
\hline
\end{tabular}

Figure S116. ${ }^{2} \mathrm{H}\left\{{ }^{1} \mathrm{H}\right\} \mathrm{NMR}$ spectrum $\left(92 \mathrm{MHz}, \mathrm{CHCl}_{3}, 25^{\circ} \mathrm{C}\right.$ ) of the purified deuterium labeling product after the catalytic deuteration of diethylsilane with $\mathrm{D}_{2}(10 \mathrm{bar})$ and $\mathrm{Ba}\left[\mathrm{N}\left(\mathrm{Si}^{i} \mathrm{Pr}_{3}\right)_{2}\right]_{2}(1 \mathrm{~mol} \%)$ as catalyst precursor at $120^{\circ} \mathrm{C}$ for 24 hours. 


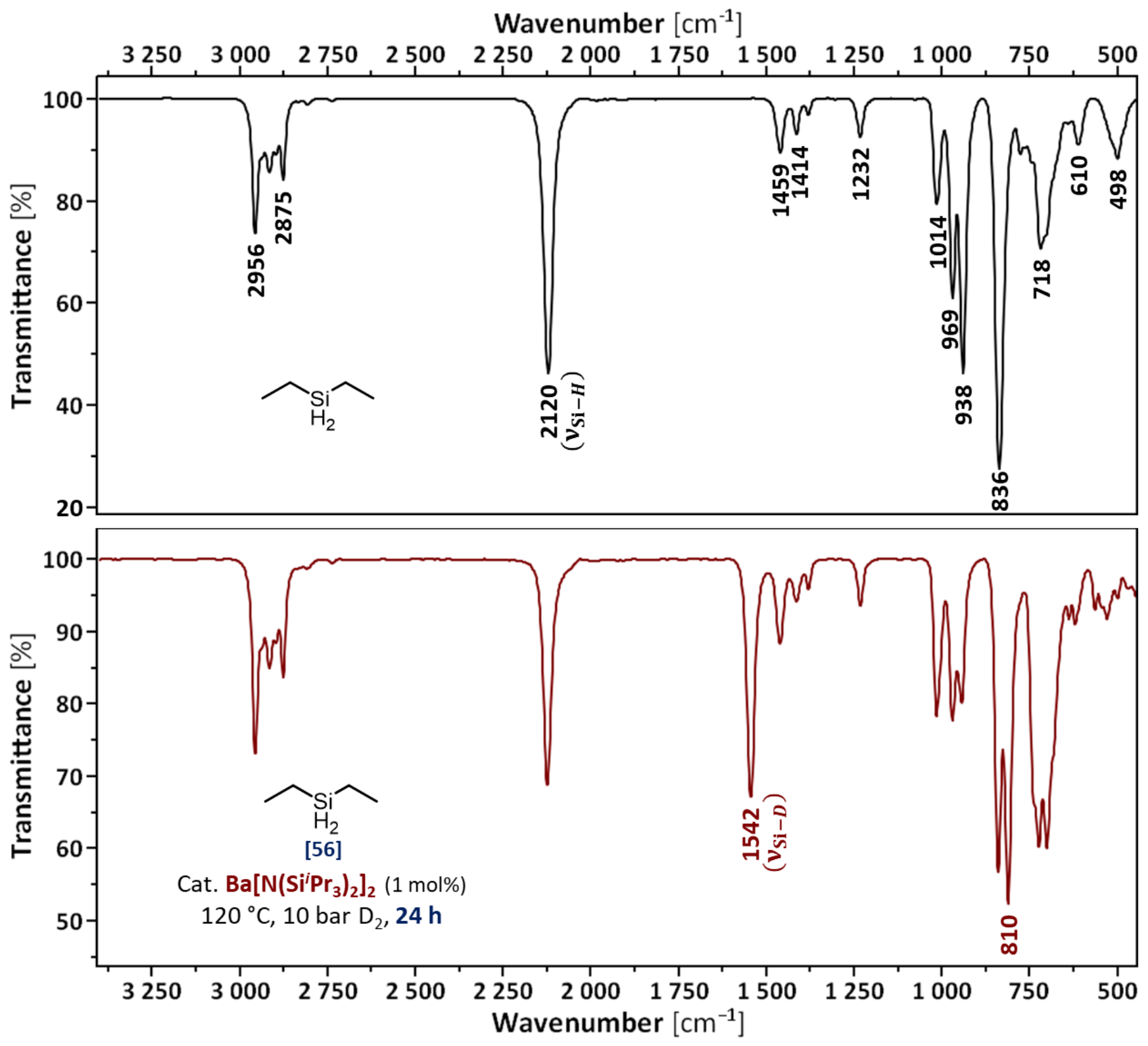

Figure S117. Stacked FT-IR spectra of $(a)$ the authentic diethylsilane substrate and $(b)$ the catalytically deuterated product isolated after the deuteration with $\mathrm{D}_{2}$ (10 bar) and $\mathrm{Ba}\left[\mathrm{N}\left(\mathrm{Si}^{i} \mathrm{Pr}_{3}\right)_{2}\right]_{2}(1 \mathrm{~mol} \%)$ as catalyst precursor at $120^{\circ} \mathrm{C}$ for 24 hours. 

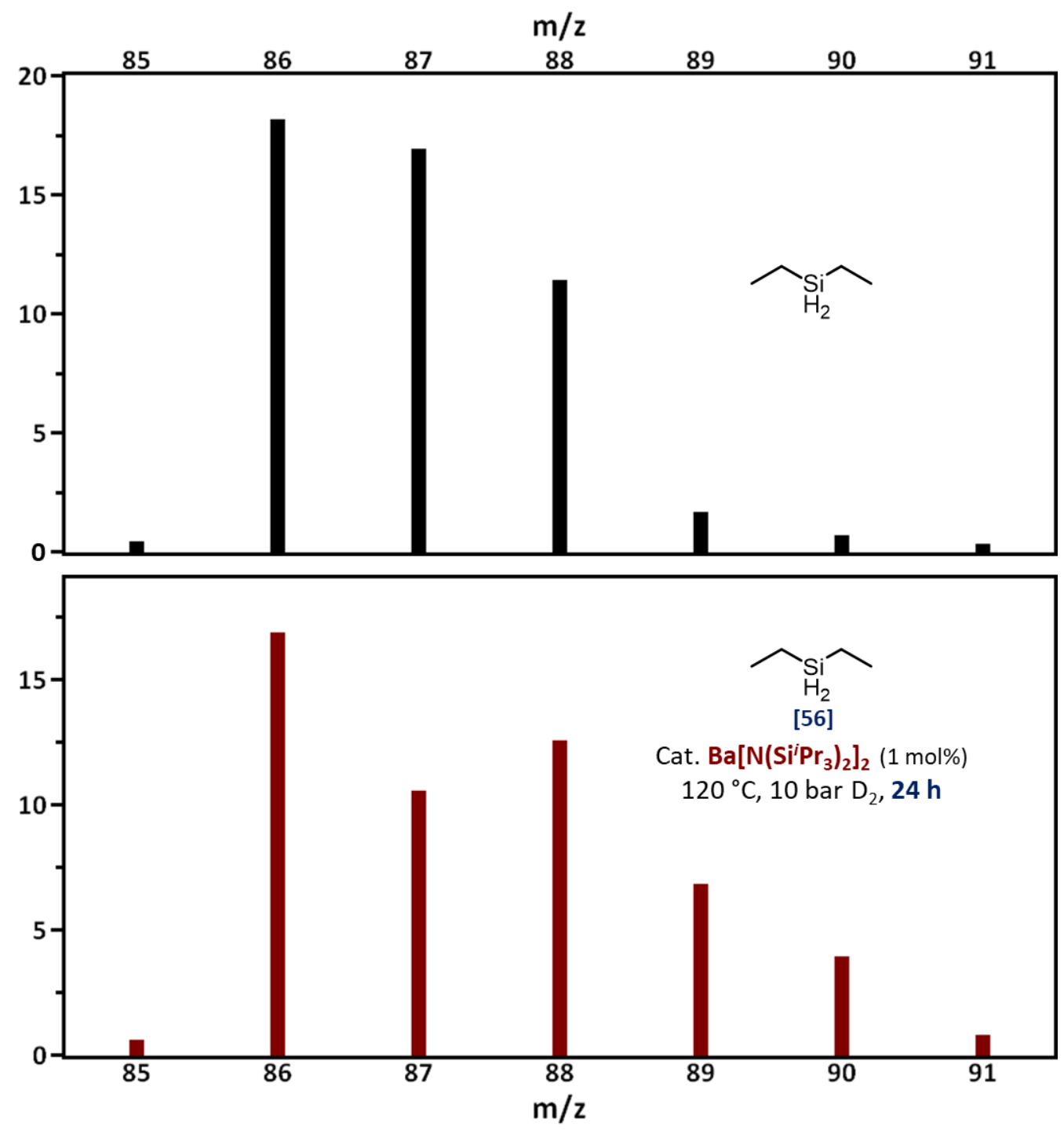

Figure S118. Stacked mass spectra of (top) the authentic diethylsilane substrate and (bottom) the partially deuterium-labeled product obtained after the catalytic deuteration with $\mathrm{D}_{2}$ (10 bar) and $\mathrm{Ba}\left[\mathrm{N}\left(\mathrm{Si}^{\mathrm{i}} \mathrm{Pr}_{3}\right)_{2}\right]_{2}(1 \mathrm{~mol} \%)$ as catalyst precursor at $120^{\circ} \mathrm{C}$ for 24 hours. 
(a)

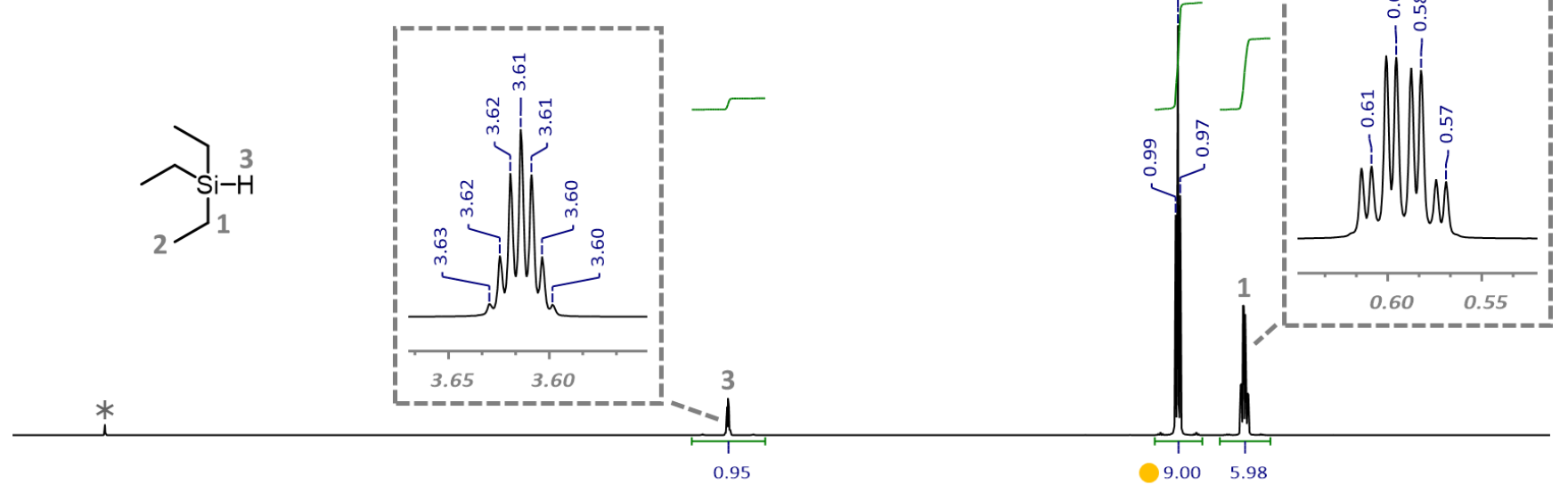

(b)

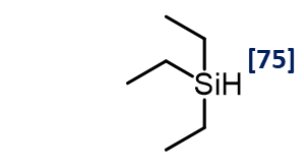

Cat. Ba[N(SiPr $\left.)_{3}\right]_{2}(1 \mathrm{~mol} \%)$ $120^{\circ} \mathrm{C}, 10$ bar $\mathrm{D}_{2}, 24 \mathrm{~h}$

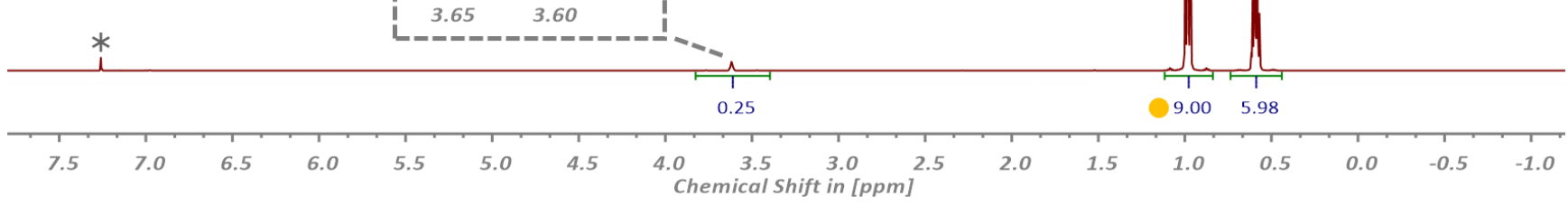

Figure S119. Stacked ${ }^{1} \mathrm{H}$ NMR spectra $\left(600 \mathrm{MHz}, \mathrm{CDCl}_{3}, 25^{\circ} \mathrm{C}\right)$ of $(a)$ the authentic triethylsilane substrate and (b) the distilled deuterium-labeled product after the catalytic deuteration with $D_{2}$ (10 bar) as deuterium source and $\mathrm{Ba}\left[\mathrm{N}\left(\mathrm{Si}^{i} \mathrm{Pr}_{3}\right)_{2}\right]_{2}(1 \mathrm{~mol} \%)$ as catalyst precursor at $120{ }^{\circ} \mathrm{C}$ for 24 hours. 
(a)
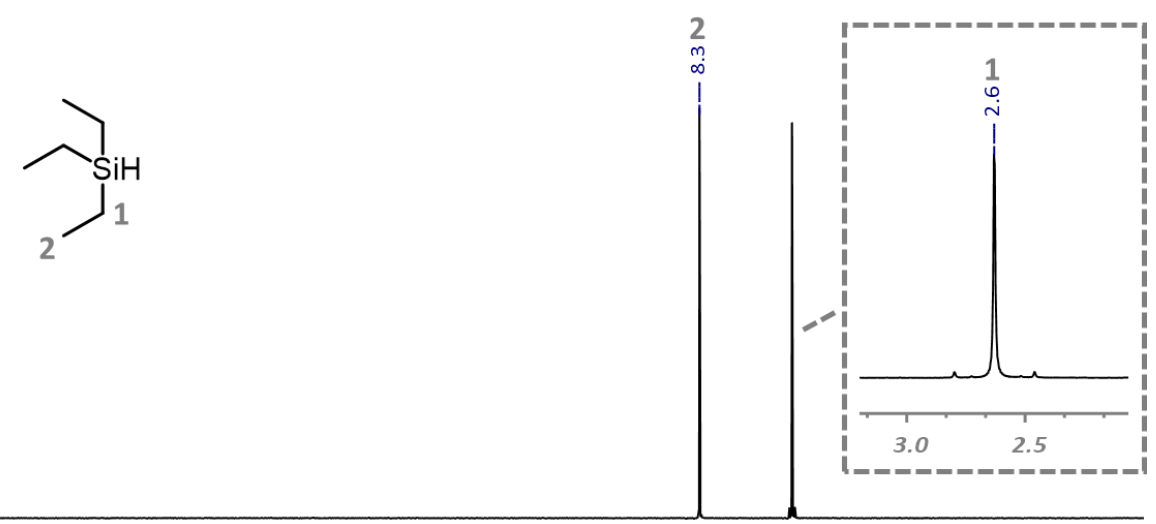

(b)

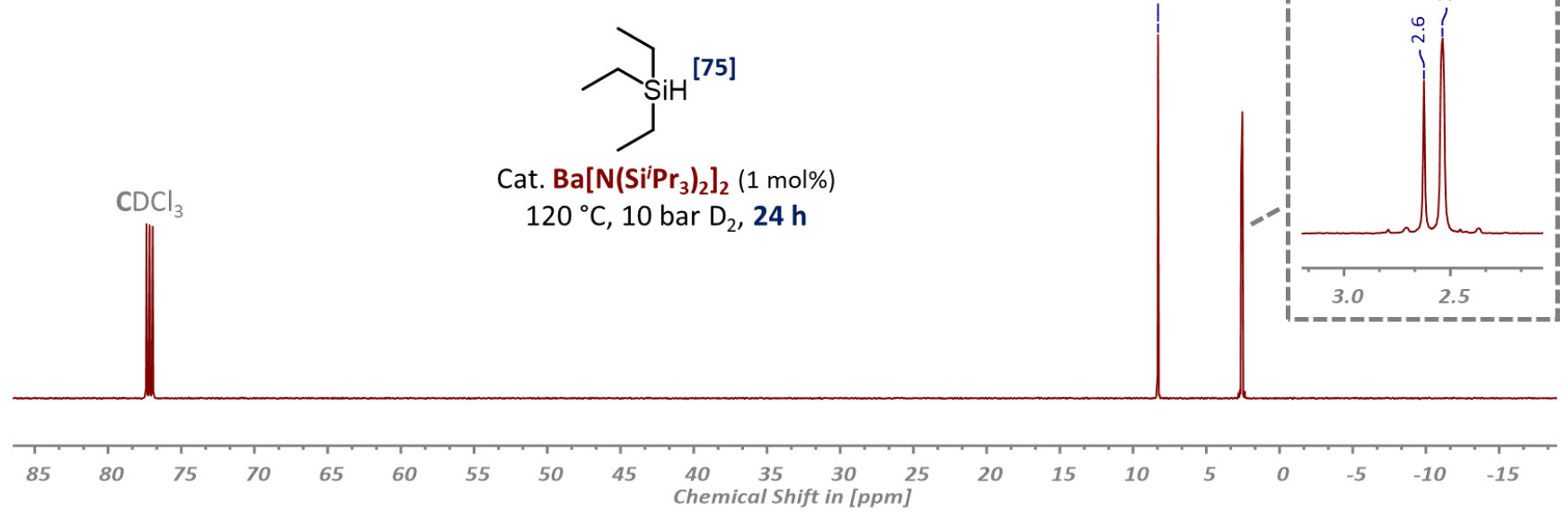

Figure S120. Stacked ${ }^{13} \mathrm{C}\left\{{ }^{1} \mathrm{H}\right\} \mathrm{NMR}$ spectra $\left(151 \mathrm{MHz}, \mathrm{CDCl}_{3}, 25{ }^{\circ} \mathrm{C}\right)$ of $(a)$ the non-deuterated triethylsilane substrate and $(b)$ the partially deuterated product isolated after the catalytic deuteration with $\mathrm{D}_{2}(10 \mathrm{bar})$ and $\mathrm{Ba}\left[\mathrm{N}\left(\mathrm{Si}^{\mathrm{i} P r}\right)_{2}\right)_{2}(1 \mathrm{~mol} \%)$ as catalyst precursor at $120^{\circ} \mathrm{C}$ for 24 hours. 


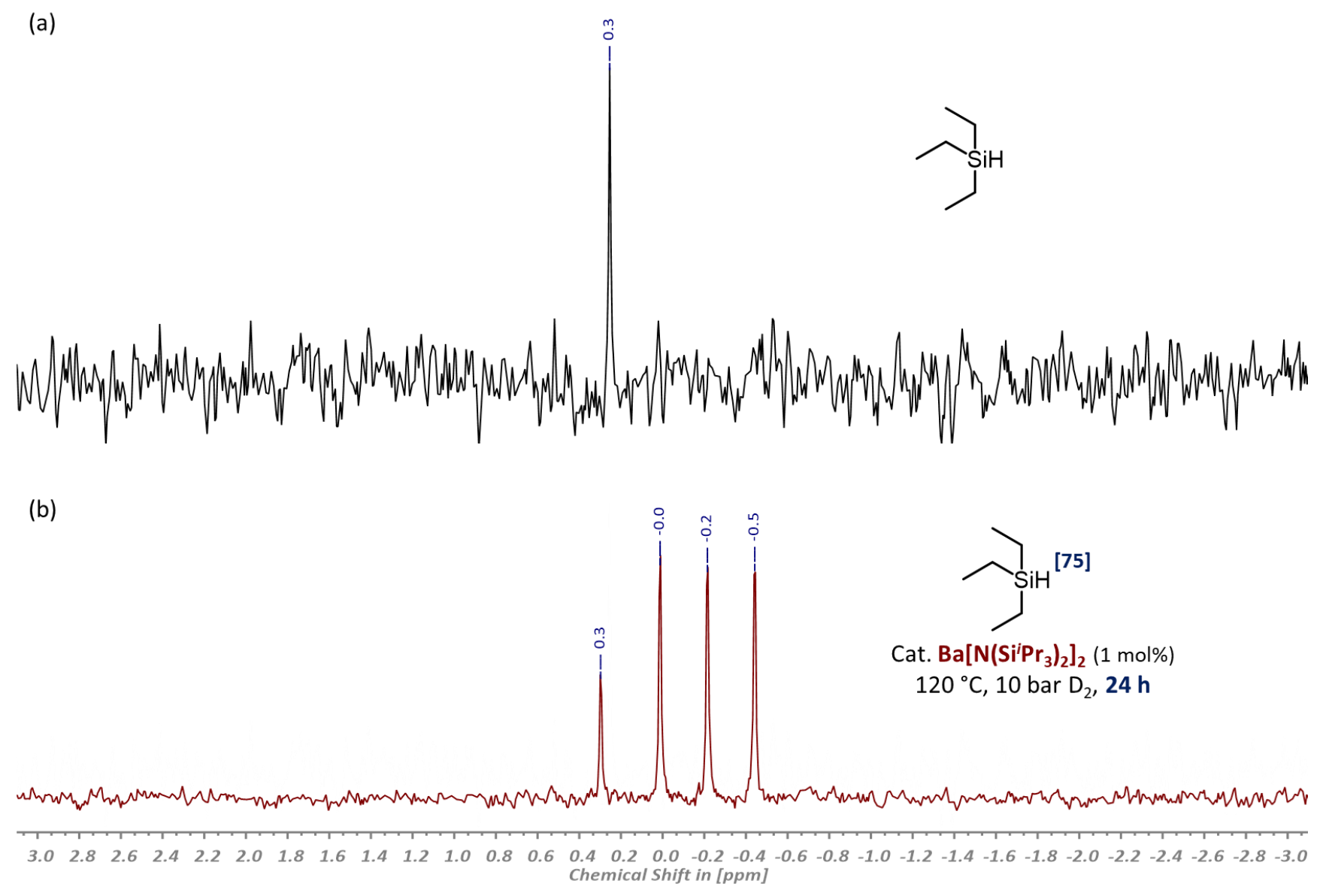

Figure S121. Stacked ${ }^{29} \mathrm{Si}\left\{{ }^{1} \mathrm{H}\right\}$ NMR spectra $\left(119 \mathrm{MHz}, \mathrm{CDCl}_{3}, 25^{\circ} \mathrm{C}\right)$ of $(a)$ the authentic triethylsilane substrate and $(b)$ the purified deuterium labeling product after the catalytic deuteration with $\mathrm{D}_{2}(10 \mathrm{bar})$ and $\mathrm{Ba}\left[\mathrm{N}\left(\mathrm{Si}^{i} \mathrm{Pr}_{3}\right)_{2}\right]_{2}$ ( $1 \mathrm{~mol} \%$ ) as catalyst precursor at $120^{\circ} \mathrm{C}$ for 24 hours. 


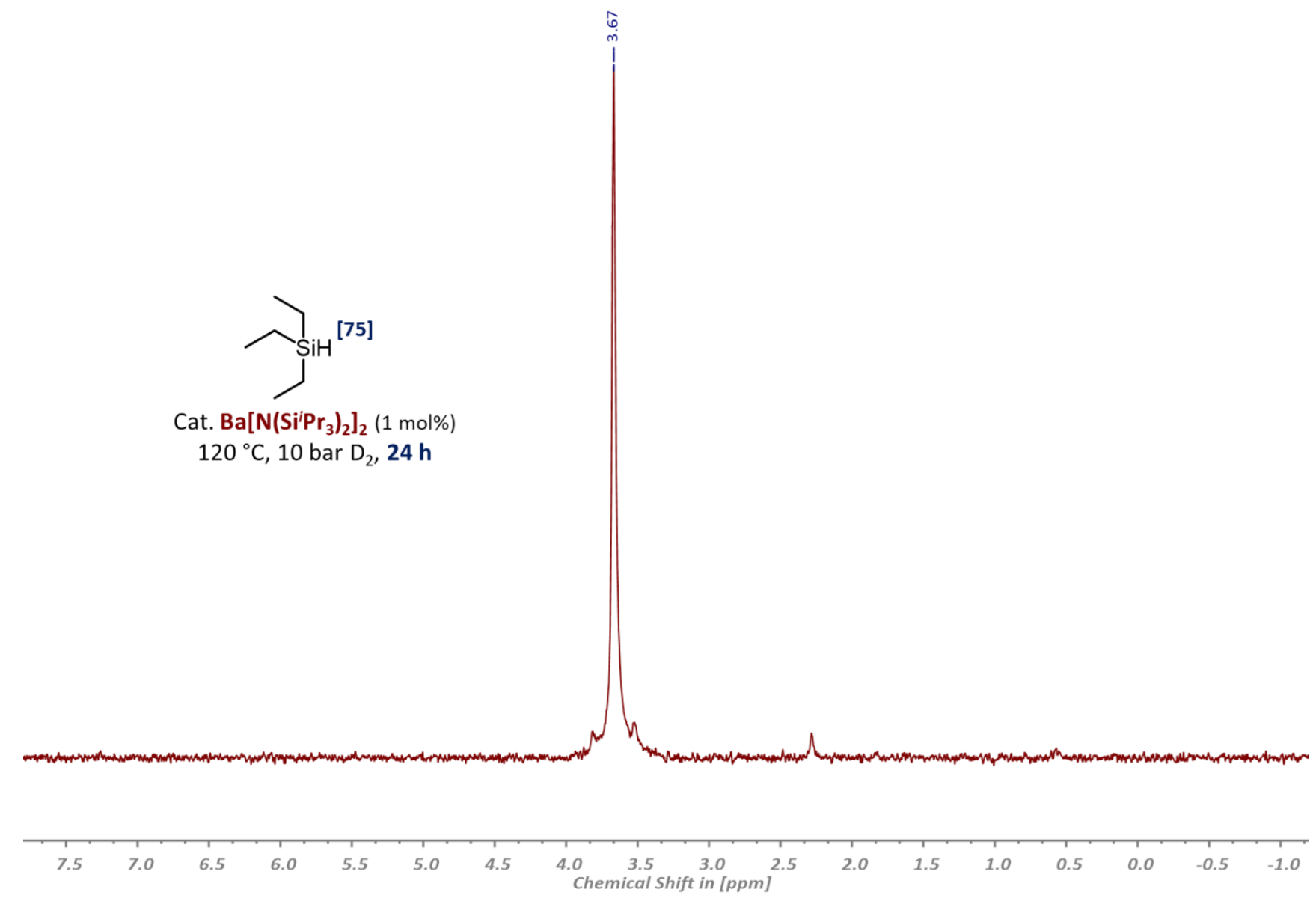

Figure S122. ${ }^{2} \mathrm{H}\left\{{ }^{1} \mathrm{H}\right\} \mathrm{NMR}$ spectrum $\left(92 \mathrm{MHz}, \mathrm{CHCl}_{3}, 25^{\circ} \mathrm{C}\right)$ of the catalytically deuterated triethylsilane product isolated after the deuteration with $\mathrm{D}_{2}(10 \mathrm{bar})$ and $\mathrm{Ba}\left[\mathrm{N}\left(\mathrm{Si}^{i} \mathrm{Pr}_{3}\right)_{2}\right]_{2}(1 \mathrm{~mol} \%)$ as catalyst precursor at $120^{\circ} \mathrm{C}$ for 24 hours. 

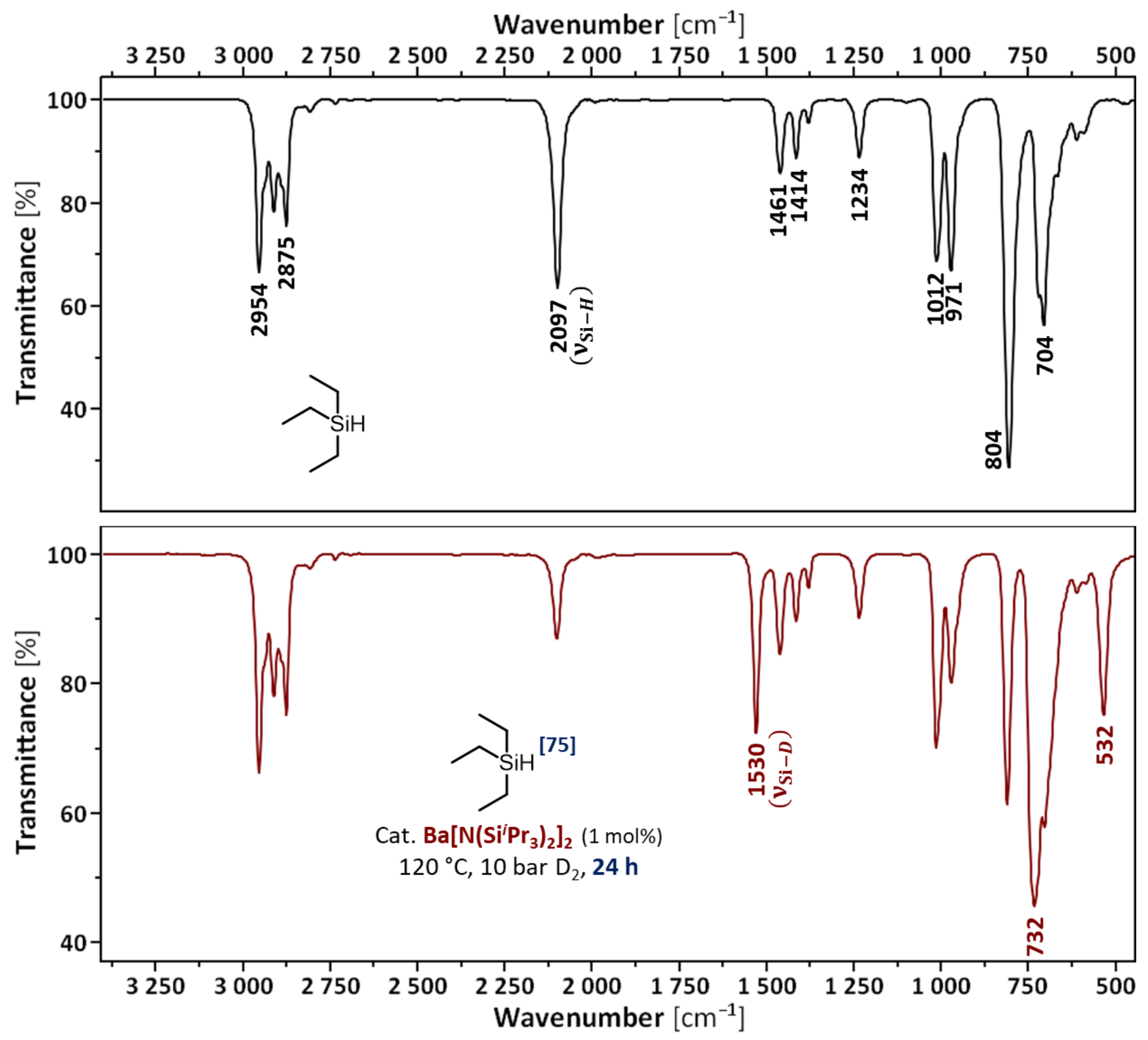

Figure S123. Stacked FT-IR spectra of $(a)$ the unlabeled triethylsilane starting material and $(b)$ the isolated deuterium-labeled product after the catalytic deuteration with $\mathrm{D}_{2}(10 \mathrm{bar})$ and $\mathrm{Ba}\left[\mathrm{N}\left(\mathrm{Si}^{i} \mathrm{Pr}_{3}\right)_{2}\right]_{2}(1 \mathrm{~mol} \%)$ as pre-catalyst at $120^{\circ} \mathrm{C}$ for 24 hours. 

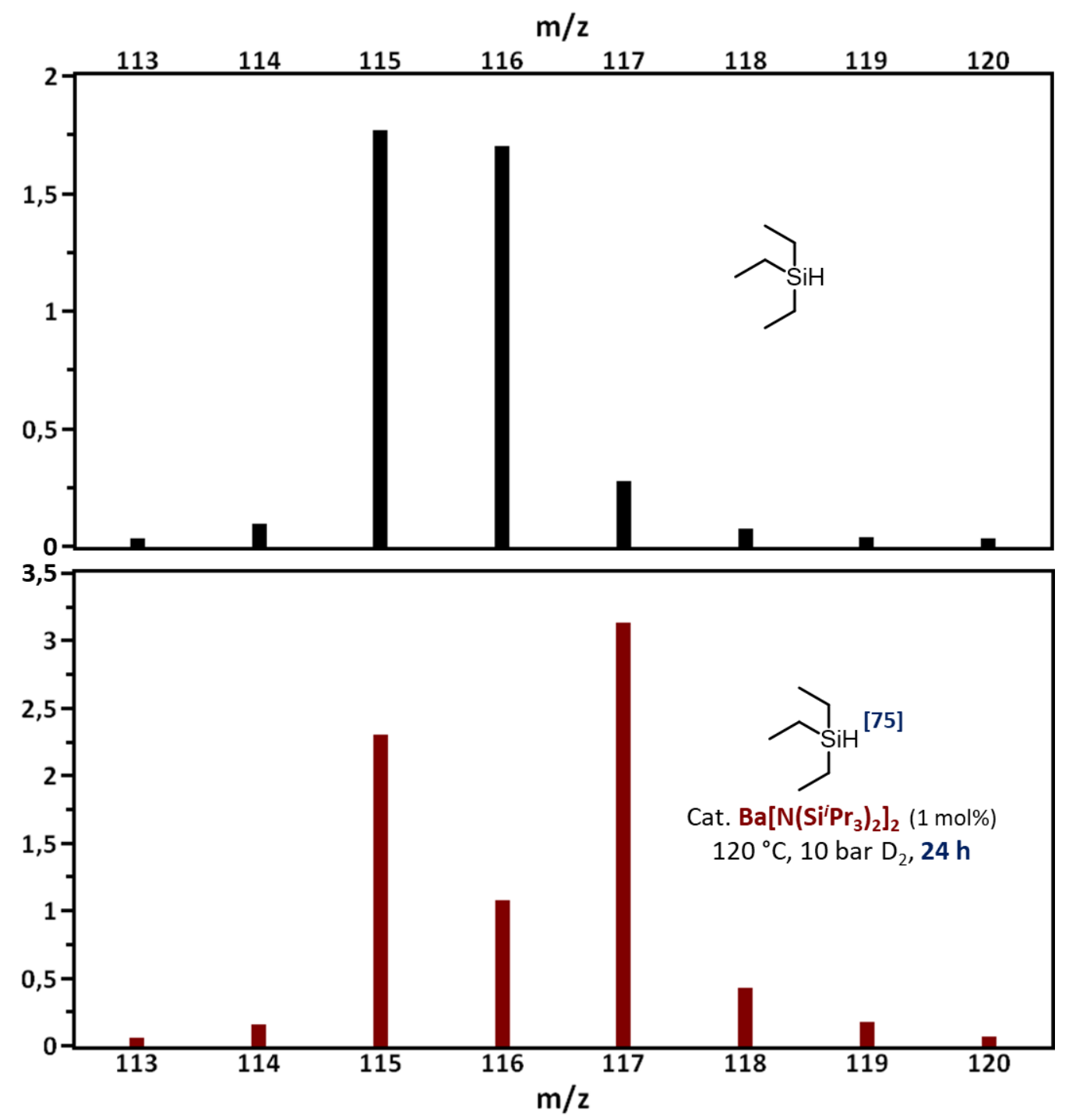

Figure S124. Stacked mass spectra of (top) the authentic triethylsilane substrate and (bottom) the deuterium-labeled product obtained after the catalytic deuteration with $\mathrm{D}_{2}$ (10 bar) and $\mathrm{Ba}\left[\mathrm{N}\left(\mathrm{Si}^{i} \mathrm{Pr}_{3}\right)_{2}\right]_{2}(1 \mathrm{~mol} \%)$ as catalyst precursor at $120^{\circ} \mathrm{C}$ for 24 hours. 


\section{Theoretical Calculations}

\section{General methods:}

All geometry optimizations were carried out using Gaussian $16 \mathrm{~A} \cdot{ }^{10}$ All structures were fully optimized on B3PW91/def2TZVPP level of theory. ${ }^{11}$ In all cases Grimme's third dispersion correction with Becke-Johnson damping (GD3BJ) was added. ${ }^{12}$ In addition, implicit solvent effects were computed using the polarizable continuum model (PCM, benzene). ${ }^{13}$ In order to determine zero-point energies and to characterize the structures as minima, frequency analysis has been applied. Structures were drawn and evaluated using Molecule (v2.3). ${ }^{14}$

Note: The following abbreviations are consistently used: $\mathrm{N}^{*}=\left({ }^{(} \mathrm{Pr}_{3} \mathrm{Si}\right)_{2} \mathrm{~N}, \mathrm{~N}^{\prime \prime}=\left(\mathrm{Me}_{3} \mathrm{Si}\right)_{2} \mathrm{~N}$.

Note: The potential energy surfaces for these weakly bound, highly ionic, complexes are very shallow which complicates the search for minima and transition states. This is especially the case for Ba complexes with long and weak ligand-Ba bonds. The transition state B5* for H/D exchange between $\mathrm{N}^{*} \mathrm{BaH}$ and $\mathrm{D}_{2}$ could not be located: the preliminary complex $\mathrm{N}^{*}(\mathrm{H}) \mathrm{Ba} \cdots \mathrm{D}_{2}$ (NIMAG $=0$ at $\left.+4.5 \mathrm{kcal} / \mathrm{mol}\right)$ converts without a noticeable barrier to complex $N^{*}(D) B a \cdots(D-H)$. Complex D-B3, a possible intermediate on the way from $\mathrm{D}-\mathrm{B} 2$ to transition state $\mathrm{D}-\mathrm{B} 4 *$, was found to have one small imaginary frequency (NIMAG =1) which is related to inversion of the ring puckering of the Meisenheimer anion. 


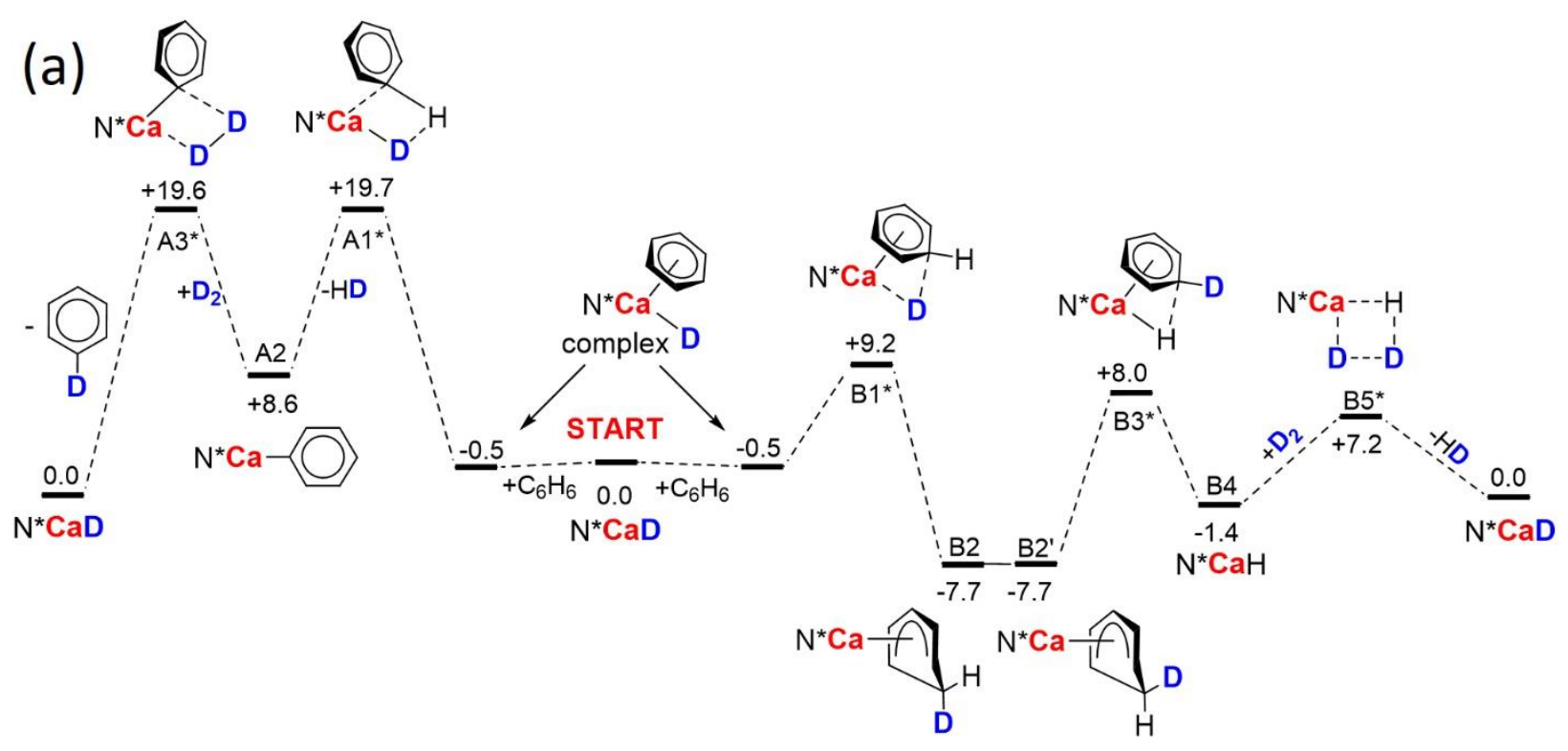

(b)

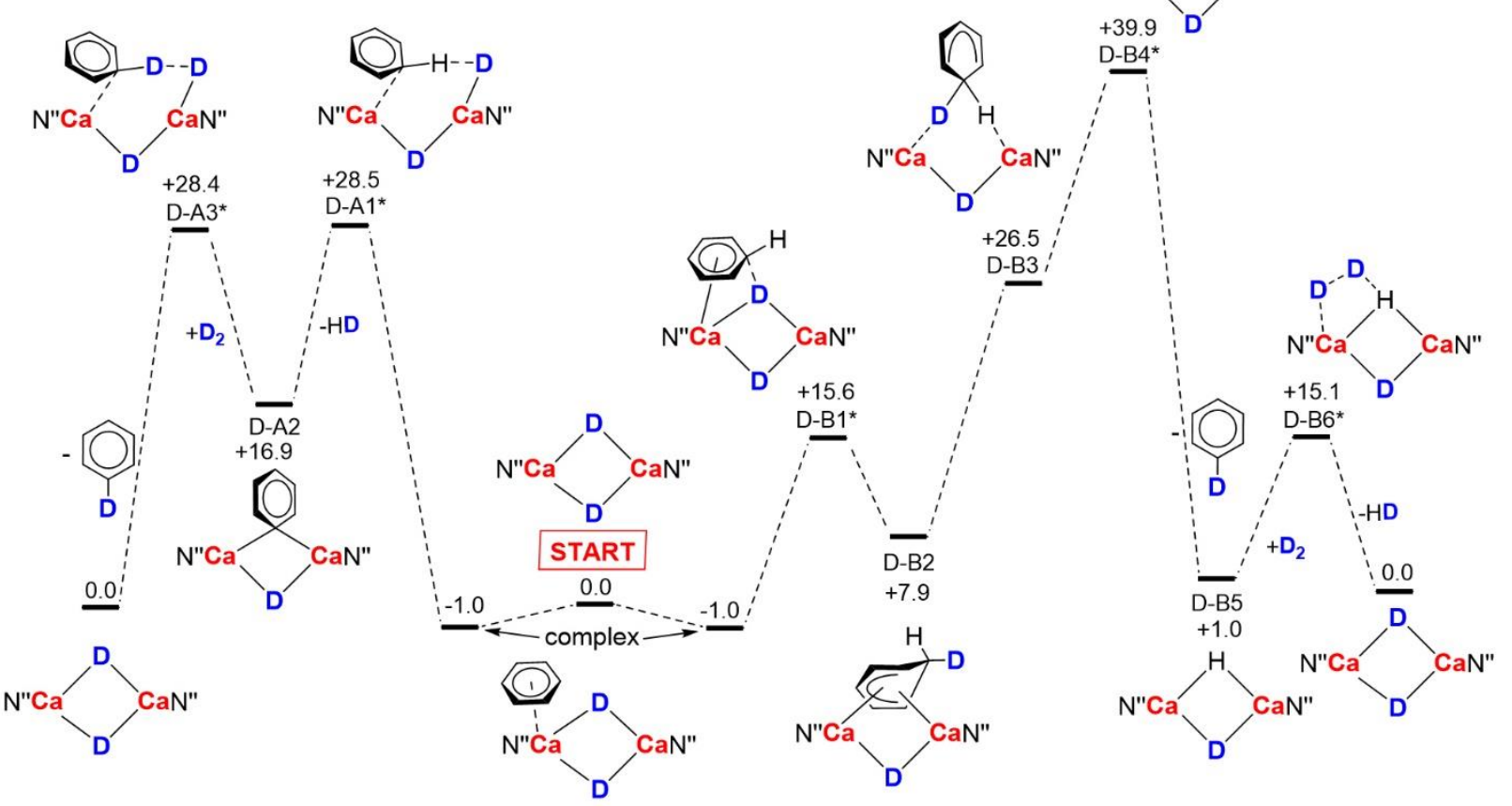

Figure S125. Calculated energy profiles for $\mathrm{H} / \mathrm{D}$ exchange between $\mathrm{C}_{6} \mathrm{H}_{6}$ and $\mathrm{D}_{2}$ following either a deprotonation/protonation pathway (A) or a Meisenheimer anion route (B) with (a) the monomeric $\mathrm{Ca}$ deuteride catalyst $\mathrm{N}^{*} \mathrm{CaD}$ or $(\mathrm{b})$ a dimeric Ca deuteride catalyst $\left(\mathrm{N}^{\prime \prime} \mathrm{CaD}\right)_{2}$; Energies $(\Delta \mathrm{H})$ in $\mathrm{kcal} / \mathrm{mol}$, B3PW91/def2tzvpp, transition states are marked by *. 


\section{References}

(1) Westerhausen, M. Synthesis and Spectroscopic Properties of Bis(trimethylsilyl)amides of the Alkaline-Earth Metals Magnesium, Calcium, Strontium, and Barium. Inorg. Chem. 1991, 30, 96-101.

(2) Martin, J.; Knüpfer, C.; Eyselein, J.; Färber, C.; Grams, S.; Langer, J.; Thum, K.; Wiesinger, M.; Harder, S. Highly Active Superbulky Alkaline Earth Metal Amide Catalysts for Hydrogenation of Challenging Alkenes and Aromatic Rings. Angew. Chem. Int. Ed. 2020, 59, 9102-9112.

(3) Isotopologues (or isotopic homologues) are compounds with the same chemical structure that differ solely in their isotopic composition (number of isotopic substitutions), e.g. $\mathrm{C}_{6} \mathrm{H}_{6}, \mathrm{C}_{6} \mathrm{H}_{5} \mathrm{D}$ and $\mathrm{C}_{6} \mathrm{H}_{3} \mathrm{D}_{3}$. The term isotopomer (or isotopic isomers) indicate isotopologues with the same mass, but differing in the positions of the isotopes, e.g. ortho- $\mathrm{C}_{6} \mathrm{H}_{4} \mathrm{D}_{2}$ and meta- $\mathrm{C}_{6} \mathrm{H}_{4} \mathrm{D}_{2}$.

See: (a) Seeman, J. I.; Secor, H. V.; Disselkamp, R.; Bernstein, E. R. Conformational Analysis through Selective Isotopic Substitution: Supersonic Jet Spectroscopic Determination of the Minimum Energy Conformation of o-Xylene. J. Chem. Soc., Chem. Commun. 1992, 713-714. (b) Muller, P. Glossary of Terms Used In Physical Organic Chemistry. Pure Appl. Chem. 1994, 66, 1077-1184.

(4) Yu, R. P.; Hesk, D.; Rivera, N.; Pelczer, I.; Chirik, P. J. Iron-catalysed tritiation of pharmaceuticals. Nature 2016, 529, 195-199.

(5) (a) Hickman, A. J.; Villalobos, J. M.; Sanford, M. S. Quantitative Assay for the Direct Comparison of Platinum Catalysts in Benzene H/D Exchange. Organometallics 2009, 28, 5316-5322. (b) Villalobos, J. M.; Hickman, A. J.; Sanford, M. S. Platinum(II) Complexes Containing Quaternized Nitrogen Ligands: Synthesis, Stability, and Evaluation as Catalysts for Methane and Benzene H/D Exchange. Organometallics 2010, 29, 257-262. (c) Emmert, M. H.; Gary, J. B.; Villalobos, J. M.; Sanford, M. S. Platinum and Palladium Complexes Containing Cationic Ligands as Catalysts for Arene H/D Exchange and Oxidation. Angew. Chem. Int. Ed. 2010, 49, 5884-5886.

(6) (a) Gottlieb, H. E.; Kotlyar, V.; Nudelman, A. NMR Chemical Shifts of Common Laboratory Solvents as Trace Impurities. J. Org. Chem. 1997, 62, 7512-7515. (b) Fulmer, G. R.; Miller, A. J. M.; Sherden, N. H.; Gottlieb, H. E.; Nudelman, A.; Stoltz, B. M.; Bercaw, J. E.; Goldberg, K. I. 
NMR Chemical Shifts of Trace Impurities: Common Laboratory Solvents, Organics, and Gases in Deuterated Solvents Relevant to the Organometallic Chemist. Organometallics 2010, 29, 2176-2179.

(7) (a) Kerr, W. J.; Mudd, R. J.; Reid, M.; Atzrodt, J.; Derdau, V. Iridium-Catalyzed Csp ${ }^{3}-H$ Activation for Mild and Selective Hydrogen Isotope Exchange. ACS Catal. 2018, 8, 10895-10900. (b) Kerr, W. J.; Reid, M.; Tuttle, T. Iridium-Catalyzed Formyl-Selective Deuteration of Aldehydes. Angew. Chem. Int. Ed. 2017, 56, 7808-7812.

(8) (a) Komuro, T.; Osawa, T.; Suzuki, R.; Mochizuki, D.; Higashi, H.; Tobita, H. Silyl-pyridine-amine pincer-ligated iridium complexes for catalytic silane deuteration via room temperature C-D bond activation of benzene-d6. Chem. Commun. 2019, 55, 957-960. (b) Fortman, G. C.; Jacobsen, H.; Cavallo, L.; Nolan, S. P. Catalytic deuteration of silanes mediated by N-heterocyclic carbene-Ir(III) complexes. Chem. Commun. 2011, 47, 9723-9725. (c) Iluc, V. M.; Fedorov, A.; Grubbs, R. H. H/D Exchange Processes Catalyzed by an Iridium-Pincer Complex. Organometallics 2012, 31, 39-41.

(9) (a) Campos, J.; Esqueda, A. C.; López-Serrano, J.; Sánchez, L.; Cossio, F. P.; de Cozar, A.; Álvarez, E.; Maya, C.; Carmona, E. A Cationic Rh(III) Complex That Efficiently Catalyzes Hydrogen Isotope Exchange in Hydrosilanes. J. Am. Chem. Soc. 2010, 132, 16765-16767. (b) Campos, J.; Rubio, M.; Esqueda, A. C.; Carmona, E. Large-scale preparation and labelling reactions of deuterated silanes. J. Labelled Compd. Radiopharm. 2012, 55, 22-38.

(10) Gaussian 16, Revision A.03, Frisch, M. J.; Trucks, G. W.; Schlegel, H. B.; Scuseria, G. E.; Robb, M. A.; Cheeseman, J. R.; Scalmani, G.; Barone, V.; Petersson, G. A.; Nakatsuji, H.; Li, X.; Caricato, M.; Marenich, A. V.; Bloino, J.; Janesko, B. G.; Gomperts, R.; Mennucci, B.; Hratchian, H. P.; Ortiz, J. V.; Izmaylov, A. F.; Sonnenberg, J. L.; Williams-Young, D.; Ding, F.; Lipparini, F.; Egidi, F.; Goings, J.; Peng, B.; Petrone, A.; Henderson, T.; Ranasinghe, D.; Zakrzewski, V. G.; Gao, J.; Rega, N.; Zheng, G.; Liang, W.; Hada, M.; Ehara, M.; Toyota, K.; Fukuda, R.; Hasegawa, J.; Ishida, M.; Nakajima, T.; Honda, Y.; Kitao, O.; Nakai, H.; Vreven, T.; Throssell, K.; Montgomery, J. A., Jr.; Peralta, J. E.; Ogliaro, F.; Bearpark, M. J.; Heyd, J. J.; Brothers, E. N.; Kudin, K. N.; Staroverov, V. N.; Keith, T. A.; Kobayashi, R.; Normand, J.; Raghavachari, K.; Rendell, A. P.; Burant, J. C.; Iyengar, S. S.; Tomasi, J.; Cossi, M.; Millam, J. M.; Klene, M.; Adamo, C.; Cammi, R.; Ochterski, 
J. W.; Martin, R. L.; Morokuma, K.; Farkas, O.; Foresman, J. B.; Fox, D. J. Gaussian Inc., Wallingford CT, USA, 2016.

(11) (a) Becke, A. D. Density-functional thermochemistry. III. The role of exact exchange. J. Chem. Phys. 1993, 98, 5648-5652. (b) Perdew, J. P.; Chevary, J. A.; Vosko, S. H.; Jackson, K. A.; Pederson, M. R.; Singh, D. J.; Fiolhais, C. Atoms, molecules, solids, and surfaces: Applications of the generalized gradient approximation for exchange and correlation. Phys. Rev. B 1992, 46, 6671-6687. (c) Weigend, F.; Ahlrichs, R. Balanced basis sets of split valence, triple zeta valence and quadruple zeta valence quality for $\mathrm{H}$ to $\mathrm{Rn}$ : Design and assessment of accuracy. Phys. Chem. Chem. Phys. 2005, 7, 3297-305. (d) Weigend, F. Accurate Coulomb-fitting basis sets for H to Rn. Phys. Chem. Chem. Phys. 2006, 8, 1057-1065.

(12) Grimme, S.; Ehrlich, S.; Goerigk, L. Effect of the Damping Function in Dispersion Corrected Density Functional Theory. J. Comp. Chem. 2011, 32, 1456-1465.

(13) Marenich, A. V.; Cramer, C. J.; Truhlar, D. G. Universal Solvation Model Based on Solute Electron Density and on a Continuum Model of the Solvent Defined by the Bulk Dielectric Constant and Atomic Surface Tensions. J. Phys. Chem. B 2009, 113, 6378-6396.

(14) Molecule, Version 2.311, N. van Eikema Hommes, Erlangen, Germany, 2018. 